\title{
Coordination in a macroeconomic game : its design and its role in education and experiments
}

Citation for published version (APA):

Woltjer, G. B. (1995). Coordination in a macroeconomic game : its design and its role in education and experiments. [Doctoral Thesis, Maastricht University]. Datawyse / Universitaire Pers Maastricht. https://doi.org/10.26481/dis.19950413gw

Document status and date:

Published: 01/01/1995

DOI:

10.26481/dis.19950413gw

Document Version:

Publisher's PDF, also known as Version of record

\section{Please check the document version of this publication:}

- A submitted manuscript is the version of the article upon submission and before peer-review. There can be important differences between the submitted version and the official published version of record.

People interested in the research are advised to contact the author for the final version of the publication, or visit the DOI to the publisher's website.

- The final author version and the galley proof are versions of the publication after peer review.

- The final published version features the final layout of the paper including the volume, issue and page numbers.

Link to publication

\footnotetext{
General rights rights.

- You may freely distribute the URL identifying the publication in the public portal. please follow below link for the End User Agreement:

www.umlib.nl/taverne-license

Take down policy

If you believe that this document breaches copyright please contact us at:

repository@maastrichtuniversity.nl

providing details and we will investigate your claim.
}

Copyright and moral rights for the publications made accessible in the public portal are retained by the authors and/or other copyright owners and it is a condition of accessing publications that users recognise and abide by the legal requirements associated with these

- Users may download and print one copy of any publication from the public portal for the purpose of private study or research.

- You may not further distribute the material or use it for any profit-making activity or commercial gain

If the publication is distributed under the terms of Article $25 \mathrm{fa}$ of the Dutch Copyright Act, indicated by the "Taverne" license above, 


\title{
Coordination in a Macroeconomic Game
}

\author{
Its design and its role in \\ education and experiments
}

\section{PROEFSCHRIFT}

ter verkrijging van de graad van doctor

aan de Rijksuniversiteit Limburg te Maastricht, op gezag van de Rector Magnificus, Prof.mr. M.J. Cohen, volgens het besluit van het College van Dekanen, in het openbaar te verdedigen op donderdag 13 april 1995 om 16.00 uur

door

Gerard Bastiaan Woltjer

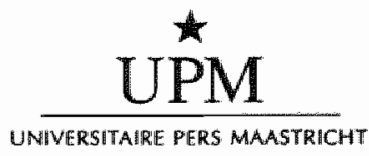


Promotor:

Prof.dr. I. Muysken

Beoordelingscommissie:

Prof.dr. J.A.H. Maks (voorzitter)

Prof.dr. A.B.T.M. van Schaik (Katholieke Universiteit Brabant)

Prof.dr. A. van Witteloostuijn

CIP-DATA KONINKLIJKE BIBLIOTHEEK, DEN HAAG

Woltjer, Gerard Bastiaan

Coordination in a macroeconomic game: Its design and its role in education and experiments / Gerard Bastiaan

Woltjer. - Maastricht "Universitaire Pers Manstricht. - Ill.

Thesis Rijkstmiwersiteir Limburg Mastricht. - With ref.

ISBN 90-5278-179-6

Subject laeadings: experimental economics / economics ; education

I economics; games.

Geert Woljer, Masstricht 1995

Druk: Datawyse Maastricht / Krips Repro Meppel 


\section{Contents (short)}

Preface

Chapter 1 Introduction $\ldots \ldots \ldots \ldots \ldots \ldots \ldots \ldots \ldots \ldots \ldots$

1.1 The need for a macroeconomic game $\ldots \ldots \ldots \ldots \ldots \ldots \ldots$.

1.2 The macroeconomic coordination problem $\ldots \ldots \ldots \ldots \ldots \ldots$

1.3 How most economists avoid the fundamental macroeconomic coordination problem $\ldots \ldots \ldots \ldots \ldots \ldots \ldots \ldots \ldots$

1.4 A further investigation of the coordination problem $\ldots \ldots \ldots \ldots \ldots 15$

1.5 The role of a macroeconomic game in teaching and researc $9 \ldots \ldots \ldots 16$

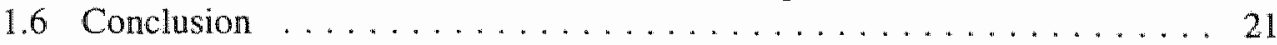

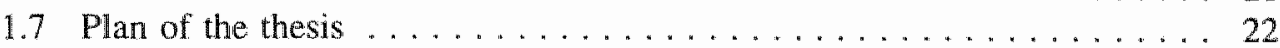

Chapter 2 Didactics and (macro-) economics . . . . . . . . . . . . 24

2.1 Introduction . . . . . . . . . . . . . . . . . . . 24

2.2 Psychological foundations of (economics) teaching $\ldots \ldots \ldots \ldots 26$

2.3 Application of the method to a standard textbook ........... 35

2.4 Towards an application of the teaching principles in textbook writing . . 47

2.5 Application of the theory to the game $\ldots \ldots \ldots \ldots \ldots \ldots \ldots \ldots$

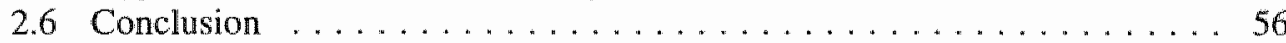

Chapter 3 The road to experimental macroeconomics .......... 57

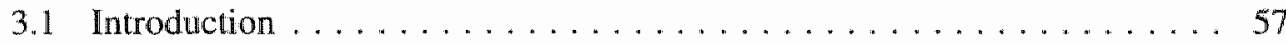

3.2 Economic theory, econometrics and experimental economics ...... 57

3.3 An experimental line in microeconomics: double auction markets .... 61

3.4 Methodological issues . . . . . . . . . . . . . . . . . 63

3.5 A macroeconomic experiment $\ldots \ldots \ldots \ldots \ldots \ldots \ldots \ldots \ldots$

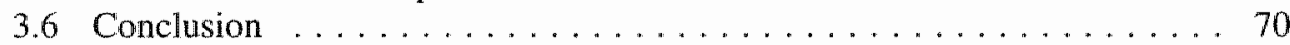

Chapter 4 A Neoclassical growth model with individual firms ......71

4.1 Introduction . . . . . . . . . . . . . . . . . . 71

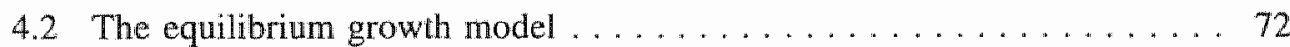

4.3 Imperfect competition on the output market $\ldots \ldots \ldots \ldots \ldots \ldots . . \ldots 1$

4.4 Imperfect competition on the labour market $\ldots \ldots \ldots \ldots \ldots \ldots . . . . .69$

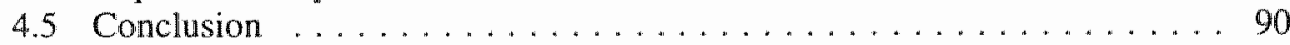

Appendix 4A. The equilibrium growth path $\ldots \ldots \ldots \ldots \ldots \ldots \ldots$

Appendix $4 \mathrm{~B}$. The solution of the profit maximization problem with imperfect competition . ..................... 93

Chapter 5 Disequilibrium in the game economy $\ldots \ldots \ldots \ldots \ldots$

5.1 Introduction . . . . . . . . . . . . . . . . . . . 100

5.2 The introduction of putty-clay technology . . . . . . . . . . . 101

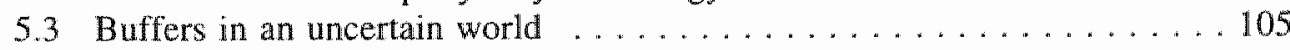

5.4 The distribution of output over consumption and investment goods . . . . 110

5.5 Money and monetary policy $\ldots \ldots \ldots \ldots \ldots \ldots \ldots \ldots \ldots \ldots$ 
5.6 Government policy . . . . . . . . . . . . . . . . . 113

5.7 Concluding comments . . . . . . . . . . . . . . . 114

Chapter 6 Operationalization of the game $\ldots \ldots \ldots \ldots \ldots \ldots \ldots \ldots$

6.1 Introduction . . . . . . . . . . . . . . . . . . . 115

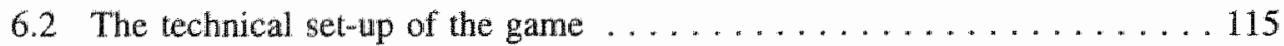

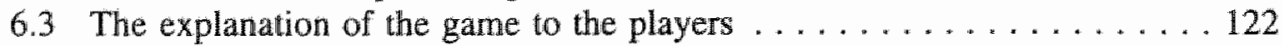

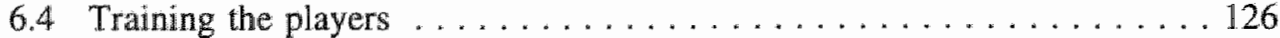

6.5 Game instruction and teaching principles $\ldots \ldots \ldots \ldots \ldots \ldots \ldots$

6.6 Concluding comments . . . . . . . . . . . . . . . 143

Appendix $6 \mathrm{~A}$. The start procedure for the game. . . . . . . . . . 145

Chapter 7 Educational evaluation ................ 146

7.1 Introduction . . . . . . . . . . . . . . . . . . . 146

7.2 The game in the study of economics and business administration . . . . 147

7.3 A short introduction to economics with the help of the game $\ldots \ldots \ldots 158$

7.4 An introductory course in economics for law students $\ldots \ldots \ldots \ldots 163$

7.5 Conclusion . . . . . . . . . . . . . . . . . . 173

Appendix 7A. The questionnaire at the end of the game for students in economics and management. . . . . . . . . . . . . 174

Appendix 7B. The business cycle descriptions . . . . . . . . . . 175

Appendix $7 \mathrm{C}$. The questions in the categorization experiment. . . . . . 176

Appendix 7D. Correlations between the separate questions and the factors of the OAT 1993. . . . . . . . . . . . . . . . . . . 177

Chapter 8 The game as an experimental method .......... 179

8.1 Introduction . . . . . . . . . . . . . . . . . . . . . . 179

8.2 Experimental requirements of the game $\ldots \ldots \ldots \ldots \ldots \ldots \ldots \ldots$

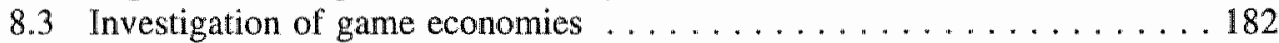

8.4 Macroeconomic gaming as a research strategy . . . . . . . . . . 193

8.5 Conclusion: the game as a potential research strategy . . . . . . 200

Appendix 8A. The development of national income of 11 game economies. . . 201 Appendix 8B. The content of the automatic players. . . . . . . . 203

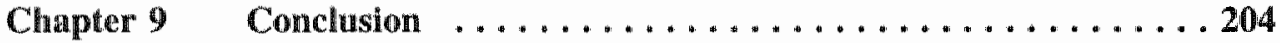

References ............................... 209

Nederlandse samenvatting $\ldots \ldots \ldots \ldots \ldots \ldots \ldots \ldots \ldots \ldots \ldots$

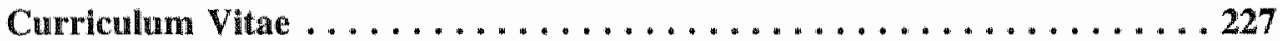




\section{Contents (long)}

Preface

Chapter 1 Introduction $\ldots \ldots \ldots \ldots \ldots \ldots \ldots \ldots \ldots \ldots$ i

1.1 The need for a macroeconomic game $\ldots \ldots \ldots \ldots \ldots \ldots \ldots \ldots$

1.2 The macroeconomic coordination problem $\ldots \ldots \ldots \ldots \ldots \ldots$

1.3 How most economists avoid the fundamental macroeconomic coordination problem $\ldots \ldots \ldots \ldots \ldots \ldots \ldots \ldots \ldots \ldots$

1.3.1 The IS-LM approach $\ldots \ldots \ldots \ldots \ldots \ldots \ldots \ldots . \ldots . \ldots$

1.3.2 Monetarists and New Classicals . . . . . . . . . . . . . 11

1.3.3 New Keynesians and Post Keynesians . . . . . . . . . 12

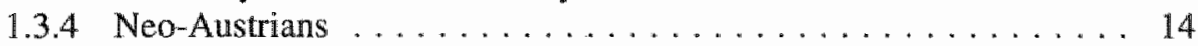

1.3 .5 Conclusion . . . . . . . . . . . . . . . . . . 15

1.4 A further investigation of the coordination problem . . . . . . . . 15

1.5 The role of a macroeconomic game in teaching and research $\ldots \ldots \ldots 16$

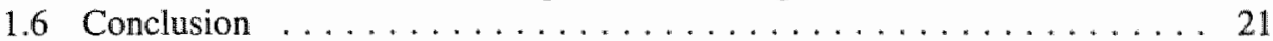

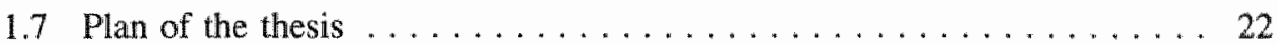

Chapter 2 Didactics and (macro-) economics $\ldots \ldots \ldots \ldots \ldots \ldots 24$

2.1 Introduction . . . . . . . . . . . . . . . . . . . 24

2.2 Psychological foundations of (economics) teaching $\ldots \ldots \ldots \ldots 26$

2.2.1 Comparisons between novices and experts $\ldots \ldots \ldots \ldots \ldots 26$

2.2.2 The human knowledge structure $\ldots \ldots \ldots \ldots \ldots \ldots \ldots \ldots$

2.2 .3 Learning . . . . . . . . . . . . . . . . 30

2.2 .4 A Cognitive theory of motivation .............. 31

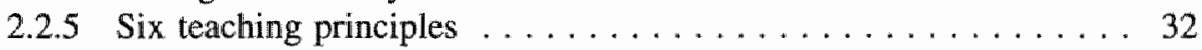

2.3 Application of the method to a standard textbook $\ldots \ldots \ldots \ldots \ldots 35$

2.3.1 The production possibility frontier $\ldots \ldots \ldots \ldots \ldots \ldots \ldots$

2.3.2 Aggregate supply and demand and the multiplier . . . . . . 40

2.3 .3 Conclusion .......................... 44

2.4 Towards an application of the teaching principles in textbook writing ... 47

2.5 Application of the theory to the game $\ldots \ldots \ldots \ldots \ldots \ldots \ldots \ldots$

2.6 Conclusion ............................... 56

Chapter 3 The road to experimental macroeconomics $\ldots \ldots \ldots \ldots \ldots 57$

3.1 Introduction . . . . . . . . . . . . . . . . . . 57

3.2 Economic theory, econometrics and experimental economics ....... 57

3.3 An experimental line in microeconomics: double auction markets . . . . 61

3.4 Methodological issues ........................ 63

3.5 A macroeconomic experiment . . . . . . . . . . . . . . 66

3.6 Conclusion . . . . . . . . . . . . . . . . . . . 70 
Chapter 4 A Neoclassical growth model with individual firms ....... 71

4.1 Introduction . . . . . . . . . . . . . . . . . 71

4.2 The equilibrium growth model . . . . . . . . . . . . . 72

4.2 .1 The real model . . . . . . . . . . . . . . . . 72

4.2 .2 The monetary sector . . . . . . . . . . . . . 77

4.2 .3 Disaggregation of the business sector $\ldots \ldots \ldots \ldots \ldots \ldots 78$

4.3 Imperfect competition on the output market $\ldots \ldots \ldots \ldots \ldots \ldots \ldots 81$

4.3.1 The demand for output $\ldots \ldots \ldots \ldots \ldots \ldots \ldots \ldots . \ldots \ldots$

4.3 .2 Price setting and equilibrium profits . . . . . . . . . 83

4.3.3 The effect of imperfect competition on equilibrium growth . . . 88

4.4 Imperfect competition on the labour market . . . . . . . . . . . . . 89

4.5 Conclusion . . . . . . . . . . . . . . . . . . . . 90

Appendix 4A. The equilibrium growth path ............... 91

Appendix $4 \mathrm{~B}$. The solution of the profit maximization problem with imperfect competition ...................... 93

Chapter 5 Disequilibrium in the game economy $\ldots \ldots \ldots \ldots \ldots \ldots$

5.1 Introduction .............................. 100

5.2 The introduction of putty-clay technology . . . . . . . . . . 101

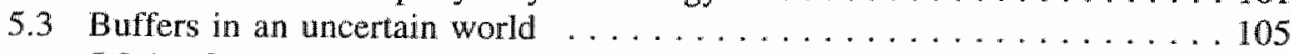

5.3.1 Output market: stock of final products and the utilization rate of capital . . . . . . . . . . . . . . . . . . . . 105

5.3.2 The investment market: the delivery time and price for machines . 106

5.3.3 The labour market and unemployment ............. 108

5.4 The distribution of output over consumption and investment goods $\ldots \ldots 110$

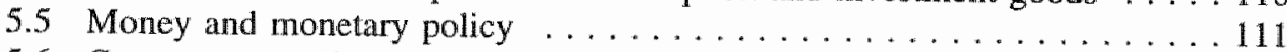

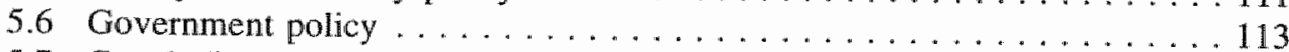

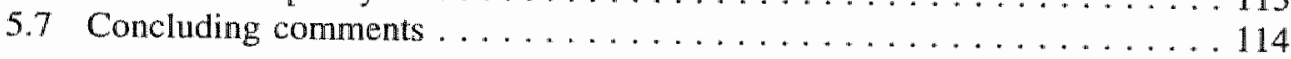

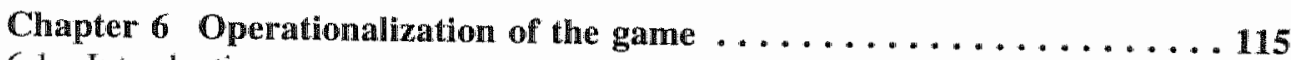

6.1 Introduction . . . . . . . . . . . . . . . . . . . 115

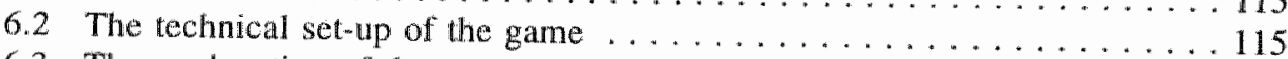

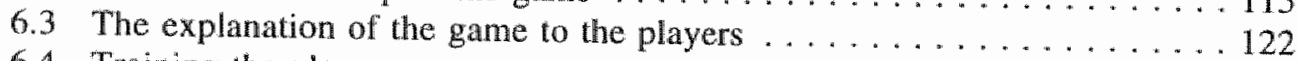

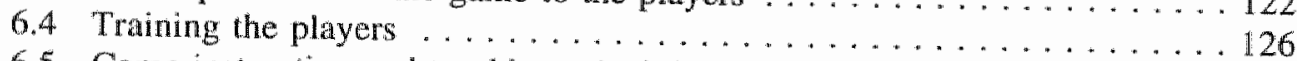

6.5 Game instruction and teaching principles $\ldots \ldots \ldots \ldots \ldots \ldots \ldots \ldots$

6.6 Concluding comments . . . . . . . . . . . . . . . . . 143

Appendix $6 \mathrm{~A}$. The start procedure for the game. . . . . . . . . . 145

Chapter 7 Educational evaluation

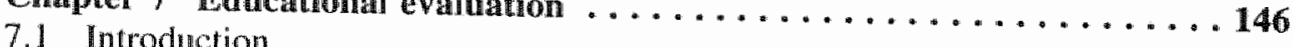

7.2 The game in the study of economics and $\ldots \ldots \ldots \ldots \ldots \ldots \ldots \ldots$

72.1 The organization of the games and business administration . . . . . 147

7.2 .1 The organization of the game $\ldots \ldots \ldots \ldots \ldots \ldots \ldots \ldots \ldots$

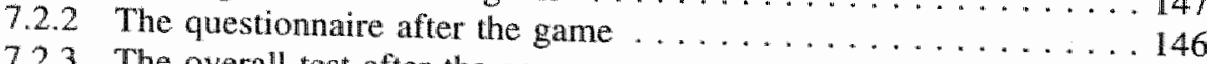

7.2 .3 The overall test after the game $\ldots \ldots \ldots \ldots \ldots \ldots \ldots \ldots \ldots . \ldots \ldots$

7.2 .5 Differences between OAT-scores of players and non-players . . . . 155

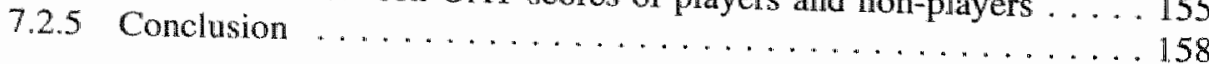


7.3 A short introduction to economics with the help of the game $\ldots \ldots \ldots 158$

7.3.1 Design of the course ... . . . . . . . . . . . . . 159

7.3 .2 A test for pattern recognition . . . . . . . . . . . . 159

7.3.3 Concluding comments $\ldots \ldots \ldots \ldots \ldots \ldots \ldots \ldots \ldots \ldots \ldots . \ldots \ldots$

7.4 An introductory course in economics for law students $\ldots \ldots \ldots \ldots 163$

7.4.1 Design of the course ................... 163

7.4.2 Test score and participation of students ............ 164

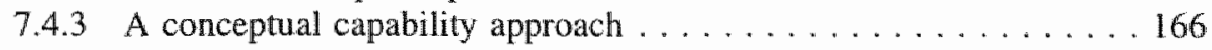

7.5 Conclusion . . . . . . . . . . . . . . . . . . . 173

Appendix 7A. The questionnaire at the end of the game for students in economics and management. . . . . . . . . . . 174

Appendix 7B. The business cycle descriptions . . . . . . . . . . . . 175

Appendix 7C. The questions in the categorization experiment. . . . . . . 176

Appendix 7D. Correlations between the separate questions and the factors of the OAT 1993. . . . . . . . . . . . . . . 177

Chapter 8 The game as an experimental method $\ldots \ldots \ldots \ldots \ldots$. $\ldots \ldots 9$

8.1 Introduction . . . . . . . . . . . . . . . . . . . . . . . 179

8.2 Experimental requirements of the game $\ldots \ldots \ldots \ldots \ldots \ldots \ldots \ldots$

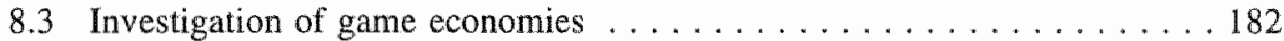

8.3.1 The setting of the game economies $\ldots \ldots \ldots \ldots \ldots \ldots 2$

8.3.2 Descriptive analysis: Expectations and stability . . . . . . 183

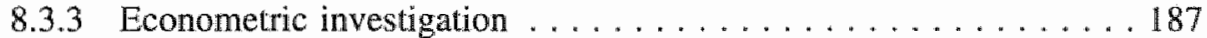

8.3.4 The game as a computer simulation $\ldots \ldots \ldots \ldots \ldots \ldots \ldots 19 \ldots \ldots$

8.3.5 Mixing human and computer players $\ldots \ldots \ldots \ldots \ldots \ldots 2$

8.3.6 Conclusion ......................... 192

8.4 Macroeconomic gaming as a research strategy $\ldots \ldots \ldots \ldots \ldots \ldots 193$

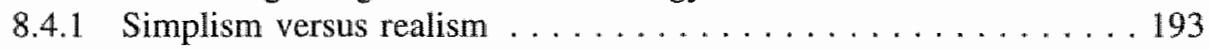

8.4 .2 More sectors . . . . . . . . . . . . . . . . . . 193

8.4.3 Improvement of market structure . . . . . . . . . . . 195

8.4 .4 A monetary sector . . . . . . . . . . . . . . . . . . 196

8.4.5 Technological development and maintenance cost of machines ... 198

8.4 .6 Government as a player . . . . . . . . . . . . . . . . . . . 199

8.4 .7 Conclusion . . . . . . . . . . . . . . . . . . . . . 199

8.5 Conclusion: the game as a potential research strategy . . . . . . 200

Appendix 8A. The development of national income of 11 game economies. . . 201

Appendix 8B. The content of the automatic players. . . . . . . . . 203

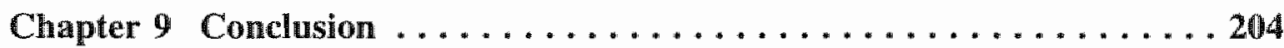

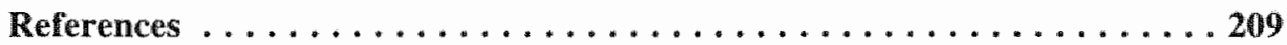

Nederlandse samenvatting $\ldots \ldots \ldots \ldots \ldots \ldots \ldots \ldots \ldots . \ldots . \ldots . \ldots 219$

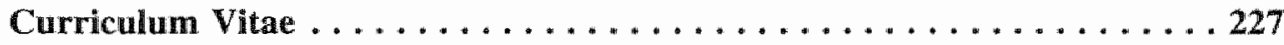




\section{Preface}

This dissertation has a long history. When I started my plans about a dissertation, it was to be about the role of expectations in investment decisions and the consequences of those decisions for macroeconomic stability. I developed a decision theory with the help of cognitive psychology and applied it to the shipbuilding industry in the Netherlands. My assumption was that the shipbuilding industry hung on too long in the Netherlands, with the consequence that it grew in a period of great excess demand, but then had to decline rapidly in a period of rising unemployment. From a rational point of view it would have been better if the shipbuilders had accepted their comparative advantage earlier.

But going deeper into this problem revealed to me that it is difficult to find out what the real beliefs were and also to find out what the real perspectives of the shipbuilding industry were. A fundamental problem in this type of research is that the researcher does not know how the world really is, and has only very limited information about the expectations in such a society.

In the same period I had developed a game for teaching microeconomics. It was meant to investigate the free exchange process and also had a variant with investment decisions. The combination of the problem in my research project and the experience in designing games generated my idea to develop an experimental game. Such a game should have the advantage that the researcher knows the world, where the opportunities to get information about expectations would be much greater. This was at the end of 1989.

The first game was ready in January 1990. It was a game played in a limited number of rounds. But in the game one had to make decisions simultaneously about a whole year without knowing the decisions of the other players in advance. Therefore, the game was more like gambling than like rational decision making. This implied that the period of time the game was played should be divided into much smaller periods. The consequence was that the game should be played on a computer network. The first version was presented in April 1990. The program of about 3000 lines was not robust enough to be played with students who always investigate the limits of a program. Also the presentation of the information in the game had to be improved. It required two years to develop a program that satisfied these requirements and could be played both on DOS-machines and MacIntosh computers. 
The program had grown to more than 20,000 lines at that moment. As discussed in this thesis, the educational results were far from satisfying at that moment. It required a further year to solve those educational problems. At that moment the game had gained sufficient acceptance in the faculty to invest in a professional computer programmer. He is now working on the final details of the game program.

The suggestion to write my thesis on the game came from my promotor Joan Muysken. In first instance I expected that the thesis would deal mainly with the experimental results of the game, but when time went on it became clear that the development of a game was a project in itself. The second part of the thesis, the educational approach of economics, was also an idea of my promotor's. I had been working a long time on a block at the law faculty that integrated economics, history and political philosophy. I had changed from the economics faculty to the law faculty because I was very disappointed about the formal and traditional approach of teaching economics at the economics faculty. I developed an approach that was centred on decision making of human beings and followed the opportunity cost approach consistently. This implied an integration between microeconomics and macroeconomics that was only introduced to economics students at the last phase of their study. Muysken thought it would be useful to write down my ideas about teaching economics and thought that my approach in the game was related to my approach at the law faculty. The result is this dissertation that will be finished almost at the same time as the final version of the game.

In writing this dissertation I have worked almost always alone. To a large extent this was a consequence of my own attitude, where I was very dissatisfied about the mainstream approach in econonics, but was also very uncertain about my own approach. I was afraid losing the stark and, in my opinion, fundamental points, by working too much together with people starting from the mainstream approach. As a consequence, till very recently no one knew what I was doing, and I had to solve all my problems on my own. But "If someone tries to gather wood alone, all his efforts will be in vain".'

I am very grateful for the cooperation with the group of game leaders, consisting of Jack Birner, Piet Eichholtz and Jan Nijhuis, who always believed in the game and gave me strength to continue with this project. I thank Huub Spoormans for the intensive cooperation in the block about law, market and the state, where we tried to integrate history, economics and political philosophy. I thank Lex Borghans for reading the manuscript in its very first version. He was the first one who gave me comments on the general ideas. I thank Joan Muysken for the freedom he gave me in developing my own line of thought. I an very grateful for Wim Gijselaers for useful ideas about the educational research in this thesis and his comments on chapter 2, and I hope we can develop a lot of issues together in the future. I thank Paul Hick and Hub van Kan for always helping me when I got into trouble playing the game on the computer network. Maarten Vendrik checked my results of chapter 4 . Bob Wilkinson corrected my English grammar. Sabine Woltjer designed the cover and checked the summary in Dutch. Camiel de Leeuw assisted me in running the game and analysing data with SPSS. I thank Arjen van Witteloostuijn for his comments on my disser-

\footnotetext{
'Ghanaian expression.
} 
tation, of which I was able to apply only a small part. I hope that some of them can be developed further in common research projects. I am very happy with the continuous support of Erik van Ballegoy, who did a lot of work on the game as a student-assistant and later on, even in his own time. Without his continuous enthusiasm work would have been much more difficult. I thank Ron van der Wal for working on a complletely new version of the computer program for the game. I look forward for the finat version.

Last but not least I thank my parents for always being there, and Sabine for entering my life and illuminating my life with even more music than before.

Both this dissertation and the development of the game were a lonely journey. This is partly a consequence of my character, but partly a consequence of the difficulty of communicating ideas that are not well developed yet. Now that I have formulated a number of points that are important to me, I hope and expect that my capability to communicate with others will improve, so that the future will be one of collaboration with others. 


\section{Chapter 1}

\section{Introduction}

\subsection{The need for a macroeconomic game ${ }^{1}$}

A fundamental problem in macroeconomic theory is the extent to which a free market macroeconomy can be regarded as a self-regulating system (Leijonhufvud, 1981:104). The problem arises in a monetary world with irreversible investment, uncertainty, and ex-post complementarity of capital and labour. The analysis of this problem requires dynamic analysis. One may call this problem the fundamental free market macroeconomic coordination problem, but for the sake of brevity, we will refer to it as the fundamental macroeconomic coordination problem or simply the macroeconomic coordination problem. Keynes (1936) introduced this problem as a central issue in economic science. We distinguish two approaches with respect to this problem. The first approach, Keynes (1936:3) called it the Classical theory ${ }^{2}$, argues that a free market economy with a sound monetary system is a self-regulating system. In the second approach, the theory of Keynes, it is argued that government intervention is required to stabilize a free market economy. This coordination controversy has not been solved yet.

In mainstream economics ${ }^{3}$ the coordination issue has been avoided instead of solved, by stating that the Classical case holds in the long run with flexible prices, and the Keynesian case holds in the short run where prices are fixed. This conflicts with Keynes (1936:269), who states that the coordination problem also holds for a free market economy with flexible prices and wages:

"To suppose that a flexible wage policy is a right and proper adjunct of a

\footnotetext{
"One of main the reasons for developing the macroeconomic game was the fundamental macroeconomic coordination problem discussed in this chapter. There is no doubt that the game has a much wider range of applications, both in research and in teaching. In this chapter I follow Leijonhufvud (1981) and Garretsen (1992) in arguing that the fundamental macroeconomic coordination problem is neglected in mainstream economics.

${ }^{2}$ Keynes refers David Ricardo, James Mill, John Stuart Mill, Marshall, Pigou, Edgeworth, and Say. In this dissertation we include all lines of thought consistent with this approach. So, also Walrasian, Wicksellian and Monetarism are included in the heading "Classical".

${ }^{3}$ As found in many current textbooks on economics, such as Mankiw (1992). Barro and Grill (1994), Begg. Fischer and Dombusch (1994) and Samuelson and Nordhauys (1992).
} 
system which on the whole is one of laissez faire, is the opposite of truth."

In contrast to Keynes"s view and based on a strong inturtion, mainstream economics postulates that a competitive market economy ${ }^{4}$ without government intervention will tend towards a general equilibrium. Mainstream economics (i.e. IS-LM analysis) redefined the controversy between Keynes and the Classics as a controversy about wage and price flexibility. This type of analysis avoids the fundamental problem of the coordination of independent decision makers who for their (investment) decisions have to make expectations about other firms" decisions which depend on the latter's expectations (Garretsen, 1992:28).

Because mainstream economics textbooks assume that coordination takes place instead of explaining the process that leads towards coordination, many non-economists perceive economics as an abstract and counter-intuitive science. For non-economists it is very difficult to imagine what equilibria look like in the real world. But also for economic research it may be useful to investigate the macroeconomic coordination problem in detail. In most theoretical economic models the conclusions bear to a large extent on the assumption that in a free market economy with flexible prices and wages all markets converge towards equilibrium. ${ }^{5}$ It is not superfluous to test such a fundamental assumption and to investigate the process that leads to this result (see Fisher, 1983).

When one wants to investigate the process of adjustment towards equilibrium, a different type of analysis is required. One has to investigate the information that is available to decision makers and the methods of decision making by the actors. In order to understand the dynamics of a free market economy one has to investigate to what extent human decision makers are able to coordinate their activities. In the real world this is very difficult because the real world is immensely complex and never does satisfy all the requirements of a completely free market economy.

In natural sciences like physics this problem is solved through experiments. Fundamental theories are tested by doing systematic experiments in the laboratory. Experiments are also an integral part of teaching physics. Until recently, experiments in economics have been exceptional in research as well as in teaching. Since the 1960 s experimental economics has grown to become a small, although respected, branch of microeconomic theory. Most of the experiments are focused on rather simple market structures or very abstract general equilibrium systems. None of these experimental systems is adequate to investigate the fundamental coordination problem in a market economy. The reason for this lack of macroeconomic experiments is simple: because it is already difficult to model a simple experimental market, it seems almost impossible to integrate those markets into a complete market economy with money, uncertainty, irreversible investment and complementarity of capital and labour ex post.

Despite the difficulties, I took the challenge to create an experimental

\footnotetext{
A competitive market is one in which both buyers and sellers believe that their own buying or selling decisions have no effect on the market price (Begg. Fischer, Dornbusch, 1984:163).

s Coordination problems are explained by institutional barriers to market adjustment, especially on the labour market.
} 
macroeconomic world. The experimental world is modelled as an interactive computer game on a computer network. The game can be used for teaching as well as for experiments. The focus of this thesis is on the development of a macroeconomic game that can be used in teaching macroeconomic dynamics and its microeconomic fundamentals as well as in theoretical research on the problems of macroeconomic stability and its microfoundations.

In order to gain an insight into the role of the coordination problem in current macroeconomic theory, the rest of this chapter focuses on the development of macroeconomic theory from this perspective. First, the basic formulation by Keynes will be developed and investigated. Then the mainstream IS-LM semi-solution of the macroeconomic coordination problem will be discussed. As a reaction to this solution New Classical economics developed. New Keynesian economics is a reaction to the New Classicals. Although those analyses care about macroeconomic coordination, all of them are examples of research strategies that assume instead of prove the solution of the coordination problem.

At first sight, Neo-Austrians seem to focus on the coordination issue. They explicitly define the problem. But, perhaps except for Lachmann, the Neo-Austrians too do not really investigate the macroeconomic coordination problem. Although they do inquire into the possibility of a disequilibrium, they postulate that competition generates a tendency towards (Walrasian) coordination.

After this historical tour, a sketch of a process analysis of the coordination problem is developed (section 4). This is a story around the coordination issue, and seems to be more amenable to learning than abstract equilibrium concepts. Both for research and for teaching the creation of an experimental macroeconomic world can be very useful for getting a better grasp of the coordination problem (section 5 ). It has to emphasized that the usefulness of the game does not depend on agreement with the importance of the fundamental macroeeconomic coordination problem; the game is completely consistent with traditional macroeconomics. This chapter will conclude with a plan of this dissertation.

\subsection{The macroconomic coordination problem}

Leijonhufvud $(1968,1981)$ has been one of the few economists who focused attention on the fundamental macroeconomic coordination problem. In his opinion, "the central issue in macroeconomic theory is ... the extent to which the economy, or at least its market sectors, may properly regarded as a self-regulating system. ... The social problem to which the issue of the system's self-regulatory capabilities pertains we may term "the coordination of economic activities." .... Full coordination "for our purposes means simply that existing markets clear; it does not mean "efficient allocation.'.... When the issue is put in this very general, diffuse way and with reference to real-world systems rather than particular classes of models, modern economic theory can as yet provide no answer" (Leijonhufvud 1981:104-105).

The coordination problem is central in the 'General Theory of Employment, Interest and Money" by Keynes (1936). This book was written as an attack on the implicit assumptions of the Classical theory of unemployment. According to Keynes, 
the special assumptions implicit in Classical theory are not "those of the economic society in which we actually live". As a result the teaching of Classical theory "is misleading and disastrous if we attempt to apply it to the facts of experience" (p 3).

According to Keynes ( $\mathrm{p} x \mathrm{xxii}$ ), "important mistakes have been made through extending to the system as a whole conclusions which have been correctly arrived at in respect of a part of it taken in isolation." Classical theory uses microeconomic principles to explain macroeconomic features. According to microeconomic theory, free markets with normal supply and demand schedules tend towards equilibrium in the sense that excess supply will induce a decline in the market price and therefore a fall in excess supply, while excess demand will result in a rise of the market price and therefore a decline in excess demand. This process is the consequence of competition by demanders or suppliers who are not able to buy or sell at the current market price and therefore will accept a lower or higher price respectively. In this line of reasoning it is implicitly assumed that a change in price does not influence the supply and demand schedules, the so-called ceteris paribus clause. When this theory is applied to macroeconomics, the validity of this assumption cannot be taken for granted:

\begin{abstract}
"Though an individual whose transactions are small in relation to the market can safely neglect the fact that demand is not a one-sided transaction, it makes nonsense to neglect it when we come to aggregate demand. This is the vital difference between the theory of economic behaviour of the aggregate and the theory of the behaviour of the individual unit, in which we assume that changes in the individual's own demand do not affect his income." (p 85)
\end{abstract}

For example, a decrease in the wage rate may imply liquidity restrictions on the expenses of wage earners. Therefore, a decrease in wages may recuce the demand for consumer products. Because "every weakening in the propensity to consume regarded as a permanent habit must weaken the demand for capital" (p 106), such a decline in consumer demand may result also in a decline in investment demand and hence aggregate demand.

According to Keynes, Classical thought is "deeply steeped in the notion that if people do not spend their money in one way they will spend it in another" ( $\mathrm{p} 20$ ). This idea is implicitly founded in the quantity theory of money according to which "prices depend on the quantity of money" (p 12). As a consequence "wage bargains between the entrepreneurs and the workers determine the real wage" (p 11).

When the Classical theory of unemployment holds, only frictional and "volun" tary' (in modern terms called 'structural') unemployment are possible. "Voluntary" unemployment arises, in Keynes"s view, "due to the refusal or inability of labour, as a result of legislation or social practices or of combination for collective bargaining or of slow response to change or of mere human obstinacy, to accept a reward corresponding to the value of the product to its marginal productivity" (p 6). But according to Keynes, this restriction on declines in money wages during a recession is not supported by the facts. In recessions money wages fall, but prices fall even more (p 9-10). As a consequence, involuntary unemployment may emerge. "Men are 
involuntarily unemployed if, in the event of a small rise in the price of wage-goods relatively to the money wage, both the aggregate supply of labour willing to work for the current money-wage and the aggregate demand for it at that wage would be greater than the existing volume of employment" (p 15). This definition implies that Say"s law that "the aggregate demand price of output as a whole is equal to its aggregate supply price for all volumes of output" (Keynes, p 26) is not satisfied.

Except for Wicksell, almost all Classical authors assumed instead of proved the equality of the aggregate demand price and the aggregate supply price. Keynes disputed this assumption through an elaboration of the theory of money and interest. According to Keynes, Say's law implies that consumption and investment adjust through the interest rate towards aggregate supply (p 30-31). For example, a decline in the propensity to consume induces a decline in the rate of interest and thus increases investment demand. ${ }^{6}$

When it is not assumed a priori that the quantity theory of money holds, a monetary theory of the interest rate is needed. A theory that explains why the interest rate will not automatically fall to the appropriate level is developed in Book IV of the General Theory. This theory opens the discussion why aggregate supply and aggregate demand need not be equal. Keynes describes this as "a vitally important chapter of economic theory which remains to be written and without which all discussions concerning the volume of aggregate employment are futille" (p 26).

Although Keynes (1936) was the first whose investigation of the fundamental coordination problem resulted in an attack on the stability hypothesis, Wicksell (1935) had already recognized the coordination problem as a dynamic problem. Wicksell (1935:160) accuses the advocates of the quantity theory that they "make the mistake of postulating their assumptions instead of clearly proving them. That a large and a small quantity of money can serve the same purposes of turnover if commodity prices rise or fall proportionately to the quantity is one thing. It is another thing to show why such a change of price must always follow a change in the quantity of money and to describe what happens." In order to tackle this problem Wicksell distinguishes between the natural rate of interest where "the demand for loan capital and the supply of savings exactly agree" (p 193), and the market rate of interest. The natural rate of interest may change. "If the prospects of the employment of capital become more promising, demand will increase and will at first exceed supply; interest rates will then rise and stimulate further saving at the same time as the demand from entrepreneurs contracts until a new equilibrium is reached at a slightly higher rate of interest." But, according to WickselL, this rise in the interest rate can be delayed, "because banks never alter their interest rates unless they are induced to do so by the force of outside circumstances" (p 204). The "difference between the actual loan and normal rates, which have already designated as a major cause of fluctuations in commodity prices, arises less frequently because the loan rate changes spontaneously whilst the normal or real rate remains unchanged but on the contrary because the normal rate rises or falls whilst the loan rate remains the unchanged or only tardily follows it... Therefore, the influence of banks on com-

\footnotetext{
"It has to be emphasized that the possibility of substitution between capital and labour is implicit in this line of argument. This is a central point for Hayek, but is not emphasized in Keynes (1936).
} 
modity prices is a consequence of their passivity, and not of their activity, in the loan market"s (p 205).

Although Wicksell's line of reasoning is focused on underpinning the Quantity Theory, he opens the possibility of involuntary unemployment: "It is, of course, not impossible for the rise in prices to be counteracted to a certain extent by an increase in production, for example if previously there had been unemployment, or if higher wages had induced longer working hours, or even by the increasing roundaboutness which is undoubtedly invoked by a fall in interest rates, even if it occurs artificially. But all these are secondary considerations. As a first approximation we are entitled to assume that all production forces are already fully employed, so that the increased monetary demand principally takes the form of rivalry between employers..." (p 195).

Keynes's (1936) attack on Classical theory may be seen as a consequence of a thorough investigation of those "secondary considerations". According to Keynes, "the succession of boom and slump can be described and analysed in terms of the fluctuations of the marginal efficiency of capital relatively to the rate of interest" (p 144). "The schedule of the marginal efficiency of capital is of fundamental importance because it is mainly through this factor (much more than through the rate of interest) that the expectation of the future influences the present" (p 145). It" "seems likely that the fluctuations in the market estimation of the marginal efficiency of different types of capital... will be too great to be offset by any practicable changes in the rate of interest" ( $\mathrm{p}$ 164). Therefore, the General Theory can be seen as an attack on the ability of the interest rate to coordinate investment and saving.

Keynes develops Wicksell's idea that the interest rate is determined through convention (Wicksell, 1935:204). According to Keynes the interest rate "may fluctuate for decades about a level which is chronically too high for full employment; particularly if it is the prevailing opinion that the rate of interest is self-adjusting, so that the level established by convention is thought to be rooted in objective grounds much stronger than convention, the faillure of employment to attain an optimum level being in no way associated, in the minds either of the public or of authority, with the prevalence of an inappropriate range of rates of interest" ( 204 ).

This implies that, in Keynes's view, the fundamental cause of instability has to be found in the lack of adjustment of the market interest rate to the natural interest rate. This lack of adjustment can be seen as an information problem; the banks do not have sufficient information to estimate the marginal efficiency of capital. Leijonhufvud (1981:140) stresses that even a difference in perception of the marginal efficiency of capitall by banks and firms may cause coordination problems. For example, when the marginal efficiency of capital as perceived by the firms decreases, each bank observes that it becomes more difficult to lend capital. But the banks do not know to what extent this is a general problem. Therefore, they may delay the adjustment of the interest rate. As a consequence, investment will be lower than saving.

According to Keynes (1937b:11), uncertainty is the ultimate cause of the inequality of the market interest rate and the natural interest rate. If "our knowledge of the future was calculable and not subject to sudden changes, it might be justified to assume that the liquidity-preference curve was both stable and very inelastic... In these conditions we might reasonably suppose that the whole of the available resources would normally be employed; and that the conditions required by the 
orthodox theory would be satisfied". This implies that the role of expectations and uncertainty is essential in the argumentation of Keynes.

Keynes (1936) argues that a fundamental cause of uncertainty can be found in investment. "It is by reason of the existence of durable equipment that the economic future is linked to the present. It is, therefore, consonant with, and agreeable to, our broad principles of thought, that the expectation of the future should affect the present through the demand price for durable equipment" (p 146). The existence of money makes the problem worse because this creates the opportunity not to invest everything that has been saved. "Investments which are "fixed" for the community are thus made 'liquid' for the individual" (p 153).

Because investment decisions have to be made in a world where the future is unknown, the "actual results of an investment over a long term of years very seldom agree with the initial expectation. Nor can we rationalize our behaviour by arguing that to a man in a state of ignorance errors in either direction are equally probable, so that there remains a mean actuarial expectation based on equi-probabilities" ( $\mathrm{p} 152$ ).

Conwentions have an important role to play in such an uncertain world. Keynes defines conventions as ". the existing state of affairs will continue indefinitely, except in so far as we have specific reasons to expect a change." For Wicksell this was the fundamental reason that banks reacted too slowly to changes in the marginal efficiency of capital. According to Keynes, conventions may improve the predictability of behaviour. The "above conventional method of calculation will be compatible with a considerable measure of continuity and stability in our affairs as long as we can rely on the maintenance of the convention" (p 152; see also Heiner, 1983).

Keynes (1936) contends that the importance of conventions for the valuation of stock has important consequences in the capital market. Most professional investors and speculators "are, in fact, largely concerned, not with making superior long-term forecasts of the probable yield of an investment over its whole life, but with foreseeing changes in the conventional basis of valuation a short time ahead of the general public" (p 154). "Thus the professional investor is forced to concern himself with the anticipation of impending changes, in the news or in the atmosphere, of the kind by which experience shows that the mass psychology of the market is most influenced" (p 155). "When the capital development of a country becomes a byproduct of the activities of a casino, the job is likely' to be ill-done" (p 159).

But even if there were no short term speculation, stability is not guaranteed. "Even apart from the instability due to speculation there is the instability due to the characteristic of human nature that a large proportion of our positive activities depend on spontaneous optimism rather than on a mathematical expectation, whether moral or hedonistic or economic" ( 1 161). "We should not conclude from this that everything depends on waves of irrational psychology. On the contrary, the state of longterm expectation is often steady, and, even when it is not, the other factors exert their compensating effects. We are merely reminding ourselves that humar decisions affecting the future, whether personal or political or economic, cannot depend on strict mathematical expectation, since the basis for making such calculations does not exist" (p 162).

When we summarize the coordination issue, we may state that the "coordination problem is a consequence of the individual lack of knowledge about the behaviour of 
other agents in the economy" (Garretsen, 1992:44). This lack of knowledge is especially important when current behaviour has important consequences for the future, i.e. in the case of investment decisions. "The crucial question in a decentralized economy is how the price mechanism may establish a degree of coordination that ensures full employment" (Garretsen, 1992:44).

From this point of view, the difference between Keynes and the classics can be formulated as follows. According to Classical theory, the market system automatically generates homeostatic tendencies when the economy has been deviated. In the Keynesian view no such mechanisms exist and even destabilizing mechanisms emerge. In most theories one of those is assumed instead of proved.

Leijonhufvud $(1981: 109,119)$ formulates the hypothesis that within some range from the general equilibrium path (the 'corridor') the homeostatic tendencies will dominate, while outside this 'corridor' the destabilizing tendencies will be more important. In that case one has an 'effective demand failure' that is the consequence of the failure of the markets to transmit messages about desired transactions from one side to the other. This is related with the feature of physical and financial buffers in an economy that may have stabiliding effects (Leijonhufvud, 1981:123). Outside the corridor the buffers may be exhausted or people may revise their permanent income expectations towards non-general equilibrium values and behave accordingly.

One would expect that economists would try to test fundamental hypotheses like this extensively. But the contrary is true. Most economists avoid the issue by assuming stability or instability without proof. Only in very simple general equilibrium systems without investment or money have proofs for convergence of the free market towards equilibrium been established. "This is the story of mainstream economics, which Garretsen (1992, chapter 3) characterizes as "the right answers to the wrong question".

\subsection{How most economists avoid the fundamental macroeconomic coordination problem}

In the development of mainstream economic theory after the General Theory, the fundamental macroeconomic coordination issue has not been investigated further. This may be caused by the manner in which Keynes summarized his theory in chapter 18, called 'The General Theory of Employment Restated'. In this chapter he did not even mention the coordination issue. In this section we will discuss briefly the development of economic theory that followed the General Theory. The IS-LM representation of the controversy between Keynes and the Classics has become the mainstream interpretation of the General Theory. This induced a reaction to the implicit assumptions about expectations in the Keynesian models. This reaction initiated the New Classical approach that can be seen as a revival of Classical theory. At the same time the Neo-Austrian approach developed from the Austrian approach. Although the Neo-Austrian approach recognizes the coordination problem, it is also Classical in nature. The New Classical approach induced a reaction, the New Keyne-

\footnotetext{
See for example Fisher (1983) or Hahn (1962).
} 
sian approach. The New Keynesians attacked the New Classicals with their own instruments: the rational expectations hypothesis in combination with equilibrium. So, they also avoided the coordination problem.

\subsubsection{The 1S-LM appraach}

Immediately after the publication of the General Theory, Hicks (1937) incorporated the General Theory of Keynes in a general equilibrium framework. This is the wellknown IS-LM framework. His IS-LM model was like this:"
$M=L(Y, i)$
$\mathrm{Y}_{\Uparrow}=\mathrm{I}(\mathrm{Y}, \mathrm{i})$
$Y_{1}=S(Y, i)$

where $\mathrm{M}=$ money supply, $\mathrm{L}=$ money demand function, $\mathrm{Y}=$ national income, $\mathrm{i}=$ interest rate, $Y_{1}=$ income earned in investment trades, $\mathbb{I}=$ investment function, and $\mathrm{S}$ = saving function. Hicks (1937:468) summarizes the General Theory as a theory that assumes that:

$\partial \mathrm{I} / \partial \mathrm{Y}=0$

$\partial \mathrm{S} / \partial \mathrm{i}=0$

As a consequence, he saw the General Theory as a special case of the IS-LM model.

This implies that the controversy between Keynes and the Classics became a discussion about elasticities. The problems of uncertainty and imperfect information (and therefore the instability of the elasticities) disappeared. This took the thrust out of Keynes's argument, because the "only thing which Keynes removed from the foundations of Classical theory was the deus ex machina - the auctioneer which is assumed to furnish, without charge, all the information needed to obtain the perfect coordination of the activities of all traders in the present and through the future" (Leijonhufvud, 1981:15). Since in the IS-LM framework "the auctioneer is assumed to take care of the coordination issue, Keynes's emphasis on the independent impact of expectations on the decisions of economic agents disappeared" (Garretsen, 1992:44-45).

In the IS-LM model of Patinkin (1965:330) real balance effects have been explicitly modelled, while a bond market has also been introduced. In such a model involuntary unemployment can only be explained by wage or price rigidities. According to Garretsen (1992), Patinkin's version of the IS-LM model, combined with a labour market characterized by sticky nominal wage rates, constitutes the core of the Neoclassical synthesis. In this synthesis the theory of effective demand and liquidity preference are incorporated into the Classical theory. Because of low speeds of adjustment one may assume that the Keynesian theory is true in the short run, while the Classical theory holds in the long run.

\footnotetext{
8 Hicks (1937:472). The notation used is modernized.
} 
The IS-LM model seemed to be inconsistent with Walrasian General Equilibrium Theory. This problem was recognized by Clower (1965) and Leijonhufvud (1968,1981). This was the incentive to introduce a fixprice general equilibrium model where false trading is allowed for. In the fixprice model agents can be rationed in their demand and supply. Therefore, excess demand functions must include quantity constraints besides relative prices. This type of analysis started with Barro and Grossman (1976) and Malinvaud (1977). They show that at given wages and prices an equilibrium is possible in the sense that no one has a reason to regret his decisions. But they do not explain the path towards equilibrium nor the reasons why wages and prices would be sticky.

The synthesis approach has some fundamental problems in it. One of these is the microfoundation of macroeconomic theory. The short run inflexibility of prices and wages is assumed instead of explained. For this reason macroeconomics can be separated from microeconomics in introductory textbooks. The causes of the inflexibility of prices and wages are treated as a different issue. The microeconomic foundations of the macroeconomic theories is only for advanced students. Dynamics is analysed as a sequence of equilibria.

The fixprice approach is not consistent with the General Theory. When Keynes (1936:27) uses models with fixed prices, it is for the sake of presentation but not fundamental to his theory: "In this summary we shall assume that the money wage and other factor costs are constant per unit of labour employed. But this simplification, with which we shall dispense later, is introduced solely to facilitate the exposition. The essential character of the argument is precisely the same whether or not money-wages are liable to change." This is in fundamental contrast to the ISLM model where with flexible wages and prices the Keynesian problem is solved.

While Keynes's theory was fundamentally monetary in character, this aspect has been blurred in the IS-LM model. Where Keynes focused on the instability of money clemand because of speculative factors, money demand in the IS-LM model is a stable relationship. Although Keynes did not pay much attention to money supply, it is plausible that it is influenced by speculative forces, too. In the IS-LM approach money supply is exogenous or at most related in a stable manner with some other variables. Therefore, the fundamental problems around the stability of the supply and demand functions have been reduced to an empirical question about the size of the coelficients in the money supply and demand functions.

In summary, the mainstream IS-LM approach skipped the coordination problem and restricted itself to the analysis of two types of equilibria: for the long run a Walrasian flexprice equilibrium, for the short run a Keynesian fix price equilibrium. The investigation of the coordination processes behind those equilibria has been avoided.

\footnotetext{
Keynes discusses the consequences of flexible wages in chapter 19.
} 


\subsubsection{Monetarists and New Classicals}

The IS-LM model lacks a theory of price adjustment. The missing link has been found in the Phillips-curve that assumes a negative relation between inflation and unemployment. This relation can be derived from the principle of aggregate excess demand. When aggregate excess demand is higher, more markets will have axcess demand. Elementary price theory tells us that prices tend to rise when there is excess demand. Therefore, the higher aggregate demand, the higher the inflation rate. But at the same time aggregate excess demand implies that producers try to increase production and therefore raise labour demand. As a consequence, the higher aggregate demand, the lower the unemployment rate. Hence, the aggregate relationship between unemployment and inflation can be explained by a common third variable: aggregate excess demand.

The Phillips-curve approach provided a lot of criticism, especially from what has been labelled monetarism. For example, Friedman (1968) introduced an adaptive expectation mechanism into the model. As a consequence, the Phillips-curve became a relation between the level of unemployment and the acceleration of the inflation rate. This implied that only for a short time could an expansionary policy set the unemployment rate at a lower level than what Friedman called the natural rate of unemployment. In the long run the inflation rate necessary to generate a lower unemployment rate would reach infinity. As a consequence, at some moment inflation must be restrained by reducing aggregate demand. Therefore, an inflationary period with low unemployment will be followed by a deflationary period with high unemployment.

In fixprice general equilibrium theory the stickiness in prices is assumed ad hoc. This theoretical objection to the fixprice literature has received most attention. The New Classicals attacked the fixprice as well as the adaptive expectations assumption on its irrationality.

This attack is not inconsistent with the view of Keynes on conventions; according to Keynes (1936:152), "... the existing state of affairs will continue indefinitely, except in so far as we have specific reasons to expect a change." The New Classicals go further and assume rational expectations in the sense that they assume that the expectations of the actors in the economy can be modelled as if they are the same as the predictions of the relevant theory (see Muth, 1961:315). This implies that expectations are in equilibrium. Furthermore, the New Classicals assume market clearing.

In New Classical theory it is assumed that a free market economy tends towards a Walrasian general equilibrium. The existence of fluctuations is explained by stochastic disturbances (see Van Zjip, 1992:198). Expected shocks do not influence the equilibrium system. Therefore, disequilibria are explained by unanticipated shocks. Those shocks have an impact on real economic activity through changes in relative prices. Garretsen (1992:51) describes the further development as follows: "Subsequent research has been directed for a considerable part towards the sources of propagation of the initial shock, for instance, through capital and inventory accumulation, adjustment costs of factor inputs or consumption smoothing, on the one hand, and on the implications for the effectiveness of policy of the derived results, on the other hand." As "King (1981) has put forward, information on monetary aggregates is 
available too promptly to support the assumption about the global ignorance of individuals on empirical grounds. In order to tackle some of the issues, the real equilibrium business cycle approach, following the pioneering articles by Kydland and Prescott (1982) and Long and Plosser (1983) has been expanding wery rapidly during the $1980 \mathrm{~s} . . .$. [It is] directed towards the explanation of empirical regularities within the context of a stochastic version of the Neoclassical model of economic growth." 10

In summary, the monetarists as well as the New Classicals start from the assumption that in a free market economy with flexible wages and prices, and rational expectations, the coordination problem is solved. Differences between the natural rate of unemployment and the market rate of unemployment are explained by errors in expectations. In the New Classical approach those expectational errors are generated by random disturbances. Those disturbances can be real in character or caused by government policy. Because the last rype of unpredictability can be avoided, both monetarists and New Classicals stand for a stable and predictable goverument policy.

\subsubsection{New Keynesians and Post Keynesians:}

The New Keynesian approach can be seen as a reaction to the New Classical approach. New Keynesians attack the Walrasian equilibrium characteristics of the New Classical models, but use their rational expectations assumption. They search for microfoundations of price and wage rigidities and show that under certain conditions multiple equilibria exist because of strategic complementarity.

With respect to price and wage rigidities imperfect competition and externalities have an important role. For example, when in a market with imperfect competition a firm reduces its price, it will gain market share at the cost of a lower contribution margin per unit sold. Therefore, it may be that for the individual firm a price decline is not beneficial. But in the aggregate a decline in the average price level increases the real value of money supply and therefore aggregate demand. This benefit is distributed over all firms. So, in this case an externality emerges that may prevent macroeconomic adjustment (Hargreaves Heap, 1992: section 6.3). This example may illustrate that most of those theories focus on the reasons for and implications of imperfect price adjustment (Blanchard, 1987:1). They do not investigate the macroeconomic coordination problem.

The literature about strategic complementarity, the so-called coordination failure approach, seems to be more relevant for the fundamental macroeconomic coordination problem. This approach shows that also in flexprice economies stable Nash equilibria are possible that are less efficient than Walrasian general equilibrium (Coopen and John, 1988). But strategic complementarity models are non-monetary in character (Gordon, 1990), and therefore neglect the fundamental coordination mechanisms implicit in the dynamic Classical theory of, for example, Wicksell. Nevertheless some of them at least show the importance of expectations in the theories about sunspot equilibria and overlapping generations models (see for example Hargreaves

\footnotetext{
See McCallum (1988) for a critical approach.
} 
Heap, 1992, chapter 5). But even when the New Keynesians analyse multiple equilibria they focus on equilibrium positions, and therefore avoid the dynamics of the macroeconomic coordination problem (Cooper and John, 1988). Although in the New Keynesian tradition the possibility of indeterminate or multiple solutions is accepted, they continue to focus on equilibria. In the literature on coordination failures, for example, Nash equilibria are the analogue of cooperative equilibria in the New Classical theory. Questions about the dynamics of the system in disequilibrium situations or the choice of the relevant equilibrium remain unanswered (see also De Vroey, 1990:243-44).

Monetary Post-Keynesian economics does recognize the macroeconomic coordination problem introduced by Keynes (Davidson, 1978, Minsky, 1986). They try to build a complete system on the ideas formulated in the General Theory. it First, they do not believe in the possibility for the central bank to manage the money supply, because of the importance of what they call creditmoney. The existence of substantial "unused overdraft facilities" and "open credit lines" implies that the stock of money is not an adequate indicator of liquidity. The utilization of credits is at the discretion of the banks' borrowers, not the banks themselves. Furthermore, they argue that the monetary authorities are generally reluctant to apply liquidity constraints to the banks because of their function as 'lender of last resort' (Arestis, 1992: section 8.3). Therefore, the interest rate is the most important instrument available for monetary policy.

Second, monetary Post-Keynesians emphasize the role of fundamental uncertainty in investment decisions. Especially the sales perspectives are assumed to be very important. "Animal spirits" and the role of expectations in investment are emphasized. But although there is a rich analysis of the effects of expectations on present economic behaviour, there is very little on the determinants of those expectations (Arestis, 1992: 100).

Third, monetary Post-Keynesians approach the economy as an open evolutionary system instead of a chain of temporary equilibria. Therefore, they emphasize historic time instead of Jogical time. This implies a focus on processes instead of equilibria.

Fourth, the monetary Post-Keynesians emphasize the role and endogeneity of institutions. They stress the importance of retained profits for finance and give it a role in the determination of the profit margin (Arestis, 1992: X). They perceive the economy as consisting of big corporations (megacorps) in an oligopolistic relation to each other. Also the labour market is determined by institutions instead of free market dynamics. This focus on institutions implies that they do not concentrate on the dynamics of a free market economy with relatively small firms. In that sense the fundamental coordination problem is irrelevant in this institutionalist Post-Keynesian analysis.

In summary, while New Keynesian economics focuses on equilibria, Post Keynesian economics tries to analyse evolutionary processes. Where the New Keynesians emphasize imperfect adjustment of prices and wages, the Post-Keynesians stress the inability of monetary authorities to regulate the supply of money and credits. Because the role of monetary feedback mechanisms is central to the macroeconomic

"They also draw heavily from Kalecki. 
coordination problem, this part of Post-Keynesian economics may be important for the investigation of the macroeconomic coordination problem.

\subsubsection{Neo-Austrians}

Hayek (1945:78) defined the economic problem in society as "...how to secure the best use of resources known to any of the members of society, for ends whose relative importance only these individuals know." His central question is how the market system coordinates the plans of individual agents. In order to solve this problem, one has to analyse how people acquire and communicate knowledge, and form their expectations (Van Zijp, 1992:66).

According to Hayek, this coordination of plans is of central importance for understanding the business cycle (see Nentjes, 1993:5). When for example the market interest rate differs from the natural one, the plans of investors and savers are not coordinated adequately. In this sense the Hayekian business cycle is Wicksellian in nature.

Hayek adds to the Wicksellian problem of overinvestment and underinvestment the problem of malinvestment. This malinvestment is caused by the information distortion induced by disequilibrium interest rates. When a boom starts as a consequence of an interest rate that is too low, capital-intensive production methods appear as more attractive than they are. As a consequence, during the boom the capital stock will become too capital-intensive compared with the General Equilibrium solution. Furthermore, because in the beginning of the boom prices will be more flexible than wages, one may expect that the real wages will decline. This reinforces the tendency towards production methods that are too capital intensive. The change towards more capital intensive methods implies that especially the investment sector will expand. When the boom approaches its end, it becomes clear that errors have been made and one tries to correct the errors. Therefore, the investment goods producing sector has to decline. This requires an adjustment period. This adjustment period causes the recession.

Lachmann $(1943,1956)$ reformulated Hayek's problem in a more open manner as the problem to explain sequences of discoordination situations (Van Zijp, 1992:92). This implies there is no a priori reason to assume a tendency towards equilibrium. Expectation formation and knowledge acquisition are essential processes that have to be analysed on an individual level. Lachmann's approach is consistent with the fundamental coordination problem. But he does not reach operational conclusions. This approach has not be taken up by the other Austrians, who continue to assume a tendency towards coordination (Van Zijp, 1992:94).

Since the 1970s the Austrian School of Economics has been revived as the NeoAustrian school. Despite the fact that Hayek (1937) argued that no a priori reasons exist for a tendency of coordination through the market, most Neo-Austrians suggested that they did (see Van Zijp, 1992:103). For example, Kirzner (1973:222) argued that profit opportunities arise when some prices are not correct. Profit opportunities reflect coordination failures. Motivated by the profit perspectives entrepre- 
neurs will be allert for discovering those profit opportunities. ${ }^{12}$ But then Kirzner assumes instead of proves that each profit opportunity that is grasped removes a coordination failure.

In summary, although the Neo-Austrian approach recognizes the coordination problem, it does not really investigate it. Because of the a priori bias towards stability and the reluctance to perform empirical analysis, the results are not very satisfying.

\subsubsection{Conclusion}

The fundamental issue of the extent to which a free market economy is able to coordinate the plans of individuals in such a manner that general market clearing results, is avoided in the bulk of economic literature. The scarce attempts in NeoAustrian and New- and Post-Keynesian economics to discuss the problem do not result in very satisfactory results. The Neo-Austrians fail because they assume instead of prove that profit opportunities improve coordination, while the Neo- and PostKeynesians focus on the existence of multiple equilibria but have difficulties in analysing the dynamics of the system. Therefore, the fundamental macroeconomic coordination problem has not been solved yet.

\subsection{A further investigation of the coordination problem}

In most economic studies the solution of the coordination problem in a free market economy is assumed instead of proved. This is not very satisfactory. Therefore, in this section the problem will be elaborated. This elaboration will be in the Wicksellian tradition. The Wicksellian underpinning of the Quantity Theory of Money will be expanded with an explicit speculative mechanism. Consistent with Keynes (1936) this theory will be labelled as the Classical theory. In this context the Classical theory underpins the assumption that a free market economy tends towards general market clearing. The attack on those stabilization mechanisms will be called $K e y n c-$ sian.

According to Classical theory, recessions are corrected automatically. One may distinguish two fundamental adjustment mechanisms: the interest mechanism and the price mechanism. ${ }^{13}$ The first adjustment mechanism is the interest rate. When for some reason aggregate demand declines, less money is needed to perform transactions. Therefore, the demand for money will decline. As a consequence, somewhere in the economy excess liquidities will arise. The owners of those excess liquidities have the choice between hoarding them and lending them against a positive interest rate. All rational actors will choose the latter alternative. But in order to lend those liquidities to others, one has to accept a lower interest rate. Through such a competition process the interest rate will decline. This implies that the opportunity cost of

\footnotetext{
${ }^{12}$ Loasby (1982:119) and Shackle (1973) say that the entrepreneurs create new profit opportunities.

${ }^{13}$ See for example Ackley (1987:286).
} 
borrowing ${ }^{14}$ declines. Investment and consumption will become cheaper. So, investment and consumption demand will rise. This process will continue until the aggregate excess supply of liquidities thas vanished. Because the interest rate has been lower than the natural rate during this process, the interest rate will rise afterwards.

Speculation may improve the effectiveness of the interest mechanism. When the actors in the economy have expectations that are consistent with Classical theory, they expect that the decline in the long term interest rate will be temporary. Therefore, it $\mathbb{U}$ s profitable to accelerate planned investment projects. The elasticity of demand with respect to the long term interest rate will be higher when one expects that a low long term interest rate is only temporary. But this holds only if one also expects that aggregate demand will recover in the near future. For this reason the stabilizing effect of the adjustment of the interest rate depends to a large extent on optimistic expectations about the future.

The second Classical adjustment mechanism is through the adjustment of wages and prices. When aggregate supply is higher than aggregate demand, competition will result in a fall of prices. Because in a recession investment demand declines a lot more than consumption demand, one may expect that the supply price of the investment goods will decline ${ }^{15}$ more than the supply price of consumption goods. Therefore, capital intensive production methods will become relatively profitable. ${ }^{16}$ This may stimulate investment demand.

Speculation may reinforce the effect of the decline in prices on aggregate demand. When, consistent with Classical theory, the actors in the economy expect that the price of investment goods will rise at the end of the recession, it will be profitable to accelerate the execution of planned investment projects before the end of a period of low prices. Therefore, also the effect of the decline in prices depends to a large extent on optimistic expectations about the future.

Because during a recession capital costs are fixed costs, one may expect that the required contribution margin on labour cost will decline during a recession. Therefore, during a recession wages will decline less than prices. This may soften the decline in labour income because of unemployment, and therefore have a stabilising effect on consumption demand.

The decline in prices may reinforce the effect of the interest mechanism because, according to the Quantity Theory of Money, the decline in prices implies that the demand for liquidities declines. This increases the excess supply of liquidities and hence the incentive to reduce the interest rate. Furthermore, when one expects the decline in prices to be only temporary, one may expect a rise in prices in the future. This implies that the expected real interest rate will be lower than the nominal interest rate. Therefore, this effect also relies to a large extent on optimistic expectations about the future.

Monetarist authors have also emphasized the real balance effect of changes in prices. When the price level declines during a recession, the value of the stock of

\footnotetext{
${ }^{14}$ Or not saving.

15: And the quality of the investment goods may rise.

16 This is consistent with Hayek's theory that incorect interest rates may result in malinvestment.
} 
money rises. When one expects the decline in prices to be continuous, one may see this as a rise in wealth. In that case, one may expect that consumption rises. This may stimulate consumption.

In summary, when for some reason aggregate demand declines, then according to Classical theory the following adjustment mechanisms may start:

1. On the market for credits

a. the demand for credits declines and

b. the supply of credits rises, so:

c. the interest rate declines, so:

d. the demand for final products rises.

2. On the product market

a. the demand for products declines, so:

b. the price of products declines, so:

c. the quantity of products demanded rises.

3. On the labour market

a. the demand for labour declines, so:

b. the nominal wage rate declines, but:

c. the prices of consumer products decline faster, so:

d. the reall wage rises, so:

e. the decline in the demand for consumer products will be lower than otherwise would have been the case.

The adjustment mechanisms will be more effective when one expects that the decline in the interest rate, price level and aggregate demand are temporary.

The Keynesians attack the implicit assumptions in Classicall theory. First, they can attack the assumption about the stabilizing effect of speculation. When during a recession severe problems have to be solved, it may be reasonable to expect that a decline in the interest rate or prices and wages will be of longer duration. When one expects that the reduction in the interest rate will continue, it will be profitable to wait till the further decline in the interest rate has been effectuated. Therefore, when one expects the interest rate to continue to decline, it is wise to delay investment and consumption outlays.

The same holds when one expects the decline of the price of investment goods to continue. If one waits till the decline has been realized, the investment outlays will be lower. Because most investment projects are expected to become profitable only after the end of the recession, there is ample reason to expect a delay of the investment outlays to be profitable. Furthermore, when one expects that demand will remain low for a long time, one will not perceive many profitable investment opportunities, even when the interest rate and the prices of investment goods are extremely low. In summary. when the expectations are contrary to the Classical assumptions, speculation has destabilizing instead of stabilizing effects.

Second, the Keynesians can attack the assumption of a flexible interest rate. The flexibility of the long term interest in periods of recessions is limited. The absolute minimum is a nominal interest rate of 0 percent. But in a situation where one expects the long term interest rate to rise, it may be wise to hold back on the lending of 
excess liquidities till the interest rate is higher (speculative motive for holding liquidities). Furthermore, in a period of uncertainty liquidity may be more important than in normal periods (precautionary motive). Finally, in an uncertain period like a recession the risk of investments is higher than in normal periods. For this reason at risk premium on the interest rate will be required. As a consequence, the long term interest rate will have a threshold that is far above the level of zero.

When excess liquidities are not used, some disequilibrating mechanisms may start. First, because of a lack in aggregate demand national income will decline. Especially the income of the unemployed people will decline. As a consequence they will be restricted in their consumption opportunities. Thus, consumption will decline. Therefore, aggregate demand will decline further. This is the multiplier. About the same holds for investment demand: when final demand is low, there is no reason to invest (investment accelerator).

Expectations are an essential element in the controversy between Keynes and the Classics. To a certain extent it seems to be a type of self-fulfilling prophecy. When people think that the situation will remain bad, consumption and investment will be low and so the pessimism will be reinforced. When they think the situation will become better, they will expand and use the cheap opportunities to invest. But this latter mechanism will only work when opportunities are really availlable. Otherwise, the lack of opportunities will punish the actors who had incorrect expectations. In summary, the process of adjustment during recessions has to be analysed as an interaction between real restrictions and expectations.

This type of analysis is quite different from the mainstream analysis of the difference between Keynes and the Classics. Where in the mainstream approach it is a difference between fixprice and flexprice, in my formulation both Keynes and Classics generate predictions about the behaviour of a free market economy with flexible wages and prices. Leijonhufvud (1981) is one of the very few researchers who has formulated a hypothesis about this coordination issue. According to him, the behaviour of the system may be different with small disturbances than with big disturbances. When disturbances are small, there is ample reason to expect that the disturbance is temporary. Therefore, the market adjustment mechanisms may be sufficient to restore equilibrium. But when disturbances are big, the interest rate will not be able to adjust enough to restore equilibrium and so the disequilibrium forces will win the battle. Following this idea, one can think of a 'corridor' where Classical theory will be adequate and out of which Keynesian destabilizing mechanisms will occur.

In the Leijonhufvud approach, macroeconomic instability is intimately related to the decision making of the investors. The investors are forced to decide under fundamental uncertainty. This uncertainty is caused by the interdependence of the investment decisions. For example, when one investor decides to invest during a severe recession, he will lose his money. But when all investors expand their expenses, this may be sufficient to bring the recession to an end, making most investments more profitable. As a consequence, the behaviour of each investor depends on the expectations about the behaviour of the other investors. And this may result in prisoner's dilemma type situations. As a consequence of such dilemmas it is not evident that excess liquidities are always used when it is profitable from an aggregate point of 
view. Therefore, the Keynesian problem is fundamentally a problem of externalities.

In the Lejornhufvud approach disequilibrium is an essential characteristic of a free market economy. Investment decisions are based on expectations about future opportunities that depend partly on still unknown decisions of other investors. The process of decision making under fundamental uncertainty is very difficult to model formally, but can be explained rather easily in an intuitive way. The intuitive description of adjustment paths is not very difficult to understand when it is explaned by a few simple stories of decision makers in specific situations. From a disequilibrium context, macroeconomics is the logical consequence of thinking in microeconomic decision making.

In conclusion, the controversy between Keynes and the Classics is fundamentally a controversy about expectations and market dynamics. It is a dynamic problem that: requires the analysis of processes instead of equilibria. Although this may be difficult to incorporate in a mathematical model, it is rather easy to understand intuitively.

\subsection{The role of a macroeconomic game in teaching and research}

The avoidance of the coordination issue may be one of the most important causes of the feeling of many lay people that economics is an abstract and counterintuitive science. Especially the limitation to the use of equilibria is very counterintuitive in a world where those equilibria cannot be perceived directly. Mayer (1993:7) suggests that mainstrean economists focus on mathematical precision at the cost of empirical truth. ${ }^{17}$ He argues that economists focus on those parts of a line of reasoning that can be proved easily, where they attribute the strength of those strongest parts to the entire argument. He calls this the 'principle of the strongest link' (p 57). This may explain why mainstream economics is very precise on the analysis of the consequences of imperfections in a market system, and implicitly suggest that the fundamental macroeconomic coordination problem is not important.

Although economists may rationalize the coordination problem away by thinking in their own elegant mathematical worlds, for lay people this creates the feeling that the world analysed by economists is not the world they live in. The approach sug* gested in section 1.4 may be one step in the direction of a more realistic (but less precise) method for teaching and investigating economics. With respect to teaching, students may get a better feeling of the abstract principles of a market economy through introspection and stories that are intuitivelly plausible. Because the coordination problem approach requires insight in the dynamics of the market system, one can explain the basic principles of economics with the help of stories. It may be helpful to ilucidate the theory with the help of stories from real world history and newspaper articles. This approach will be developed in chapter 2. But first we may investigate the role of a macroeconomic game in understanding the coordination

\footnotetext{
${ }^{17}$ Butos (1986:337) explains the limitations of New Classical economics by their focus on mathematical techniques: "... New Classical economists limit their conceptualization by the techniques available, while for Hayek the conceptualization of a problem points to the limitations of available techniques."
} 
process.

Because the fundamental macroeconomic coordination problem is very difficult to analyse mathematically, one may search for other methods of investigation. The case study approach may be such a method; one that is easier to use in teaching than in research. Another technique is the method of laboratory experimentation. This approach is applicable both in teaching and research.

The challenge picked up in this dissertation is to develop a macroeconomic experimental model of the coordination problem. Because Hayek, the Classicals and the Keynesians are conflicting theories about the solutions of the fundamental macroeconomic coordination problem, the game has to be consistent with all of them. Therefore, the experimental world is a world with independent decision makers that are connected with each other through free markets. Because in a Classical world substitution between capital and labour is essential, the firms must have technologies with substitution possibilities between capital and labour. Because in a Hayekian world owerinvestment and malinvestment have an important role in the explanation of business cycles, possibilities for substitution have to be limited in the short run. Because in a Classical world perfect competition is assumed on all markets, the markets in the experimental world have to be at least as competitive as in the real world. Because in the Keynesian model investment demand is an important explanation for the business cycle, the market for investment goods has to be modelled explicitly in the experimental world. Because the fundamental controversy about the stability of the free market economy focuses on the demand for investment goods, it is important that the investors can be perceived explicitly in the experimental world. The most important decision makers in this context are the firms. Therefore, in any case the firms must be modelled as independent decision makers in the game. Because of the central role of credits for investment, the monetary sector would be the second part that should be modelled explicitly as independent decision makers. The choice of which decision makers are modelled explicitly and which only as a computer model depends on the focus of investigation.

The decision makers in a macroeconomic game can be modelled as computer programs as well as human decision makers. Computer players may help to understand the dynamic features of the system. But expectations have a fundamental role in the controversy about the macroeconomic problem. When New Classicals or New Keynesians assume rational expectations, the process by which those are formed is not clear and not easy to model. Therefore, it may be necessary that real human beings play the game.

When an experimental game is used in the context of teaching, it is obvious that the best way to get an intuitive grasp for the macroeconomic system is to participate in it. When the students have to decide for themselves to hire or fire labour, they will be more open to theories that explain unemployment. When in a recession they are engaged in a competitive process reducing the prices, they will betier understand its causes. Furthermore, when they are able to play the game a second or a third time, they will learn that the performance of an economy depends partly on the experience of the decision makers. When the players are able to reap profits from better predictions, they will be motiwated to gain a better insight into the system dynamics.

If the game does not avoid the coordination problem, the players will be able to 
feel the relation between microeconomics and macroeconomics. For example, in a recession they will learn that it is profitable to set prices lower than the integral cost price, and hence feel the difference between fixed and variable cost. They have to think about the structure of their capital stock, and hence learn the substitution principle. In a boom they will find out that it is profitable to raise their prices, and therefore may learn about inflation. They will experience the accelerator principle when they try to expand at the same time as others. In summary, in playing the game students will get an intuitive understanding of the decisions that are implicitly described in textbook theories. One may assume that this improves understanding of those theories. When the economics course is focused on the coordination problem, playing the game will increase understanding of what this coordination problem is about.

In summary, a macroeconomic game can have a role in fundamental economic research as well as in teaching economic principles. Although the economic principles discussed in section 1.4 are a useful background for understanding the game, the game is also useful in traditional courses in economics.

\subsection{Conclusion}

Most economic theories assume equilibrium in some way or another. Those theories do not solve the problem described by Hayek (1937:46):

"The statement that, if people know everything, they are in equilibrium is true simply because that is how we define equilibrium. The assumption of a perfect market in this sense is just another way of saying that equilibrium exists but does not get us any nearer an explanation of when and how such a state will come about. It is clear that, if we want to make the assertion that, under certain conditions, people will approach that state, we must explain by what process they will acquire the necessary knowledge."

The analysis of such a process is difficult to trace mathematically. Therefore, it is not surprising that in research as well as in teaching this process analysis of the coordination problem has been avoided by most authors. This is regrettable because an insight into the fundamental macroeconomic coordination problem is an important aspect of understanding macroeconomic dynamics and relating microeconomic principles to macroeconomic theory. This avoidance of the fundamentals may both explain why fundamental economic controversies have not been settled and the difficulties non-economists have in understanding economic theory. This dissertation describes the development of a game that can be used as an experimental setting for investigation of the dynamics of a free market economy as assumed in monetarist theory, Hayekian theory as well as in Keynes (1936). In teaching, such a game can be helpful in showing the decision making problems that are implicit in most theories. In research such a game can be used as an experimental world that can help to get a better grasp of the fundamental dynamics of a free market economy. If a theory about a free market economy cannot explain the dynamics in the very simple game 
economy, how could it ever be able to explain a real world economy?

\subsection{Plan of the thesis}

In chapter 2 the usefulness of an experimental macroeconomic game in teaching will be investigated. For this reason some fundamentals of teaching are discussed more thoroughly. Cognitive psychology is a useful instrument for this. But the approach to teaching economics is also related to the content of economics. According to Keynes, economics is more a method of thinking than a set of well-defined theories: "The theory of economics does not furnish a body of settled conclusions immediately applicable to policy. It is rather a method than a doctrine, an apparatus of the mind, a technique of thinking which helps its possessor to draw the correct conclusions" (Keynes, Collected Works, vol. VII, p 856). Because economics is a method of thinking, students have to be trained to apply this apparatus to real situations instead of to artificial numerical or mathematical examples. This implies that economics can only be mastered by applying the basic principles in many different situations. One of those situations may be a game that is a world consistent with the fundamental theories. In such a game students will be able to participate actively in an economic world. This is a useful supplement to the application of economic methods to real world examples. In the game one can understand macroeconomic phenomena as the consequence of human decisions.

In chapter 3 the experimental method will be investigated. Because this method has been developed especially in microeconomics, a microeconomic line of experimentall research will be used as an illustration of the general approach in experimental economics. A macroeconomic game will be discussed to show the complexities of macroeconomic experiments. A set of criteria for good experiments will be discussed.

If one likes to use a game as an experimental setting for testing fundamental macroeconomic theories, the model behind the game has to be consistent with all those theories. Therefore, the model has to be very general. In chapter 4 the model behind the game is derived from a simple general equilibrium growth model.. The equilibrium model becomes a game at the moment the equilibrium conditions in the game are replaced by market institutions. If the firms had New Classical rational equilibrium expectations, the economy would follow the general equilibrium growth path. But if the decisions of the firms are different from that, the economy will behave differently. Hayekian overinvestment as well as Keynesian multiplier- and accelerator processes become possible. Chapter 5 elaborates on the extensions of the game model that are necessary to allow for disequilibrium.

An economic model is necessary but not sufficient to make a game. In order to create a game from the model a lot of problems have to be solved. For example, what information must be available for the players and what instruments do they need to structure it? How fast must time go on? How to make the computer programs foolproof? How to instruct the players? The last question especially is fundamental. For teaching purposes the players have to learn from their errors during the game. In experimental settings the game has to model an economy with informed and able 
decision makers who know what they are doing. When the players do not understand enough of what they are doing, the results will have no value. Hence, the training of players is an essential part of the game for teaching purposes as well as for experimental purposes. The teaching principles discussed in chapter 2 can be applied in the design of such a training program. This is the topic of chapter 6 .

The first results and perspectives of the game are discussed in chapters 7 and 8 . In chapter 7 techniques will be elaborated that can be used to evaluate both the basic principles approach to teaching economics and the perfornance of the game. Factor analysis of questionnaires and examinations, conceptual organization tests and tests for the ability to recognize theory in stories are developed and applied. Chapter 8 investigates the opportunities for using the game as an experimental method. The first part of chapter 8 discusses a research strategy consisting of a combination of theory, simulation and experiments with human beings. Two games played in June 1993 are used as an illustration. Because the construction of the computer program for the game is not complete at this moment, systematic experiments have not been possible yet. The second part of chapter 8 investigates opportunities to expand the game. Finally, chapter 9 summarizes the main argument. 


\section{Chapter 2 \\ Didactics and (macro-) economics}

\subsection{Introduction}

Although the game developed in this thesis can be used for a lot of purposes, the investigation of the fundamental macroeconomic coordination problem was the main reason for $\mathrm{its}$ development. The neglect of this coordination problem in mainstream economics may explain why a lot of students experience economics as counter-intuitive. In this chapter the approach to teaching economics will be investigated more deeply. The teaching principles derived in this chapter will be applied in chapter 6 in discussing the training programme for the players of the game. In this chapter the focus will be on the didactic aspects of teaching economics in general.

You may expect that people with an economics training will be better at solving real world economic problems than people with a training in a different subject. Nevertheless, Voss et al. (1986) did not find this relation; they only found a relation between the level of general training and the ability to solve economic problems. This is in contrast with the findings of two studies in physics (McCloskey and Kohl, 1983; McCloskey. Washburn and Felch, 1983) that showed a clear relation between the training in physics and the ability to solve real-life physical problems. Voss et al. (1986:295) explain the difference by the "relative mapping of the tasks between the classroom and everyday life. Specifically, the tasks used in the physics research mapped quite closely onto the physics principles that were studied, whereas the tasks employed in our study were mapped closely to economic issues found in everyday life, even though the concepts evoked by the task are part of the course contents of introductory economics courses. ... Such a conclusion suggests that instruction in introductory economics courses is oriented toward leaming the subject matter of economics requisite to majoring in economics rather than learning about the intricacies of economic operations found in everyday life."

Similar conclusions have been drawn by other investigators. With respect to graduate education Colander (1990: 187-191) perceives a lack of realism and an inclination to present prejudices. "Students feel a lack of reality in what they study because, by design, there is little reality there; the focus on techniques and modelling precludes it. There are such differing views among schools because the views are built into the models and techniques the students learn. Students do not learn - and 
are not meant to learn - to question or to assess those models. ... And that's what I' $m$ saying is wrong with graduate education. It doesn't give students the tools they need to deal with the economic problems they will face." Hansen (1991:186) also detects the problem in the focus on technique instead of content: "academic economics and graduate training have become increasingly preoccupied with formalism and technique, to the exclusion of studying real-world problems and issues that can be illuminated by some blend of theoretical, empirical, and institutional research."

The focus on technique in the economics programmes can be explained partly as the consequence of a selection process of teachers. Klamer and Colander (1990:26) describe this process as follows: "Students come into graduate school wanting economics to be relevant, and they are taught theory and techniques that point out the complexity of the problems. But they quickly come around; they perceive the incentives in the system. They are convinced that formal modelling is important to success, but are not convinced that the formal models provide deep insight into or reflect a solid understanding of the economic institution being modeled." This is consistent with what Colander (1990:193) states: "The selection process is screening out those individuals with the interpretive skills to deal effectively with reasonably interpreting nonformal empirical evidence. Students who go into and get through graduate economics programs are those who accept technical modelling for its own sake. And these will become the next generation of teachers. ... Graduate programs teach technique, leaving students to learn interpretive skills and sensibility on their own. Most don "t." As a consequence for most teachers to "try to relate your model to reality means entering into an uncharted area, an area for which you have no training."

Colander (1990:193) suggests the introduction of methodologies used in sociology as a solution to the problem in economics teaching: "In sociological methodology, models serve an organizing role. They structure one's thinking about a problem and make it possible to consider the problem in an orderly fashion. To serve this purpose, they do not have to be precise; in fact. precision can destroy the purpose of the model by diverting one's focus from the general ideas to the technical aspects of the model - by making it more difficult to keep in the back of one"s mind the applicability of the model. If this sociological methodology were adopted, economics would be more meaningful, and graduate economics would be less cynical." Although sociology is not very successful in explaining reality, this methodological approach may be useful for teaching economics.

Some authors think the use of mathematics is part of the teaching problem in introductory economics and other sciences. With respect to science Linn (1986:190193) mentions that in many courses mathematics is an arificial barrier that can be avoided. Chiang (1974:5) writes about the risk of using mathematics in economic research: "an economist with mathematical training is subject to the dual temptations of (1) limiting himself to problems that can be solved mathematically and (2) adopting inappropriate economic assumptions for the sake of mathematical convenience. Unless he is careful, therefore, he may become preoccupied with, and engulfed in, mathematical techniques instead of economic principles. In other words, one may unwittingly let mathematics assume the status of master rather than servant." While

"Referring to Ridgeway (1983) and Rowe (1983) 
mathematics is a temptation for professional economists in their research, it is even more in their teaching because in teaching they are restricted much more in the mathematical techniques that can be used. This may be one explanation of why students in economics feel such a gap between economic theory and economic reality.

In this chapter some causes of the problems in economics courses will be investigated and an alternative approach will be introduced. First, six teaching principles will be derived from cognitive psychology (section 2.2). Second, with the help of those teaching principles the content of an introductory textbook in economics will be analysed (section 2.3). Part of the problem with mainstream economics textbooks can be explained by the avoidance of basic problems like the fundamental coordination problem discussed in chapter 1. Therefore, in section 2.4 the opportunities for an alternative approach are discussed. This approach may be characterized as a principles-based approach in contrast to the traditional model-based approach. The six teaching principles developed in section 2.2 are applied to this approach. Finally, in section 2.5 the six teaching principles are applied to the game that will be developed in chapter 4.

\subsection{Psychological foundations of (economics) teaching}

In order to understand teaching, one has to know about the learning process, including the motivation to learn. In order to understand the learning process, one has to know about the structure of human knowledge. The comparison between problem solving of experts and novices gives a lot of information about the knowledge structure. This is, in reverse order, the structure of this section.

\subsubsection{Comparisons between novices and experts}

The comparison between expert and novice problem solving shows a lot about the structure and functioning of human knowledge. Glaser (1991:137) finds that studies "of expert-novice differences in problem solwing reveal that a major difficulty for novices is inferring certain elements that are not explicilly described in the problem and adding these to the representation or interpretation of the problem situation." It is evident that experts have more knowledge than novices. But this is not the most fundamental difference. "The problem-solving behaviour of experts and novices reveals that experts differ from novices in both the extent of their knowledge and its organization" (Glover, 1990:28). The "knowledge of the expert is organized and is apparently organized in such a way that it is accessible within a number of problem contexts." Glover et all. (1990:23) formulates it as follows: "Clearly, one aspect of expertise is recognizing the value of knowledge in its widest possible set of contexts. Research evidence suggests that when faced with a problem, experts are more likely to use a wide array of knowledge because it is organized and contextually linked in a

\footnotetext{
(1980).

Gagné (1985:235). Regarding physical problems she refers to Chi et al. (1981) and Larkin et al.
80 ).
} 
system of great breadth and depth." In summary, the expert not only has more knowledge, but has especially knowledge that is betrer organzed and is accessible from different contexts.

A lot of evidence suggests that in problem solving novices focus on the solution, while experts reason from the assumptions towards the conclusions. Voss (1986:234) finds in protocols of the solution of ill-structured problems that experts frame it in a causal structure, while novices enumerate direct solutions. Glover et al. (1990:28) summarizes the literature when he writes that experts "spend more time trying to understand difficult problems as well as devising methods that work forward to solution. In contrast, novices tend to begin problem solving before they thoroughly understand the task, and respond erratically, in many cases attempting to work backward from what they believe the solution will be." Gagné (1985:145) writes: "It seems surprising that the expert would use the simpler working-forward strategy and the novice the more powerful means-ends analysis. However, the expert's workingforward strategy is based on a great deal of experience in which he or she has llearned which moves work at what times. In some sense, the expert's behaviour is not strategic at all. Rather, he or she is automatically recognizing known patterns and applying the action sequences associated with those patterns." This was first perceived in chess (De Groot, 1965; Chase and Simon, 1973), but also in for example team sports and electronics (Allan Burnett, 1985); Egan and Schwartz, 1979). Therefore, pattern recognition is one of the important capabilities of experts.

Besides domain-specific knowledge, experts also have so-called meta-knowledge or strategic knowledge (Glover, 1990:28). According to Glaser (1991:133-134) "research on expert-novice comparisons in a host of domains shows that experts' experience allows them to judge the difficulty of problems accurately and assess their progress. Such self-regulatory skills vary in individuals and appear to be less developed in those with performance difficulties, as well as in novices in a domain." Gagné (1985:165) writes: "Planning becomes more important as individuals gain expertise based on increased knowledge."

The problem solving strategy of experts is intimately related to the organization of their knowledge structure. "The better organization of experts" knowledge explains their ability to relate many problems to a few fundamental laws. According to Bereiter and Scardamalia (1992:524/5) expert "mental models tend to be fully consistent with the experts' formal knowledge, unlike naive mental models. Resnick (1987), speaking with reference to mathematics learning, suggests that growth in understanding requires the continual transformation of formal knowledge into intuitive understanding in order that it may support the further growth of formal knowledge." "Protocol studies of live physicists" ... suggest that informal thinking is carried out with models that are consistent with the formal models, but that differ from them in fundamental ways (Bobrow, 1985). The informal models are causal and dynamic, whereas the formal models represent equilibrium states."

Experts rely heavily on automatic procedures called productions (Gagne (1985: 103). When knowledge is organized as a set of propositions (i.e. declarative knowledge), the retrieval process of this knowledge is slow, because the search for it involves a multi-dimensional search process (see section 2.2.2). In productions the search process has been automatized, so that the search process starts with a standard. 
search path. As a consequence, when knowledge moves from a declarative to a procedural representation, the performance it underlies speeds up dramatically (Gagné, $1985: 121)$.

In summary, compared with the novice the expert has more knowledge that is better organized and that cal be approached from more domains. The knowledge structure of the experts has reached a high level of consistency, especially between formal (i.e. equilibrium) and intuitive (i.e. causal) knowledge. A lot of knowledge is incorporated in productions. An expert has more meta-knowledge.

\subsubsection{The human knowledge structure}

One may try to understand the differences between novices and experts by developing a model of human thinking. It is generally accepted that human thinking is performed in short-term memory. But short-term memory cannot hold more than seven units of information (see for example Miller, 1956). Bereiter and Scardamalia (1992:529) mention three ways in which this limitation is overcome: the use of long-term memory, chunking and automaticity. All those methods depend to a large extent on the structure of the long-term memory. The central idea in modern cognitive psychology is that human thinking is based on a network of knowledge.

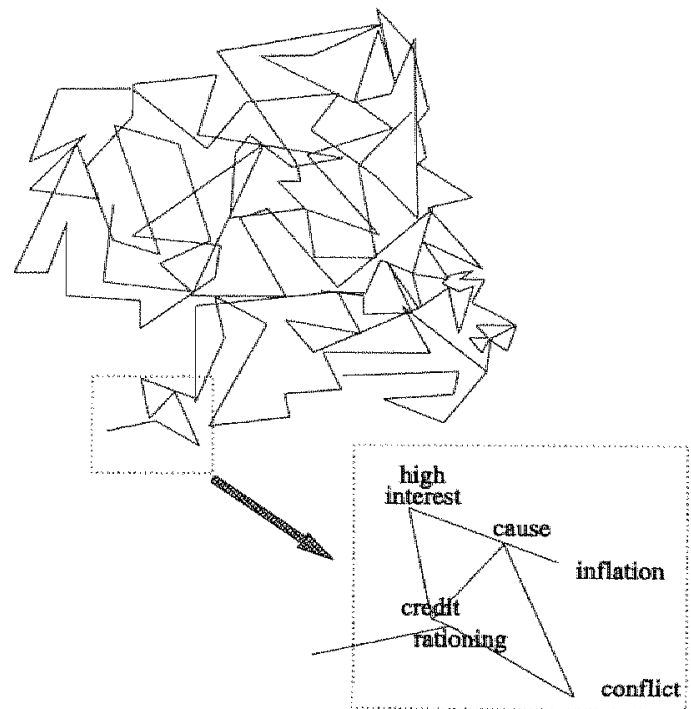

Figure 2.1 A knowledge structure. This network can be called a knowledge structure (Glaser, 1991:132).

One may imagine a knowledge structure as consisting of schemata (see figure 2.1). A schema can be defined as "a modifiable information structure that represents generic concepts stored in memory. Schemata represent knowledge that we experience - interrelationships between objects, situations, events and sequences of events that normally occur. In this sense, schemata are prototypes in memory of frequently experienced situations that individuals use to interpret instances of related knowledge... A schema can be thought of as a theory or internal model that is used and tested as individuals instantiate the situations they face. As is the case for a scientific theory, a schema is compared with observations, and if it fails to account for certain aspects of these observations, it can be either accepted temporarily, rejected, modified or replaced. Like a theory, a schema is a source of prediction and enables individuals to make assumptions about events that generally occur in a particular situation, so that the knowledge they infer goes beyond the observations that are available in any 
one instance" (Glaser, 1982:100). Therefore, a schema can be seen as a theory in the mind.

The knowledge incorporated in a schema can be programmed in different manners. Gagne (1985:35) dustinguishes three types of knowledge: propositions, productions and images. A proposition is defined as a basic unit of information, corresponding roughly to one idea. Those propositions are linked to each other in networks. Propositions that share topics are more closely related to each other than those not sharing topics. Experts in a topic have a lot of connections between specific and general propositions, and hence are better able to chunk information. Productions are condition-action rules that perform specified actions under specified conditions. Productions are linked in production systems, where the action taken by one production creates the conditions of another production. Productions represent automaticity. Glover et al. (1990:172) refer to production systems as schemata in action. Finally, images represent information continuously thather than discretely. They are used in working memory to reason about entities that have a spatial dimension. Glover et al. (1990:130) remark that generally speaking, "when students construct images associated with to-be-learned information, their memory performance is enhanced."

One may try to understand the differences between experts and novices by means of this model. The human mind is seen as a knowledge structure in long term memory with information processing going on in short term memory that has a very limited capacity. "This implies that only a "few propositions in the propositional network are active in working memory at a given time." One may call this awareness. "Spread of activation is the process whereby activation spreads from an active proposition to the propositions that are closest to it. As activation spreads, the initially active proposition becomes inactive."

"When for example a question is asked, the elements of this question are stored in short term memory. Through a pattern recognition process this information is related to information in long term memory. The internal representation of the question activates propositions that share concepts with the question that started the retrieval process. Activation spreads from these propositions to related propositions until the answer to the question is found... If an answer cannot be retrieved, it can be constructed by bringing logical processes to bear on activated propositions so that a plausible answer is generated" (Gagné, 1985:71-75).

According to this model, the differences between remembering, problem solving and perception are much smaller than they seem to be. On the side, considerable "evidence suggests that retrieval is reconstructive (e.g. Mandler, 1984; Spiro, 1977, 1980). In other words, rather than remembering the entirety of a memory event, only key elements of an episode are stored, guided by schemata" (Glover et al., 1990:60" see also page $90,139,147$ ). With respect to problem solving, considerable evidence suggests that the recognition of patterns is even an important part of logic games like chess.

This model of problem solving explains the differences between novices and experts. First, the better organization of knowledge implies that the different propositions are related to each other in an efficient manner. This implies that the spread of activation goes automatically to the fundamental principles. Second, the ability to approach the knowledge from different contexts implies that the knowledge has been 
related to a lot of relevant schemata that may be activated alt a certain moment. Third, the consistency of the different parts of the knowledge structure diminishes the chance that incorrect information is used or incorrect conclusions are derived. Fourth, the automaticity of a lot of the knowledge structure can be seen as standard paths that can be followed. Because the number of choices is minimized, it requires less effort in short term memory. Finally, when the expert is able to recognize patterns and to relate them to standard solution strategies, it is evident that planning becomes easier.

\subsubsection{Learning}

A novice becomes an expert through learning. Learning can be seen as changing the knowledge structure. With respect to learning there is an important difference between declarative and procedural knowledge. "Declarative knowledge is knowledge about facts and things, knowledge that something is the case. In contrast, procedural knowledge is knowledge about how to perform certain cognitive activities, such as reasoning, decision making and problem solving" (Glover, 1990:64). Procedural knowledge is mostly 'automatized'.

Learning of declarative knowledge "is a process of constructing new knowledge on the basis of current knowledge" (Glaser, 1991:132). Gagné (1985:77) mentions three principles of knowledge acquisition:

"1. New propositions cue the retrieval of related prior knowledge through the spread of activation.

2. The new propositions and the prior knowledge may stimulate the student's generation of other new propositions (this process is called elaboration).

3. All the new propositions (both those presented by the environment and those generated by the learner) are stored close to the related prior knowledge that was activated during learning.*

Rumelhart and Norman (1978,1981) and Rumelhart $(1984)^{3}$ distinguish three types of learning of declarative knowledge. First, one may add new information to preexisting schemata. This is called accretion. Second, one may improve existing schemata through modification and refinement as a consequence of feedback. Especially it becomes easier to use the schemata in different contexts (Schmidt al., 1989). This is called tuning. Third, one may create new schemata in memory. This is called restructuring. New schemata appear to be learned by seeing analogies with existing schemata.

The acquisition of procedural knowledge seems to be quite different. Neves and Anderson (1981; cited in Glover, 1990:20-22) distinguish three steps. The first is the encoding of declarative knowledge. For example, a young pianist learns which finger he has to use for which tone. The second is proceduralization of this knowledge. For example, the young pianist practises the different scales. This implies that the declarative knowledge is transformed into procedural knowledge. The procedures can be

\footnotetext{
${ }^{3}$ See Glover $(1990: 167,182)$
} 
executed directly, without consciousness, and are therefore much faster. Finally, composition, where the different procedures are integrated and combined. For example, the young piamist learns to use the correct fingers when playing complicated pieces of music.

Gagné $(1985: 132,133,321)$ remarks that the optimal strategy for learning procedural knowledge is different from that for learning declarative knowledge. While for declarative knowledge successful learners are more likely to use elaboration and organization as strategies, for procedural knowledge repetition with feedback seems the most efficient strategy. Glover et al. (1990:20) mentions also the importance of an efficient distribution of practice over time for the acquisition of procedural knowledge.

Gagné (1985:102-103) distinguishes two main types of procedural knowledge: pattern-recognition and action-sequence. "The former underlie classification skills, whereas the latter underlie the ability to carry out sequences of symbolic operations." Pattern recognition is learned through generalization of examples, and discrimination between examples and non-examples. Action-sequences are learned through proceduralization of declarative knowledge into procedures and composition of those procedures into bigger ones.

When we try to summarize those theories of learning, it is clear that the dis tinction between procedural knowledge and declarative knowledge is rather vague. Therefore, I prefer to follow Glover et al. (1990:172) in referring to production systems as schemata in action. Proceduralization can be seen as the transformation of declarative knowledge in automatic procedures. It will be clear that automaticity has advantages in speeding up the process, but will create errors when the procedures are not adequate. Every sportsman or musician knows the difficulties of unlearning incorrect techniques.

In summary, new information activates part of the existing knowledge structure. Which part depends not only on the information but also of the part of the knowledge structure that is active at the moment the information enters (context). When a student elaborates new knowledge, links are created within and between schemata. Because new knowledge is stored near to the knowledge that was activated during learning, it is important for learning that the existing knowledge is activated during the learning process. Modification and refinement of the knowledge structure improves the organization of the material and removes inconsistencies. Proceduralization improves speed, but may have a cost in a loss of flexibility. The restructuring and composition processes create new schemata and may improve organization. Because pattern recognition within different contexts is an important part of the functioning of the expert, this requires explicit training, too.

\subsubsection{A Cognitive theory of motivation}

Time spent on learning is influenced considerably by motivation. Therefore, motivation is very important for learning. Gagne (1985:302,317,318) mentions that modern cognitive psychologists see a more important role for cognitive than for emotional causes of motivation. Although many people hold the theory that reinforcers work 
because they are pleasant, from another point of view one may see them as providing information. "If we had sought pleasure at the expense of information for the past 4 million years, it is doubtful that we would have survived as a species." How may this cognitive mechanism work?

In the evolution of the human species it must have been very important that available information is used in problem solving. Therefore, a feeling of uncertainty must arise when information seems to be inconsistent. "Uncertainty is produced when we experience something novel, surprising, incongruous, or complex (Berlyne, 1960)."4 But inconsistency can also be endogenously generated without new information. Piaget $(1967 ; 1980)$ postulates an important role for cognitive conflict in motivation. "The interesting proposal in Berlyne"s theory is that thoughts affect the direction and intensity of behaviour; that is, they affect motivation. When uncertainty arises, it is natural that a moderately aroused state arises. This state may be called curiosity. Curiosity leads to exploratory behaviour. Therefore, students naturally seek to elaborate on and organize new information. If they cannot, for example because the new information does not remind them of anything, they may become "unmotivated $^{2 * 5}$.

But, on the other hand, too much uncertainty without adequate methods to reduce it will inhibit motivation, too. Furthermore, attribution theory suggests that people must expect a relation between effort and success for motivation. Thus curiosityproducing techniques will be effective only when they generate an optimal arousal level and people expect to be effective in finding solutions.

\subsubsection{Six teaching principles}

From the model of human information processing and the learning principles, one may derive teaching principles.

The first principle derives from the fact that new knowledge is stored near to the knowledge that is active at the moment the knowledge is presented. Therefore, teachers have to relate knowledge in some way to what the students already know and existing knowledge has to be activated before the new knowledge is presented (Glover et al., 1990:27,128,130; Schmidt et al., 1989).

The second principle focuses on the organization of the knowledge structure. In Gagné"s (1985:71-72) opinion "organization of declarative knowledge involves generating propositions that represent relationships between subsets of knowledge. Organization during learning aids in retrieval of information by providing effective retrieval cues." According to Linn (1986:176) instruction "emphasizing knowledge organization appears to influence problem solving because it makes the information relevant to solving a particular problem readily available to the learner. Thus Eylon and Reif (1984) demonstrated that hierarchical knowledge organizations which are congruent with the problem-solving situation result in better problem solving than irrelevant knowledge organizations." This implies that the organization of the information has to

\footnotetext{
Gagne (1985:304, 305)

Gagné (1985:101).
} 
be consistent with the structure of the problems in which the student will have to apply this knowledge.

Glover et al. $(1990: 113,129,130)$ remark that for improved memory performance knowledge has to be organized well and as much as possible in advance. Furthermore, because the organization of knowledge determines the use of information, it has to be organized in a manner that students can use it in practice. Finally, the teaching has to be focused on fundamental meaning instead of superficial aspects.

Glaser (1991:133-137) remarks that because "textbooks are an important part of the teaching process, it is disappointing that most textbooks encourage students neither to construct the organized knowledge that is needed for thinking nor to acquire further knowledge." One may hope that textbooks provide features that assist students in building their own models of information. Especially "texts designed for young children should deal with issues of background knowledge and coherence. They should also explicate learning goals that enable students to recognize the relative importance of the facts and information they supply, so that students can eventwally carry out this activity on their own as they read more advanced presentations and try to understand the texts of the world outside school."

The third teaching principle derives from cognitive theory of motivation. Gagné (1985:101) suggests that teachers have to find out "what the students know that can be related to the new information and, as frequently as is needed, to remind them of these connections." Furthermore, one may stimulate intrinsic motivation by presenting controversial problems or generate curiosity by other methods.

The fourth teaching principle derives from the importance to create links between schemata. Gagné (1985:71-72) defines elaboration as "the process of generating new ideas related to the ideas being received from external sources." "Elaborations generated at the time of learning new information can facilitate retrieval by providing alternative pathways for spread of activation. Elaboration can facilitate constructions by providing more information for logical reasoning processes to use in constructing an answer."

In this context Linn $(1986: 181,195)^{6}$ reports that to "help students construct productive science concepts, researchers concur that covering a few science topics in depth rather than many in a fleeting fashion will have a more lasting impact. Researchers and educators allke note that students can "learn more by learning less". Such coverage makes it possible for instructors to link new ideas to related ones and establish which ideas are encompassing and which are specific." "It would seem useful to intensify the science curriculum in order to emphasize a small number of conceptions and to present those conceptions in a variety of domains. In this way, intuitive conceptions might eventually be replaced by conceptions held by expert scientists."

The lifth principle focuses on the importance of pattern recognition in different contexts. According to Glover et al. (1990:27,146), knowledge has to be related to as many contexts as possible, because information is encoded in combination with the context. Furthermore, because most problems in practice are ill-defined, students must be trained in representing ill-defined problems in a problem space. Students should be

\footnotetext{
6. With respect to economics, see also Heyne (1983.IX)
} 
trained in the search for the critical aspects of a problem, and in the ability to find useful analogies ( $p$ 169, 182). Glaser (1991:137) emphasizes the importance of "the acquisition of problem schemata that allow the student to recognize a problem as belonging to a category that involves specific principles that guide solution." This last process may be characterized as pattern-recognition. Gagné $(1985: 117,132)$ mentions that knowledge and action sequences have to be related to pattern recognition procedures. He suggests that a teacher can make a large difference in learning pattern recognition through the careful selection of examples and nonexamples.

The sixth teaching principle derives from the fact that one has to economize on the very limited cognitive sources. Therefore, knowledge has to become automatic through practice with feedback (Glover et al., 1990:59,182); Glaser, 1991:137). But because of the limited working capacity of the human mind, big procedures cannot be built directly. One has to start with small ones as building blocks and gradually build bigger ones from the building blocks. The process of combining the building blocks Gagne (1985:119) has called composition.

Because proceduralization is only beneficial when it is unlikely that the action sequences have to be changed and the speed is beneficial, the selection of procedures to be automatized is very important. Procedures improve speed but at the cost of rigidity. Therefore, the choice of procedures to be created is very important for the quality of the skills developed (Gagné (1985:130)).

In summary, the following teaching principles can be derived from the cognitive theory of learning:

1. Prior knowledge. The presentation of new knowledge has to be sufficiently related to the available knowledge of the student. The student's relevant knowledge has to be activated before new knowledge is introduced.

2. Causal organization. Texts, lectures and other educational devices must help the students to organize information congruent with the problem situations they may be expected to meet. It is very important that students understand the causal relationships.

3. Motivation. Study is a goal-directed activity. Cognitive theory assumes that inconsistencies between schemata and information or inconsistencies between schemata are very important motivating forces.

4. Elaboration. The educator must stimulate the student to elaborate the information. Covering a few science topics in depth rather than many in a fleeting fashion will have a more lasting impact. Especially, the student must develop (causal) intuitive knowledge that is consistent with formal theory.

5. Context. Students must be trained to use information in different contexts. Especially, they must develop problem schemata in order to become able to recognize patterns.

6. Routine. Training with feedback is useful to automatize thought patterns that have 
to be used a lot. The choice which processes to practise determines to a large extent the likelyhood that errors occur.

\subsection{Application of the method to a standard textbook}

In general, introductory courses in economics are not the favourite of students who have another subject as their main course. Students in management, law, history, etc. have the feeling that economics is abstract, mathematical and not applicable to the real world. This is surprising, because topics of econonics are discussed in the daily news every day, while everyone makes economic decisions as a buyer of products or a supplier of labour. One may try to understand this paradox by using the teaching principles developed in section 2.2. In most courses in economics a textbook is the centrepiece. Therefore, the analysis of a standard textbook in economics will be used as an example of the type of analysis. Because the "current set of textbooks, by and large, are clones of the one great textbook written in this century, Samuelson's, written almost forty years ago", as Stiglitz (1988:171) mentions a little bit overstating the case, the most recent version, Samuelson and Nordhaus (1992), seems to be a good choice?

In order to limit the presentation, two central issues out of this textbook will be analysed: the production possibility frontier, and aggregate supply and demand analysis. The first topic is presented as an important starting point of economcs, while the second topic is presented as the main line of the discussion about macroeconomics. The discussion of the topics will be restricted to the six teaching principles developed in section 2.2. Because the focus is on the general approach and not on the specific textbook, practical issues like the use of summaries, or graphicall presentation methods, are not discussed.

\subsubsection{The production possibility frontier}

Because Samuelson and Nordhaus discuss the production possibility frontier in chapter 2 as the second of three sections about "basic problems of economic organization", one may assume that this is a fundamental concept from the perspective of Samuelson. Let us investigate how they introduce such a concept. I will follow the six teaching principles.

The first principle is about the activation of prior knowledge. Relevant knowledge has to be activated before new knowledge is introduced. Samuelson and Nordhaus start section $2 \mathrm{~B}$ about society"s technological possibilities with:

"Why are we concerned with the fundamental questions of what, how" and for whom? Because people want to consume far more than an economy can produce. Recall the law of scarcity stated in the last chapter: goods are

\footnotetext{
"Even though the fourteenth edition has been improved in a lot of aspects compared with the thirteenth edition, some problems that are more fundamental to the mainstream approach remain.
} 
scarce because there are not enough resources to produce all the goods that people want to consume.

Faced with the undeniable truth that goods are scarce relative to wants, an economy must decide how to cope with limited resources. It must choose among different potential bundles of goods (the what), select among different techniques of production (the how), and decide in the end who should consume the goods (the for whom). In this section we use several examples to illustrate some of the key choices that every society must make."

At first sight this seems a good start, because the new concept is related explicitly to three questions of economic organization that are according to Samuelson fundamental. But on second thoughts one may question to what extent those questions are not too abstract to trigger schemata in the minds of students. This doubt is reinforced after reading the text that follows the small heading "the production possibility frontier". First, the three fundamental questions of organization are repeated. Then some examples are presented:

"Consider an economy with only so much labor, so much technical knowledge, so many factories and tools, and so much land, water power, and natural resources. In deciding what shall be produced and tow, the economy is deciding in reality just how to allocate its resources among thousands of different possible commodities. How much land should go into wheat growing? Or into housing the population? How many factories will produce computers? How many will make pizzas?"

Those questions are interesting for persons who begin to understand something of the market mechanism and are surprised that such a market mechanism sometimes coordinates decisions surprisingly efficiently. But for novices, those questions are trivial and therefore irrelevant. Because the students do not have a story about the coordination problem in their minds, the short suggestive remarks don't trigger schemata by the students.

The text goes on to argue that simplifications are necessary to resolve the problems discussed, and gives some further examples:

"These issues are complicated even to discuss, much less to resolve. Therefore, we must simplify. Let us assume that only two economic goods (or classes of economic goods) are to be produced. For dramatic purposes we can select guns and butter to illustrate the problem of choosing between military spending and civilian goods. This example applies equally to America"s massive mobilization during World War II, to the issue of how to pay for the operation "Desert Storm" in Saudi Arabia in 1991, and to the choices of military versus civilian spending faced by any nation."

When students read this passage, they may understand that it is necessary to simplify, but it is not clear why one chooses two goods and what relevant questions can be answered by using the concepts. One cannot assume that this type of example triggers 
schemata.

After discussing the production possibility frontier and the efficiency concept Samuelson and Nordhaus present some new examples. One may hope that those are more effective:

"Taking into account the possibility of unemployed resources throws light on the experience in World War II of two countries: the United States and the Soviet Union. After 1940, how was the United States able to become the "arsenal of democracy" and to enjoy civilian living standards higher than ever before? Largely by taking up the slack of unemployment from the Great Depression and moving toward the PPF.

The case of wartime U.S.S.R. was different. The Soviets had little unemployment before the war and were already on their rather low productionpossibility frontier. To move northwest along their PPF the Soviets had no choice but to substitute war goods for civilian goods - with consequent privation.

Business-cycle depressions are not the only reason why an economy might be inside its PPF. An economy might suffer from inefliciency or dislocations because of strikes, political changes, or revolution. Such a case occurred during the early 1990 s in Poland after that country substituted a free market economy for its socialist command economy. Because of the dramatic changes in the economic system, output fell and unemployment rose as people attempted to adapt to the changed prices, laws, and incomes. A political and economic revolution pushed Poland temporarily inside its PPF.

Polish leaders hope that this inefficiency will be but a temporary setback. They foresee that a free market will boost incentives for efficient production. If they are right, Poland will soon move back toward its PPF, and indeed the PPF will begin to shift outward as the economy begins to grow rapidly."

Those examples are a little bit more developed. If the students have enough knowledge about those situations, it may stimulate them to formulate inefficiencies in terms of the PPF and perhaps they will even recognize that all those situations are about choice. But will the students get the feeling that formulating situations with the help of PPF is a useful exercise?

Furthermore, it is disappointing that after the concept is introduced, the questions in the introductory part about for example 'Desert Storm' are not answered. In summary, although Samuelson and Nordhaus try to activate prior knowledge, one may expect this to be almost without result.

The second teaching principle is about the organization of knowledge. A text must help students to create a model in their mind. Samuelson and Nordhaus try to do this by introducing the PPF as the central concept and then relating it to other concepts. After the introduction they present a production-possibility frontier of the choice between guns and butter in words, as a table and as a graph. The PPF is defined as follows: 
"The production-possibility frontier (or PPF) shows the maximum amounts of production that can be obtainedl by an economy, given the technological knowledge and quantity of inputs available. The PPF represents the menu of choices available to society."

Although this definition is clear, it does not illustrate clearly the purpose of the concept. But that may be accomplished by linking other concepts to the PPF. First, productive efficiency is defined and related to the PPF:

"Productive efficiency occurs when society cannot increase the output of one good without cutting back on another good. An efficient economy is on its production-possibility frontier.

One further point about productive efficiency can be illustrated using the PPF: Being on the PPF means that producing more of one good inevitably requires sacrificing other goods. When we produce more guns, we are substituting guns for butter. Substitution is the law of life in a full-employment economy, and the production-possibility frontier depicts the menu of society's choices."

Second, other items are related to the PPF:

- "our definition of economics as the science of choosing what goods to produce"."

- the definition of scarcity.

- illustration of the three basic problems of economic life: what, how, and for whom.

- "the general point that we are always choosing among limited opportunities."

This list is not a very good organizing device. Why is the definition of scarcity not related to the last item? Does the PPF really give an illustration of the three basic problems of economic life? According to the first item it seems to be only an answer on the "what?' and not on "how and for whom'. In summary, the PPF is a very poor organization device for economic thought.

Third, some examples of choices are presented as a PPF: the choice between luxuries and necessities, private and public goods, and capital investment and current consumption. Such a broad scope of examples seems to be useful to generalize the PPF concept.

Fourth the concept of opportunity cost is introduced:

"the opportunity cost of a decision arises because choosing one thing in a world of scarcity means giving up something else. The opportunity cost is the value of the good or service forgone."

\footnotetext{
${ }^{8}$ This seems to be somewhat in contrast with the definition in chapter 1: "Economics is the study of how societies use scarce resources to produce valuable commodities and distribute them among different people." (p 3)
} 
This concept is introduced as something new and is illustrated but not defined by the PPF. In my opinion this is correct. But why is it that Samuelson introduces the PPF instead of opportunity cost as the fundamental concept? In this manner the PPF seems to be a very artificial organizing device. Another example shows that opportunity cost can be different from out-of-pocket costs, and therefore is not related to the PPF al all.

Finally, the law of diminishing returns is introduced:

"We can also use the production-possibility frontier to illustrate one of the most famous economic relationships: the law of diminishing returns."

If you expect an explanation of the relation between the PPF and the law of diminishing returns, you will be disappointed. The law of diminishing returns is defined with the help of a table, and it is stated that "ultimately, dimimishing returns will prevail for most technologies." The following two examples illustrate the principle: that Asian countries are so poor "because there are so many workers per acre of land" and that the law of diminishing returns holds even in studying. Finally the definition of diminishing returns is presented.

"The law of diminishing returns holds that an increase in some input, with other inputs held constant, will increase total output. But after some point, the extra output resulting from additional doses of inputs will tend to become smaller and smaller."

So, the law of diminishing returns seems to be a new concept, that is totally unrelated with the PPF. Therefore, the PPF is not a logical device to organize the topics of the section where the concept is introduced.

If you expect that a concept introduced in the beginning of a book is used extensively in the rest of the book, you will become disappointed. The PPF is used to illustrate the principle of comparative advantage and only mentioned in defining efficiency and technological change. What is the relevance of introducing seemingly irrelevant concepts in the beginning of a book without using them in the rest of the book? ? $^{10}$

In summary, Samuelson and Nordhaus have tried to organize a lot of concepts and problems around the PPF. But because of the artificiality of the concept, they were not successful in developing a logical and appealing line of reasoning with the help of the concept. They introduced a number of concepts and related or defined them with the help of the PPF. It does not result in more than repeating that inefficient economies are within the PPF and that one has to choose on the PPF. They failed to show how the PPF can help to organize thought about economics. Although the PPF is a useful concept for formal modeling, it is not a concept that helps intuitive understanding.

\footnotetext{
"Is this really true?

10 The same also holds for other concepts introduced in this introduction, such as 'opportunity cost", and the law of diminishing marginal returns.
} 
The third principle is about motivation. For motivation one has to show the relevance of the things that are presented. The questions asked in the introductory parts and the examples are attempts to accomplish this. But from a motivational point of view, the examples miss a very important feature: they do not present something unexpected or novel. They onlly restate problems everyone can understand. They don't show that you can use this very abstract concept to solve new problems. Although for the expert a PPF may seem a concept that summarizes a lot of vague notions, one cannot expect a novice to be able to appreciate this aesthetic quality.

The fourth principle is about elaboration. This is a strong point in the text. As shown a lot of relations are created. The examples will be effective to relate intuitive knowledge to the concept of the PPF. Almost all questions for discussion at the end of the chapter stimulate the student to formulate economic problems in terms of the PPF. But none of them helps to investigate the limits of the concept.

The fifth principle, the problem of context and pattern recognition, seems to be tackled also in Samuelson. Many choices are presented as PPFs in the text while the questions expand this terrain even further.

Finally, with respect to creating automaticity, the student has a lot of opportunities to transform problems into a PPF graph, supposed that the student really does the exercises at the end of the chapter.

Overall then, we may conclude that the text is effective with respect to the last three teaching principles, while it is not effective with regard to the first three. The fundamentall problem seems to be that the authors are not successful in showing that the PPF is useful as a device to organize the novice's thought.

\subsubsection{Aggregate supply and demand and the multiplier}

The macroeconomic part of Samuelson and Nordhaus starts in chapter 23 with an overview of macroeconomic concepts and goals. Then the concepts of aggregate supply and demand are introduced. After a chapter about measurement of national output and income, consumption and investment are discussed as determinants of aggregate demand. Chapter 26 develops the theory further and introduces different views. In chapter 27 the multiplier model is discussed. Chapters 28 and 29 discuss money and monetary policy. Part six discusses economic growth, the business cycle, inflation, fiscal policy and the discussion on economic stabilization. Just as in the case of the production possibility frontier we will analyse the text with the help of the six teaching principles of section 2.2 .

First, to what extent does the text activate prior knowledge of the students? The text starts with a number of questions:

"Why did production and prices in American and much of the industrial world collapse during the Great Depression of the 1930s? Why is it during this period that millions of people were unable to find work and were living on the ragged edge of starvation? What forces propelled America into a sustained boom during World War 11 and then again during the Vietnam
war?" 
Can we expect that those questions really trigger a schema in the mind of the students? Perhaps, when they have followed a course in history. But in order to trigger schemata effectively, one has to describe those periods in more detail. Furthermore, the amswers to those questions cannot be found in the text that follows those questions. This text is about macroeconomic concepts and goals.

After discussing the goals and instruments of economic policy Samuelson and Nordhaus introduce the concepts of aggregate supply and aggregate demand. Let us look at the introduction of aggregate supply:

"Aggregate supply refers to the total quantity of goods and services that the nation's businesses are willing to produce and sell in a given period. Aggregate supply (often written as AS) depends upon the price level, the productive capacity of the economy, and the level of costs.

In general, businesses would like to produce at full capacity and sell all their output at high prices. However, in certain circumstances, prices and spending levels may be depressed, so businesses might find they have excess capacity. Under other conditions, such as during a wartime boom, factories may be operating at capacity as businesses scramble to produce to meet all their orders."

Does this argumentation really have a meaning to the novice reader? I doubt it. Concepts like 'productive capacity" and 'price level' are very abstract, and therefore will not trigger a schema for the students. After an introduction on the demand curve the authors continue:

"Supply and demand curves are often used to help analyze macroeconomic equilibrium. Recall that in chapter 4 we used market supply and demand curves to analyze the prices and quantities of individual products. An analogous graphical apparatus can also help us understand the major macroeconomic issues of aggregate output and price determination. Using aggregate supply and demand, we can see how monetary expansion leads to rising prices and higher output. We can also see why increases in efficiency may lead to higher output and to a lower overall price level. Moreover, this powerful analysis will explain why a rise in world oil prices can lead to "stagflation", the unhappy circumstance where stagnation is combined with inflation."

Do the authors hope that students already analyse those examples? Do they expect that students understand their relevance? If the students did, they would already have available the schemata that they are supposed to learn by reading the book. Therefore, one may conclude that the text is not organized in such a manner that relevant schemata are activated before the start of the analysis.

Neither in those quotations nor in the rest of chapter 23 does the text explain the 
aggregate supply and demand curves." On page 409 Samuelson remarks that there is a difference between aggregate and microeconomic supply and demand curves:

\begin{abstract}
"We must be careful not to confuse the macroeconomic AD or AS curves with the microeconomic DD or SS curves. The microeconomic supply and demand curves show the quantities and prices of individual commodities, with such things as national income and other goods" prices held as given. By contrast, the aggregate supply and demand curves show the determination of total output and the overall price level, with such things as the money supply, fiscal policy, and the capital stock held constant. The two sets of curves have a family resemblance, but they explain very different phenomena."
\end{abstract}

But when it is not explained which mechanism is behind the AS and AD curve, this remark is without meaning. Therefore, the text in chapter 23 does not help the students really to understand the thoughts behind the AS and AD curves. This implies that it will be very difficult for students to relate those curves to existing schemata (except for the schema developed for microeconomic demand and supply). Also in later parts of the text the AD and AS curves are used to state some laws. But when an adequate explanation is lacking, students are not able to relate the issues to existing schemata.

As an example let us investigate the explanation of the slope of the AD curve in chapter 26 :

"The decline in the real money supply will affect aggregate demand through the monetary mechanism to be discussed in detail in later chapters. In brief what happens is that, as the real money supply falls, money becomes relatively scarce and a period of tight money ensues. What are the symptoms of tight money? Interest rates and mortgage payments rise, the stock market declines, the exchange rate on the dollar rises, and credit becomes harder to obtain. Tight money leads to a decline in investment, net exports, and even consumption. In short, a rise in prices with a fixed money supply, other things being equal, leads to tight money and produces a decline in total real spending. The net effect is an upward movement along a given AD curve."

This brings the explanation back to a monetary mechanism that is explained much later in chapter 29. One may expect that the role of money supply is even more abstract and difficult to understand than presenting the AS/AD analysis only as an analogue of microeconomic demand and supply analysis.

In summary, Samuelson and Nordhaus systematically present laws in general terms that will be difficult to relate to existing schemata and that cannot be understood at the moment they are presented. The explanation is delayed till the end of the

\footnotetext{
"It is surprising that the authors have dropped the explanation in the thitteenth edition where under the heading "Long-run vs. Short-Run Aggregate Supply" the slope of the AS curve is
explained by stickiness in prices.
} 
part on macroeconomics.

With respect to the second teaching principle, organization, Samuelson and Nordhaus try to explain everything with the AD/AS schedulle. Thein model is quite clear: a number of factors influence aggregate demand and aggregate supply, where the prices and output are determined by the equilibrium position from those curves. In chapter 23 they explain macroeconomic history between 1960 and 1991 with the help of those curves (avoiding problems that are inconsistent with it). In chapter 25 they develop the theory of investment and consumption as parts of $\mathrm{AD}$ and $\mathrm{AS}$. In chapter 26 they explain the reasons for the slopes of the $\mathrm{AD}$ and $\mathrm{AS}$ curves by a monetary mechanism. The explanation of this mechanism is delayed till chapter 29.

In summary, Samuelson and Nordhaus present the theory by first giving some simple analytic devices as the $A S$ and $A D$ curve without fundamental explanations. Then, step by step, they fill in the missing explanations. Although links are made with problem situations students may be expected to meet, this method of organization makes it very difficult for students to understand the causal relationships. Therefore, although the use of one explanatory scheme for a lot of problems is good from the point of wiew of organization, one may doubt to what extent this organization is effective when the foundations of the scherne are not clearly explained. I expect that such an approach teaches students to use analytical instruments that are only partly understood.

With respect to motivation one may ask to what extent the presentation of an insufficiently understood $\mathrm{AD} / \mathrm{AS}$ curve approach without critique is really motivating. Just as with the PPF one may question the adequacy of the suggested explanations. Consider for example page 410 , where the authors discuss the effect of a supply shock on prices and output:

"How can we understand the combination of falling output and rising prices? The sudden rise in the cost of raw materials constituted a supply shock, which we can depict as a sharp upward shift in the aggregate supply curve. An upward shift in AS indicates that businesses will supply the same level of output only at substantially higher prices. Figure 23-9 illustrates a supply shift."

Figure 23-9 shows the general result that prices rise and GNP declines. Superficially this seems a good explanation of the mechanism at work. But if the student thinks further, he may find an easy solution to solve the problem of falling output: a rise in $A D$. A rise in $A D$ will help to solve the problems with output, although at the cost of a higher price level. The student may ask why governments did not try this solution to the output problem. But the discussion of this problem is delayed till chapter 33. Therefore, the students will stop with an incomplete understanding as well as a feeling that everything is explained too easily. By avoiding inconsistencies in the text the force of intrinsic motivation is lost.

The authors try to stimulate elaboration by explaining a lot of situations with AS/AD analysis. For example, in chapter 23 they explain macroeconomic history between 1960 and 1991 with the help of AS/AD analysis and relate it to stabilization policy. Furthermore, they include a lot of exercises at the end of the chapter. They 
present graphs of the development of investment and relate them with historic phenomena. $\mathrm{AS} / \mathrm{AD}$ analysis is used many times in chapters 23 to 34 . In this context the text seems to be very effective in covering a few science topics in depth rather than many in a fleeting fashion.

But when one looks more carefully at the type of elaborations, it becomes clear that none of them helps the student to grasp an understanding of the conditions when the AS/AD analysis cannot be applied. Even more fundamental. the issue is avoided, for example in the above-mentioned case where AS/AD analysis can only explain a rise in the price level but not inflation. This reveals a fundamental part of the approach: don't create uncertainty about the tools that have been learned.

With respect to context the book presents a lot of graphs, examples and exercises to translate real world situations in AS/AD analysis. With respect to creating automatic procedures the text seems to be as helpful as a text can be to create automatic procedures of this type.

In summary, also for the AS/AD analysis the book seems to score high on the last three criteria, but rather low on the first three. The AS/AD analysis may be a useful device for the novice to structure his thought. But the avoidance of causal explanations will create difficulties for students to understand the foundations of the analysis they are expected to use. The approach stimulates the students to become believers instead of critical thinkers.

\subsubsection{Conclusion}

With respect to AS/AD analysis Samuelson and Nordhaus (1992) have a clear organization around a limited number of concepts. They give a lot of opportunities to elaborate and proceduralize the thinking pattern in different contexts. The same holds for PPF analysis, although the result is less convincing than with the AS/AD analysis.

But although Samuelson and Nordhaus try to create a systematic approach ordered around a limited number of concepts, the organization is not satisfactory if one wishes the students to understand the causal relationships. By organizing the text in such a manner that one starts with insulficiently understood AS and AD curves, that are underpinned six chapters later, one trains the student to use incompletely understood analytical instruments. Furthermore, by applying those principles to examples that are much more complicated, the students are trained in "easy thinking". The avoidance of controversy in the presentation implies that an opportunity is missed to motiwate students. Furthermore, the focus on the use of the instruments presented without showing their limitations implies that critical thinking in cause and effect is not stimulated. This implies that a lot of opportunities to elaborate the fundamental mechanisms behind the PPF or AS/AD concept are not used.

One may wonder to what extent the educational problems in the AS/AD framework are fundamental to the framework or only to Samuelson's presentation of it. First, it has to be stated that the same type of problems as in Samuelson and Nordhaus (1992) are also found in modern textbooks in macroeconomics like Hall and Taylor (1991). Second, the AS/AD analysis is a rather mechanistic approach to macroeconomics. It suggests stable $\mathrm{AS}$ and $\mathrm{AD}$ curves that can be changed through 
exogenous changes. As shown in chapter 1, this avoids the fundamental coordination problem in an economy. Fundamental assumptions about expectations, or the ability to manage the money supply are avoided in this approach. Therefore, this type of analysis will remain fundamentally superficial when the coordination mechanisms behind it are not discussed.

This points to a fundamental characteristic of the mainstream textbook: its focus on formal models. ${ }^{12}$ In order to get those models manageable one has to start with simple models. This method implies that one starts with very simple abstract models and then introduce complications step by step. With respect to microeconomics one starts with a perfect market and then introduces complications into it through monopoly and oligopoly. With respect to macroeconomics one may start with aggregate demand and supply analysis without explanation and then introduces the more fundamental mechanisms behind it. This method of presentation, the method of decreasing abstractness, seems to be very useful when one tries to teach models.

But the method of decreasing abstractness has its cost. First, it will be difficult to satisfy the prior knowledge principle. While the student studies the basic theories he elaborates on the mathematical principles involved instead of on the economic knowledge he has. It requires a lot of time before the student is able to apply the theory to explain reality. Therefore, it is difficult to relate the theory from the beginning to intuitive understanding by the students. Because of the discrepancy between the simple model and reality, it is not surprising that the authors have difficuities in relating the abstract new knowledge to the schemata the students already have. As a consequence, almost all methods to activate knowledge of the students will fail because reality is too complex to understand with the simple abstract theories. ${ }^{13}$

Second, it will be difficult to satisfy the principle of causal organization. Although the method of decreasing abstractness helps to organize the material, it does not help to organize the knowledge congruent with the problem situations the students will meet. Furthermore, because the abstract principles are founded on mechanisms the students do not understand yet, it will be almost inevitable that the students do not understand the causality behind their knowledge; They become believers instead of critical investigators.

Third, also with respect to the motivation principle, difficulties can be expected. Because the benefits of the knowledge will only become evident after a rather long time of study, for most students it will be difficult to become intrinsically motivated for economics. With respect to the fourth principle (elaboration), it is possible to elaborate the abstract principles learned in a lot of contexts as long as one accepts some distortions due to too much simplification. But because the causal mechanisms behind the laws are not clearly understood by the students, teachers will avoid the creation of uncertainty through elaborating the limits of the principles taught.

\footnotetext{
${ }^{1}$ Even in mainstream books that are without mathematics, the focus is on the formal modteils instead of the reall world.

13 This does not imply that all theory has to be excluded from economics teaching. It implias that teaching theory has to start with discussing questions that can be undershood, and presenting theoretical issues as an answer to those questions. Mathematical models become usefull when the sudent appreciates the questions to be answered with them.
} 
Regarding the fifth and sixth teaching principles, context and rowtine, the method of decreasing abstractness seems to be rather effective. With some effort one may show the thought patterns in a lot of different contexts. Because the same thought pattern is trained continuously it will be rather easy to routinize it.

It may be clear that the model-based approach combined with the method of decreasing abstractness has its attractive sides. But the analysis of Samuelson and Nordhaus (1992) show that the model-based approach has its fundamental weakness in that it is difficult for the students to relate it to intuitive thought. We have already seen that the difference between novices and experts in physics is that the intuitive knowledge of the novices is less consistent with formal theory than the intuitive knowledge of the experts. In economics, students have some intuitive understanding of economic phenomena before they start their study. When one approaches economics from this side, it seems wise to focus the teaching of economic theory on the development of intuitive knowledge that is consistent with economic theory instead of on formal but counter-intuitive theory.

With Keynes one may question to what extent economics can be seen as a number of well-defined theories:

"The theory of economics does not furnish a body of settled conclusions immediately applicable to policy. It is a method rather than a doctrine, an apparatus of the mind, a technique of thinking which helps its possessor to draw the correct conclusions" $"$.

If this interpretation of economics is correct, teaching economics has to be focused on asking questions instead of giving answers. Because mainstream textbook theory is focused on models, it trains people to solve well-defined artificial problems. One may question to what extent the exercise in solving artificial problems helps students to develop their ability to tackle real world problems. The analysis of Samuelson and Nordhaus (1992) as an example of a mainstream textbook as well as the suggestion in chapter 1 that mainstream economics avoids fundamental questions, may lead to the conclusion that the problem of teaching economics lies more in economics than in the process of teaching itself.

In this respect one may follow Heyne (1983:X) who writes: "We must attempt less and thereby accomplish more. An introductory course should distinguish itself as much by what it excludes as by what it incorporates. Unless it is our aim to impress students with the esoteric quality of economists" knowledge, we should teach no theory in the introductory course that cannot be put to work immediately." Although Samuelson and Nordhaus seem to be consistent with Linn $(1986: 181,195)$ in that they try to organize economic theory around a limited number of principles, it seems to be difficult to put those principles into work immediately. For this reason, it may be necessary to search for alternative fundamental concepts that are more easy to apply. One may ask of those concepts that they are useful for students to answer motivating questions with the help of theory.

1s Keynes, Collected Works, VII: 856, cited in P. Heyne (1983:XIX). 


\subsection{Towards an application of the teaching principles in textbook writing}

In the last section it has been suggested that the Classical model-based approach has some disadvantages in relating theory to prior knowledge, discussing the limits of the concepts used, and in motivating persons. Furthermore, because the fundamental mechanisms behind the models are neglected in most textbooks, even a seemingly well-structured text does not have an organization that is consistent with causal (i.e. intuitive) thought. This implies that the fundamental problem in teaching economics is a matter of content, not only of educational features.

Based on this line of thought $\mathbb{I}$ developed course in economics for law students. This resulted in a syllabus that is partly organized according to the principles discussed here. The content of this section is to a large extent based on this syllabus. I will try to develop an integrated set of fundamental economic principles that can be applied directly to real world situations and that is as coherent and intuitive as possible. This implies that when students elaborate or improve the organization of their knowledge, they will not find 'black boxes' they are not able to understand.

When looking for fundamental concepts in economic theory the definition of economics is a good starting point. Most courses start with a definition that is derived from Robbins (1932:16): the study of "human behaviour as a relationship between ends and scarce means which have alternative uses". From this definition one may derive that economics is about human decision making. Decision making implies choice between at least two alternatives. When one chooses one alternative, another alternative is sacrificed. The benefits are defined as the value of the alternative that has been chosen. The cost equals the value of the alternative sacrificed. The difference between benefits and costs is the profit. Therefore, maximizing profits is nothing else than trying to make the best decisions. From the definition of costs and profits, it will be clear that what is the best decision depends on values. Therefore, economics is related to the values of human beings.

When one tries to train students in thinking in costs and benefits, one can help them with two simple questions:

- what alternatives are relevant?

- how are they evaluated?

Those two simple and intuitive questions can be helpful in improving decision making and in understanding the decisions of other people. Concepts like fixed, variable, marginal and average costs can be introduced as instruments to discuss the relevant alternatives for different rypes of decision. For example, when you have a car and drive an extra kilometre with that car, only variable costs are relevant. But when you and your partner want to drive a car at the same moment, you need an extra car, and therefore the integral costs are relevant. ${ }^{15}$ The concept of externality can already be introduced at this level as a consequence of the second question; the market value of the alternatives depends on who bears the costs and benefits. Furthermore, the value of a good depends on the people that evaluate.

${ }^{15}$ See Frank (1994), chapter 1 for a lot of other examples. 
This approach is fundamentally different from the standard textbook approach in that it uses concepts to ask questions instead of building models. Economics is presented as a science that helps to ask the right questions, not as a set of models. Models are presented as attempts to answer questions. Let us investigate the opportunities of this approach with respect to the six teaching principles. First, the theory is rather easy to relate to prior knowledge. It is intuitive and can be applied to almost every decision. Second, because the principle of organization is directly derived from the logic of choice, no artificial constructs like the production possibility frontier or indifference curves are necessary. ${ }^{16}$ Therefore, it will be rather easy to teach the theory according to the principle of causal organization. With respect to the third principle (motivation), this approach challenges the teacher to show how answers to the two questions give surprising results. For example, the questions may be applied to the choices open to drugs addicts; many of them feel the fundamental choice is between getting drugs with or without criminal activities instead of using or not using drugs. The more difficult it is for them to get drugs without criminal activities (i.e. the higher the price), the easier they go for criminal activities. Fourth, elaboration is also easy by varying systematically the type of relevant alternatives. The limits of the concept can be investigated by asking to what extent the cost of thinking about alternatives is worth the benefit of better decisions, or the dangers of computing too much and working with numbers that are too easy to manipulate. Fifth and sixth, because examples of the theory can be found in almost every domain, students can be stimulated to ask the questions in a lot of different contexts. ${ }^{17}$ Just as in the traditional approach, routinization can be accomplished.

Since choice, scarcity and opportunity cost are the most fundamental concepts in economics, it is possible to develop the rest of economic theory on those concepts. For example the opportunity cost principle can be applied in introducing the demand concept because demand is the consequence of the decisions of potential demanders.

One of the decisions that may be analysed is the decision to set a price. For example, when the OPEC in 1973/74 forced a rise in the price of oil, the benefits were much higher than the costs; in the short run the demanders of oil did not have many alternatives. When the OPEC countries raised their price, their sales would not become much less, while on each barrel sold the benefits would rise. This is an introduction to the theory of monopoly power that every layman can understand. ${ }^{18}$

When a problem like the oil price of the OPEC countries has been formulated, it is easy to introduce technical concepts like the price elasticity of demand in an intuitive manner. In 1973 it was very important for the OPEC to know that the benefits of a rise in prices were bigger than the costs. Therefore, it is significant to know that the revenues are at a maximum when the price elasticity of demand is -1 ; this creates a logical benchmark between elastic and inelastic demand. In this manner even a technical concept like the price elasticity of demand can be introduced as the

${ }^{6}$ Although it mabe illuminating to apply the principles to these generally used constructs.

${ }^{17}$ In order to be effective, the student must understand the context in which the theory is applied.

18 Should one wish to introduce technicalities at this point, one may give a graphical or mathematical illustration of the decision problem of the OPEC countries with the help of the monopoly
model. 
answer to a question. In developing the theory further with respect to the context of the OPEC, the loss in market share of the OPEC and the deciline in the oil price in the 1980 s can be explained as an answer to the question "which alternatives are relevant?". "This avoids the suggestion in many traditional texbooks that the price elasticity of demand is a constant. This may be elaborated by arguing that short run demand is less elastic than long run demand and the demand for OPEC oil is more elastic than the demand for oil in general. Furthermore, one may show that the price elasticity of demand depends on the price level; while around the price level of 1974 the demand for OPEC oil was not very elastic, around the price level of 1980 the demand for OPEC oil was very elastic.

The question "what alternatives are relevant?" is a useful instrument to think about elasticities. The analysis of the alternatives of potential non-OPEC oil producers can be used to explain why a rise in the price of oll caused a rise in the competing oil supply: the law of supply. The fact that creating new production takes time (a story about the oil industry may illuminate this) explains why monopoly power is much less in the long rum than in the short run (this can be formalized with the help of the elasticity concept). In this context the perfect market can be iniroduced as a situation where so many alternatives are available that no one can set a higher price without losing all its customers to competitors. This example shows how concepts like monopoly and perfect competition that are introduced in standard textbooks as concepts surrounded by a lot of seemingly unrealistic assumptions, can also be introduced as the logical consequence of questioning real world problems.

A lot of problems discussed as separate topics in mainstream textbooks, can be analysed as applications of the basic concepts introduced here. For example, the principle of comparative advantage is a direct application of the opportunity cost concept, while the limits of it can be investigated by the structural problems that emerge when changes according to comparative advantages are realized. This is another application of the elasticity concept. One may also introduce speculation as an example of cost-benefit analysis. Thus, the focus on a limited number of fundamental concepts does not imply that other topics have to be sikipped. As long as topics can be analysed with the fundamentals to be trained (and this will be so when the concepts are really fundamental), specilic topics can be used as an elaboration of the fundamental topics.

Continuing this line of organizing theory (from cost-benefit analysis to supply and demand), behavioural interdependencies like oligopoly and other prisoner's dilemmas can be introduced. Those behavioural interdependencies can be explained as examples of externalities, i.e. situations where social cost is not equal to private cost. The investigation of the role of moral, law and expectations cam be analysed in this type of situation. The Cournot model and other oligopolistic models may be used as examples of the analyses of the consequences of expectations. Because real world behavioural interdependence is difficult to tackle in a formal framework, one has to be satisfied with a rather inprecise framework of thought. But if one wishes to illustrate the principles with mathematical formulas, it is easy to include the textbook theory. Therefore, the prisoner's dilemma can be used as a useful integrating device for a lot of different problems.

These micro-economic examples may show how the educational aspects of what 
has to be taught is intertwined with the content of economic theory. For example, the general approach of working with extremes like monopoly and perfect competition is replaced by more dynamic concepts like opportunity cost and monopoly power. Oligopoly theory is presented as a dynamic theory of behavioural interdependences and is integrated into the theory of externalities. Even monopoly power can be presented as an externality problem.

In mainstream textbooks, macroeconomics is almost unrelated with microeconomics. The microfoundations of macroeconomics is seen as an advanced topic or at least a topic that is introduced at the end of a course in macroeconomics. Prior to the fourteenth edition, Samuelson and Nordhaus even discussed macroeconomics before microeconomics. The reason for this phenomenon can be found both in traditional microeconomics and traditional macroeconomics. First, because traditional microeconomics is formal in character, it is difficult to apply to real world behaviour discussed in macroeconomics. Aggregation of behavioural equations is a very difficult topic. Second, because macroeconomics is in first instance presented as a Keynesian system, the multiplier-type processes are difficult to integrate with microeconomics. Only AS/AD analysis has an analogy in microeconomic demand and supply analysis.

Because most macroeconomic problems are directly or indirectly related to the use of money in the economic system, money is a good starting point for macroeconomic theory. The General Theory of Keynes was written as an attack on the Quantity Theory of money. Therefore, the controversy between the Classical and Keynesian approach can only be understood by the investigation of the role of money in coordinating the macroeconomy.

Money is a good, just as other goods. Therefore, also money can be introduced by applying cost-benefit analysis. On the demand side the transactional, precautionary, and speculative motives to hold money are just exercises in thinking about costs and benefits. On the supply side, the analysis of costs and benefits of a bank (or goldsmith) can show why the supply of money is limited in the long run. It will illuminate that all money is a type of credit.

The view of money as credit can be used as a starting point for a dynamic theory of inflation. For example, when a government or bank creates money, this implies that the level of credits rises. Because subjects will only pay interest on credits when they want to buy goods for these credits, the demand for goods rises. ${ }^{19}$ When the supply of goods does not change, this implies excess demand. In first instance stocks decline and employees do overwork (almost always forgotten in introductory courses in economics), butt gradually firms will raise prices because both the level of stocks and the possibility of getting labour are limited. This whole introduction is an application of microeconomic supply and demand analysis and founded on the cost-benefit theory of decision making.

With this introduction to the functioning of money students already get a feeling for macroeconomic dynamics. But this line of thought can be used for a lot of other processes, for example the introduction of a new technique. To introduce new tech-

${ }^{19}$ This is already a simple illustration of Walras's law. 
niques investment is needed. This implies a rise in the demand for credits. ${ }^{20}$ If the supply of credits doesn't rise, the interest rate will rise; this is a simple application of the law of supply and demand on the market for credits. As a consequence of the higher interest rate other projects will be cancelled. When the total volume of credits does not rise, aggregate demand will not rise. This shows already at an elementary level that an expansion of money is a precondition for a boom.

When banks increase the stock of money as a consequence of the increased demand, the number of credits rises and therefore aggregate demand rises. This creates a boom. But when the investment has been done, it may be that firms do not see perspectives for further investment. Therefore, the disturbances generated (i.e. overinvestment as a consequence of overoptimism) may induce a recession. This can be illustrated with a lot of real world examples.

The introduction of a line of reasoning is not sufficient. One has to train the students in this type of reasoning. The investigation of Classical compared with Keynesian lines of thought can be a useful exercise. It is helpful to explain that some economists believe in the stability of a free market economy without government intervention (Monetarists), while others expect that a free market is inherently unstable and hence see a role for government intervention (Keymesians). By starting with the stabilizing mechanisms in the market economy, one can show that those mechamisms are simple applications of microeconomic theory. When after a period of overinvestment the demand for investment goods declines, it is obvious that the demand for credits declines, too. As a consequence, banks ${ }^{21}$ will be left with excess liquidities. They may try to get a profit out of these liquidities by lending. But in order to do that, they have to reduce their price for lending, the interest rate. This lower interest rate may induce some people to borrow more money. But they will be only prepared to pay the interest when they can use the credits for investment or consumption. As a consequence, the demand for some consumer and/or investment goods rises. This illustrates that the market for credits may stabilize the economy through adjustments of the interest rate. The credit market helps to close the circular flow. The same line of reasoning can be held for the market of investment goods. Notice that the whole line of reasoning concerns decision making about demand, supply and price setting: all of these are applications of microeconomics.

The role of expectations and speculation can be introduced at this point. When one believes that the decline in the interest rate, the price of investment goods, and the decline in demand is temporary, it is beneficial for investors to invest in the current cheap period instead of in the future. Therefore, speculation reinforces the adjustment process. The relevance of this speculation can be illustrated with some real world examples. The recession in the first half of the 1920 s in the Netherlands may be used as an illustration of this adjustment process.

The 1930s may be used as an example to illustrate the essential role of excess liquidities in the monetarist adjustment mechanisms. When in the 1930 s banks went bankrupt, liquidities were destroyed and hence money supply declined. The 1930 s can

${ }^{20}$ Or a decline in the supply of credits.

21 When instead of the banks other institutions or private persons remain with excess liquidities the principle remains the same. 
be discussed as the mirror image of the mechanisn described in the discussion of money creation. 22

The 1930 s can also be used for the confrontation of Classical ${ }^{23}$ and Keynesian lines of thought. Keynesian theorists suspect that the problem in the 1930 s was an illustration of a fundamental weakness in the free market society. When an economy changes fast, the Neoclassical adjustment process may require too much time. A lot of uncertainty arises. As a consequence, banks and other holders of liquidity decide not to use their capacity to lend money; They expect that the cost generated by the high risk of loosing money is too high. This discussion extends the cost-benefit analysis for lenders, and illustrates the reasons for risk premiums on interest rates. It is related to speculative and precautionary motives for holding money, and therefore explains why the circular flow can be disturbed.

The circular flow is an important concept to grasp in order to understand the difference between microeconomics and macroeconomics. In microeconomics it is assumed that when the price on a market changes, demand does not change. This assumption is not evident on a macroeconomic level. When for some reason aggregate demand declines, this implies that sales decline, production declines and therefore employment and income decline. As a consequence of this decline in employment and income, demand may decline further (the multiplier). As a consequence of the decline in demand there is no reason to expand capital stock, and therefore investment will decline too (the investment accelerator). When as a consequence of the decline in employment wages decline, this will only aggravate the problem, because the decline in wages reinforces the decline in demand.

You may ask how a Classical author could attack this line of thought. The role of money is important in such an attack: according to Wallas's law, a decline in aggregate demand also implies a decline in the demand for money. As a consequence, somewhere in the circular flow excess liquidities emerge. The interest rate will decline. This induces a rise in investment and consumption. Consistent with the Quantity Theory of money this process continues till the excess liquidities are eliminated. A Keynesian author may respond that when speculative and precautionary motives come into the picture, excess liquidities remain unused.

When the circular llow has been. opened, it is easy to understand that some destabilizing mechanisms will start to work. The multiplier and investment accelerator can be used as examples if they are discussed in an intuitive manner as above. It is

\footnotetext{
32 One may wonder to what extent these types of illustrations are of interest for modern studentus. This is only a problem when the historical connotation is not explained. When one uses this type of illustration, ore must tall a rather extensive story about those times in order to create a context from which the students can approach this problem. The theoretical explanation must be the solution to a problem that arises in the story; just as in detective novels. But this also holds when one uses modern examples. The use of stories from a long time ago will become especially interesting when one continues the story up to modern times. When the same explanation scheme can be used in the explanation of a long period of history, the students will both learn more about history and will be trained in the recognition of the rellevant pattems. It is training in the use of knowledge in different
contexts.
}

I use the term Classical as a contrast with Keynesian. Therefore, Classical includes Monetarist, Neoclassical, erc. 
important to show the decision making processes and expectations behind those mechanisms. When no one is able to stop this downward spiral, government intervention may be necessary to solve this prisoner's dilemma. ${ }^{24}$ When the government borrows the excess reserves of money in the economy and uses them to buy goods (or lower taxes), the dilemma can be solved. Those ideas can be illustrated by pleas for the acceptance of government deficits in the 1930s, and by stories about some recessions (illustrated with real world data about the variables that have been discussed in the theory).

Although the theories discussed in this dynamic real world approach are not inconsistent with standard textbook macroeconomics, the focus is different. From the beginning the focus is on causal mechanisms and general (dis-) equilibrium features of an economy. It is a systematic application of microeconomic principles and therefore helps to improve the understanding of those principles. Macroeconomics is microeconomics with one fundamental extension: the circular flow.

What are the consequences of this approach in the light of the six teaching principles? First, it is easy to relate the theory to prior knowledge. Because the theory is presented as a set of questions and mechanisms instead of a set of models, the theory can be seen as a systematization of knowledge the student already has in a rudimentary form. Therefore, the basic principles are not completely new. Second, the causal organization of the theory is easier than in the mainstream model-based approach. Because the theory is developed as a solution to reall world problems, it is easier for students to organize theoretical concepts congruent with problem situations they can imagine. Because the presentation of the theory is causal in character, it will be much easier for students to develop an intuitive understanding of the theory than when the approach is derived from models with a lot of seemingly unrealistic assumptions. Because the complete body of economic theory is created as a hierarchy of principles, the student is challenged to reduce problems to basic concepts. We should not forget that this approach is not inconsistent with the use of formal models to increase understanding causal theory. Third, motivation problems can be solved to a large extent by this more intuitive approach. Because each concept is introduced starting with a real world problem, the relevance of the concepts can be made clear to the students from the start. When the teacher is able to create surprises in the presentation of the problems, intrinsic motivation may be stimulated even more. Fourth, because the whole body of economic theory is developed as the application of a limited number of fundamental principles, those principles are elaborated by each extension of the theory. The fundamental economic schemata will be used a lot more than in traditional courses that are based on presenting models instead of basic principles. The procedure can be used both for the development of wery short and elementary courses and more technical courses. Fifth and sixth, because the number of principles is very limited and the range of applications very wide, it is easy to develop patten recognition schemata in different contexts and routinize the problem solving schemas.

\footnotetext{
${ }^{24}$ As a consequence, Keynesian fiscal policy has to be presented as an application of the theory of the prisoner's dilemma.
} 


\subsection{Application of the theory to the game}

Although a textbook combined with lectures is the core of almost all courses in economics, such an approach is very passive in nature. Bereiter and Scardamalia (1992:532) derive from cognitive theory a different list of teaching principles around the learning process. They see 'cognitive apprenticeship' as the "unifying concept to embrace what is distinctive about the emerging cognitive approaches to teaching." They mention six educational envisionments for 'cognitive apprenticeship' (see Collins, Brown, and Newman, 1989): modelling, coaching, scaffolding, articulation, reflection and exploration. Modelling is the demonstration of thought processes. Coaching is the assistance of a teacher when students need it. Scaffolding is the help the teacher provides to reach complete success, where the help has to be withdrawn in steps. Articulation is the verbalization by the student of their own knowledge and cognitive processes. Reflection is the comparison of different processes, especially that between the process of a student and an expert. Exploration is the independent search of students to define the problems. In this vision, curricula "might include (at appropriate levels of difficulty) more of the kinds of problems experts actually deal with" (p534). In order to accomplish such an active learning process, different methods are required.

An approach much used in business administration is the case study method. This method is difficult to apply in mainstream economics courses because of the difficulty already mentioned of applying the models presented directly to the real world. It can be more easily integrated into the approach presented in section 2.4. An approach more adapted to mainstream economics is the use of model simulations, perhaps in the form of games. For example, students can implement a government policy in a macroeconomic simulation model. In order to enhance motivation such a simulation can be presented as a game; the players with the best macroeconomic performance are the winners. This method helps to get a better feeling for the model implemented in the simulation program.

In the context of the teaching method presented in section 2.4 it is important for students to get a better grasp of the fundamental importance of the decision making process behind all economic phenomena. Especially with respect to macroeconomics this is very difficult. Therefore, in this thesis a game will be developed that is focused on the relation between decision making, market dynamics and the business cycle.

The fundamental features of the game can be characterized as follows. First, the game focuses on the fundamental coordination issue discussed in chapter 1 . The central issue is the coordination of independent decision makers. Therefore, the players are the decision makers. Because an economy is an interactive system, the game has to be interactive, too. Second, because macroeconomics is about long term developments, the game has to simulate a long period. For educational reasons, the duration of the game must not be too long. In order to create an opportunity for short term interaction and at the same time to simulate a long term process, the game must have a real time character. The game in this thesis computes the results on a monthly base, and can simulate in half a day 10 to 15 years of performance. Third, because not all decision makers can be players, a choice had to be made for the most import- 
ant actors in the economy. In first instance the firms have been chosen. Therefore, the other actors in the economy are modelled by simple computer routines. Fourth, because economic theory discusses decisions in a complex environment, the full complexity has to be felt by the players. Therefore, al. decisions modeled in simple economic theory have to be made by the players. For this reason, the players make decisions about investment, labour hiring and firing, and wage and price levels.

Just as in a real world economy the players in the game econony are fundamentally interdependent. On a macroeconomic level they sell the machines in which the other players invest. On a microeconomic level they compete on the same markets. Therefore, the game is capable of showing the fundamental interdependencies between microeconomic decisions, competitive processes and macroeconomic dynamics. For example, when for some reason many firms increase their investment demand, aggregate demand rises, other firms may think that it is beneficial for them to expand, too. In that case a raging boom emerges. But when firms perceive the increase in demand as temporary, the economy can be more stable.

What can a game like this accomplish for the six teaching principles developed in section 2.2? First, with respect to the principle of prior knowledge one may perceive the game as an instrument to give the students a feeling for the coordination problem through direct experience. Such an experience may activate the knowledge the student already has. But such a process will require a lot of incentives by the game leader to help the student to perceive the game as more than a game. For example, they must get some assignments that relate experience in the game explicitly to economic theory. Also with respect to the second principle (causal orgamization) the game can be helpful. Chapter I showed that because of the fundamental macroeconomic coordination problem macroeconomic stability is closely related to the strategy of firms. If it is true that profits of firms depend on their capability to anticipate macroeconomic developments, the game may help students to practise with those fundamental relationships. But also here active help is needed to organize thought by the students. Third, garnes are motivating, especially when the results depend on skill. Furthermore, because of the interactive nature of the game, when decisions are made on incorrect assumptions, the inconsistency between the schemata of the student and the results of the game may stimulate curiosity and hence motivation. But then the players have to learn the game to the extent that profits are realized by rational decision making and not just luck. Fourth, as long as a game gives the benefits of creative thinking about the economy, students can elaborate their knowledge in many ways. Fifth, because part of the results of the firms is the consequence of quick recognition of changes in the environment, students have an incentive to learn to recognize patterns in the context of the game. But it will require a lot of help to generalize the experience to other contexts. Finally, one may acquire routine in the application of some fundamental principles through training with feedback. For this purpose it is very important that the game generates adequate feedback to the player's decisions.

The game can have a role both in a principles-based and a mainstream approach to economics. The game is a world where studlents can apply the basic lines of reasoning to real situations. For example, when the investment accelerator is discussed in theory, it is a rather mechanistic rule. By real world examples you can 
show that in practice it is less extreme. But in the game the students decide themselves about investment. They will experience for themselves the role of expectations in the mechanism. But they will also feel that there is some truth in the investment accelerator mechanism.

In conclusion, the game that is developed in the rest of this thesis may have a useful role in learning about the macroeconomic coordination issue as well as other topics of macroeconomics. But a large part of the effect of a game depends on its ability to give sufficient feedback and relate the experiences to theories, prior knowledge, and real world knowledge.

\subsection{Conclusion}

Cognitive psychology suggests that knowledge is created by adapting existing schemata. Theoretical knowledge is only used in real world situations when those situations are contexts that trigger the theoretical schemata. Therefore, teaching economics has to start with the activation of the correct or incorrect knowledge that already exists. The teaching process must be focused on the adjustment and extension of this knowledge structure. Students have to be trained explicitly in the application of the new schemata. Because an important difference between experts and novices can be found in the ability to structure information according to fundamental principles, the teaching process has to focus on those fundamental principles.

In section 2.3 it has been argued that well-known textbooks as Samuelson and Nordhaus (1992) are not structured according to those teaching principles. This seems to be the consequence of the focus on models instead of fundamental principles. This same focus may explain the avoidance of the fundamental coordination issue by mainstream economics (see chapter 1 ): it is very difficult to model this coordination problem. In section 2.4 a principles approach to economics has been developed. This approach seems to be more consistent with the teaching principles than the mainstream approach. Finally, in section 2.5 it has been suggested that a game where the players take the decisions that generate macroeconomic results can be a useful instrument to improve economic insight. Such a game fits well into a principles-based approach because it motivates the students to apply the basic principles during active participation. But also in a mainstream course the game can help students to increase their insight into economic mechamisms. Especially the role of human behaviour in macroeconomic systems is an example of a theoretical problem that is not easy to perceive in the real world. For this purpose in the next two chapters an experimental world is designed that is as consistent as possible with different theoretical perspectives. But as mentioned in section 2.5 a lot of attention to educational aspects is needed to make the game really work. A game like this can only be effective when it is explicitly related to a theoretical framework. This is developed further in chapter 6 . 


\section{Chapter 3}

\section{The road to experimental macroeconomics}

\subsection{Introduction}

In chapter 1 it has been argued that the macroeconomic coordination problem has been systematically neglected. An experimental approach seems capable of improving understanding of this problem. Experimental economics is a rather new branch of economics. Perhaps the first experiment was a classroom experiment by Chamberlin (1948). In the 1960s a lot of pioneering work was done. In 1985 the Journal of Economic Literature established a separate bibliographical category 'Experimental Economic Methods' (Roth, 1987:1).

Almost all economic experiments are micro- and mesoeconomic in character. Experiments in macroeconomics are exceptional and the results are usually disappointing. The reason for this is obvious: when it is already difficult to model relatively simple microeconomic systems, it will be almost impossible to model complex macroeconomic systems. Nevertheless in this dissertation the design for a macroeconomic experimental world will be developed.

Before starting this adventure, it will be useful to investigate the opportunities and problems with economic experiments. In section 2 the fundamental ideas behind economic experiments will be discussed. To illustrate the dynamics of experimental research, an example of a line of experimental research will be discussed more deeply: the double oral auction market. It will be followed in section 4 by a discussion of some methodological issues. In section 5 a game called Expansio will be discussed to investigate problems in doing macroeconomic experiments. Finally, some methodological issues with respect to a game focused on the macroeconomic coordination problem will be discussed.

\subsection{Economic theory, econometrics and experimental economics}

Economics may be seen as a formal as well as an empirical science. It is a formal science in the sense that most economic theories start from a list of assumptions about the objective functions of economic actors and the "rules of the game" and then 
deductively derive their conclusions.' A large part of the debates in economic theory concentrate on the plausibility of the assumptions and correctness of the derivations.

Economics is an empirical science in the sense that it pretends to be able to explain economic realities. Much research in econometrics is focused on estimating the coefficients of theoretical models with the help of empirical data. In this type of research it is assumed that the model is correct, while only the size of the effects have to be known. A second part of empirical research tries to test and modify econornic theories. This research may concentrate on testing either the assumptions or the conclusions of the theories. Third, empiricall research may be used to collect data about the real world without an explicit theoretical connotation. Those data may yield new facts that may stimulate the development of new theories.

Traditionally economists use field data to estimate the coefficients of their models and to test and modify their theories. In experimental economics the data are from laboratory worlds. With respect to the first type of empirical research, the estimation of coefficients, it will be exceptional that laboratory data are useful. If one wants to use coefficients estimated in experimental systems for the real world, one has to assume that they are the same in the experimental world as in the real world. ${ }^{2}$ In most cases that is not very plausible. For example, the coefficients in a consumption function are assumed to depend on a lot of unknown factors and institutions and so wil] differ between the real world and experimental worlds.

With respect to the second type of empirical research, the testing and modification of theories, laboratory experiments may be very useful. In theoretical reasoning we assume that everything is constant except for the variables tackled in the theory explicitly (the ceteris paribus condition). In the real world the ceteris paribus condition clearly does not hold. When data are collected in the real world, many more variables than those incorporated in the theory change. A stochastic error term is introduced in order to catch the factors that are assumed to be constant in the theory, but are not constant in the world from which the data are gathered. In order to estimate the model, assumptions about the error term are necessary. Therefore, an econometric test of a theory with non-experimental data does not test the theory, but a combination of the theory and the assumptions about the stochastic variables. In experiments it is the challenge to design the world in such a manner that the variables included in the theory can be controlled, where other influences are avoided as much as possible.

A lot of experiments are focused on the third type of empirical research, the generation of stylized facts. Many experiments have been inspired by a lack of theory. For example, although theories of competition analyse equilibrium situations extensively, they do not tell much about the path towards equilibrium. For this reason several experiments have been set up on different market systems. For example, the performance of double auction markets have been compared with single auction markets.

\footnotetext{
'Compare Hey (1991:7-9).

although the experimental settings are just as real as the non-experimental world, I will use the term 'real world" for the non-experimental world. See Plott $(1989: 1112,1165)$.
} 
As will be clear from chapter 1, the primary goal of the development of the game is to test and develop theories. Therefore, we focus our attention on the advantage of experimental data relative to field data for the testing and modification of theories. As mentioned above, testing with the help of field data implies testing a combination of the theory and the empirical validity of the assumptions of the stochastic error term. The consequences of this joint testing procedure can be disastrous. If the theory survives the test, one can argue that this is caused by the error term that is not as independent from the theoretical variables as is assumed in the testing procedure. When the theory is rejected, this can be explained by the error term, too. For this reason it is not surprising that inconsistent theories survive together. For example, when Friedman and Schwartz $(1963 ; 1982)$ tested the causal relationship between money supply and national income, their tests seemed consistent with their theory. But when those results were interpreted from the perspective of Keynesian theory, the results could be explained by other mechanisms such as the dynamics of the expectation formation process (see Kaldor, 1972; Weintraub and Habibagahi, 1972). Even after Thatcher and Reagan applied the monetarist theory of Friedman to real world economies in the 1980s, the controversy could not be settled.

When in physical sciences the real world does not answer questions posed by theory, controlled experiments are designed. The researcher creates an experimental world in which he can isolate the factors that are relevant from a theoretical point of view, and controls the exogenous variables as much as possible. Fundamental research in the physical sciences is only accepted when it is tested under controlled conditions. From this point of view it is surprising that economists use only nonexperimental data to test their theories.

Hey (1991:1) expresses his amazement that main stream (i.e. neoclassical) economists do not check their fundamental propositions with experimental tests, but mevertheless pretend to have a very general theory that can be applied to all decisions of all human beings. For example, neoclassical theory assumes that human behaviour can be described as the maximization of an objective function under constraints. On a fundamental level this is a tautology and cannot be tested empirically. But in each neoclassical model the objective function as well as the constraints have to be defined. For example, many neoclassical models assume that money income is maximized under a budget restriction. Therefore, it does not seem superfluous to test to what extent people really maximize when they face a budget restriction and are rewarded for their decisions. This experimental setting is rather easy to realize. But only the last decades has this method started to become accepted (Hey 1991).

In testing formal theories experimental data have some advantages compared with non-experimental data. First, good experimental data are less polluted by irrelevant information. For example, the data about the effects of the Thatcher policy are polluted by information about the political trust in Thatcher, the international economic situation, the existence of labour unions, etc.. In an experiment one may try to create a world for which the theory pretends to generate predictions: a closed national economic system without political problems. Such a world has to be consistent with the fundamental assumptions of the theory, but limits the number of irrelevant complexities as much as possible.

Second, because the experimenter has created the experimental world, the 
researcher knows more about the experimental world than about the reall world. For example, it is very difficult for a non-experimental researcher to get information about preferences. In an experiment artificial utility functions can be designed by rewarding the participants in real money (Hey, 1991). Furthermore in an experimental world it is much easier to communicate with the participants than in the real world.

Third, where in many real world research projects researchers have to get the most out of the very limited amount of relevant data, the experimental world creates the opportunity for replication. Many experiments are rather cheap and can be replicated as many times as the researcher likes. The number of observations is almost unlimited in experimental worlds. Furthermore, the researcher can vary control variables systematically and therefore is able to compare results in economic systems which have only minor differences. For example, much research has been done on markets for lemons with experimental worlds that differ in their institutional settings or the asymmetry of information (Plott, 1989:1159). A conclusion of these types of experiments has been that sometimes less information results in a higher level of efficiency than more information.

Fourth, because the experimental world can be manipulated by the researcher, it may be possible to design a crucial experiment. In the real world it is very exceptional that crucial experiments can be done (Smith. 1990:159). But in experiments it may be possible to create siltuations that distinguish fundamentally between different theories. For example, Plott and George (1992) have performed some experiments showing that in rather large set of markets adjustment behaviour can be characterized as quantity adjustment as a consequence of differences between the supply and demand price (Marshallian hypothesis) instead of price adjustment as a consequence of differences between the quantity supplied and the quantity demanded (Walrasian hypothesis). They have shown this by designing experimental markets that are stable in the Marshallian type of market adjustment and unstable in the Walrasian type, and vice versa.

Fifth, experiments may also have a disciplinary function. When you try to design an experiment it becomes clear that many implicit assumptions are made in theories. Roth (1987:12) writes in this context: "One of the disciplines that experimentation imposes is that, in order even to begin an experiment, it is necessary to specify many details of the environment that are not addressed by most economic theories. Much of the work of experimental economists therefore concerns aspects of economic phenomena that are not addressed by other kinds of economic research." This phenomenon will be illustrated in the development of the experimental game described in chapter 4 . The creation of an experimental world which is consistent with the fundamental assumptions of macroeconomic theory requires a lot of decisions on the road from abstract economic theory towards a world where real human beings are able to make dynamic decisions.

One may question how the experimental approach is related to other approaches like simulation, field data, and formal theory. One dimension on which the approaches can be compared is the level of abstraction. Case studies try to explain a real world phenomenon as precisely as possible. Econometric analysis on field data requires a 
higher level of abstraction. Laboratory experiments describe a more formal world, where formal theory is very abstract. In computer simulations, the level of abstraction can be lower than in formal theory, because one is not forced to find analytical solutions. But the level of abstraction is higher than in laboratory experiments, because one has to formalize human behaviour in abstract formulas. Therefore, on the dimension of abstraction those five methods can be presented as:

$\begin{array}{ll}\text { Case } & \begin{array}{l}\text { econometrics laboratory } \\ \text { on field } \\ \text { data }\end{array}\end{array} \quad \begin{aligned} & \text { computer } \\ & \text { study }\end{aligned} \quad$ formal theory

No abstraction)

(highly abstract)

The choice of the level of abstraction in testing a theory depends on what part of the theory has to be tested. First, the consequences of a theory can be tested by computer simulations. This is useful for the investigation of the consequences of assumptions of the behaviour of individuals for the behaviour of the system. For example, one may model a market system and investigate the behaviour of the market with different combinations of decision rules for the players. A drawback of computer simulations is that it forces behaviour into mathematical equations. It may be that real actors are different. Especially learning behaviour is difficult to model. Therefore, one may substitute the artificial decision makers by real human decision makers. This is the setting of laboratory experiments. This type of experiments can be divided in experiments with individuals and experiments with groups. Experiments with one player focus on the behaviour of this player as determined by the environment. But many systems are interactive in character. For example, in negotiations on markets the actors develop expectations about the future behaviour of other actors. In that case behaviour may be different when a person plays with a computer program than when he plays with a human being. The results of bargaining experiments where players implicitly use justice are not very convincing when they bargain with a computer.

Although laboratory experiments have incorporated more aspects of the field than simulations, some choices have been made with respect to the level of abstraction. Therefore, one has to investigate to what extent the experimental world is comparable with the real world. This is the problem of external validity of the results. But when one compares the experimental world with abstract theory, theory is more abstract than a well-designed laboratory experiment, and therefore not more realistic.

\subsection{An experimental line in microeconomics: double auction markets}

A lot of work has been done on decisionmaking under risk, game theory (especially around the Prisoner's dilemma), and auction markets. In this section a well developed line of experimental research will be studied: the double auction market.

In the oral double auction market the participants are "either physically present 
in the same location or telephonically linked so that they can all communicate with each other. There is an auctioneer who administers the auction process but who otherwise takes a passive role. The active role is taken by the agents themselves, who are free to call out bids (offers to buy) or asks (offers to sell) depending upon whether they are potential buyers or potential sellers. If we confine our attention to a good which is traded in discrete units - for simplicity one at a time - then, at any time, there is at most one bid and one ask outstanding. Agents can either accept the bid or ask or can make their own bid or ask. A new bid must exceed any outstanding old bid, although it could fall short of previously accepted bids; similarly a new ask must be less than any outstanding old ask, although it could be greater than previously accepted asks. The process of calling out, and accepting, bids or asks continues until no new bids or asks are forthcoming and trade has ceased" (Hey, 1991:185).

The experimental model for such a market is straightforward. The preferences are modelled by a special application of derived demand theory called induced preference theory (see Plott, 1989:1112, Smith, 1980:157-158). The utility of goods traded in experimental markets is determined by the amount of money the experimental subjects get according to a predetermined redemption value schedule. The cost of goods is determined by a cost schedule at which the sellers may get the traded goods. The buyers make money by buying goods from the sellers and reselling them to the experimenter. The difference is the consumer's surplus. The buyers keep this money. The sellers make money by purchasing goods from the experimenter at a predetermined cost schedule and selling them to the buyers. The difference is the profit. The sellers keep this money. In this way, cost and utility in experiments can be induced from real life utility of money for the experimental subjects.

The double auction market experiments show a fast adjustment towards equilibrium relative to for example single auction markets and sealed bid auctions (see for example Plott, Smith, 1980, Plott, 1989). In experimental markets, even with 3 or 4 sellers and as many buyers, the market price converges towards equilibrium very rapidly. ${ }^{3}$ This seems to contrast with competitive price theory which requires that the number of buyers and sellers is so large that each becomes a price taker. Despite the fact that in the double auction markets the participants were not price takers, competitive equilibrium theory was applicable. Those data cannot be explained with current theory (see Smith, 1980:375).

In traditional price theory it is suggested that perfect information would generate more efficient results than imperfect information. Yet, in experimental markets where the exchange surplus is mainly gathered by one part of the market, the adjustment process becomes slower when information about the situation of the other participants improves (Smith, 1980:166-169). This shows how interpersonal utility considerations may influence market performance. Until now, theory has not much to say about this. Although a lot of experimental data have been generated about the equilibrium path, a theory to explain the data is not available yet.

In traditional price theory the focus of attention is on the number of participants in a market. Experimental data show that the difference in performance between a

"In 3 or 4 rading periods when the subjects are experienced with the institution, but are not familar with the particular induced values. See Smith $(1982: 945)$. 
double auction market and a sealed bid market is bigger than that between a double auction market with three suppliers and one with ten suppliers. The results suggest that rather than market structure in the traditional meaning of the word, the institutional setting of the markets is relevant for market performance.

This requires much more insight into behavioural dynamics of decision makers in different institutional settings. At this moment theory about those processes is lacking, because almost all economic theory assumes equilibria. This example may be sufficient to show how experimental data may be used to test theories and to develop new theoretical questions.

\subsection{Methodological issues}

A theory in the social sciences defines the structure of a system and then derives conclusions about the behaviour of that system. What criteria are relevant to develop an experimental world in which one can test and develop such theories?

First, the experimental world has to be consistent with the assumptions in the theory. A well designed experiment creates the opportunity to test the predictions of an economic theory precisely on the domain to which it is intended to apply (Roth, 1986:249). For example, classical duopoly theory predicts the behaviour of profit maximizing firms with a given demand function and a given cost function. For such a system at least two inconsistent predictions were available: the Bertrand model and the Cournot model. According to the Cournot model a Nash equilibrium would result., according to the Bertrand model competition would go on till the general equilibrium would have been reached. In order to test those theories, one has to build a system that is consistent with the common assumptions, and let the players play.

Profit maximization is an important assumption in oligopoly models. Therefore, one would like to have an incentive for the players to do this. When experimental decision making is investigated by experiments in thinking, the dynamics of the decision making may differ from real world decision making." Therefore, it is common practice in economists" experiments to rewand players with money, so that they have a 'real' motivation to maximize (induced preference theory; see section 3.3). When instructions are used to induce role-playing behaviour (i.e. acting as if profits were real) the results are more likely to be sensitive to particular experimenters, subject groups, and other sources of variability (see Smith, 1980:349). Hence, in most microeconomic experiments the actors are rewarded with a little bit more money per hour than they can earn in real life."

Second, because the experimental world is assumed to be somewhere between the real world and the theory, the experiment must induce no artificial mechanisms that canmot be expected to be present in the real world. Players in a game may have other motives and costs than presented in the formal model. For example, agents may have subjective transaction costs or altruistic motives. Smith (1990:159) assumes that

\footnotetext{
* Kahneman and Tversky (1984) is an example of this type of experiment.

Neverthelless, many social psychologists doubt the effect of money as an incentive. See for anple Kahneman (1988:14).
} 
the problem of altruistic motives can be reduced by withdrawing information about the competitors outside the experiment. Most researchers in experimental economics assume that the problem of subjective transaction costs can be solved by setting the monetary rewards so high that they dominate the subjective costs or by giving the subjects a commission per transaction.

Third, the experiments have to be set up in such a manner that the effects on the dependent variables are caused by the independent variable. This is called internal validity. ${ }^{6}$ One of the most important advantages of experimental settings is the ability to control for individual differences. For example, while in the real world for one type of market only one type of market institutions is available, in the laboratory one may test for differences between different institutions in the same type of markets. Therefore, an important methodological requirement for good experiments is the ability for systematic variation of variables that can be important.

Fourth, it is important that adequate measurement methods are used. For example, when an experimenter asks about expectations of the future level of sales, he must be sure that the players are able to give informed expectations about that variable at that moment, and have no motivation to give biased predictions.

Fifth, one may hope that the findings of the experiments can be extrapolated to situations outside the specific research situation (external validity). A lot of criticism of experiments is focused on the external validity of laboratory experiments: to what extent do the propositions tested in laboratory experiments apply to non-laboratory environments? As defined in the first requirement for good experiments, when the experiments are correctly designed they must be consistent with the theory. Therefore, when the experiment is not consistent with the real world, neither is the theory. In that case the experimental design may show some hidden assumptions in the theory. When general theories are really general they have to be applicable to all special cases. Models "believed to be applicable to complicated naturally occurring processes should certainly be expected to help explain what occurs in simple, specialcase laboratory markets" (Plott, 1989:1112).

Which type of external validity problems can be expected? Experimental worlds differ from the 'real world'. In many experimental worlds the decisions are made by students instead of 'real businessmen'. The effect of the type of decision makers can be investigated by varying the subject pools in the experiments. Plott $(1989: 1168)$ notes that until now no subject pool differences which bear on the reliability of economic theory have been reported.

A more fundamental problem may be that other laws operate in a simple experimental world than in the real world. In the experimental world the social situations are ad hoc, while in the real world businessmen are embedded in social relationships and friendships. When long run developments are simulated in experiments, time has to go on much faster than in the real world. This may be a reason why most experimental research has been done on temporary phenomena like auction markets, and much less on long term phenomena like the business cycle.

Dyer et al. (1989) serves as an example of the consequences of the difference between experimental and real worlds. They find that even experienced business

\footnotetext{
"See for example Sears, Peplau, and Taylor (1991:23).
} 
executives in the construction contract industry are just as prone to the so-called "winner's curse" as "naive" students. Because the experts did function very well in the real world, they conclude that "the executives have learned at set of situation specific rules of thumb which permit them to avoid the winner's curse in the field but which could not be applied in the lab." This implies that the essential mechanism behind real world dynamics (the formation of rules of thumb) is not explained in the theories. Therefore the experimental results imply a quest for better theory. Perhaps they imply also a quest for better experiments, where subjects get a sufficient training in skills before the experiment starts.

One methodological issue, the necessity of monetary rewards, requires some further attention. Monetary rewards can be very important in satisfying the first two criteria for good experiments, i.e. the consistency of assumptions and the avoidance of artificial mechanisms. By such a method formal preference functions can be transformed into decision situations that are real for the players in the sense that they have monetary consequences for the players that are comparable with the interests in the real world markets. Those monetary rewards are set at a level at which it can be assumed they dominate other motives like transaction costs and boredom. In discussing the motivational aspects in microeconomic experiments Smith (1982:935) refers to the "game value' as a motivating force; this "explains why results with maximizing behaviour are sometimes obtained in experiments with no monetary rewards". But Smith (1976:277-78) shows some evidence that the results of experiments are less consistent in experiments without monetary rewards. He explains this by boredom and transaction costs.

In analysing the importance of monetary incentives in experiments, it may be wise to discriminate between different types of experiment. First, the game value of experiments differs a lot. The market experiments described in Smith (1976) are not very challenging to play. When the players have got familiar with the principle, the game is not interesting any more. Therefore, the players in this type of experiment are prone to boredom and will feel the transaction costs heavily. In games that are played for fun, the game remains interesting till the end. For example, in amateur chess competitions the dedication of the players to the game seems to be no problem. So, when a game is intrinsically motivating, there is no necessity for monetary rewards.

Second, the importance of maximizing behaviour may differ considerably in different experiments. For example, when the focus is on the efficiency of markets, it is very important that players try to get the maximum out of the game. But when the focus is on the ability of prices and interest rates to coordinate activities in an economy, it is less important that players really maximize profits. Furthermore, even when one uses monetary incentives for firms in a game economy, the importance of the rewards differs significantly from the real world. For example, real firms face the risk of bankruptcy, something that will be very difficult to simulate in experimental settings. Furthermore, the motivation of managers in real firms is a complex issue of

${ }^{7}$ See Hey (1991:198). 
which profit maximization is only a small part. ${ }^{8}$ So, in games where it is not very important that the utility functions are completely known by the experimenter, the use of monetary rewards will be less important.

In summary, five criteria are formulated with respect to experiments:

1. Consistency with the assumptions of the theory

2. Avoidance of disturbing mechanisms

3. Internal validity

4. Adequate measurement

5. Externall validity

The importance of monetary incentives depends heavily on the type of motivation that is implied in the theory and the efficiency of other motivating forces.

\subsection{A macroeconomic experiment}

Experiments on macroeconomic systems are exceptional. Most of the very scarce examples are experiments about the behaviour of governments, labour unions and the like, while macroeconomic dynamics, including the solution of the free market coordination problem, is incorporated in the mathematical model. "Therefore, while these types of investigations is very useful for other purposes, it is of no use for the investigation of the fundamental macroeconomic coordination problem.

As far as I know, only one experimental study investigates the relation between decisions of firms and macroeconomic performance: the dissertation by Fiedler (1979). ${ }^{10}$ The design of the game as well as the problems he met are very familiar to me. For this reason we will investigate Fiedler's study more extensively in this section. Furthermore, such a case study gives the opportunity to apply the criteria developed in section 3.4 .

The game described by Fiedler is called Expansio. The purpose of the game is the investigation of the decisions of firms in the investment and consumer goods industry in a closed economy with exogenous labour saving technological development in a linear homogeneous Cobb Douglas production function $(\mathrm{p} \mathrm{12,54)}$ and a constantly growing labour supply ( $\mathrm{p} 1$ ). The game is derived from a neoclassical twosector equilibrium growth model of a closed economy. The 8 to 16 players in the game represent the firms. Half of the firms produce investment goods, the other half consumer goods. The players decide about their production by their planned use of capital stock and the planned capital productivity (and hence implicitly their planned labour demand). Those decisions of the firms are exogenous to the computer model, while the other variables in the model are simulated by the computer program. The

\footnotetext{
${ }^{8}$ See for example Marris (1964), Willianson (1964) and Cyert and March (1963).

${ }^{9}$ See for example Gremmen (1989) and Tietz (1972).

10 I learned about it when II met Professor $\mathbb{R}$. Selten long after I had finished the design of my game.
} 
firms are asked to maximize long term profits. The computer calculates the decisions of the other sectors in the growth model: consumption, labour supply, govemment and the banking sector (p 2,5).

The purpose of the game is not made very clear by Fiedler. Based on his presentation of the results, the following objectives can be formulated:

a) comparison of the behaviour of the experimental game with the equilibrium growth path;

b) investigation of expectation formation of the firms;

c) investigation of the differences in performance of the firms.

These objectives may have important consequences for the design of the game. Let us investigate the methodological criteria discussed in section 3.4.

First, consistency with the assumptions of the theory is required. In order to compare the behaviour of the experimental game with an equilibrium growth patlin Neoclassical growth theory can be used as a frame of reference. In this theory it is assumed that markets are very flexible. To what extent is this true in the Expansiogame?

In the labour market demand for labour determines the employment level as long as labour demand is lower than labour supply and higher than a minimum level of employment. Outside this range firms are rationed in their employment level or forced to employ more people than they want. The rationing of labour shortage over firms is proporlional to the growth in labour dernand by the firms (p 59-64). The real wage is determined by labour productivity, the unemployment rate and the growth in the employment level. Therefore, the reward of labour is not a decision variable of the firms, while rationing of labour does depend to a large extent on the labour demand decisions of the firms. This seems not very plausible, and is not consistent with Neoclassical theory where markets are cleared by price adjustment.

Sales of consumer goods equal production, while price is determined by a con sumption function that depends on labour income and other income with an elasticity of demand of -1 . Therefore, the market of consumer goods is forced to be always in equilibrium. Suppliers of consumer goods are never rationed; all variations in supply are sold through the price mechanism. This seems to be extremely Neoclassical, and prevents Keynesian unemployment in the sector of consumer goods.

The market for investment goods is also modelled as a market clearing model. The investment decision consists of a decision about planned investment as well as the maximum price the player is prepared to pay for the investment goods. The players are not allowed to invest more than half of their current capital stock, while firms with a bad financial position can be restricted in their investment or can even be forced to sell part of their capital stock (p 16). Implicitly a demand schedule for investment goods can be derived from those decisions of the players.

Firms that produce investment goods can supply them from stock, from production and from a decline in the stock of capital used for their own production. Firms that produce consumer goods can only sell capital goods that are used by their own production. Each firm decides about a minimum price at which he accepts to sell the investment goods. From the decisions of the firms a supply curve of investment goods can be derived. When this supply curve is combined with the demand curve the equilibrium price can be determined by the intersection of the two curves ( $p \quad 15$ - 
$18,43,58-93)$. Therefore, the market for investment goods is cleared a priori and nonprice rationing is excluded.

In summary, for the markets of consumer and investment goods market clearing is forced through price adjustment, whereas for the labour market fixed prices are assumed. This may be consistent with the mainstream model of a market economy where wage adjustment is much more difficult than adjustment of prices. But it removes important dimensions of freedom and therefore restricts the set of outcomes in a manner that is difficult to justify. In any case Fiedler (1979) presents no justification.

The second criterion is the avoidance of disturbing mechanisms. This is a difficult task. Fiedler is not successful in doing so. First, the ratioming scheme on the labour market may induce gambling behaviour. When excess demand on the labour market can be expected, it is profitable to demand more labour than is needed. This implies that labour demand can be seen as a gamble that depends on the decisions of the other players.

The rationing scheme on the market for investment goods has some unpleasant characteristics, too. On the demand side, the firms set a maximum price for all the investment goods they like to buy. They get either all investment goods or no machines at all. This, too, is a gamble, while in the real world it will never be like that. On the supply side firms will have difficulties in setting their minimum price of machines, because at that moment they do not know the wage rate. Therefore, the information available for the decision makers is far less than assumed in theory or can be expected to be available in the real world.

With respect to the third criterion, internal validity, the contral of variables is not very systematic. It is surprising that government is introduced in the experimental model. Although government makes the game more like the real world, it complicates the game and the interpretation of its conclusions.

On the fourth criterion, measurement, the lack of information for the players may create difficulties for them to develop informed expectations. Although Fiedler asks the players about their expectations for prices and the wage rate, it is difficult to imagine what the meaning of these expectations is.

The lifth criterion, extemal validity, is not relevant as long as the other problems are not solved.

Because of the problems in the design of the Expansio game, the results are disappointing. First, Fiedler compares the results of the game with the general equilibrium growth path, but does not even try to explain the differences. Second, the compares the realized developments with the expectations of the players. Although it is good that he forced players to write down their expectations, the game is too obscure for the players to have informed expectations. Third, he tries to explain differences in the development of firms. The results that are statistically significant are not very revealing. For example, firms that did make really stupid decisions did have worse results than less stupid players. Let me present one example of a conclusion that follows from his analysis:

"the players in the consumption good sector have the best results when they 
- use the whole capital stock for production;

- derive the capital productivity on the recent development of the wage-price ratio;

- invest cautiously" (p 310; the translation is mine).

This type of conclusion is not very informative.

Although until now the discussion has been rather critical towards the Expansio model as an experimental setting, 15 years ago it would have been very difficult to develop a more realistic model. There were good reasons for others to avoid this type of project. Too many practical problems blocked the road. For example, the necessity to put the data into one big computer, implied that only a small number of rounds could be played, while the number of decisions had to be limited in order to render the fitting of the decision sheets manageable.

Given the problems with the Expansio game, the game that will be developed in this dissertation has to circumvent the problems in the Expansio game. Because of the improwements in computer technology, the problem of the long duration per round in Expansio can be avoided. The players may get the feeling that decision making is almost a continuous process, so the coordination problems that induced undesirable gambling behaviour can be avoided. Furthermore, the short duration of a round implies that within a day more rounds can be played. With the game discussed in this thesis about 20 years on a monthly base (i.e. 240 rounds) can be played within a day.

Although Fiedler ( $p$ 139-144) did not discuss the above mentioned theoretical problems, he signals some other practical problems that are relevant for the game developed in chapters 4 and 5 of this dissertation. First, Fiedler had problems to attract enough people to play the game. A first solution to this problem is the improvement of the motivational quality of the game (see chapter 6). When this is not effective, monetary rewards can be considered. Second, Fiedler had to economize on the scarce facilities and was forced to do each experiment in one long day. As a consequence, the players became tired and less concentrated at the end of the game. This problem can be solved by increasing the variation during the game, or by spreading the game over more days. Third, although the game leaders stimulated to do it, it was difficult to force the players to write down the arguments behind their decisions. This can be explained by the fact that the game was not intuitive enough for the players and training of the players was not sufficient. Fourth, a bad decision of one player influences the other players too much when the number of players is small. A larger rumber of players solves this problem. Furthermore, playing the game in groups of more than one player can create discussions within the groups and hence improve the quality of the decisions. Finally, Fiedler suggests that it would have been beneficial if players had played the game a second time.

Inspired by the problems in the game developed by Fiedler, some requirements for the game developed in this thesis can be derived. First, it is very important to be explicit about the theoretical assumptions in the theory to be tested. Second, it is essential that the design of the game prevents interfering mechanisms. This implies at least that the players are able to understand the game. The markets have to be 
modelled as intuitively as possible. Third, internal validity requires a careful choice of variables to be manipulated. Therefore, the focus will be on a minimalist approach in the model; ewerything that is not strictly necessary for the investigation of the problem at hand has to be avoided. Fourth, with respect to measurement it is very important to design a viable set of questions to investigate the behaviour and expectations of the players. In summary, good macroeconomic experiments require a very careful design.

\subsection{Conclusion}

Experiments seem to be a useful device to test and develop theories. Although until now most experiments are focused on utility-based theories, the focus in this thesis will be on macroeconomic theories. The experience with this type of experiment is rather disappointing. Part of the disappointment can be explained by problems in the design of the game. The correction of those problems requires a rigorous approach in developing an experimental world that is consistent with the foundations of macroeconomic models. This implies a strict distinction between behavioural equations and other equations. Section 3.5 shows that it is difficult to prevent artificial mechanisms to interfere in the macroeconomic system. This implies that institutions are consistent with the problems that have to be investigated. Furthermore, internal validity requires control ower the relevant variables. In a complex system such control can be very difficult. Especially control over behaviour of the subjects requires a lot of attention. To the extent that differences between the populations cannot be controlled, measurement of relevant characteristics of the subject will be important. External validity is less important than seems at first sight, because the experimental game developed in this thesis is focused on improving theory, not on the simulation of the real world. When the theories are sufficient to describe the real world, the results of the game will be so, too. 


\section{Chapter 4 \\ A Neoclassical growth model with individual firms}

\subsection{Introduction}

The macroeconomic coordination problem as defined in chapter 1 is the main concern of the economic game in this dissertation. The macroeconomic coordination problem is defined as the problem of coordination of decisions of independent economic actors in a free market economy with flexible wages and prices, ex ante substitutability of labour and capital, and many suppliers and demanders. In almost every theory about macroeconomic coordination Walrasian general equilibrium theory is a natural point of reference. The Neoclassical growth model is a lucid and simple example of such a general equilibrium model. Therefore, the game has been developed around the Neoclassical model of equilibrium growth. This model can be used as a benchmark to compare developments of the game. The basic model is discussed in section 4.2 .

The Neoclassical growth model is defined on an aggregate level. But the macroeconomic coordination is about the coordination between independent actors. For reasons of simplicity only the firms are modelled as independent decision makers. But when the Neoclassical growth model is disaggregated with respect to the firms, the size of the firms is not determined. The introduction of demand inertia, and therefore short run imperfect competition, solves this problem. When a firm has a higher price than the equilibrium price, the firm does not lose all its sales directly, but only a small percentage. In section 4.3 the equilibrium characteristics of this competition model are compared with those of the perfect competition model. Section 4.4 shows that the same line of reasoning can also be used in the labour market.

The investigation of the general equilibrium characteristics is the topic of this chapter. But just as the real world, the game will never be in a perfect equilibrium. When we allow for disequilibrium, a different set of institutions is required. This is the topic of chapter 5 . 


\subsection{The equilibrium growth model}

Almost all macroeconomic theories use the Walrasian general equilibrium as a benchmark. Therefore, it is a logicall point of reference for the game too. Because for both educational and experimental reasons simplicity is important, the simplest general equilibrium model is used as a starting point: the Sollow (1956) growth model without technological change. After the derivation of the real growth model (4.2.1), money supply is introduced (4.2.2). Section (4.2.3) shows that in general equilibrium the microeconomic and macroeconomic production functions are consistent with each other, but that a solution has to be found to determine the size of the firm.

\subsubsection{The real model}

A textbook description of the Solow growth model discusses the model without explicit distinction between behavioural and equilibrium equations on the one hand and technical and institutional equations on the other. Because the purpose of our game is to substitute equilibrium conditions and the behavioural equations of firms by players, it is important to make a sharp distinction those two categories of equations. Therefore, the presentation of the growth model will be a little bit different from that in standard textbooks. The equations that are relevant for the computer program of the game will be presented first. The behavioural equations and the equilibrium conditions of the growth model that are not in the computer program are determined by the decisions of the players. The behavioural equations of the growth model are only useful to analyse the general equilibrium characteristics of the game.

The presentation of the growth model starts with constraints and definitions (a). Although the consumption function is a behavioural equation, it will not be determined by the players. Therefore, the consumption function is also part of the computer model, and is defined separately (b). This already defines the main characteristics of the game. The other parts of the general equilibrium model, i.e. the equilibrium conditions, depend on the behaviour of the players in the game. The equilibrium growth path is used as a point of reference for the game results. Therefore, with the help of the market equilibrium conditions (c) the equilibrium growth path of the game economy will be derived (d). Finally, the equilibrium prices that are consistent with this equilibrium growth path are obtained from profit maximization of the furm (e).

\section{a. Definitions and comstraints}

Technology is the most important part of Neoclassical growth models. In order to have simple aggregation characteristics, a Cobb Douglas production function with constant returns to scale is chosen: 
$Q=\alpha K^{1-\beta}$

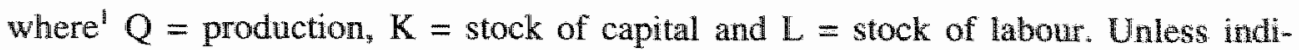
cated otherwise, all variables in this section are in real terms and for period for flow variables, or at the beginning of period $t$ for stock variables. The production function (4.2.1) can be written as:

$g_{y} \approx \beta g_{k}+(1-\beta) g_{y}$

where:

$g_{X}=\frac{X-X_{-1}}{X_{-1}}$

with as an indication of the time lag.

The second constraint is the exogenous growth rate of labour supply:

$L^{s}=\left(\mathbb{d}+g_{L}\right) L_{-1}^{s}$

where $L^{s}$ is labour supply. The third constraint is the physical deterioration rate of capital $\delta$ that is assumed to be a constant percentage of capital stock. ${ }^{2}$

$D=\delta K$

where $\mathrm{D}=$ depreciation on capital stock. The capital stock at the beginning of period $t$ is determined by investment and depreciation:

$K=K_{-1}+I_{n-1}-D_{-i}$

where $\mathbb{I}$ is investment in capital stock. Demand $Y^{\text {d }}$ is defined as:

$Y^{d}=C^{a}+I^{d}$

where $\mathrm{C}^{\mathrm{d}}=$ consumer demand and $\mathrm{I}^{\mathrm{d}}=$ investment demand. Income $\mathrm{Y}$ is defined as:

$Y=C+I$

where $\mathrm{C}=$ consumption and $\mathrm{I}=$ investment.

Savings $\mathrm{S}$ are defined as:

$S=Y-C$

From (4.2.6) and (4.2.7) it follows that:

$I=Y-C=S$

\footnotetext{
${ }^{1}$ For notational convenience the time subscript $t$ is omitted when the variable refers to the current period.

${ }^{2}$ Because production technology in the game is represented by a putty-clay production function instead of a putty-putty production function, replacement inwestment in the game is somewhat more complicated in the game than in equation $(4,2.3)$.
} 


\section{b. The consumption function}

Because the game focuses on the behaviour of firms, consumption behaviour is modelled as an equation in the computer model. The consumption function has been modelled as simply as possible. It is assumed that consumption depends on net national income in the previous period. ${ }^{3}$

$C^{d}=c Y_{-1}$

$(0<\mathrm{c}<1)$

where $\mathrm{C}^{d}=$ consumption demand. According to definition (4.2.1b) this equation can be written as:

$C^{d}=\frac{c}{1+g_{Y}} Y$

In the game's computer program a more general consumption function has been chosen":

$C^{d}=c_{1}\left(Y_{-t, p}-D_{-L, P}\right)+c_{z} Y_{w,-1}+C_{w w}$

$\left(0<c_{1}<1 ; 0<c_{2}+c_{1}<\mathbb{1}\right)$

where $Y_{L P}=$ average real national income of the last $L P$ periods $s^{5}, D_{L P}=$ average depreciation of the last LP periods, $Y_{w_{0}-1}=$ real wage income of the last period, and $\mathrm{C}_{a, i}=$ autonomous real consumption. This consumption function has the advantage that the effect of wage income and non-wage income can be separated (as assumed by some models of Post-Keynesian economists). But the results are not fundamentally different from those derived for (4.2.8). Therefore, we use (4.2.8) for the further development of the equilibrium model.

\section{c. The equilibrium conditions}

In order to investigate the equilibrium path of the game, equilibrium conditions have to be introduced. Those equilibrium conditions are not a part of the game model; they hold only when all players behave according to the general equilibrium model. First, because stock represents a cost in an economy with stable growth and complete certainty, there is no reason for stocks of final products. Therefore:

$Y^{*}=Q$

where $Y^{s}=$ supply of output and $Q=$ production. Second, equilibrium on the market

\footnotetext{
${ }^{3}$ For the sake of presentation we use gross national income instead of net national income as the independent wariable in the consumption function.

"Real income in (4.2.8a) is defined as nominal income divided by the price index. Therefore, it is implicitly assumed that the aggregate price elasticity of demand equals -1 .

s LP stands for long period.
} 
for output implies:

$Y^{d}=Y^{s}$

Equilibrium on the market for consumer goods implies:

$C=C^{d}$

Because in this model investment is determined by savings, equilibrium on the market for investment goods implies that investment demand equals realized investment $t^{6}$ :

$I^{d}=I$

Finally, equilibrium on the labour market requires:

$L=L^{s}$

Equations (4.2.1)-(4.2.13) define the complete equilibrium growth model that consists of 13 equations and 13 endogenous variables. ${ }^{7}$ Equations $(4.2 .1)-(4.2 .8)$ define the main characteristics of the game. Equations (4.2.9)-(4.2.13) define the conditions for the long term equilibrium growth path of the game.

\section{d. The equilibrium growth path of the game economy}

The set of equations can be solved as follows. From (4.2.7a) and (4.2.8a) we can derive:

$S=\left(1-\frac{c}{1+g_{y}}\right) Y$

From (4.2.1b), (4.2.3), (4.2.4), (4.2.7a) and (4.2.8c) it follows that:

$$
g_{K}=\frac{K-K_{-1}}{K_{-1}}=\frac{I_{-1}}{K_{-1}}-\delta=\frac{S_{-1}}{K_{-1}}-\delta=\left(1-\frac{c}{1+g_{Y,-1}}\right) \frac{Y_{-1}}{K_{-1}}-\delta
$$

Because according to (4.2.2) and (4.2.13) the growth of the stock of labour is exogenous, endogenous variations in the growth rate of national income $g_{Y}$ are caused only by variations in the growth rate of capital stock $g_{k}$. When the growth rate of the capital stock is higher than the growth rate of labour supply $\left(g_{K}>g_{L}\right)$, then according to $(4.2 .1 \mathrm{a})$ :

$g_{Y}=g_{K}+(1-\beta)\left(g_{L}-g_{K}\right)<g_{K}$

When $g_{Y}<g_{K}$, by definition:

\footnotetext{
* Investment demand is adjusted to savings through the interest rate. If the consumption function were sensitive to the interest rate, equilibrium would be reached by adjustment of both saving and investment demand.
}

${ }^{7}$ These endogenous variables are: $Q, K, L, L, D, Y^{d}, Y^{s}, Y, C d, C, I^{d}, I$, and $S$. 
$\frac{d\left(\frac{Y}{K}\right)}{d t}<0$

where represents time. After substitution of this result in the equation for the growth of capital stock, it follows that:

$\frac{d g_{K}}{d t}<0 \quad$ when $g_{Y}<g_{\mathbb{K}}$

When the growth rate of capital stock is lower than the growth rate of labour supply, the complementary story holds. Therefore, the equilibrium growth model described by equations (4.2.1)-(4.2.13) tends towards a stable equilibrium, such that:

$g_{K}=g_{Y}=g_{L}$

If $g_{K}>g_{L^{*}}$ then $\frac{d g_{K}}{d t}<0$

If $g_{K}<g_{K^{*}}$ then $\frac{d g_{K}}{d t}>0$

This is the traditional textbook result. ${ }^{8}$

\section{e. Equilibrium prices in the game economy}

It is possible to derive real (in contrast to nominal) prices consistent with the equilibrium growth model. Following the Neoclassical tradition, firms maximize the net present value of aggregate profits, given the production function and all prices:

$\max _{L t} N P V=\max _{L, t} \sum_{i=0}^{\infty} R \pi=\max _{L, t} \sum_{i=0}^{\infty} R(P Y-W L-P, D)$

subject to:

$Q=a K^{B} L^{1-\beta}$

$K=I_{-1}+(1-\delta) K_{-1}$

$Y=Q$

$P_{1}=P$

where NPV $=$ net present value of profits, $\mathrm{P}=$ price level of output, $\mathrm{P}_{\mathrm{I}}=$ price of investment goods, $W=$ wage rate, $\pi=$ profits, $i_{s}=$ nominal interest rate in period $s$,

\footnotetext{
see appendix $4 \mathrm{~A}$ for the long term equilibrium growth path.
} 
$r_{s}=$ real interest rate: $r_{s}=i_{s}-g_{p,+1}$, and $R=\frac{1}{\prod_{s=1}^{r}\left(1+r_{s}\right)}$. Condition (4.2.16) follows from the assumption that the output market is homogeneous.

From this set of equations the equilibrium real wage rate and real interest rate are determined":

$\frac{W}{P}=(1-\beta) \frac{Q}{L}$

$r=\beta \frac{Q}{K}-\delta$

Therefore, equilibrium prices consistent with the macroeconomic growth model exist. This completes the real equilibrium growth model. ${ }^{10}$ It has to be emphasized that the model in this section is the description of the equilibrium path of the game, not the description of the game model itself.

\subsubsection{The monetary sector}

It is easy to introduce a monetary sector into the real growth model. Consistent with the Quantity theory of money, the behavioural equation for the demand for money is defined as:

$M^{d}=P Y$

where $\mathrm{M}^{\mathrm{d}}=$ demand for money. In equation (4.2.19) it is assumed that the velocity of money equals 1 . This can be modelled by defining the length of the period in such a way that the velocity of money equals 1 .

One may assume that the growth rate of money supply is determined exogenously by the Central Bank:

The first order conditions for this maximization problem are:

$$
\begin{aligned}
& \frac{\partial N P V}{\partial L}=P \frac{\partial Q}{\partial L}-W=P(1-\beta) \frac{Q}{L}-W=0 \\
& \frac{\partial N P V}{\partial I_{-1}}=\frac{P}{P_{1}} \frac{\partial Q}{\partial K}-r-\delta=\beta \frac{Q}{K}-r-\delta=0
\end{aligned}
$$

The factor price equations follow directly from these equations.

10 It will be clear that the maximization problem $(4.2 .15)$ is not determined with respect to $Q$. In this section the maximization problem is used to deriwe equilibrium prices. In section 4.3 the consequences of this indeterminacy problem will be investigated. 
$M^{*}=g_{M} M_{-i}^{s}$

where $M^{\text {s }}=$ money supply. In the game it is assumed that the stock of money equals the demand for money $\mathrm{M}^{\text {s: }}$

$M=M^{d}$

where $M=$ money in circulation. When the money market is in equilibrium demand equals supply:

$M^{d}=M^{*}$

By means of equations $(4.2 .19)-(4.2 .22)$ the price level and the equilibrium inflation rate are determined:

$P=\frac{M^{3}}{Y}$

So:

$g_{F^{\nu}}=g_{M}-g_{Y}$

From (4.2.18) and (4.2.23a) the equilibrium nominal interest rate can be derived:

$i=r+g_{p}=\beta \frac{Q}{K}-\delta+g_{M}-g_{Y}$

where $\mathrm{i}=$ nominal interest rate."

In summary, equations (4.2.1)-(4.2.13) define the basic equilibrium model. Equations (4.2.17) and (4.2.18) introduce real wages and interest rates into the equilibrium model. With equations (4.2.19) $(4.2 .23)$ the price level and money market are defined, while equation (4.2.24) determines the nominal interest rate. ${ }^{12}$ With those equations the equilibrium growth model is complete.

The growth model is the equilibrium growth path of the game economy. This implies either that all players make all decisions consistent with the behavioural equations of the general equilibrium model or that equilibrium is forced on the economy. But in games with real players, the behaviour of the economy is generated by independent market participants. Therefore, the behaviour of a real game economy is much more complex than in the general equilibrium model.

\subsubsection{Disaggregation of the business sector}

Because the focus of research is on the relation between microeconomic behaviour of firms and macroeconomic stability, it has to be shown that the macroeconomic equihibrium model is consistent with rational microeconomic behaviour of firms. This

\footnotetext{
"In the game there is not a money market. When the game is in a general equilibrium, the game leader may sets an interest rate according to (4.2.24).

${ }^{12}$ With the eight extra equations eight new endogenous variables were introduced: $W, W / P, i, r_{n} P$, $M, M^{\text {a }}$ and $M^{\text {r }}$.
} 
section shows that in general equilibrium the aggregate production function is consistent with micro production functions of the same type (a), but that the size of the firms is not determinate in such a system (b).

a. The consistency of the micro and macro production function in general equilibrium

By the choice of the constant returns to scale Cobb Douglas production function (4.2.1) aggregation problems in the equilibrium model have been avoided. When all actors in the economy maximize their profits, the behaviour of the aggregate economy can be described as the maximization of exactly the same production function as the production function of the individual firms. This can be shown as follows. ${ }^{13}$

The aggregate production function can be written as:

$\sum_{j} Q_{j}=\alpha\left(\sum_{j} K_{j}\right)^{\beta}\left(\sum_{j} L_{j}\right)^{1-\beta}$

where $\mathrm{j}$ indicates the firm number. It has to be proved that in equilibrium this production function can be written as the sum of the micro production functions:

$\sum_{j} Q_{j}=\sum_{j} \alpha K_{j}^{\beta} L_{j}^{1-\beta}$

In equilibrium the first order condition with respect to capital for each firm $j$ is:

$\frac{\partial Q_{j}}{\partial K_{j}}=\beta \frac{Q_{j}}{K_{j}}=r+\delta$

The first order condition with respect to labour for each firm $\mathrm{j}$ is:

$$
\frac{\partial Q_{j}}{\partial L_{j}}=(1-\beta) \frac{Q_{j}}{L_{j}}=\frac{W}{P}
$$

Therefore, for each firm it holds that:

$$
\frac{\beta \frac{Q_{j}}{K_{j}}}{(1-\beta) \frac{Q_{j}}{L_{j}}}=\frac{r+\delta}{\frac{W}{P}}
$$

$\mathrm{SO}:$

$$
L_{j}=\frac{1-\beta}{\beta} \frac{r+\delta}{\frac{W}{P}} K_{j}
$$

In equilibrium the aggregate production function $(4.2 .26)$ can be written as:

\footnotetext{
'See Fusher(1969a and 1969b) for a more general discussion about the conditions for aggregation.
} 


$$
\begin{aligned}
\sum_{j} Q_{j} & =\sum_{j} \alpha K_{j}^{\beta}\left[\frac{1-\beta}{\beta} \frac{r+\delta}{\frac{W}{P}} K_{j}\right]^{1-\beta} \\
& =\alpha\left[\frac{1-\beta}{\beta} \frac{r+\delta}{\frac{W}{P}}\right]_{j}^{1-\beta} K_{j}^{\beta} K_{j}^{1-\beta} \\
& =\alpha\left[\frac{1-\beta}{\beta} \frac{r+\delta}{\frac{W}{P}}\right]_{j}^{1-\beta} K_{j}
\end{aligned}
$$

or alternatively:

$\sum Q_{j}=\alpha\left[\frac{\beta}{1-\beta} \frac{\frac{W}{P}}{r+\delta}\right]^{\beta} L_{j}$

In the same line of reasoning, the general equilibrium aggregate production function (4.2.25) can be written as:

$$
\begin{aligned}
\sum_{j} Q_{j} & =\alpha\left[\sum_{j} K_{j}\right)^{\beta}\left[\frac{1-\beta}{\beta} \frac{r+\delta}{W} \sum_{j} K_{j}\right]^{1-\beta} \\
& =\alpha\left[\frac{1-\beta}{\beta} \frac{r+\delta}{\frac{W}{P}}\right]^{1-\beta} \sum_{j} K_{j}
\end{aligned}
$$

The equality of (4.2.25a) and (4.2.26a) proves that in general equilibrium the production functions (4.2.25) and (4.2.26) are equal.

b. The size of the firm is not determined

In a complete model of the firm, one must be able to derive conditions for optimal behaviour. From the real factor price equations (4.2.17) and (4.2.18) it follows that:

$L=(1-\beta) Q \frac{p}{W}$

$K=\frac{\beta}{r+\delta} Q$

Substitution of $(4.2 .28)$ in $(4.2 .4 a)$ yields:

$I=\frac{\beta}{r+\delta} Q_{+1}-(1-\delta) K$

In order to complete the factor demand equation, production $Q$ has to be deter- 
mined. From the first order derivatives with respect to $\mathrm{Q}$ of the factor demand equations (4.2.27) and (4.2.28), the definition of profits, and the assumption that the price of investment goods equals the price of consumption goods, it follows that the marginal profits of production (MP) are:

$$
M P=P-W(1-\beta) \frac{P}{W}-(r+\delta) P \frac{\beta}{r+\delta}=0
$$

For the stability of a solution of the maximization problem it is required that:

$$
\frac{d M P}{d Q}<0
$$

Therefore, the size of the firm is indeterminate. This is a consequence of the homogeneity of the production function and the perfection of the input and output markets.

The indeterminacy problem in the model can be solved artificially by introducing an exogenous market share. This is clearly not a relevant solution to the problem. Another option is to introduce a non-homogeneous production function with ultimately decreasing returns to scale. Then an optimal production level for each firm exists. Adjustment will take place by entry and exit of firms instead of by production decisions of the firms themselves. Because exit and entry of firms is difficult to implement in a game, this is not a practical solution. A very plausible solution is the introduction of imperfect competition in the game. In the real world, imperfect competition is the general case; most firms are price setters. The implementation and consequences of imperfect competition in the equilibrium model is the topic of the next section.

\subsection{Imperfect competition on the output market}

Although Neoclassical theory assumes perfect competition in the long run, it is plausible that short run demand for individual firms is not perfectly elastic. First, a demand function with demand inertia for the output market will be presented that has low short term and high long term price elasticities of demand. Second, the long term equilibrium profit margin with imperfect competition will be derived in combination with the implicit long term price elasticity of demand. Finally, the stability of such an equilibrium will be investigated.

\subsubsection{The demand for output}

The general equilibrium growth model is a benchmark for the game economy. Theoretically, it remains one of the possible developments in the game economy. But in order to create independent decision makers, the equilibrium conditions in the theoretical model must be replaced by dynamic rationing institutions.

In order to disturb the growth model of section 4.2 as little as possible, the aggregate demand equation $(4.2 .5)$ will be maintained. Therefore, the aggregate demand has to be distributed over the firms. Consistent with microeconomic theory, 
aggregate demand will be distributed over firms according to relative prices. The elasticity of demand is greater in the long run than in the short run. This is formalized by the introduction of a lagged market share in the demand equation: ${ }^{14}$

$$
Y_{j}^{d}=\frac{P_{j}^{d} \frac{Y_{j-L^{p}}}{Y_{-L^{p}}}}{\sum_{j} P_{j}^{\mu} \frac{Y_{j-L^{p}}}{Y_{-L^{p}}}} Y^{d}=\left(\frac{P_{j}}{P}\right)^{j} \frac{Y_{j-L P}}{Y_{-L P}} Y^{d d}
$$

with:

$$
P_{t}^{\mu}=\sum_{j} P_{j, t}^{\mu} \frac{Y_{j,-1}}{Y_{t}}
$$

$(\mu<0)$

where $\mathrm{j}$ refers to firm $\mathrm{j}, Y_{j}=$ quantity sold, $Y_{j}^{d}=$ quantity demanded, $P_{j}=$ price set by firm $j, \mu=$ the short term psendo-price elasticity of demand, and $Y_{L \mathbb{P}}=$ the average sales of the last LP periods. ${ }^{15}$ In this function the price elasticity of microeconomic demand is approximately equal to $\mu^{16}$ The intuition behind this function is simple. Imagine a shop in the consumer sector. Such a shop will have a group of regular customers. Those customers are buyers by habit. This implies that they only switch to another shop when they discover that the other shop is cheaper. This process requires time. For this reason a firm will not lose all its customers immediately when it sets a higher price. ${ }^{17}$

Notice that this demand equation has nothing to do with disequilibrium. Only the distribution of aggregate demand over the firms has been discussed.

${ }^{14}$ Keser (1992:6) follows Selten (1965) in a linear type of model for a duopoly:

$Y_{j}^{d t}=Y_{j,-1}^{d}+0.5\left(p_{i,-1}-p_{i,-i}\right)$.

For this game a linear function is not useful, because it implies a different demand function for different sizes of firms. Meydam (1991:38) uses a relative price model without lagged demand as the orly argument in his competitive function. He uses an adjustment cost function for prices to create dynamic effects.

${ }^{15}$ The definition of the price index $P_{1}$ in (4.3.2) is chosen for reasons of consistency; the sum of the market shares has to be 1 .

${ }^{16} \mu$ equals the micro-economic price elasticity of demand only approximately, because the denominator changes when relative prices change. But with a large number of firms this effect is very small compared with the effect of the price change in the numerator. Therefore, the influence of changes of an undividual price on the denominator will be neglected in our derivations.

${ }^{17}$ In the game it is assumed that when the price of a firm is one percent higher than the average price, the firm loses about 4 percent of its customers per year. So, when a shop is ten percent more expensive, the market share declines by forty percent per year. 


\subsubsection{Price setting and equilibrium profits}

The introduction of the microeconomic demand function (4.3.1) requires a reformulation of the profit maximization problem of the firm. The firm changes from a price taker into a price setter. Therefore, it is necessary to investigate the consequences of this change in institution for the optimal behaviour of the firm. Remember that the analysis is focused on the general equilibrium growth path.

In order to investigate price behaviour and profits, one has to investigate both revenues and costs. Let us investigate revenues first. In demand equation (4.3.1) it is assumed that firms with a relatively low market price will attract new customers. Those customers will stay as long as the price of the firm remains at the average price level. This implies that the optinal size of the firm depends on the history of the firm (hysteresis). So, the benefit of a lower price in period $t$ is a gradual rise in market share in all periods starting with period t. Those benefits are at the cost of a lower profit margin in period $t$.

Let us investigate the decision problem of the firm more thoroughly. With the extension of the model with equation (4.3.1) the maximization problem for the firm changes into: ${ }^{18}$

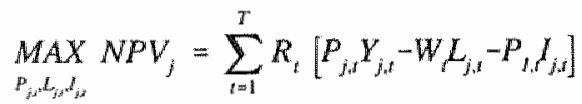

subject to:

$$
\begin{aligned}
Y_{j, t} & =\alpha K_{j, t}^{\beta} L_{j, t}^{1-\beta} \\
K_{j, t} & =I_{j, t-1}+(I-\delta) K_{j, t-1} \\
Y_{j, t} & =\left(\frac{P_{j, n}}{P_{r}}\right)^{\eta \mu} \frac{Y_{j, t-1}}{Y_{x-1}} Y_{t}
\end{aligned}
$$

where:

$$
\begin{aligned}
& P_{t}^{\mu}=\sum_{j} P_{j, s}^{\mu} \frac{Y_{j, t-1}}{Y_{t}} \\
& R_{t}=\prod_{s=1}^{i} \frac{1}{1+i_{f}}
\end{aligned}
$$$$
\alpha>0 ; 0<\beta<1 ; \mu<0 ; 0<\delta<1
$$

Appendix $4 \mathrm{~B}$ shows the formal derivation of the solution of this maximization problem. Here we will discuss the solution more informally. We analyse the decision of a

18 The equations used are $(4.2 .15),(4.2 .1),(4.2 .4 a)$ and $(4.3 .1)$; for simplicity of exposition we assume here that LP equals 1 . 


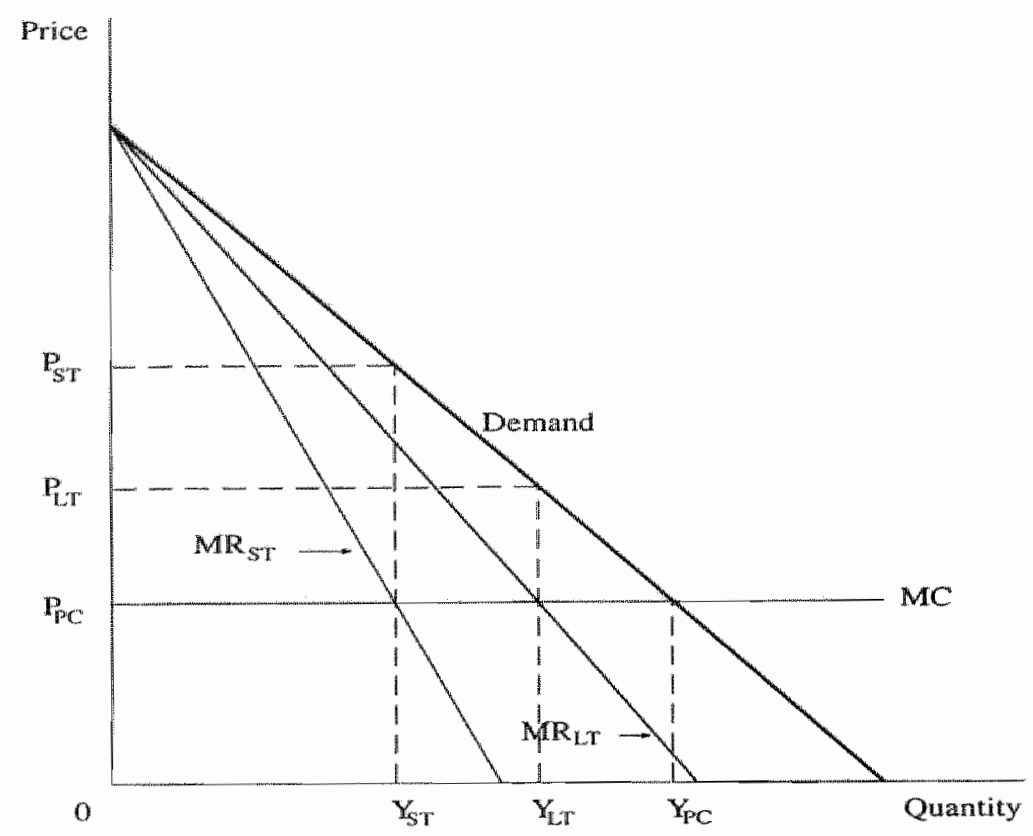

Tigure 4.1 Long term and short term profit maximization.

firm for period 0 .

When a firm maximizes its short term profits, the situation would be one of monopolistic competition. The short run marginal revenue curve is indicated by $M R_{S T}$ in figure 4.1, the marginal cost curve by MC. When the firm maximizes profits for period 0 , it sells $\mathrm{Y}_{\mathrm{ST}}$ at price $\mathrm{P}_{\mathrm{Sr}}$. In the case of perfect competition the firm would sell $Y_{P C}$ at a price $P_{P C}$.

The situation becomes more complicated when the firm maximizes long term profits $(T=\infty)$. When the firm computes the benefits of setting its price lower than the short term monopoly price $P_{S T}$ for period 0 , the increase in market share ${ }^{19}$ has not only consequences for period 0 , but also for all periods after 0 (see equation 4.3.6) ${ }^{20}$ Let us assume that the firm sets its price at the average price for all $t>0$. Then a rise in the market share in period 0 implies a rise in market share in all future periods. Therefore, when the firm expects the profit margin in the future to be positive, a rise in market share implies a rise in the net present value of the future profits. When the net present value of the future profits is included in the cost-benefit analy-

\footnotetext{
19 As a consequence of the negative slope of the short run demand curve for individual firms.

${ }^{20}$ Implicitly we assume that the price decision of other firms is not influenced by the decisions of our firm. This is plausible when each firm has only a small share of the total market.
} 
sis of the firm, the long term marginal revenue $\left(\mathrm{MR}_{\mathrm{Lr}}\right.$ in figure 4.1$)$ will be higher than the short term marginal revenue. Therefore, a firm that maximizes long term profits will have a lower equilibrium price (i.e. $P_{L T}$ in figure 4.1 ) than a myopic firm (i.e. $\mathrm{P}_{\mathrm{ST}}$ ).

The net present value of the future profits of a higher market share in period 0 depends on two crucial factors: the growth rate of national income and the interest rate at which the profits are discounted. Let us assume for simplicity that both are expected to be constant in the future. Furthermore, let us assume that the pricing policy of the competitors is not influenced by the price decisions of an individual firm. According to $(4.3 .6)$, sales for $t=1$ are $\left(1+g_{Y}\right) Y_{0}$. When the profit margin in period 1 equals $\mathrm{PM}_{1}$, the net present value of the profits on those sales in period 1 equals:

$\frac{1+g_{Y}}{1+r} Y_{0} P M_{1}$

In general the net present value of the profits in period $t$ can be written as:

$$
\frac{\left(1+g_{y}\right)^{7}}{(1+r)^{t}} Y_{0} P M_{t}
$$

The net present value of the profits for periods $I$ to $\infty$ generated by a rise of $Y_{0}$ with 1 can be written as:

$$
M P_{L T}=\sum_{t=1}^{\infty} \frac{\left(1+g_{v}\right)^{t}}{(1+r)^{t}} P M_{t}
$$

where $M P_{L T}=$ marginal profits in period 1 to $\infty$ of a rise in sales in period 0 by 1 .

We may investigate the equilibria with different combinations of $\mathrm{r}$ and $\mathrm{g}_{\mathrm{Y}}$. Let us first inwestigate the situation where $g_{\gamma} \geq r$. In this case the net present value of future profits $M_{L T}$ is infinite as long as $P_{\|}$is positive. Therefore, when $g_{Y} \geq r$, profit maximizing firms will expand as long as the profit margin is positive. As a consequence, the equilibrium profit margin equals 0 , and equilibrium production will get the perfectly competitive value of $\mathrm{Y}_{\mathrm{PC} \text {. }}$

Another boundary situation arises when the interest rate reaches infinity. Then the net present value of the future profits equals 0 , so the firm will maximize its short term profits. The short term monopoly price $\mathrm{P}_{\mathrm{ST}}$ with the short term monopoly production $Y_{S T}$ will emerge.

Finally, when $g_{\gamma}<r$ and $r$ is finite, the net present value of the profits for period 1 to $\infty$ will be finite at a positive profit margin, and reaches 0 when the profit margin approaches 0 . Therefore, when $g_{Y}<r$ the equilibrium profit margin will be between the margin with short term monopoly pricing and 0 . The equilibrium price $P_{L T}$ will be between $P_{S T}$ and $P_{P C}$ with an equilibrium level of sales $Y_{L T}$ between $Y_{S T}$ and $Y_{P C}$ (see figure 4.1).

When we assume that $g_{Y}<r$ and $P M_{1}=P M_{1}$ for all $t>0$, equation (4.3.7) can be written as: 
$M P_{L T}=\frac{\frac{1+g_{Y}}{1+r}}{1-\frac{1+g_{Y}}{1+r}} P M_{1}=\frac{1+g_{Y}}{r-g_{Y}} P M_{1}$

Total marginal revenue equals the sum of these long term marginal profits and short term marginal revenue. This is indicated in figure 4.1 by drawing the line $M R_{L T}$ above the line $\mathrm{MR}_{\mathrm{s} T}$. The vertical distance between this curve and the short term marginal revenue curve $\mathrm{MR}_{\mathrm{ST}}$ is $\mathrm{MP}_{\mathrm{LT}}$.

Appendix $4 \mathrm{~B}$ shows that the curve $\mathrm{MR}_{\mathrm{LT}}$ is analogous to the short term marginal revenue curve ${ }^{21}$ by:

$M R_{L T}=P\left(1+\frac{1}{\mu_{L T}^{*}}\right)$

where the long term psendo-price elasticity of demand $\mu_{L T}{ }^{*}$ is defined as:

$\begin{aligned} \mu_{L T}^{*} & =\mu \frac{1+r}{r-g_{Y}} & & \text { for } g_{Y}<r \\ & =-\infty & & \text { for } g_{Y} \geq r\end{aligned}$

This long term pseudo-price elasticity of demand will be used in the rest of this section.

We may summarize the revenue side of the output decision as follows. If the growth rate of national income is higher than the interest rate, the equilibrium of the firm will be the same as with perfect competition. When the growth rate of national income is lower than the interest rate, monopoly pricing becomes relevant.

When we investigate the cost side of the output decision, we must first investigate the use of capital and labour. The optimal capital-labour ratio can be derived from the Cobb Douglas production function (see appendix 4B):

$\frac{K_{y, t}}{L_{j, l}}=\frac{\beta}{1-\beta} \frac{W_{t}}{C C_{t}}$

where the cost of capital $\mathrm{CC}_{1}$ is defined as: ${ }^{22}$

$C C_{t}=\left(1+i_{p}\right) P_{l, t-1}-\left(1-\delta_{s}\right) P_{l, t}=P_{l, r-1}\left(i_{t}+\delta-g_{P_{i}}\right)$

where $P_{1,1}=$ price of investment goods in period t. Cost of capital equals interest cost

${ }^{21}$ In the short run, the marginal revenue curve is defined by:

$M R_{S T}=p\left(1+\frac{1}{\mu_{S r}}\right)$

22 This is the traditional result for the cost of capital. See for example Nickell (1978:10). 
plus depreciation cost minus the profits from an increase in value of the capital stock.

Equation (4.3.10) is the traditional result of a Cobb Douglas production function, where the ratio of factor costs depends on the coefficient $B$. When this equation is substituted in production function (4.3.3), the factor demand equations become:

$$
\begin{aligned}
& L_{j, t}=\left(\frac{1-\beta}{\beta} \frac{C C_{t}}{W_{r}}\right)^{\beta} \frac{Y_{j, t}}{\alpha} \\
& K_{j, s}=\left(\frac{\beta}{1-\beta} \frac{W_{t}}{C C_{r}}\right)^{1-\beta} \frac{Y_{j, t}}{\alpha}
\end{aligned}
$$

As a consequence of equations (4.3.12) and (4.3.13) the marginal cost function can be written as:

$$
\begin{aligned}
M C_{s} & =A C_{t}=W_{t} \frac{L_{j, s}}{Y_{j, t}}+C C_{t} \frac{K_{j, t}}{Y_{j, t}} \\
& =W_{t}\left(\frac{1-\beta}{\beta} \frac{C C_{t}}{W_{t}}\right)^{\frac{1}{\alpha}}+C C_{\mathrm{r}}\left(\frac{\beta}{1-\beta} \frac{W_{t}}{C C_{t}}\right)^{1-\beta} \frac{1}{\alpha} \\
& =\left(\frac{\beta}{1-\beta}\right)^{1-\beta} \frac{W_{t}^{1-\beta} C C_{r}^{\beta}}{\alpha \beta}
\end{aligned}
$$

"This implies that marginal cost (that because of constant returns to scale and exogenous factor prices equals average cost) is an increasing function of the factor prices. Because in equilibrium marginal revenue equals marginal cost, the equilibrium price is determined with equations (4.3.14) and (4.3.8). Substituting this result in equation (4.3.5) determines equilibrium production, while equations (4.3.12) and (4.3.13) determine factor demand.

Because in equilibrium marginal revenue equals marginal cost, according to (4.3.8), (4.3.9) and (4.3.15) the profits of a firm equal $\frac{P}{\mu_{L T}^{*}} Y$. When $g_{Y}<\mathrm{r}$, these profits are positive.

In summary, in a market form defined by equation (4.3.1) the equilibrium price can be higher than in a market where all suppliers are price takers. This implies that when one firm changed from a perfectly competitive situation towards a monopolistic situation, it would reduce its sales and its factor demand. But what is true on a micro level is not necessarilly true on a macro level. In the next section we will investigate to what extent monopoly pricing influences the macroeconomic equilibrium. 


\subsubsection{The effect of imperfect competition on equilibrium growth}

In section 4.3 .2 it has been shown that market competition is perfect as long as the growth rate of national income is not higher than the interest rate. In this section we will assume that the growth rate of national income is lower than the interest rate. Consequently, monopoly pricing becomes relevant.

Section 4.2 showed that the real general equilibrium growth model is completely determined by the production function, the growth rate of labour supply and the saving rate. The price level is determined by sales and money supply. Therefore, the nominal price level and the values of the real variables do not depend on the profit margin. The introduction of imperfect competition influences only the equilibrium wage and the equilibrium interest rate. Because on an aggregate level the ratio between capital and labour does not change, the factor price ratio will not change. But in accordance with (4.3.8) the ratio between price and marginal cost will change:

$M C_{1}=\left(1+\frac{1}{\mu_{L T}^{*}}\right) P$

Because, according to the money demand function (4.2.19) and assuming equilibrium on the money market (4.2.22), the price level does not change when money supply and real national income remain constant (equation (4.2.23), marginal cost declines. According to the marginal cost function (4.3.14) and the conclusion that the factor price ratio will not change, both factor prices have to be $\left(1+1 / \mu_{L T}\right)$ lower than in al situation of perfect competition.

Therefore, the wage equation becomes:

$\frac{W}{P}=\left(1+\frac{1}{\mu_{L T}^{\circ}}\right)(1-\beta) \frac{Y}{L}$

The cost of capital equation becomes:

$C C=r+\delta=P\left(1+\frac{1}{\mu_{L T}^{*}}\right) \beta \frac{Y}{K}$

so:

$i=r+g_{i r}=\left(1+\frac{1}{\mu_{L T}^{*}}\right) \beta \frac{Y}{K}-\delta+g_{p}$

Like the equilibrium model with perfect competition, the equilibrium model with imperfect competition has no aggregation problems. The only difference with the argument in section 4.2 is that the factor price equations (4.2.17) and (4.2.24) are replaced by (4.3.17) and (4.3.19). 


\subsection{Imperfect competition on the labour market}

Supply on the labour market can be modelled analogously to demand on the output market. This implies that labour supply to firm $j$ depends on labour share in the last period and its relative wage:

$L_{j}^{s}=\frac{W_{j}^{v} \frac{L_{j .-L P}}{L_{-L P}}}{\sum_{j} W_{j}^{v} \frac{L_{j-L P}}{L_{-L P}}} L^{s}$

where $L_{j, t, p}=$ average labour stock of firm $j$ during the last $L P$ periods, $L_{j}^{s}=$ labour supply to firm $j, W_{j}=$ wage set by firm $j$, and $v=$ pseudo wage elasticity of demand. This equation implies that the share in the market for labour does not change when a firm has the average wage level. When the firm sets its wage higher than average, it attracts gradually new labour. ${ }^{23}$

The line of reasoning for the labour market is completely analogous to that for the output market. This implies that marginal cost of labour can be written as:

$$
M C_{L T}=\left(1+\frac{1}{v_{L T}^{*}}\right)
$$

where the long term pseudo-wage elasticity of supply is $v_{\mathrm{LT}}{ }^{*}$ is defined as:

$$
\begin{aligned}
v_{L Y}^{*} & =v \frac{1+r}{r-g_{L}} & & \text { for } g_{L}<r \\
& =0 & & \text { for } g_{L} \geq r
\end{aligned}
$$

This implies that the wage equation becomes:

$$
\frac{W}{P}=\left(1+\frac{1}{v_{L T}^{*}}\right)(1-\beta) \frac{Y}{L}
$$

Therefore, the only difference between perfect competition on the labour market and wage setting by firms with supply inertia is that the wage rate will be lower. Because saving is assumed not to be influenced by this lower wage rate, the equilibrium growth path is not influenced. The only difference with the argument in section 4.2 is that the wage equation $(4.2 .17)$ is replaced by $(4.4 .4)$.

23 Such a mechanism is plausible when one defines the wage rate as labour cost i.e. including training and search costs. 


\subsection{Conclusion}

The equilibrium growth model discussed in this chapter is developed as a benchmark for developments in the game economy. First the equilibrium characteristics of the game have been derived from a general equilibrium growth model. It has been shown that the size of the firms is determined when demand inertia are introduced. On both the labour market and the output market the assumption of demand and supply inertia is plausible from both a theoretical and an empirical point of view. It has been shown that equilibrium growth does not depend on market structure of the output and labour market.

When just as in the real world the game is played with independent decision makers, a coordination problem arises that implies both uncertainty and disequilibrium. This implies that the assumption of equilibrium is not plausible. The next chapter will expand the game model to one that both allows for equilibrium and disequilibrium. 


\section{Appendix 4A. The equilibrium growth path}

The growth path can be derived as follows.

First, substitute (4.2.14) into (4.2.1a):

$g_{Y}=\beta g_{K}+(1-\beta) g_{L}=\beta\left[\left(1-\frac{c}{1+g_{Y,-2}}\right) \frac{Y_{-1}}{K_{-1}}-\delta\right]+(1-\beta) g_{L}$

$Y_{+1}=\left(1+g_{Y+1}\right) Y=\left[1+\beta\left(\left(1-\frac{c}{1+g_{Y,-1}}\right) \frac{Y}{K}-\delta\right)+(1-\beta) g_{L+1}\right] Y$

$K_{+1}=\left(1+g_{K_{*}+1}\right) K=\left[1+\left(\left(1-\frac{c}{1+g_{Y_{*}-1}}\right) \frac{Y}{K}-\delta\right)\right] K$

$\frac{Y_{* 1}}{K_{+1}}=\left[\beta+\frac{(1-\beta)\left(1+g_{L, 41}\right)}{1+\left(1-\frac{c}{1+g_{Y, 1}}\right) \frac{Y}{K}-\delta}\right] \frac{Y}{K}$

According to the equilibrium conditions on the consumer and investment markets (4.2.11) and (4.2.12), definition (4.2.7a) and consumption function (4.2.8a), planned investment equals savings:

$l^{d}=I=S=Y-C=Y\left(1-\frac{c}{1+g_{Y}}\right)$

Remembering that according to (4.2.4), (4.2.3) and (4.2.1b):

$I=D+K_{+1}-K=\left(\delta+g_{K,+1}\right) K$

we can conclude that:

$Y\left(1-\frac{c}{1+g_{Y}}\right)=\left(\delta+g_{K,+4}\right) K$

$g_{K,+1}=\left(1-\frac{c}{1+g_{Y}}\right) \frac{Y}{K}-\delta$

Because in the steady state it holds that $g_{K}=g_{Y}=g_{L}$ : 


$$
\left(\frac{Y}{K}\right)^{*}=\frac{\delta+g_{k_{\alpha,+1}}{ }^{*}}{1-\frac{c}{1+g_{Y}{ }^{*}}}=\frac{\delta+g_{L}{ }^{*}}{1-\frac{c}{1+g_{L}{ }^{*}}}
$$

where "indicates the long term equilibrium level. 


\section{Appendix 4B. The solution of the profit maximization problem with imperfect competition}

In this appendix the following steps will be taken:

a) reformulation of the maximization problem

b) derivation of the first order conditions

c) derivation of the factor demand equations as a function of production

d) derivation of the marginal cost function

e) derivation of the equilibrium profit margin

f) the steady state solution and the definition of a long term pseudo price elasticity of demand

a) The maximization problem

The maximization problem has been written as:

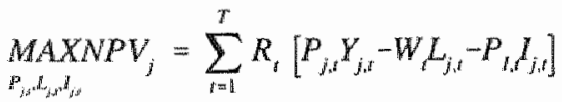

subject to:

$Y_{j, t}=\alpha K_{j, s}^{\beta} L_{j, s}^{1-\beta}$

$K_{j, s}=I_{j, s-1}+(\mathbb{1}-\delta) K_{j, t-1}$

$Y_{j, t}=\left(\frac{P_{j, t}}{P_{s}}\right)^{\mu t} \frac{Y_{j, t-1}}{Y_{r-1}} Y_{r}$

where ${ }^{1,2}$ :

$P_{y}^{\beta}=\sum_{j} P_{j, t}^{\mu} \frac{Y_{j, r-1}}{Y_{t-1}}$

$R_{t}=\prod_{s=1}^{s} \frac{1}{1+i_{s}}$

$\alpha>0 ; 0<\beta<1 ; \mu<0 ; 0<\delta<1$

As explained in the main text, $\mathbb{P}_{4}$ is not the general price level in a conventional sense, but a reference price level in the process of price setting of firms. In the derivations it is assumed that the first derivative of $P_{1}$ with respect to $P_{j, t}$ is 0 , i.e. that the number of firms is large.

${ }^{2}$ Biy substituting $K_{j, 1-1}$ recursivelly, (4.3.4) can be written as:

$K_{j, s}=\sum_{s=0}^{r-1} I_{j, s}(1-\delta)^{t-s-1}+(1-\delta)^{t} K_{0}$ 
The definition of the price index in (4.3.6) is introduced to guarantee that:

$$
Y_{i}=\sum_{j} Y_{j, s}
$$

By substituting $Y_{j, 1-1}$ recursively, $(4.3 .5)$ can be written as:

$$
\begin{aligned}
Y_{j, t} & =\left(\frac{P_{j t}}{P_{t}}\right)^{\mu} \frac{Y_{j, t-1}}{Y_{i-1}} Y_{t} \\
& =\prod_{s+1}^{i}\left(\frac{P_{j, s}}{P_{s}}\right)^{\frac{Y_{j 0}}{Y_{0}}} Y_{t}
\end{aligned}
$$

By substituting (4.3.4) into (4.3.2) and substituting (4.3.5a) into (4.3.2) and (4.3.3), the maximization problem becomes:

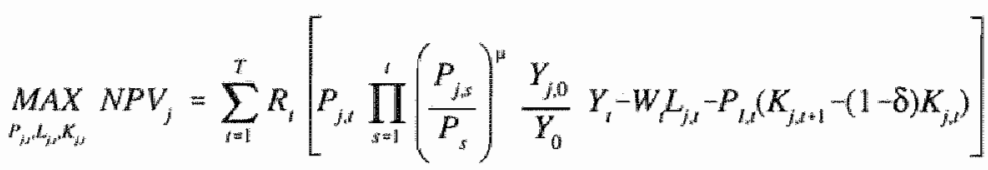

subject to:

$\alpha K_{j, s}^{\beta} L_{j, s}^{1-\beta}-\prod_{s, s i}^{\prime}\left(\frac{P_{j, s}}{P_{s}}\right)^{\mu} \frac{Y_{j, 0}}{Y_{0}} Y_{t}=0$

The Lagrange function Lag is defined with the Lagrange multipliers $\lambda_{t}$ for the restrictions (4.3.3a). Hence $\lambda_{1} / R_{1}$ represents the marginal costs as well as the marginal benefits.

b) The first onder conditions

The first order conditions of this Lagrange function can be written as:

$$
\begin{aligned}
& \frac{\partial L a g}{\partial P_{j, t}}=R_{t} Y_{j, t}(1+\mu)-\lambda_{t} \mu \frac{Y_{j, t}}{P_{j, f}}+\sum_{t t=t+1}^{r}\left(R_{t, t} P_{j, f t}-\lambda_{t, t}\right) \mu \frac{Y_{j, t}}{P_{j, t}}=0 \\
& \frac{\partial L a g}{\partial L_{j, t}}=-R_{t} W_{t}+\lambda_{t} \frac{Y_{j, s}}{L_{j, t}}(1-\beta)=0 \\
& \frac{\partial L a g}{\partial K_{j, t}}=R_{t} P_{t, t}(1-\delta)-R_{t-1} P_{l, s-1}+\lambda_{s} \frac{Y_{j, s}}{K_{j, s}} \beta=0
\end{aligned}
$$

This is a set of $4 \mathrm{~T}$ equations $((1),(2),(3)$ and (4.3.3a)), and $4 \mathrm{~T}$ endogenous variables $\left(P_{j t}, \mathbb{L}_{j i}, K_{j l}\right.$, and $\left.\lambda_{i}\right)$. 
c) Derivation of the factor demand equations

First, the optimal factor proportion will be derived. The factor proportion does not depend on the level of production because of constant returns to scale. When equation (2) is multiplied by $B / K_{j, 1}$, equation $(3)$ is multiplied by $(\mathbb{1}-B) / L_{,, 4}$, and then equation (2) is subtracted from equation (3), the following result emerges:

$$
\beta \frac{R_{t} W_{i}}{K_{j, r}}+\frac{(1-\beta)\left(1-\delta_{p}\right) R_{i} P_{l, t}-(1-\beta) R_{t-1} P_{l, j w 1}}{L_{j, s}}=0
$$

Therefore:

$$
\frac{K_{y, r}}{L_{j, s}}=\frac{\beta}{1-\beta} \frac{W_{s}}{(1+i) P_{l, r+1}-\left(1-\delta_{p}\right) P_{x, t}}=\frac{\beta}{1-\beta} \frac{W_{t}}{C C_{r}}
$$

(Note that $R_{\mathrm{l}-1}=\left(1+\mathrm{i}_{\mathrm{l}}\right) \mathrm{R}_{\mathrm{t}}$ )

where the cost of capital $\mathrm{CC}_{\mathrm{t}}$ has been defined as:

$$
C C_{t}=\left(1+i_{p}\right) P_{t, i-1}-\left(1-\delta_{t}\right) P_{l, t} \approx P_{t, i-1}\left(i_{s}+\delta-g_{p_{s}}\right)
$$

The factor demand equations can be derived with the help of equations (4.3.10) and $(4.3 .3):$

$$
\begin{aligned}
& L_{j, t}=\left(\frac{1-\beta}{\beta} \frac{C C_{t}}{W_{t}}\right)^{\beta} \frac{Y_{j, t}}{\alpha} \\
& K_{j, t}=\left(\frac{\beta}{1-\beta} \frac{W_{t}}{C C_{t}}\right)^{1-\beta} \frac{Y_{j, t}}{\alpha}
\end{aligned}
$$

d) derivation of the marginal and average cost function

The Lagrange multiplier $\lambda_{\mathrm{t}}$ represents marginal costs in period t. Therefore, the present value of marginal cost in period $t$ is represented by $\lambda_{\mathrm{v}} / \mathrm{R}_{\mathrm{t}}$. When the production function (4.3.3) is substituted into first order condition (2) and the capital/labour ratio is replaced by (4.3.8), the marginal cost function can be written in the factor prices and the coefficients of the production function: 


$$
\begin{aligned}
\frac{\lambda_{i}}{R_{i}} & =W_{i} \frac{L_{j, t}}{Y_{j, t}} \frac{1}{(1-\beta)} \\
& =\frac{W_{t}}{\alpha(1-\beta)}\left(\frac{L_{j, s}}{K_{j, t}}\right)^{\beta} \\
& =\left(\frac{\beta}{1-\beta}\right)^{1-\beta} \frac{W_{t}^{1-\beta} C C_{t}^{\beta}}{\alpha \beta}
\end{aligned}
$$

Since marginal cost is independent of scalle, average cost equals marginal cost.

\section{e) Derivation of the equilibrium profit margin}

The equilibrium profit margin can be derived by multiplying first-order condition (1)

with $\frac{P_{j e}}{\mu Y_{j t} R_{y}}$ :

$$
\frac{1+\mu}{\mu} P_{j, t}=\frac{\lambda_{t}}{R_{t}}-\sum_{t: t a t+\mathbb{T}}^{T}\left(P_{j, t t}-\frac{\lambda_{t d}}{R_{t i}}\right) \frac{R_{t t}}{R_{t}} \frac{Y_{j, t}}{Y_{j, t}}
$$

Because $\lambda_{\mathrm{l}} / \mathrm{R}_{\mathrm{t}}$ represents marginal cost $\mathrm{MC}_{\mathrm{jn}}$ *

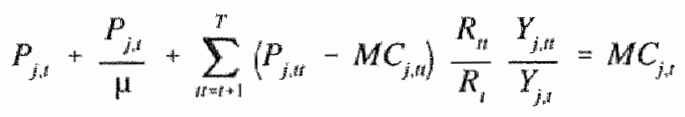

This equation is the simple optimum condition that marginal revenue equals marginal cost. Marginal revenue consists of three terms. First, the price of the marginal unit $P_{j u}$ Second, the loss in revenues as a consequence of the lower price that is needed to sell the marginal unit: $P_{j l} / \mu$. Third, because market share in period tt depends on market share in period t, a rise in sales in period $t$ implies a rise in sales in all periods after $t$, the profits on those extra sales in the periods after $t$ are revenues of the extra unit of sold in period t. This thind term can be analysed as follows. Because market share in period tt depends on market share in period t, selling one extra unit in period $t$ implies selling $Y_{j, t} / Y_{j, t}$ extra units in period $t$, where $Y_{j, t} / Y_{j, t}$ represents the growth of sales between period $t$ and $t \mathrm{t} . \mathrm{P}_{\mathrm{j}, \mathrm{t}}-\mathrm{MC}_{\mathrm{j}, \mathrm{t}}$ represents the profit margin on those extra units sold in period tt. Therefore, $\left(\mathrm{P}_{\mathrm{j}, \mathrm{t}}-\mathrm{MC}_{\mathrm{j}, \mathrm{th}}\right) \mathrm{Y}_{\mathrm{j}, \mathrm{t}} / \mathrm{Y}_{\mathrm{j}, \mathrm{l}}$ represent the extra revenues as a consequence of increasing production in period $t$ by one unit. The term $R_{\mathrm{t}} / \mathrm{R}_{\mathrm{t}}$ transforms this to the present value of these extra revenues.

The profit margin in period $t$ follows directly: 
$P_{j, t}-M C_{j, s}=-\frac{P_{j, t}}{\mu}-\sum_{t=t+1}^{F}\left(P_{j, t s}-M C_{j, t t}\right) \frac{R_{t, t}}{R_{t}} \frac{Y_{j, t t}}{Y_{j, t}}$

The net present value of the future profits depends on the discounted profit margin per unit of production $\left(\mathrm{P}_{\mathrm{js}}-\mathrm{MC}_{\mathrm{js}}\right)$, and the change in output. According to $(4.3 .5)$

$$
\frac{Y_{j, v f}}{Y_{j, s}}=\left[\prod_{s=f+1}^{n}\left(\frac{P_{j s s}}{P_{s}}\right)^{\mu}\right] \frac{Y_{\mathrm{ts}}}{Y_{t}}
$$

holds for $t t>t$. This implies that the change in output of firm $j$ depends on the one hand on changes in prices relative to those of other firms, and on the other hand on exogenous changes in aggregate demand.

f) the steady state solution and the definition of a long term pseudo price elasticity of demand

When the economy is in a steady state and all firms are in equilibrium, the following conditions must hoid for all $\mathrm{j}$ and $\mathrm{t}$ :

$$
\frac{M C_{j, t}}{\left(1+g_{p}\right)^{t}}=M C
$$

$g_{Y, i}=g_{Y}^{*}$

$r_{i}=r^{*}$

The first condition implies that the real marginal cost in prices of period 0 are constant. The profit margin that is consistent with such a steady state is according to $(4):^{3}$

\footnotetext{
${ }^{3}$ Note that $1+r_{s}=\left(1+i_{s}\right) /\left(1+g_{p, s}\right)$
} 


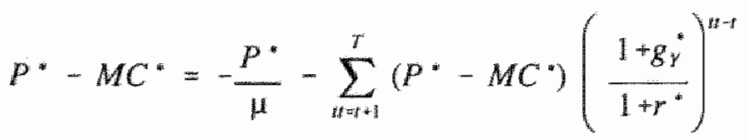

$$
\begin{aligned}
& =-\frac{P^{*}}{\mu}-\frac{\frac{1+g_{Y}^{*}}{1+r^{*}}-\left(\frac{1+g_{Y}^{*}}{1+r^{*}}\right)^{T-i+1}}{1-\frac{1+g_{Y}^{*}}{1+r^{*}}}\left(P^{*}-M C^{*}\right) \\
& P^{*}-M C^{*}=-\frac{P^{*}}{\mu\left[\frac{\frac{1+g_{Y}^{*}}{1+r^{*}}-\left(\frac{1+g_{Y}^{*}}{1+r^{*}}\right)^{\gamma++4}}{1-\frac{1+g_{y}^{*}}{1+r^{*}}}\right]} \\
& =-\frac{p^{*}}{\left[\frac{1-\left(\frac{1+g_{Y}^{*}}{1+r^{*}}\right)^{r-s+8}}{1-\frac{1+g_{Y}^{*}}{1+r^{*}}}\right]}
\end{aligned}
$$

When the time horizon reaches infinity and $g_{Y}^{*}<r^{*}$, this formula simplifies to:

$$
p^{*}-M C^{*}=-\frac{P^{*}}{\mu\left[\frac{1+r^{*}}{r^{*}-g_{y}^{*}}\right]}
$$

When we define:

$H_{E, T}^{*}=\mu \frac{1+r^{*}}{r^{*}-g_{Y}^{*}}$

the long term equilibrium profit margin can be written as:

$$
P^{*}-M C^{*}=-\frac{P^{*}}{\mu_{L T}^{*}}
$$

The long term equilibrium marginal revenue $\mathrm{MR}_{\mathrm{LT}}{ }^{*}$ can be written as: 
$M R_{L T}^{*}=M C_{L T}^{*}=P^{*}\left(1+\frac{1}{\mu_{L T}^{*}}\right)$

This suggests that $\mu_{\mathrm{LT}}{ }^{*}$ can be interpreted as an elasticity. It maybe called the steadystate-long-term-pseudo-price-elasticity of demand for a firm. One should realize, however, that this elasticity is an 'as if construction, because it is not an elasticity on a normal demand curve. But it can be used to explain maximizing firm behaviour as if it experiences a long term demand curve with an elasticity of $\mu_{L T}$ ".

Because according to $(6)$, when $\mu_{L T}^{*} \geq 0$ a negative profit margin is the consequence, the equilibrium profits will remain on the minimum level that is consistent with long term equilibrium, i.e. 0 . This is equivalent to an effective $\mu_{\mathrm{Lr}}$ " of $-\infty$. Because $\mu$ is negative, according to $(5) \mu_{\mathrm{LT}}{ }^{*} \geq 0$ holds when $\mathrm{g}_{Y}>\mathrm{r}$. Therefore:

$$
\begin{aligned}
\mu_{L T}^{*} & =\mu \frac{1+r^{*}}{r^{*}-g_{Y}^{*}} & & \text { for } g_{Y}^{*}<r^{*} \\
& =-\infty & & \text { for } g_{Y}^{*} \geq r^{*}
\end{aligned}
$$




\section{Chapter 5}

\section{Disequilibrium in the game economy}

\subsection{Introduction}

The neoclassical equilibrium growth model as discussed in chapter 4 implies perfect coordination of decisions. But in chapter $\mathbb{I}$ I have argued that in a general equilibrium model the fundamental macroeconomic coordination problem is avoided and not solved. If this problem is not solved, the fundamental differences between Keynes and the Classics cannot be settled. Furthermore, chapter 2 has argued that the neglect of this problem may alienate students from economics. Chapter 3 showed that the investigation of the coordination problem by experimental methods requires the development of a game where disequilibria are allowed for and where both price and quantity adjustments are possible.

Neoclassical, Hayekian and Keynesian theories of the business cycle provide different answers to this coordination problem. Those answers mainly differ in their assumptions about behaviour of firms in an uncertain world. An important part of this uncertainty arises because technology is not flexible ex post. Therefore, to investigate the fundamental macroeconomic coordination problem a putty-clay production function is more useful than a putty-putty production function. This is the topic of section 5.2 .

Uncertainty implies that firms do not know the future and therefore make errors in their decisions. To allow for those mistakes, buffers have to be introduced. Stocks are buffers to allow for differences between sales and production. The delivery time of machines is a buffer to allow for differences in investment demand and investment supply. The utilization rate of capital is a buffer that allows for sales that are lower or higher than expected at the moment of the investment decision. The implementation of buffers in the game economy is the topic of section 5.3.

The basic neoclassical growth model is a one-sector model with some 2-sector features. It is assumed that the output of firms can be used both for investment and consumer goods. But when firms are permitted to invest independently and the delivery time is used as a rationing device for machines, a 2-sector model is more plausible. In the 1-sector game the distribution of output over the two sectors is incorporated in the computer model. The model used for this division is discussed in section 5.4 . 
Even in the neoclassical system the public sector has some role; the Central Bank manages money supply. The main instrument of the Central Bank is the interest rate. Because money has no real function in the game economy (see section 4.2), public policy is focused on manipulation of the interest rate. The purpose of the policy of the Central Bank is to stabilize the economy by setting a high interest real rate during booms, and a low one during recessions. Formally this may be related to the money growth rule by setting a high interest rate when nominal national income is high, and a low interest rate when national income is low. A simple model for the banking sector is developed in section 5.5 .

When monetary policy is not effective, other types of policy are needed. The instruments of government policy in the game are discussed in section 5.6.

\subsection{The introduction of putty-clay technology}

Although simple neoclassical models use putty-putty production functions to investigate economic growth, such a production function does not generate a stable economy. When technology is of the putty-putty type, a short run general equilibrium exists for each capital stock. This implies that aggregate over-investment has no negative effect on future profits. For example, when in some periods all firms invest more than they would according to Walrasian equilibrium, with putty-putty technology a new equilibrium emerges with a higher capital-labour ratio. Equilibrium prices and wages will adjust accordingly. As a consequence, when on average firms invest too much compared with Walrasian equilibrium, the firms who did invest consistent with Walrasian equilibrium will have a less efficient capital-labour ratio than those who invested too much. This implies that optimal investment depends on optimal investment of other firms. The problem is analogous to the beauty contest problem described in the General Theory (Keynes, 1936:156), where each participant has to predict which girl will be rated the most beautiful. As a consequence, no firm has sufficient information to determine its optimal investment. Just as in the Expansio game' this will induce interfering gambling behaviour.

This impossibility of structural disequilibria has fundamental implications for the stability of aggregate demand. When all firms invest more than in Walrasian equilibrium, aggregate demand will be higher than in equilibrium. When aggregate demand is high, firms will try to produce as much as possible (i.e. full employment will be the result), and sell their stocks of output. Nevertheless, the firms can sell more at the current price. Therefore, they will set a higher price. In order to produce more, they will set a higher wage, too. Hyperinflation will be the result.

Because all firms experience excess demand and face severe restrictions on the labour market, they will try to expand through investment. As a consequence, investment and aggregate demand will remain high. Because firms can sell at all prices, a high interest rate will not solve the problem. Only physical credit rationing can stop hyperinflation in such a putty-putty economy.

The game economy with putty-putty technology can also run into a very deep

\footnotetext{
1 See section 3.5
} 
recession. When all firms invest less than according to Walrasian equilibrium, aggregate demand will be low. As a consequence, firms will reduce their wages and prices (when they are allowed to do so). Deflation will emerge. Because firms are able to produce more than they can sell they will not expand by investment. Therefore, the recession will continue. Only an exogenous change in demand, for example by a rise in autonomous consumption, can stabilize the economy.

In reality an economy is much more stable than an economy with putty-putty technology. The reason is that technology is not very flexible ex post. Therefore, it is appropriate to introduce putty-clay technology into the game. Putty-clay technology means that at the moment an investment decision is made, substitution between capital and labour is possible according to equation (4.2.1), but that after the investment decision has been made technology has fixed coefficients.

Putty-clay technology is not only necessary for the stability of the economy, it is also plausible from an empirical point of view and is consistent with almost all schools of thought. For Hayek, the choice of disequilibrium technologies as a consequence of price distortions is the essence of the business cycle (see Nentjes, 1979:228). In Keynesian theories fixed coefficients are a common assumption. But even the Neoclassical school has introduced putty-clay technology in their models (see for example Ferguson, 1969: chapter 13).

Although putty-clay technology is more difficult to tackle mathematically, it is much more intuitive for the players of a game. Putty-clay technology can be represented as a set of machines. At the moment a player buys a machine, he decides about the type of machine. When the machine is bought, he can only decide to use it. $^{2}$

For reasons of standardization, we assume that in each machine a capital stock of 1 is incorporated and that each machine has a fixed lifetime T. As a consequence, all machines can have the same price. Therefore, the type of machine can be defined by its production capacity $\mathrm{Q}_{k, \text { max }}$ :

$Q_{k, \text { naxix }}=\alpha L_{k, \text { niax }}^{1-\beta}$

where $L_{k, n a x}=$ the maximum numbers of labourers that can be employed on machine $\mathrm{k}$, and $\mathrm{Q}_{\mathrm{k} \text {,max }}=$ the maximum production that can be realized on machine $\mathrm{k}$.

For simplicity we assume fixed technological coefficients ex post. After a machine is bought, labour productivity is independent of the extent to which the machine is used. ${ }^{3}$ When a machine is not used completely, production is defined by:

$Q_{k}=Q_{k, \max } \frac{L_{k}}{L_{k, \text { max }}}=\alpha L_{k, \max }^{1-\beta} \frac{L_{k}}{L_{k, \max }}$

We assume that each machine has a lifetime $\mathrm{T}$, a delivery time DT and a date of order OT. Production is realized by the most efficient machines. Let us arrange all productive machines of firm $j$ at date $t$ (i.e. all machines for which

\footnotetext{
${ }^{2}$ Sales of machines by firms is not allowed for.

${ }^{3}$ This simplifies computations a lot; except for the marginal machine, all machines are either used completely or are not used at all.
} 
$\mathrm{OT}+\mathrm{DT}<\mathrm{t}<\mathrm{OT}+\mathrm{DT}+\mathrm{T}$ ) according to declining productivity, so:

$L_{k, \max } \leq L_{k-1, \max } \quad$ for all machines $k$

When a firm maximizes profits only the machines with the highest labour productivity are used:

$L_{k}=\min \left(1, \frac{L-\sum_{k, \pi=1}^{k-1} L_{k, k}}{L_{k, \max }}\right) L_{k, \max x}$

When $K K$ is the number of machines of firm $j$ for which $O T+D T<t<O T+D T+T$, the production of all machines together equals:

$Q=\sum_{k=1}^{K K}\left(\alpha L_{k, \text { max }}^{1-\beta} \frac{L_{k}}{L_{k, \text { max }}}\right)$

Although compared with the putty-putty version of the game, the putty-clay version of the game model differs in its behaviour out of equilibrium; the differences in behaviour on the long term equilibrium growth path are not fundamental. This is obvious in a situation of zero growth of both labour and capital. In that case the depreciation rate $\delta$ is defined by:

$\delta=\frac{1}{T}$

Each month old machines are replaced by machines of the same type.

The situation becomes more complicated when capital and labour grow at the same rate. At a positive growth rate the required replacement investment will be lower compared with a linear depreciation scheme, because the machines to be replaced are a smaller part of total capital stock than with zero growth. Therefore, the depreciation rate $\delta$ equals:

$$
\delta=\frac{1}{\sum_{s=1}^{T}\left(1+g_{K}\right)^{s-1}}
$$

When the growth rate of labour differs from the growth rate of capital, the situation becomes even more complicated. Because for each machine the labourcapital ratio is fixed ex post, the labour-capital ratio between machines differs when the aggregate labour-capital ratio changes. Let us investigate the situation for period 0 . The labour-capital ratio on an aggregate level depends on the labour-capital ratios of all machines that are active at that moment: 


$$
\begin{aligned}
& \frac{L_{0}}{K_{0}}=\sum_{i=-T}^{-1}\left[\operatorname{Ler}, \frac{I_{i}}{K_{0}}\right] \\
& =\sum_{i=-T^{t}}^{-1}\left[L r_{0} \frac{\left(1+g_{L}\right)^{b}}{\left(1+g_{k}\right)^{j}}\left(\delta+g_{k}\right)\left(1+g_{k}\right)^{j-1}\right] \\
& =\left(\delta+g_{k}\right) \frac{L c r_{0}}{1+g_{K}} \sum_{j=-T}^{-1}\left(1+g_{L}\right)^{t}
\end{aligned}
$$

where $g_{k}=$ the growth rate of capital stock. Therefore, the labour-capital ratio on machines bought in period 0 can be computed as:

$$
\begin{aligned}
L c r_{0} & =\frac{L_{0}}{K_{0}} \frac{1}{\left(\delta+g_{K}\right) \sum_{-T}^{-1}\left(1+g_{L}\right)^{t}} \\
& =\frac{L_{0}}{K_{0}} \frac{g_{L}}{\left(\delta+g_{K}\right)\left(1-\frac{1}{\left(1+g_{L}\right)^{T}}\right.}
\end{aligned}
$$

where $\mathrm{Lcr}=$ labour-capital ratio, and $\mathrm{g}_{\mathrm{L}}=$ growth rate of labour. Because

$$
\begin{aligned}
\delta+g_{k} & =\frac{1}{\sum_{k=1}^{T}\left(1+g_{k}\right)^{k-1}}+g_{K} \\
& =\frac{\left(1+g_{K}\right) g_{k}}{\left(1+g_{k}\right)^{T}-\left(1+g_{k}\right)}+g_{K} \\
& =\frac{g_{k}}{1-\left(1+g_{k}\right)^{1-T}}
\end{aligned}
$$

the solution for equation (5.2.9) is:

$$
L c_{0}=\frac{L_{0}}{K_{0}} \frac{g_{L}\left[1-\left(1+g_{K}\right)^{-T}\right]}{g_{K}\left[1-\left(1+g_{L}\right)^{-7}\right]}
$$

This shows that for each equilibrium growth path in a putty-putty context an investment policy exists that is consistent with this growth path. Although the replacement of putty-putty technology by putty-clay technology complicates the technicality of the computations, the dynamics of the equilibrium growth path does not change. 


\subsection{Buffers in an uncertain world}

In the game behavioural equations are replaced by human decision makers. Since the game is about the coordination of free decisions of independent firms, all the decisions of the firms in the model are made by the players. This implies that the players decide about their price, their wage, their labour demand and their investment in capital stock. Therefore, in contrast to the assumptions in the general equilibrium model, the behaviour of the firms is exogenous to the game model. This implies that equilibrium is not guaranteed any more. For example, sales may differ from production, labour demand may differ from labour supply, production may differ from production capacity, or investment demand may differ from investment supply. For this reason stocks and other rationing devices have to be introduced into the game model: on the output market (section 5.3.1), on the market for investment goods (section 5.3.2), and on the market for labour (section 5.3.3). Because the credit market is related intimately with monetary policy, rationing on this market is postponed to section 5.5.

\subsubsection{Output market: stock of final products and the utilization rate of capital}

Because firms are free to set their production level as well as their demand for investment goods, there is no reason to assume that $Y_{j}^{d}=Y_{j}^{s}$. Therefore, rationing has to be introduced. The determination of sales by firm $\mathrm{j}$ is straightforward:

$Y_{j}=\min \left(Y_{j}^{d}, Y_{j}^{s}\right)$

where $Y_{j}=$ quantity sold by firm $j, Y_{j}^{d}=$ quantity demanded from firm $j$, and $Y_{j}^{s}=$ quantity supplied by firm $j$. $Y_{j}^{5}$ is defined as the sum of the production level and the stock at the beginning of the period: ${ }^{4}$

$Y_{j}^{s}=Q_{j}+S t_{j}$

where $S t_{j}=$ stock of final products of firm $\mathrm{j}$ at the beginning of period $t$. The stock of final products at the beginning of the next period is defined as:

$S t_{j,+1}=S t_{j}+Q_{j}-Y_{j}$

When for some firms $Y_{j}^{s}<Y_{j}^{d}$, some demanders will be rationed. It is plausible that a demander who is rationed by the firm of his preference, tries to obtain his requirements at another firm. In the game model it is assumed that demanders search for alternative suppliers till no suppiier is able to supply the product. The rationed demand is distributed over the firms with $Y_{j}^{s}>Y_{j}^{d}$ consistent with (4.3.1). This

\footnotetext{
${ }^{4}$ It may be useful to create an extra instrument for the firms: the maximum sales level. In that case the formula becomes:

$Y_{j}^{s}=\min \left(Q_{j}+S t_{j}, Y_{j \text { max }}^{s}\right)$

where: $Y_{j, \max }^{s}=$ maximum sales set by firm $\mathrm{j}$.
} 
process continues till all demanders or suppliers are satisfied. Therefore, on a macroeconomic level, it holds that:

$Y=\min \left(Y^{4}, Y^{\prime \prime}\right)$

While in a stable growth equilibrium with certainty the optimal stock is a zero stock, this is not true in an uncertain world. When uncertainty arises, the optimal stock is a compromise between storage cost and the risk of losing customers when one is not able to deliver. Therefore, equilibrium average stock is positive in an uncertain world. The size of this stock and the type of uncertainty are an empirical matter.

The positive equilibrium stock has consequences for the cost price. Because equilibrium stock ("normal stock') must be seen as a part of normal expenses, it has to be included in the cost price. This implies that marginal revenue is lower than that assumed in chapter 4 . Therefore, at a given money supply, in equilibrium the wage level and the interest rate will be lower than that computed in chapter 4.

In a model where the capital-labour ratio of machines is fixed ex post, investment is a long term decision. Therefore, in the short run production capacity may differ from expected sales. When expected sales are lower than production capacity, the firm can decide to produce less than production capacity allows for. Also on the labour market disequilibria can emerge. For example, labour supply may be lower than needed for full use of production capacity. In both cases machines are not fully used.

When a firm makes an investment decision, it can never be sure that production capacity will be fully used in the future. Therefore, in an uncertain world optimal expected capacity" use will be lower than $1.00 \%$. This "normal utilization rate of capital" implies that fixed cost per unit of production is higher than assumed in chapter 4. This implies according to (4.3.17) and (4.3.18) that both the real interest rate and the real wage will be lower than predicted by the growth model with a $100 \%$ utilization rate of capital.

\subsubsection{The investment market: the delivery time and price for machines}

The demand for machines is determined by the investment decisions of firms, where the supply of machines is part of the output of the firms. In an ideal model one would like to have two types of firms: for consumer goods and for investment goods. In the current game these two types of firms are integrated. Therefore, the computer program has to divide the output of the firms into machines and consumer goods. This is the topic of the next section. In this section we assume that production of machines is already determined.

Firms can order as many machines as they like $e^{5}$ at a price and delivery time

\footnotetext{
"For practical reasons a maximum has been set at $5 \%$ of the capital stock per period.
} 
determined by the computer program. ${ }^{6}$ The number of orders set in period $t$ is represented by $\mathbb{I}^{\text {ord }}$. Those orders are added to a stock of orders in portfolio by the (fictive) producers of machines. These orders for the producers of machines are represented by $\mathrm{O}^{\mathrm{M}}$. This stock of orders in portfolio declines when machines are delivered. The machines delivered are represented by I. Therefore:

$O_{* 1}^{M}=O^{M}+I^{\text {ord }}-I$

Part of the orders in portfolio of the investment good industry have already been produced and are therefore on stock. This is represented by $\mathrm{S}^{\mathrm{M}}$. This stock of produced machines changes as a result of delivery and production:

$S t_{+i}^{M}=S t^{M}+Q^{M}-I$

Therefore, the number of orders that have to be produced, $O^{\text {Mamp }}$, is:

$O^{\text {Mainp }}=O^{M}-S t^{M}$

When production of machines continues at the current level, the time needed to produce the ordered but unproduced machines is:

$P T=\frac{O^{M \text {. wh }}}{Q^{M}}$

where PT is the estimated production time of unproduced machines.

Because firms produce a homogeneous output, of which machines are a part, a trader has been introduced who buys consumer goods from the firms, transforms them into machines and then delivers them to the firms who ordered the machines.? This trader buys the machines at a price asked by the firms, and sells the machines at a price and delivery time set by this fictive trader.

What delivery time must such a trader set, when for reasons of internal consistency it is desirable that the trader's stock of produced machines has not much likelyhood of being negative? The delivery time must be big enough to allow for the production of the ordered machines, including the new orders. So, because the number of new orders is unknown at the moment the delivery time is computed, a buffer time is introduced ${ }^{8}$ :

$D T_{, !}=\frac{O^{M, u n p}}{Q^{M}}+B T$

where $\mathrm{DT}_{+1}$ is delivery time of machines ordered in period $\mathrm{t}+1$, and BT is the buffer time. ${ }^{9}$

\footnotetext{
"An unknown deliwery time and price would be unrealistic and imply a lot of uncertainty for the players. This may generate the same type of problems as discussed in section 3.5 about the game Expansio.

${ }^{7}$ For intuitive reasons, it is assumed that machines are much bigger than consumer goods. Therefore, one machine equals a large number of consumer goods.

${ }^{*}$ Experience shows that a buffer of 3 months is enough.

${ }^{9}$ Because price may change between the date of order and the date of delivery, the price actually paid is adjusted for inflation.
} 
The delivery time is not the only rationing device in the market for investment goods. Just as in any market, price also is an instrument to increase or decrease the demand for investment goods. When demand for machines is higher than supply, it is plausible that the price of machines will rise. But this price will only rise more than in the market for consumer goods when excess demand is less in that market. Because the players set the average price of output, the price of investment goods is based on that price. Therefore, the price of investment goods is related to the current price of output (set by the players, and corrected for inflation) and the scarcity on the market for investment goods relative to that of consumer goods:

$P_{N,+1}=\left(\frac{1+f \frac{O^{\operatorname{manp} p}}{K^{M, Q c a p}}}{1+n \frac{C^{d}}{K^{C_{Q} \text { ecap }}}}\right)^{\zeta} P(1+\pi)$

where $\mathrm{K}^{\text {S.Qcapp }}=$ production capacity of sector $\mathrm{S}, \mathrm{C}^{\mathrm{d}}=$ consumption demand, $\mathrm{O}^{\mathrm{M}, \text { unp }}=$ number of ordered machines that are unproduced, $\zeta>0$, and $\pi$ is the average monthly inflation rate of the last six months. Machines are paid at the delivery time. The prices agreed are automatically corrected for inflation between the time of order and the time of delivery.

Because the price of investment goods is determined in advance without information about the output price at that moment or about the level of sales and production, inconsistencies may arise when the price of consumer goods would be defined independently. Therefore, for consistency in the national accounts, the price of consumer goods is artificially computed as:

$P_{C}=\frac{P Y-P_{I} I}{C}$

Although not very satisfactory from a theoretical point of view, this construction is sufficient to play the game. In a two-sector game economy this problem can be solved. The model of a two-sector game will be discussed in chapter 8 .

In summary, the delivery time of machines is a buffer in an economy that adjusts sales to production. Because in a one-sector game machines are not sold directly to the demanders, a fictive trader of machines has been introduced. This trader sets a price and delivery time in advance. The machine price is related to the prices set by the players and the relative scarcity on the machine market. The delivery time is determined by production capacity and orders on stock of the (fictive) machine industry. For the time being, equations (5.3.10) and (5.3.9) are acceptable solutions for setting the machine price and delivery time.

\subsubsection{The labour market and unemployment}

Because a firm is free to set its labour demand as well as its wage, there is no reason to assume that the distribution function of labour supply (4.4.1) guarantees that labour demand equals labour supply for each firm. In a free exchange economy the stock of 
labour for firm $j$ equals the minimum of labour supply and labour demand: ${ }^{10}$

$L_{j}=\min \left(L_{j}^{s}, L_{j}{ }^{d}\right)$

where $L_{j}^{d}=$ labour demand by firm $j, L_{j}^{s}=$ labour supply for firm $j$, and $L_{j}=$ employment in firm $\mathrm{j}$. Just as in the output market, excess supply of labour is distributed over the remaining firms by applying (4.4.1) until there is no supply or demand left. Therefore:

$L=\min \left(L^{s}, L^{d}\right)$

where $L=$ aggregate employment, $L^{d}=$ aggregate labour demand, and $L^{s}=$ aggregate labour supply.

In the real world labour market, aggregate labour supply is not fixed by the size of the labour force. Frictions in the labour market imply a natural unemployment rate. We may assume that friction unemployment is $\lambda_{\mathrm{I}}$ at the minimum wage, but that actual labour supply can be higher when the wage level is higher than a reference wage $W_{\min ^{*}}$ When we include training and advertising cost in the wage rate, it is plausible that at a higher wage some unemployed people can be trained to be productive employees. But it is evident that the labour supply equation must guarantee that actual labour supply can be never higher than the labour force. Based on these criteria the following aggregate labour supply function has been chosen:

$L^{*}=L^{s *}\left[\left(1-\lambda_{1}\right)+\lambda_{1}\left(1-\frac{2 W_{\min }}{W+W_{\text {min }}}\right)\right]$

$\left(0<\lambda_{1}<1\right)$

where $L^{s^{*}}=$ total labour force, $W_{\text {rain }}=$ minimum wage (set by the game leader), and $\mathrm{W}=$ average wage (set by the players). ${ }^{1}$ According to this function unemployment can be lower than the natural rate when the wage rate is above the minimum wage. During periods with a shortage of labour the unemployment rate will be lower than $\lambda_{1}$, because firms try to overbid each other with respect to wages. When the wage rate reaches infinity, labour supply equals the total labour force. During periods with high unemployment rates, firms will set the wage rate at the minimum wage rate that is allowed for: $W_{\min }$. In that case the level of friction unemployment equals $\lambda_{1}$. The rest of unemployment will be cyclical or structural in character.

In the game the unemployment rate is defined by the difference between the labour force and the actual employment level:

$U=L^{s *}-L$

where $U$ represents unemployment, $L$ represents employment, and $L^{*}$ represents the

${ }^{10}$ For practical reasons the maximum of the last wo periods is used as labour demand. This prevents firms losing a lot of labour when they make an error in typing in their labour demand. This implies that it requires three months to fire people.

1 Although this equation is the least satisfactory of the game model, it is sufficient for the current purpose of the game. 
Jabour force.

When labour supply is rationed, firms can attract labour at a wage rate of 0 . This is not very plausible. It forces an ad hoc element of government policy (i.e. a minimum wage level) to assure that at high unemployment rates wages remain at a reasonable level. But it is consistent with the idea of free market competition and therefore relevant in the context of a discussion about the fundamental coordination problem.

\subsection{The distribution of output over consumption and investment goods}

In the one-sector game firms produce one type of output. ${ }^{2}$ This output is used both for investment and consumption. Therefore some device has to be developed to distribute output over consumer goods and investment goods. Because supply is determined by production and stock, and stock is determined by the use of capital stock and the utilization rate of capital, all of them must be determined. We start with the long term variable, i.e. capital stock.

It is plausible that machines produce the same type of goods during their entire lifetime. Therefore, let us define $\mathrm{K}^{\mathrm{M}}$ as the number of machines that produce investment goods, and $\mathrm{K}^{\mathrm{C}}$ as machines that produce consumer goods. If depreciation is a fraction $\delta$ of capital stock in the beginning of period $t$, at the end of this period at least $(1-\delta) \mathrm{K}^{\mathrm{M}}$ capital-goods-producing machines and $(1-\delta) \mathrm{K}^{\mathrm{C}}$ consumer-goodsproducing machines remain. The new capital goods, i.e. 1 , can produce either investment goods or consumer goods. When $v$ is the share of investment that goes to the machine-producing sector, then:

$K_{+1}^{M}=(1-\delta) K^{M}+v I$

$K_{+1}^{C}=(1-\delta) K^{C}+(1-v) I$

where $0 \leq \mathrm{V} \leq 1$.

It is plausible that demand relative to supply determines the distribution of new capital goods over the two sectors. When the capital intensity of production is the same in both sectors, capital stock is proportional to supply. Therefore, $\mathrm{I}^{\mathrm{d}}{ }_{\mathrm{H}} / \mathrm{K}^{\mathrm{M}}$ indicates the tension on the market for investment goods, and $\mathrm{C}_{-1}^{\mathrm{d}} / \mathrm{K}^{\mathrm{C}}$ indicates the tension on the market for consumer goods. When the tension on both markets is the same, there is no reason to change the mix in the type of machines, so $\mathrm{V}=\mathrm{K}^{\mathrm{M}} / \mathrm{K}$. When the tension on the capital markets is higher than that on the market for consumer goods, investors will invest more in investment-goods-producing machines. A quadratic relationship has been chosen:

12 In the two-sector economy described in chapter 8 the allocation of output over consumption goods and investment goods is determined by the decisions of the players. 
$v=\min \left[\left(\frac{\frac{I^{d}}{K^{M}}}{\frac{C^{d}}{K^{C}}}\right)^{2} \frac{K^{M}}{K}, 1\right]$

When the capital stock is determined, production capacity of each sector can be defined as:

$K^{\text {Quap M }}=K^{M} \frac{K^{\text {Qcap }}}{K}$

$K^{\text {enap } C}=K^{C} \frac{K^{\text {Qcap }}}{K}$

where $\mathrm{K}^{\text {Ocap } \mathrm{C}}=$ production capacity of consumer goods, and $\mathrm{K}^{\text {Qcap }}=$ production capacity of machines. The actual production level is not only determined by the capital stock, but also influenced by the use of labour.

Let us first analyse production of the machine-producing sector. Let us assume that the normal amount of orders in portfolio is $f_{1}$ times production capacity. Therefore, in equilibrium, it holds that:

$O^{M, \text { anp }}=f_{1} K^{M, Q c a p}$

When the number of orders is lower, it is plausible that production will be set lower, but it can never be lower than the difference between aggregate production and production capacity of the consumer goods sector. When the number of orders is higher, production capacity is the limit. A simple function that satisfies these conditions is:

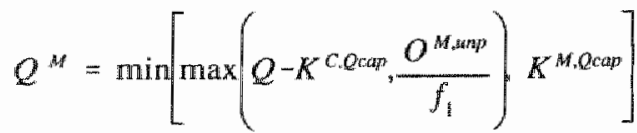

Production in the consumer-goods-producing sector is determined as a residual:

$Q^{C}=Q-Q^{M}$

This completes the distribution model of production.

\subsection{Money and monetary policy}

As discussed in chapters 1 and 2, money has an important role in the macroeconomic coordination problem. It is assumed that scancity of money is reflected in the interest rate. Because no explicit money market is modelled in the game, the interest rate is used as the main instrument of monetary policy. The interest rate has its effect through the credit market.

Until now, no credit market has been introduced explicitly. But when a firm in the game invests, it has to borrow the money for its investment. The total capital of 
the firm is financed by equity capital and borrowed capital. Because in elementary microeconomic theory it is assumed that an unlimited amount of money can be borrowed at a fixed interest rate, this condition is used in the simple version of the game. As a consequence, the firms do not make explicit financial decisions. When a firm has a negative cash flow, the required money is borrowed automatically at an interest rate set by the Central Bank (i.e. the game leader), ${ }^{13}$

At first sight this seems to be a severe restriction. But according to the theory of chapter 1 the interest rate is the only device that coordinates the decisions between the firms. In Classical theory, the interest rate is manipulated through the supply of money, but one may also try to do it directly. Therefore, in the game we may test to what extent it is possible to manipulate the interest rate consistently with Classical theory. The interest rate in the game is a policy variable of the Central Bank, and can also be manipulated by the game leader instead of the computer program.

When the economy is in equilibrium, the real interest rate can be computed by equation (4.2.18). When aggregate demand in the economy rises above the equilibrium value, according to (4.2.19) the demand for money rises, too. When the Central Bank wants to curtail this rise in demand, it has to raise the real interest rate. If we assume that $Y^{d} / Q$ indicates excess demand, the simplest adjustment rule of the real interest rate is:

$r=r_{\theta}\left(\frac{y^{d}}{Q}\right)^{\mu}$

where $\mathbb{r}_{e}=$ general equilibrium real interest rate, $r=$ real interest rate, and $\mu_{r}$ is a coefficient greater than 0 .

When the real interest rate has been determined, the problem remains to transform it into a nominal interest rate. The nominal interest rate is the sum of the real interest rate and the expected inflation rate. When the economy is out of equilibrium, the term $g_{M}-g_{Y}$ in equation (4.2.24) is of no use. During a boom the inflation rate will be higher, during a recession lower. Therefore, another solution has to be found. For simplicity, the historical inflation rate has been computed as a proxy for the expected inflation rate:

$i=r+\pi_{x^{i}}$

where $i=$ nominal interest rate, $r=$ real interest rate, and $\pi_{\mathrm{s}}=$ average inflation rate of the last $x$ months.

Although the above mentioned adjustment mechanism of the interest rate is very rough, it is sufficient to play the game. A sophisticated game leader may improve the automatic policy by manipulating the interest rate himself. He may experiment with his monetary policy to stabilize the economy. The interest rate policy can be used as an experimental variable to investigate the effects of different types of monetary policy.

In addition to rationing by the interest rate, credits are also rationed by creditworthiness of the one who borrows. For this reason some restrictions on bor-

\footnotetext{
${ }^{13}$ Some limits on investment are set with respect to the ratio of equity capital to borrowed capital, a minimum utilization rate of capital, and a maximum growth rate of capital stock.
} 
rowing for investment are introduced in the game. First, a firm can get only credits for investment when equity capital is larger than a mimimum percentage of total capital. Second, firms are not allowed to expand their capital stock by more than a certain percentage per month. Third, when there is a shortage of labour firms are not allowed to invest when they have to expand their labour stock more than a certain percentage to get a full utilization rate of capital.

In summary, money supply is manipulated indirectly by the credit market. The main instrument is the interest rate. Apart from the interest rate, some physical restrictions on investment are introduced. These restrictions mainly prevent loans being given to firms that are not worth any credit at all. But these instruments can also be used as instruments of monetary policy.

\subsection{Government policy}

If the economy were without any restrictions, it could collapse into hyper-inflation or hyper-deflation. Therefore, some government policy is inevitable. Government policy instruments are decision variables of the game leader.

First, to prevent wages becoming 0 during a period of high unemployment, a minimum wage has been introduced. No firm is able to set a wage lower than the minimum wage. This minimum wage can be defined absolutely, but also relative to the average wage level of the last period. By varying the maximum adjustment of the wage per period, the influence of wage flexibility on macroeconomic stability can be investigated.

Second, in a period of recession severe dumping may occur. Government may want to prevent excessive dumping by setting a minimum price. This price can be set absolutely, but also relative to variable cost or the average price levell of the last period.

Third, in a period of hyper-inflation government must be able to set maximum wages and prices. Those maximum wages and prices can be defined absolutely, but also relative to the average level of the last period.

Fourth, a government may like to correct the economy by fiscal policy. For simplicity, no taxes are incorporated in the game. But when the game leader wants to simulate a fiscal policy, he can manipulate aggregate demand by changing autonomous consumption. This is sufficient when one wants to experiment with the opportunities for fiscal policy to stabilize the economy.

Fifth, government may experiment with labour law. Restrictions on lay-offs of labour such as a minimum firing period or a maximum percentage of persons that can be fired can be set. ${ }^{14}$

In summary, government can manipulate the economy by a price policy, an income policy, and a fiscal policy. Because the primary purpose of the game is to investigate a free market economy without binding restrictions, for most games

\footnotetext{
1. Furthermore, the government can set a maximum and minimum utilization rate of labour. The purpose of this instrument is to prevent irrational decision making by players; in the reall world this will not be nelevant. It is also very exceptional that those restrictions are restrictive during a game.
} 
government policy was only used to limit mismanagement by the players.

\subsection{Concluding comments}

This chapter extended the game model of chapter 4 with equations that are necessary in disequilibrium. In section 5.2 putty-clay technology has been introduced. Compared with the putty-putty technology, the putty-clay technology is more intuitive for the players, more plausible empirically and more general theoretically. The rationing devices in the game have been deweloped in section 5.3. Although the introduction of uncertainty has no fundamental influence on the equilibrium behaviour of the economy, equilibrium stock will be higher, the equilibrium utilization rate of capital, and the equilibrium level of the wage and interest rate will be lower than in the model under perfect certainty in chapter 4 . Section 5.4 solves the problem of playing a onesector game with a two-sector economy. Sections 5.5 and 5.6 investigate the policy instruments in the game. The instruments of policy will become important when the game is used for systematic investigations of the possibility of Keynesian government intervention in a free market economy, but will not be investigated further.

In this chapter the focus has been on the structure of the game, excluding the behavioural equations of the firms. The behaviour of the firms is determined by the decisions of the players. This is a very important part of the economy. The training of the players is the topic of chapter 6 . 


\section{Chapter 6}

\section{Operationalization of the game}

\subsection{Introduction}

In chapters 4 and 5 the model behind the game economy has been derived. This model has to be transformed into a game that can be played easily with human players. This implies that a lot of technical problems have to be solved (section 6.2). Although decision makers in the reall world may have strong intuitions about profit opportunities, they do not know the equilibrium characteristics of the economy. The challenge in developing a game economy is to explain the decision making environment of the players without introducing phenomena that are not useful for making profits. The theoretical presentation of the game economy in chapters 4 and 5 is not relevant for the players. Section 6.3 shows how the game economy can be explained to the players. Although an intuitive explanation of the game is a necessary condition for a good game, it is not sufficient. Players must develop skills to behave adequately in the game. This requires training with feedback. Section 6.4 presents a training programme for the players. How this training programme is related to the educational criteria that were developed in chapter 2 is the topic of section 6.5 .

\subsection{The technical set-up of the game}

Although the structure of the game economy has been defined in chapters 4 and 5 , a lot of problems remain to be solved:

- The length of a period has to be defined.

- A choice has to be made about the number and type of players.

- The goal function of the players must be defined.

- The decision space of the players has to be limited in such a manner that they are as free as possible, but large errors are prevented.

- The game generates a lot of information. This information has to be structured in such a manner that players are not swamped by the facts.

- The accounting system is an important part of this information structure.

- In some circumstances the game leader may want to intervene in the economy. 
- The game has to be robust.

In this section these problems will be tackled.

First, the tength of the period in the game has to be defined. Because in the "real" world decision making is perceived as a continuous process, it would be optimall if this would be possible in the game, too. In the Expansio game discussed in chapter 3 the periods were not defined but limited to about 13 per game. Because the coordination problem that we want to investigate is a long term process where the interaction between decision makers is essential, it is important that the game consists of a long chain of short decision periods. For example, in the Expansio game artificial rationing mechanisms were introduced as a consequence of the limited number of decision periods. In order to implement rationing schemes as defined in chapters 4 and 5 , a period that is longer than a month is not feasible. When a business cycle is about 7 years, one business cycle requires 84 periods. In order to play more than two business cycles, about 200 periods have to be played. This implies that the length of a decision period is 2 minutes at most if we want to limit the durarion of the game to one day.

The large number of short decision periods implies that it is impossible to fill in forms each period. Because the players must be able to react quickly to changes in the environment, the information as well as the decisions have to be communicated very fast. Therefore, the game has been designed to be played on a computer network where the players make their decisions in a continuous flow of real time. Each simulated month the decisions of the players are sent to a central computer that transforms the decisions into results. Those results are returned as new information to the players. The results of the different periods can be presented by period and as time series.

A second issue of importance is the type and number of players. In the real world all actors are human beings. Because the number of players is limited, this is impossible in a game. In chapter 4 I have argued that for the investigation of macroeconomic coordination firms are the most important decision makers. Therefore, in the current game only the decisions of the firms are made by human players. In that case only the number and type of firms have to be determined. Ideally, both investment and consumer goods producers would have to be included. In order to be consistent with perfect competition, a large number of players for each market is required. Therefore, when the game is played with a limited number of players, only one type of player can be modelled. Therefore, the homogeneous output of the firms is divided over investment goods and consumer goods by computer.

A third problem to be solved is the definition of the goal function of the players. In chapter 4 firms maximize the net present value of their profits. When equity capital changes only through net cash flow, maximization of the net present value of future profits is equivalent to maximization of equity capital in period infinity. Therefore, the winner of the game is the firm with the highest equity capital in period infinity. Because the game stops before period infinity, the net present value of future profits has to be determined. A rough approximation of this net present value is called 'goodwill'. Because the only function of the valuation of goodwill at the end 
of the game is to prevent last round effects', it is not necessary to be too careful in its definition. In the current practice of the game, 'goodwill' has been defined as the value of the sales. The weight of the sales has been determined in such a manner that the standard deviation of equity capital and 'goodwill' over the firms are the same.

A fourth problem to be solved, is the amown of freedom for the players. One would like that all players are free to take all reasonable decisions they like. But on the other hand the economy must be prevented from being influenced too much by typing errors of players, players who like to test the robustness of the system, or players who would like to investigate the consequence of a rise of the price from 2 to $2,000,000$. Therefore, some restrictions have to be incorporated in the game. Those restrictions are to a large extent ad hoc, shaped by experience. For example, a firm is not allowed to expand its capital stock by more than $5 \%$ a month or when one may expect that the firm will not be able to get enough labour to staff the machine. When equity capital is less than $50 \%$ of total capilal the bank asks a risk premium on the interest rate, while no credits are available for investment when equity capital is less than $20 \%$. Furthermore, a firm is not allowed to set its price more than $20 \%$ lower or higher than the average price of two and a half months ago. The same holds for the wage rate. The firms are not allowed to fire more than half of their number of employees. Although the restrictions are meant to prevent errors, the restrictions must not limit the normal players in their freedom to choose. For this reason, the game leader can change the restrictions during the game. The search for optimal restrictions is a process of trial and error.

The fifth problem has to do with the presentation of information. Information has to be structured in such a manner that novice players are not swamped by the facts, while advanced players must have as much freedom as possible to organize their information. For this purpose three devices have been developed:

\section{- a hierarchy of screens}

- the use of signals to indicate dangerous situations

- online help (not implemented, yet)

With respect to the hierarchy of screens, the game has been designed in such a manner that completely inexperienced players are able to handle the computer program. For this reason the information has been structured according to three levels: ${ }^{3}$

- the decision screen

- standardized tables and graphs

- facilities to create new tables, graphs and statistics.

\footnotetext{
1 Those effects are also mitigated by not announcing the exact date at which the game ends.

In a new version of the game, most of them are implemented even as explicil instruments for government (see section 5.6)

3 The old version of the computer program is presented here. The new computer program that has been developed for Windows is structured differenty.
} 


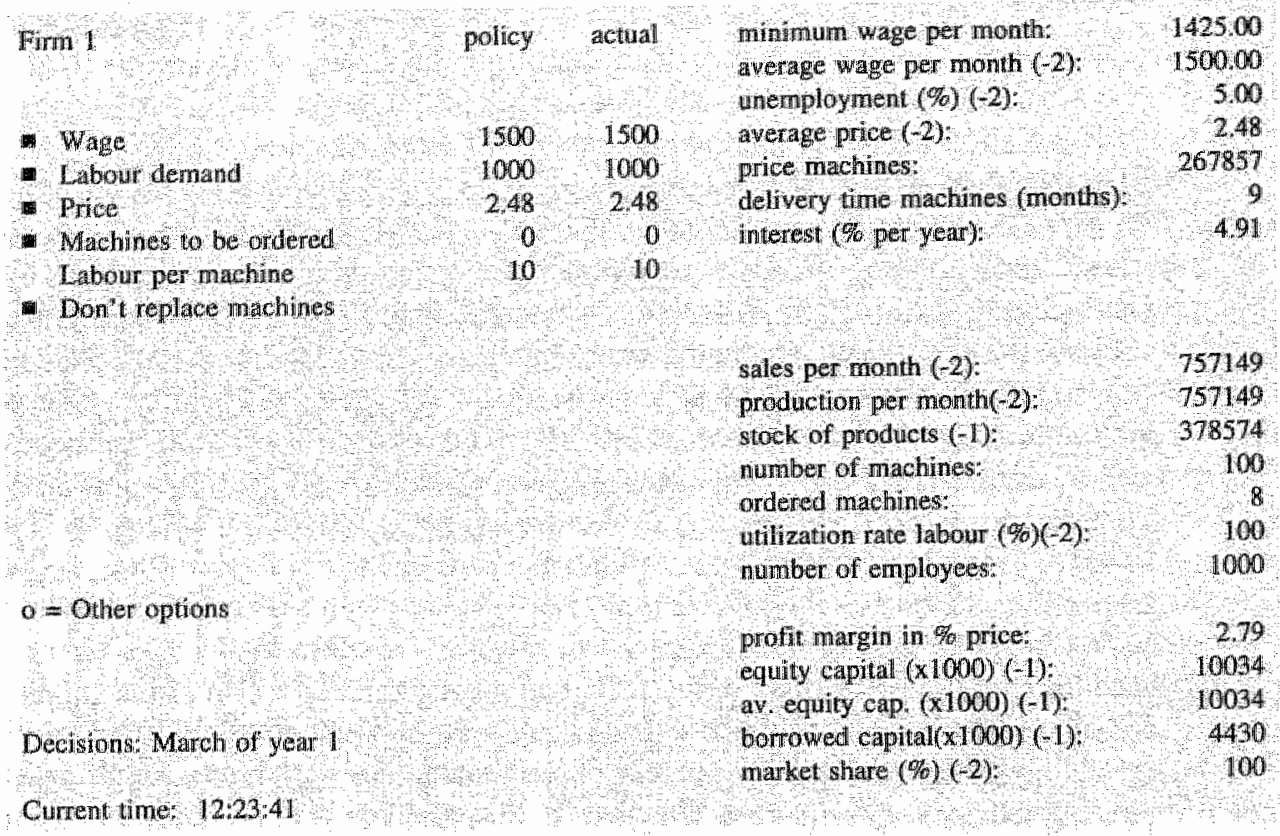

Table 6.1 The decision screen.

Menu for the other options of player number 1

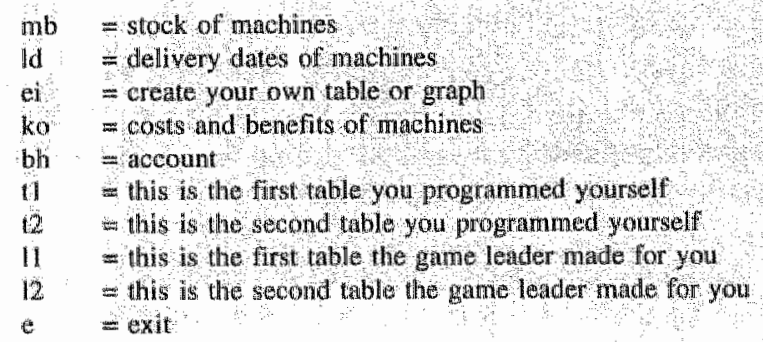

Table 6.2 The menu 'other options"

The decision screen (table 6.1 ) is the basic screen that shows recent information about the economy and the firm in combination with the decision variables. The most important information is presented on this screen; as if it were the information automatically put on the desk of the managers of the firm. In order to guide the inexperienced decision maker, variables that reach a dangerous range are presented with a red background (or in inverse video). Inexperienced players can play the game without using other screens.

When players get some experience with the game, they may choose "other options". Then a list of titles of tables and graphs is presented (table 6.2). The game 


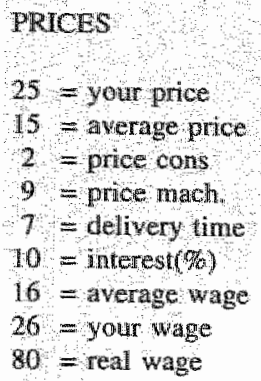

\section{NAT ACCOUNTS}

(quantites)

$11=$ natprod

$12=$ nat ine

$3=\mathrm{in} \psi$

$4=$ cons.

18 = natstock.

13 = natempl

14 = nat labdem

$5=$ unempl\%

9 - price mach.

$50=$ orderedla

$54=$ ut lab, $n$

$56=$ ut cap n

goods

1

$: 11$

abs

xygraph
NAT ACCOUNTS

(values)

39 - value nutprod

40 - watue nat ine.

$37=$ value of inv

$38=$ value of cons

6 - storage cosit

Table 6.3 "The screen 'create your own table'

leader can put items on the list, but the players can add new items on it as well. More advanced players may use those standard tables and graphs for their analysis. Special assignments help students to interpret those standard graphs.

When the players get even more experience, they can choose the option 'create your own table' of 'other options' in order to design their own tables, graphs or statistics (table 6.3). They can manipulate the information of the 80 or so monthly time series generated by the game. Just like the other screens, it can be used without prior training. Simple graphs and tables can be generated easily. Gradually players increase their skills to manipulate the lime series and learn to show selected parts of the data. When players have created a good combination of graphs and tables, they can store them as a standard graph or table by typing a name for it. Then the table or graph is added to the list in 'other options' (see table 6.2).

The signalling system is also focused on inexperienced players. When for example the stock rises to high levels, it is represented in inverse video. This indicates that there may be a problem with this variable. The variables in inverse video focus the attention of the players on the most precarious problems. In an extended version of the game, one may ask help about these (and other) variables. At this moment the players have to ask for advice from the game leader.

The sixth problem is the accounting system. The accounting system is an important part of the information system of firms. Especially the definition of profits may influence the decisions of firms. In the game the choice has been made for a microeconomic type of cost accounting, where all assets are appraised at current prices. The balance sheet at the bottom of table 6.4 shows the value of the machines 
profit gecount: for February of year I for firm 1

\begin{tabular}{|c|c|}
\hline & \\
\hline twrnover & 1875000 \\
\hline inn in slock & \\
\hline value of production & 1875000 \\
\hline labour cosst & 1500000 \\
\hline depreciation cost & 267857 \\
\hline nterest cost & 17720 \\
\hline wrage cost & 46875 \\
\hline gross profit & 42547 \\
\hline $\begin{array}{l}\text { revaluation } \\
\text {-stocks }\end{array}$ & pric \\
\hline $\begin{array}{l}\text { stocks } \\
\text { machines }\end{array}$ & $\because 8$ \\
\hline net profit & 42547 \\
\hline drvidend & 40137 \\
\hline & \\
\hline noe sheer: & numbers \\
\hline Achines cost price & 26786 \\
\hline chines: replacement value & 26786 \\
\hline achines book value & 13527 \\
\hline Lue of stock & 938 \\
\hline & \\
\hline
\end{tabular}

sales (number)

production (number)

number of employees

number of machines

inv in machines

interest rate

wage rate per nonth

757149

757149

1000

100

49

1500

248

price of machines

267857

ut rate of labour

market share( $1 \%$ )

100,00

10000

Table 6.4 The accounting system.

at cost price, replacement value and bookvalue. Bookvalue is defined as replacement value minus depreciation. A linear depreciation scheme for the technical lifetime of the machine is used. Stock (of final product) is appraised at the average market price. Total assets are computed as the sum of the bookvalue of the machines and the market value of the stocks appraised at the average market price. Borrowed capital is the diflerence between total capital and equity capital. Therefore, the items "revaluation of stock' and "revaluation of machines" have been introduced on the profit and loss account. For this reason a difference has been made between 'net profit' and 'gross profit": "net profit' equals 'gross profit' plus the revaluation of stock and machines; 'gross profit' is defined as value of production minus cost of production. The value of production is the value of the sales plus the investment in stock of output (appraised at the average market price). The cost of production is the sum of the costs of labour, depreciation, interest and storage. Storage cost per month is a percentage (5\%) of the value of stock. Interest cost is the product of borrowed capital and the nominal interest rate.

In order to determine an opportunity cost of equity capital, it has been assumed that the firm pays dividends on equity capital. Those dividends equal the product of equity capital and the nomimal interest rate. As a consequence, the opportunity cost of equity capital equals the opportunity cost of borrowed capital. From a managerial point of view this is doubtful, but it is consistent with elementary microeconomic theory and neoclassical growth models.

The seventh problem to be solved is the intervention of the game leader in the game. Ideally the economic system, including the training of the players, is such that 
Game test 2 for 2 players.

exit

Natomal incone

National produscton

Unemployment $(\%)$

Average wage

Interest rate

Minimum wage rate

Price of machines

Giovernment expenditures

Constimptionquote

Solluallility constrelim

491

1425

267857

0

0,100

0.2000
Average price

Price of machines

Deliwery dine of mathines

National stock

National onders

Ayerage equar capital

Average borrowed capital

Nominal vage rate

Real wage rate
757149

75714

500

150000

2.48

267857

37857

757149

10096607

442779

1,00

605,72

Table 6.5 Menu for decisions of the game leader during the game

no intervention of the game leader is needed. But in practice, some game economies get into big trouble without intervention. For example, when all players are extremely optimistic during the first boom in the game, the recession may be so deep that almost all firms get a negative value. In the real world this would imply bankruptcy. In a game world this is not suitable. Therefore, the players can continue the game ewen when they go bankrupt. But this implies that even bankrupt firms must have some credit facilities. Therefore, the management of credit facilities is one of the instruments with which the game leader can intervene in the game. Another instrument that has beem used is the manipulation of demand through the introduction of government expenditures. The game leader can also change the interest rate or the minimum wage level (see the left panel of table 6.5). Although it is important that these types of instruments are available for the game leader, he has to be very careful in using them; the more the game leader intervenes, the more difficult the interpretation of results becomes.

A last problem that has to be solved when one implements the game is its robusmess. Many computer networks are sensitive to trouble. It is quite usual for a player to disconnect the power from his computer, that a computer program has a system error, or that the network stops for a moment. Those troubles musi not disturb the game too much. In order to allow for those problems all information about decisions of the players and the computed results are stored on the game leader's computer as well as on the server. Procedures have been developed to restart a program of a player or the game leader on another computer, or to restart the game completely with the old data.

In summary, a lot of practical problems have to be solved before a game can be function appropriately. But a good computer program is not sufficient for a good game. At least as important is the instruction of the players. This is the topic of the next two sections.

\footnotetext{
4 The game leader can set the general characteristics of the game economy by a menu discussed in appendix 6 A.
} 


\subsection{The explanation of the game to the players}

In order to play a game well, the players must understand their decision environment. Especially when the game is used for experiments, it is very important that players lean to make informed decisions. For this reason the training programme of the players is as important for the game as the computer program. This section shows an example of such a presentation.

First, the structure of the decision screen must be explained (see table 6.1). At the bottom right side they see their goal variables, i.e. their equity capital and market share, as well as an indicator of the profit margin. The average equity capital of the other players is presented in order to stimulate competitive behaviour. The (-1) indicates that a variable is lagged one month; so, because in table 6.1 the current period is March of year 1 , equity capital is of the beginning of February of year 1 . The middle right part of the screen shows some information about the position of the firm: sales, production, employment, capital stock and the stock of final products. Furthermore, either the utilization rate of capital or the utilization rate of labour is presented; by definition only one of them can be less than $100 \%$. At the upper right side some national variables are presented. For the labour market those variables are the average wage rate, the minimum wage rate and the unemployment rate. For the output market this is the average price level. For investment decisions the interest rate, the inflation rate, and the price and delivery time of machines are relevant. At the upper left side of the decision screen, the actual situation of the decision variables of the firm is presented, i.e. price, wage, labour demand, and investment. Those variables can be changed by the player.

When the player understands the decision screen, he must be prepared for decision making. This instruction can be rather intuitive. The structure of the game economy can be explained as follows. First, the players have to maximize equity capital in period infinity. From this general but non-operational goal more operational goals can be derived. Examples of such operational goals are: market share, utilization rates of capital and labour, profit margin and stock of output. Because the value of the firm can be different from equity capital, "goodwill" is introduced as a representation of the expected future profits of the firm. Market share is used as an indication of this net present value of future profits.

Second, the effects of the decisions must be explained. One may start with the first decision variable, the wage rate per month. When a firm has a wage rate that is higher than the average wage rate, the firm may attract new employees from other

As il consequence of constant returns 10 scale, expected profits per product do not depend on market share. Therefore, all other things being equal, the net present value of future profits is proportional to market share. It is evident that other variables like the utilization rate of capital, and the stock relative to production capacity, do also influence future profits. During the game players have to be atware of those variables in their strategy. But for reasons of simplicity they are excluded from the estimation of goodwill. 
Delivery dates of machines

\begin{tabular}{|c|c|c|c|}
\hline delinery data & number of machines & maximum laboar & prodection \\
\hline Feb 2 & 2 & 18,00 & 13919 \\
\hline Dec I & 3 & 2700 & 20878 \\
\hline Dec 1 & 1 & 1000 & 7571 \\
\hline Qcet I & 1 & 1000 & 7571 \\
\hline Sep I & 1 & 10.00 & 757 \\
\hline Aug 1 & 1 & 1000 & 7571 \\
\hline avallable machines & number of machines & maximum labour & tolal production \\
\hline now & 100 & 1000 & 757149 \\
\hline after DT & 99 & 985 & 746517 \\
\hline
\end{tabular}

Table 6.6 The delivery dates of machines

firms. ${ }^{6}$ For an indication about the elasticity: at a low unemployment rate (i.e. less than the natural unemployment rate of about $5 \%$ ) a one percent higher wage rate implies about $4 \%$ more employees after a year. When unemployment is higher than the natural unemployment rate, it will be easier to attract labour. It is obvious that a rise in the wage rate diminishes the profit margin at full capacity. This can be illustrated immediately by changing the wage rate.

Labour can be hired and fired by changing labour demand. When labour demand is lower than the actual number of employees, applications for dismissals are submitted, and labour stock declines after three months. When labour demand is higher than the actual number of employees, vacancies are created. It requires at least two months to fill them, but when there are shortages on the labour market and the wage rate is not higher than the wage rate of other firms, one may not be able to attract new employees at all.

Because employees have to work with machines with a limited capacity, it is only useful to attract new employees when enough machine capacity is available. Otherwise, some employees will not be productive. In that case the utilization rate of labour will be less than 100\% (and will be presented on the decision screen in inverse video). In that case it is wise to fire employees by reducing labour demand or buying new machines. It requires three months to fire workers. The maximum number of employees that can be productive on the machines that are available after the delivery time (DT) of the new machines, can be presented by choosing ld of 'other options' (see table 6.6).

When a firm has less labour than can be used productively, the utilization rate of machines is less than 100\%. This implies that production can be expanded by

\footnotetext{
${ }^{15}$ Note that the average wage presented at the right side of the screen is the wage rate of two months ago.
} 


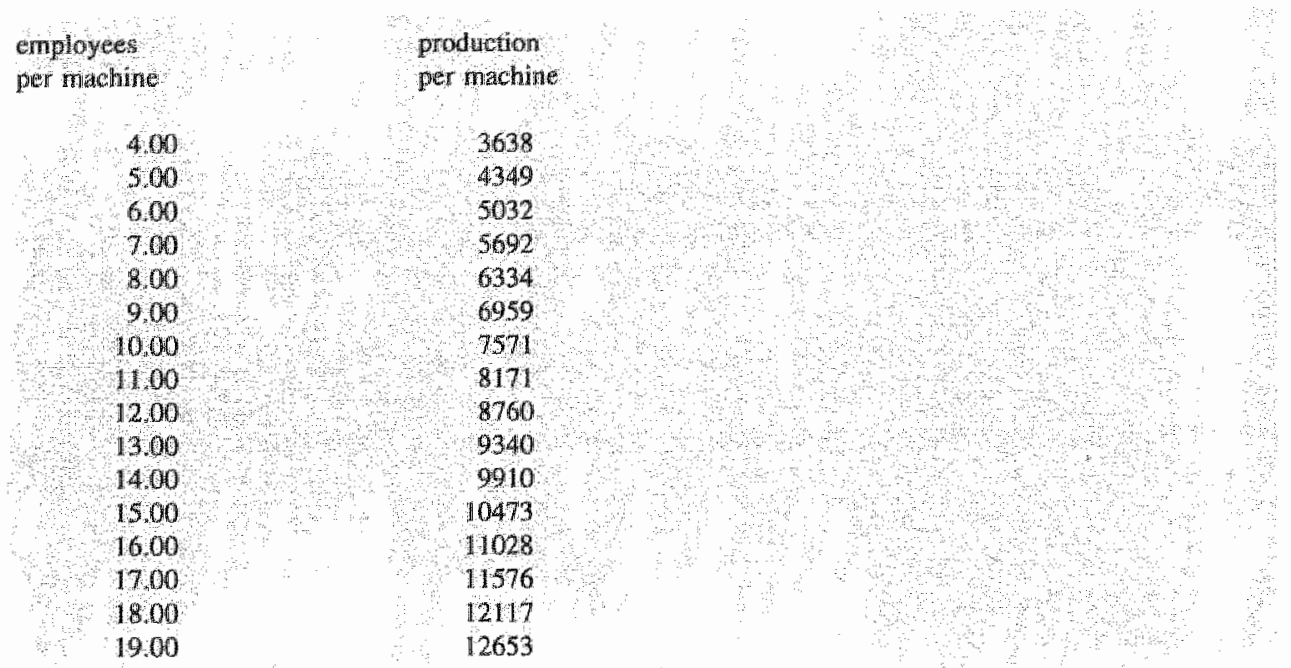

Table 6.7 The characteristics of different types of machines.

employing more labour. In first instance, the number of vacancies rises when the firm has increased its labour demand. It requires at least two months to attract new employees. When the unemployment rate is low and the wage rate is low relative to that of the other firms, it will be difficult to attract new employees. In that case a firm can only hire more labour by setting a higher wage rate.

Price is the third decision variable. When price is lower than average price in the economy, a firm can attract new customers. For an indication of the elasticity: when a firm sets a price that is $1 \%$ lower than average price, its market share may rise by about $4 \%$ per year. But when in a certain month demand is higher than production plus stock, the firm will not be able to satisfy demand and customers will leave to competitors. In the short run a firm can tackle this problem by rising its price. When the utilization rate of capital is lower than $100 \%$, a firm may try to expand production in order to improve its market share. When its utilization rate of capital is $100 \%$, a firm can only expand production through investment in new machines.

Investment in machines is the last decision variable. When a firm orders a machine, it will take delivery of the machine at the specified delivery time after the month the decision has been made. All ordered machines that have not been delivered are presented on the right side of the decision screen. By choosing Id from the menu 'other options' a player can examine the exact delivery dates (see table 6.6). Furthermore, that table shows the number of machines that will be available after the delivery time. Each machine has a lifetime of 100 months. So, after 100 months the machine cannot produce any more. Because each firm starts with a stock of 100 machines acquired one each month, every month a machine has to be replaced. It is very important that players keep this in mind. If a player prefers, he can replace machines automatically; but then he has to be careful not to forget to cancel this order when the wants to decrease his capital stock.

When a firm orders a machine, it can choose the type of the machine. Each 
Costs and benefis per machine per montl

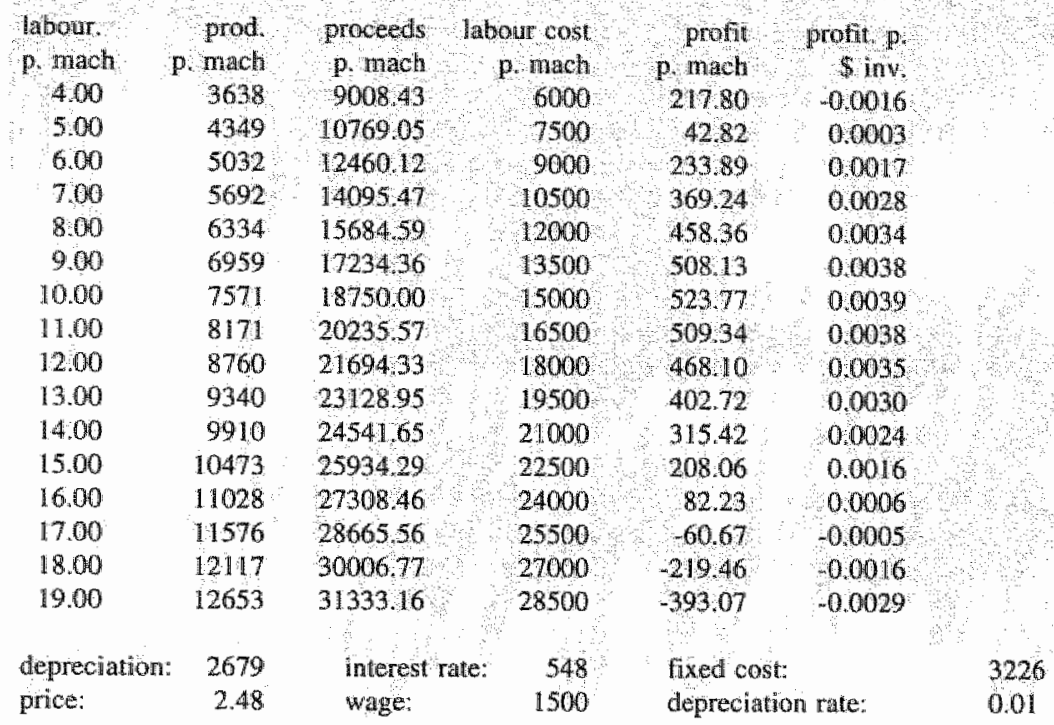

Table 6.8 Costs and benefits of different types of machines.

machine has the same price. Machines differ in their labour use and production level. The different combinations of labour use and production are cletermined by a Cobb Douglas production function. The Cobb Douglas production function can be presented intuitively in the form of a table (table 6.7). ${ }^{7}$ The type of machine can be characterized by the number of employees. For each number of employees the level of production can be computed. When such a machine is bought, the machine can produce the production indicated when the number of employees indicated is used. When half of the number of employees indicated is used on a machine, the production will also be half of the production capacity of that machine. The number of employees presented in the table is the maximum number of employees that can be used productively on the machine.

When a machine has been ordered, the type of machine cannot be changed any more. So, a change of the number of employees per new machine is of no use for the short run. Only gradually, when the new machines are being delivered, can the structure of the stock of machines be changed by changing the number of employees per new machine.

When one has more types of machine, labour is allocated automatically to the machines with the highest labour productivity; in the short run only labour cost is a variable cost. As a matter of course one can decide not to use the machine or to use the machine only for a part of its capacity by adjustment of labour demand.

\footnotetext{
${ }^{7}$ See section 5.2. It is not necessary for players to be familiar with production functions. The list of types of machines in table 6.7 suffices.
} 


\section{ASSIOMMENTS IN A BOOM}

Assigment 1. Phice policy at low stock

When your stocks become loo low, you lose benefits from sales You may consider to increase jour price. What are the advantages and disadyantages of this solution?

Assignment 2 Production polloy at low stock.

When stocks become too low, you may try to increase your production level. In the stort run expansion is only possible when the utilization rate of capital is lower than $100 \%$ Check with the help of table delivery dutes (d) the maximum number of employees that can work productively on your eurreat stock of machines. What are the advantages and disadvantages of this solution?

Assigiment 3 Invesiment policy at low stock

It may be that the utilization rate is lower than $100 \%$ because of problems to atract new employees. Is it wise to invest in such in period? If yes, what type of machines will you buy? Explain how you will attract sulfictent labour to man the machines.

Table 6.9 The first set of exercises for a boom.

The choice of the optimal type of machine is a rather advanced topic. Therefore, novice students are advised not to change the type of machines. But when they get practice with the game, many players adjust to more capital-intensive techniques in periods where it is difficult to attract employees. ${ }^{8}$ For example, option ko of 'other options" allows players to examine the profitability of machines under different prices, wages and inflation rates (table 6.8). One may choose the machine with the highest profitability at the moment the decision is taken. But when it is difficult to attract labour, a firm may choose more capital-intensive machines. More experienced players will try to get an idea of the changes in the interest rate, the real wage rate and future demand and supply.

This sketch of the game economy defines the most important features of the game model to the players. It shows that it is possible to give an intuitive explanation of the game. With the help of this information students are able to play the game in a reasonable manner. It is evident that it requires a lot of training before players are able to develop sophisticated policies. This is the topic of the next section.

\subsection{Training the players}

Performance of the game economy depends as much on the skills and motivation of the players as on the structure of the game. Therefore, the training programme can be of fundamental importance for the results. In experiments the players have to be instructed in accordance with the assumptions of the theory that has to be tested. In

\footnotetext{
${ }^{*}$ Because in Neoclassical as well as Hayekian macroeconomics substitution between capital and labour is essential, only games played with students who understand the the principle of substitution are relevant for testing those theories.
} 


\section{ASSIGNMENTS IN A RECESSION}

Assigmment 1. The cost of high siock

When your stock increases, your profits decrease The cost of high stock consist of storage cost and interest cost Storage costs are $5 \%$ of the yalue of the slock per month Study the tocount by typing bilk

By bow much do your profits change when your stock increases by 1 . mln tunits?

Assignment 2. Variable and fixed cost.

Because of the high cost of stock, you have to preven stock from being too high. One instrument is to tire people. How mach money do you save per person you fire? How much is this per product?

Instead of decreasing production you may increase your sales. Study the table of costs and benefits of machines by typing ko. The first column presents the type of machine that is defined by the maxinumin number of employees per machine. The second column shows the maximum production per machine of that type In the third column you see revenues per nachine at the current price. In the fourth column you find labour cost at the current wage. At the bottom of the table you find the fixed costs divided over clepreciation costs and interest costs. Profit per machine is the difference between the revenues on one side, and the variable plus fixed cosis on the other This can be represented as a perentage of the inyested capptal (the last column).

- What are the variable costs for a machine with 10 employees?

When you want to sell more by decreasing your price, what is the lowest price that is acceptatble for you? Why?

Table 6.10 The first set of exercises in a recession.

the context of the coordination problem this implies that the players must understand the structure of the game economy. This is also the educational purpose of the game. One can relate the educational principles discussed in chapter 2 to the training of the players. This will be done in the next section. But first, a sketch will be given of the normal training programme of the players. This sketch is rather detailed in order to give the reader a grasp of the dynamics of the game economy.

In its simplest version the game is played in two half-days, both with a duration of four hours. Students are expected to read the game manual before the garme starts. This manual describes the purpose of the game, the goals and instruments of the firms, the structure of the markets, the lay-out of the decision screen, and the instruments that may help to reach the goal. The first half day starts with half an hour of introduction by the game leader. He explains the game in the same manner as discussed in section 6.3. Then the players move to the computer room and start to play with about three persons per firm.

After about half an hour (2.5 years) players are able to perform the basic manipulations on the decision screen. At this point a short break may help the players to learn to avoid basic errors. Two sets of exercises have been designed for this purpose, one for a boom (table 6.9) and one for a recession (table 6.10). The assignments for a boom are focused on the evaluation of different types of policy. The first 

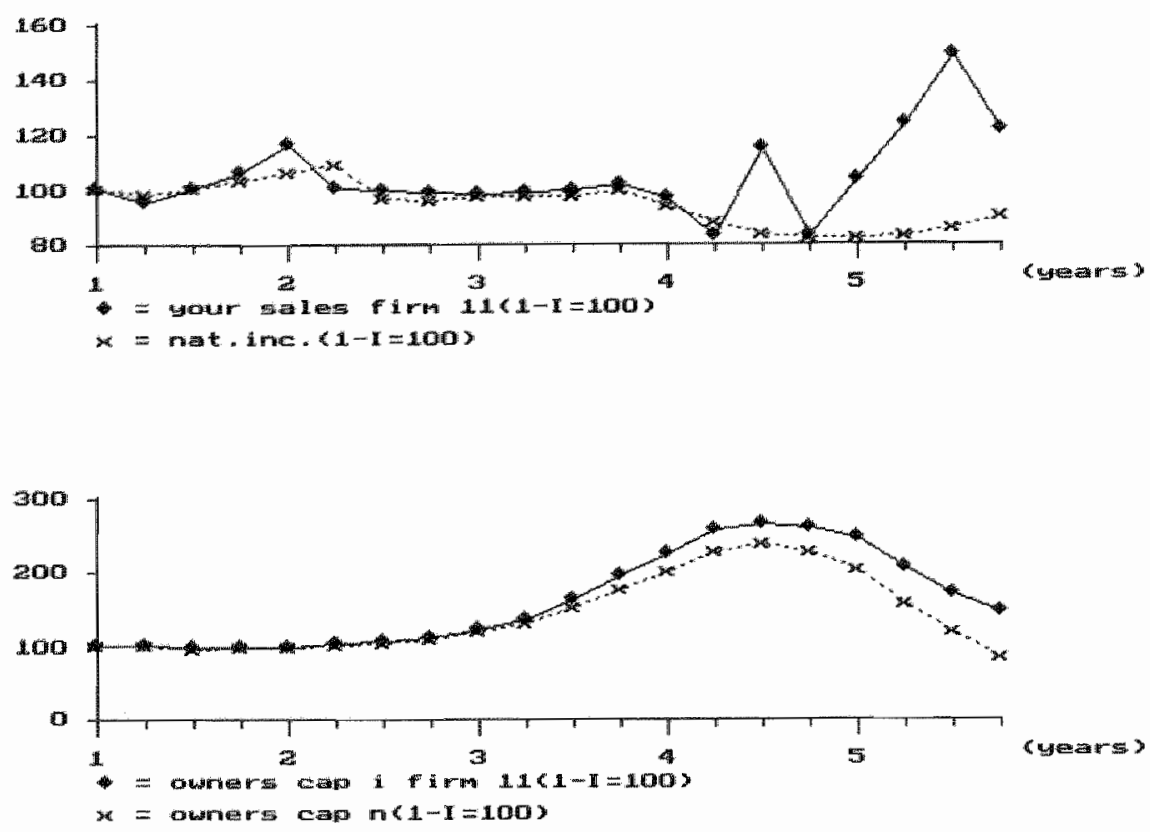

Higure 6.1. Performance of firm 11 in ECO9 during the first five years.

assignment asks about the advantages and disadvantages of an increase in price. In answering this question students learn that an increase in price is beneficial as long as it has no megative effect on stock. In the second assignment students become aware of the maximum number of employees that can be used on the machines. For example, for the player in table 6.6 it is of no use to attract more than 1000 employees. When a firm atracts new employees the utilization rate of capital, and therefore production, increases. Expansion of production is beneficial as long as the extra products can be sold. The third assignment focuses on problems on the labour market. When it is impossible to attract new employees it is pointless to invest. Therefore, in such a situation investment has to be accompanied by a rise in the wage rate to attract new employees. One may also try to reduce the need for labour by investment in labour saving machines.

The exercises about recessions (table 6.10) focus on the use of accounts and the difference between fixed and variable cost. In the first assignment students learn that a high stock implies high cost. When the stock rises by 1 million units, storage cost rises by $5 \%$ of 1 million times the price. When the price is 2.50 , this is 125,000 . Apart from this rise in storage cost, interest cost will rise, too. The second assignment focuses on the difference between fixed and variable cost. Variable cost consists only of labour cost. This cost must be compared with the marginal revenue. Because an increase in sales requires a lower price, marginal revenue is lower than price. Expansion of sales through a decrease in price is beneficial as long as marginal revenue is higher than marginal cost.

The level of difficulty of this exercise can easily be adapted to the analytical 


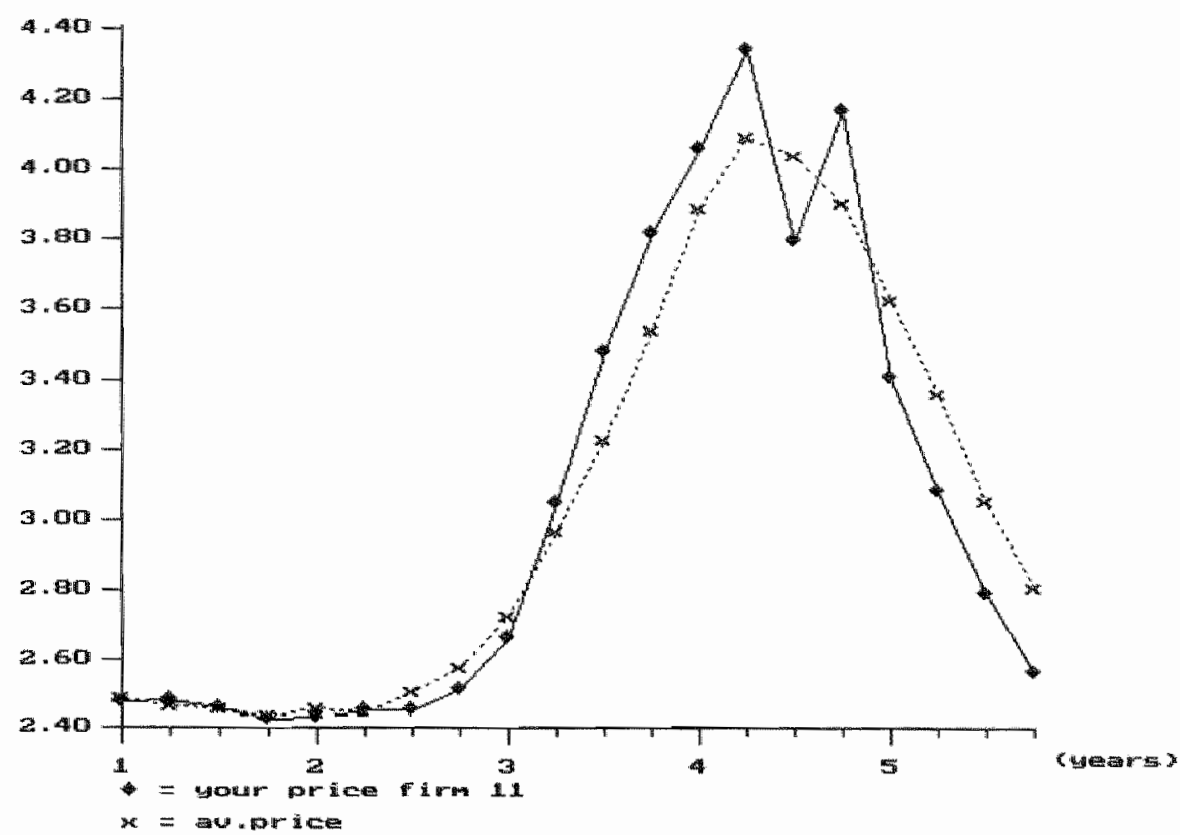

Figure 6.2 Price of firm 11 compared with average price in ECO9.

skills of students. At an introductory level, one may only focus on the fact that price has to be higher than labour cost. At a higher level, one may explain why marginal revenue is lower than price, while at an advanced level it may be useful to discuss which variables influence the long term price elasticity of demand."

After this set of exercises the game continues for about half an hour (2.5 years). Then the players have learned to apply the principles of the first set of exercises. At this moment, around year 5, standard graphs may be introduced to the students. Those graphs can be used to analyse the causes of differences in performance between firms.

With the help of the standard graph presented in figure 6.1 players investigate their performance relative to the average player. ${ }^{10}$ We will illustrate the analysis with the help of two games played with furst year students in economics and business administration: ECO9 was played on the first half day, ECO11 with the same group on the second half day. The lower panel of figure 6.1 shows that in ECO9 average equity capital rose till the second quarter of year 4 and then decreased. Starting with year 3 the performance of firm 11 is better than average performance. The upper part of figure 6.1 shows that national sales rose slowly till the second quarter of year 2 . and then declined till the end of year 4 . After a very fast decline in year 4 national sales started to rise in year 5 . The behaviour of sales of firm 11 differed from the

\footnotetext{
"Compare appendix $4 \mathrm{~B}$ for such an analysis.

19 For nostalgic reasons the graphs are reproduced here als they were in the first version of the game instead of representing them in a more elegant manner.
} 

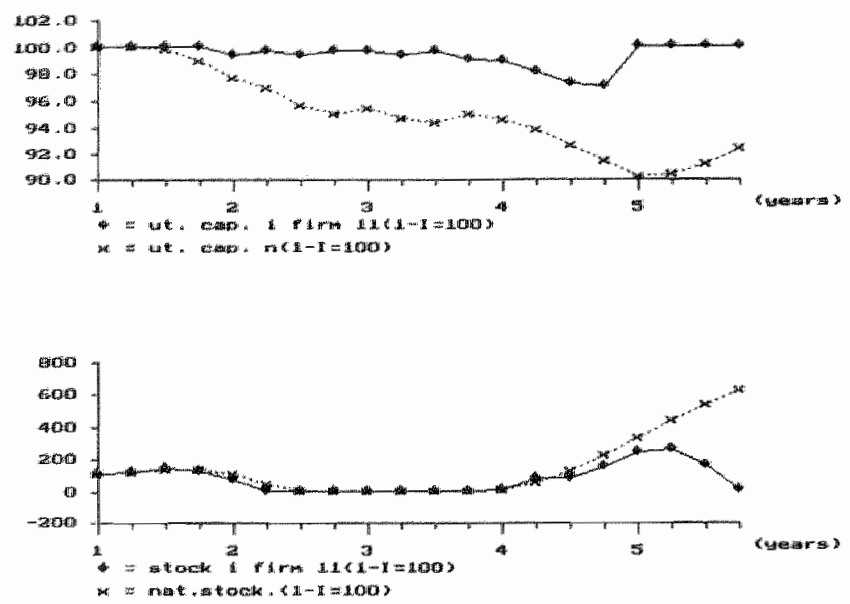

Figure 6.3 Stock and the utilization rate of capilal for firm 11 in ECO9.

national trend. Sales of firm 11 started to rise already in the third quarter of year 4 , declined in the fourth quarter, and rose very fast in year 5 .

The other graphs focus on the explanation of the results presented in figure 6.1. Figure 6.2 shows an inflationary period till year 4 , and then deflation. This suggests aggregate excess demand till the end of year 3, while around January of year 4 a recession started with aggregate excess supply. Firm 11 has a higher price during the inflationary period, and a lower price during the deflationary period. This was a wise policy; when there is aggregate excess demand customers will not leave you when your price is higher than the average price, while in a recession you will lose market share when your price is too high. Figure 6.1 and 6.2 show that the low price in the third quarter of year 4 and the high price in the fourth quarter are directly reflected in sales.

Figure 6.3 shows two important variables that may explain the development of profits: the utilization rate of capital and the stock of finished products. When the utilization rate is lower than $100 \%$, part of the machines is out of use. This implies fixed costs (i.e. depreciation and interest cost) without revenues. Therefore, the higher the utilization rate of capital, the higher the profitability of the firm." The upper part of figure 6.3 shows that the utilization rate of capital declined rather fast on a national level while it remained high for firm 11 .

The better utilization rate of capital for firm 11 requires an explanation. Because during the first four years firm 11 had a higher price than average price, the cause cannot be found in a better position on the output market. The cause has to be found on the labour market. Because everyone invested in the beginning of the game, a shortage of labour emerged. ${ }^{12}$ Figure 6.4 shows that unemployment was below the natural rate of $5 \%$ from the beginning of year 3 . Firm 11 was able to increase its employment level by setting a high wage rate. Therefore, the high wage policy

\footnotetext{
"When all other things are equal.

12 Remember that the nomal unemployment rate is about $5 \%$.
} 

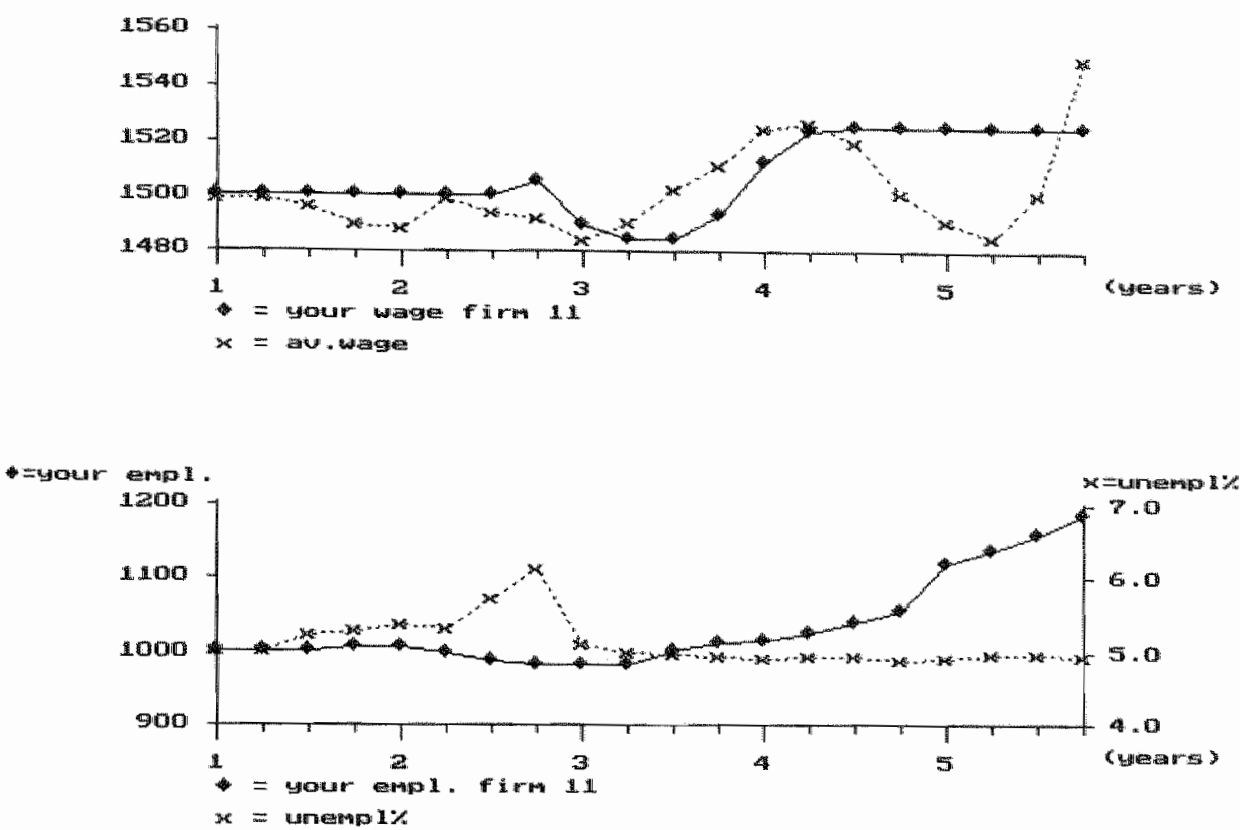

Figure 6.4 Unemployment and wage policy of firm 11 in ECO9.

explains the good results of firm 11 with respect to the utilization rate of capital.

When a firm has a high stock, it has to pay for storage and interest on the value of this stock. Therefore, the higher the stock, the lower profitability. The lower panel of figure 6.3 shows that national stock was rising fast during year 4 and 5 . The stock of firm 11 rose a bit during year 4 , but then declined in year 5 . This may be caused by the lower price of firm 11 during year 5 (see figure 6.2). In summary, firm 11 had a better than average performance both for the development of stock and the development of the utilization rate of capital. This can be explained by a more adequate price and wage policy.

Figure 6.5 shows that capital stock of firm 11 declined in the beginning of the game and remained low till the second half of year 5 . In the second half of year 5 capital stock of firm 11 became higher than average. The lower panel of figure 6.5 shows that most firms chose a low labour/capital ratio on new machines during the period with shortages of labour, and increased their labour/capital ratio in the recession. This is very inefficient in a period with shortages of labour and may be explained by the reluctance of firms to raise wages till the end of year 5 . Firm 11 did not use the labour/capital ratio as a policy instrument.

After the detailed exercises with the graphs, players are invited to write a short summary of developments in the past. In such a summary firm 11 may mention the efficiency of its emphasis on a low stock and a high utilization rate through a very alert wage and price policy. They may also mention that they were rather late in changing their price policy in year 4. They may recognize their lack of use of the labour/capital ratio on new machines as an instrument in tackling the business cycle. 

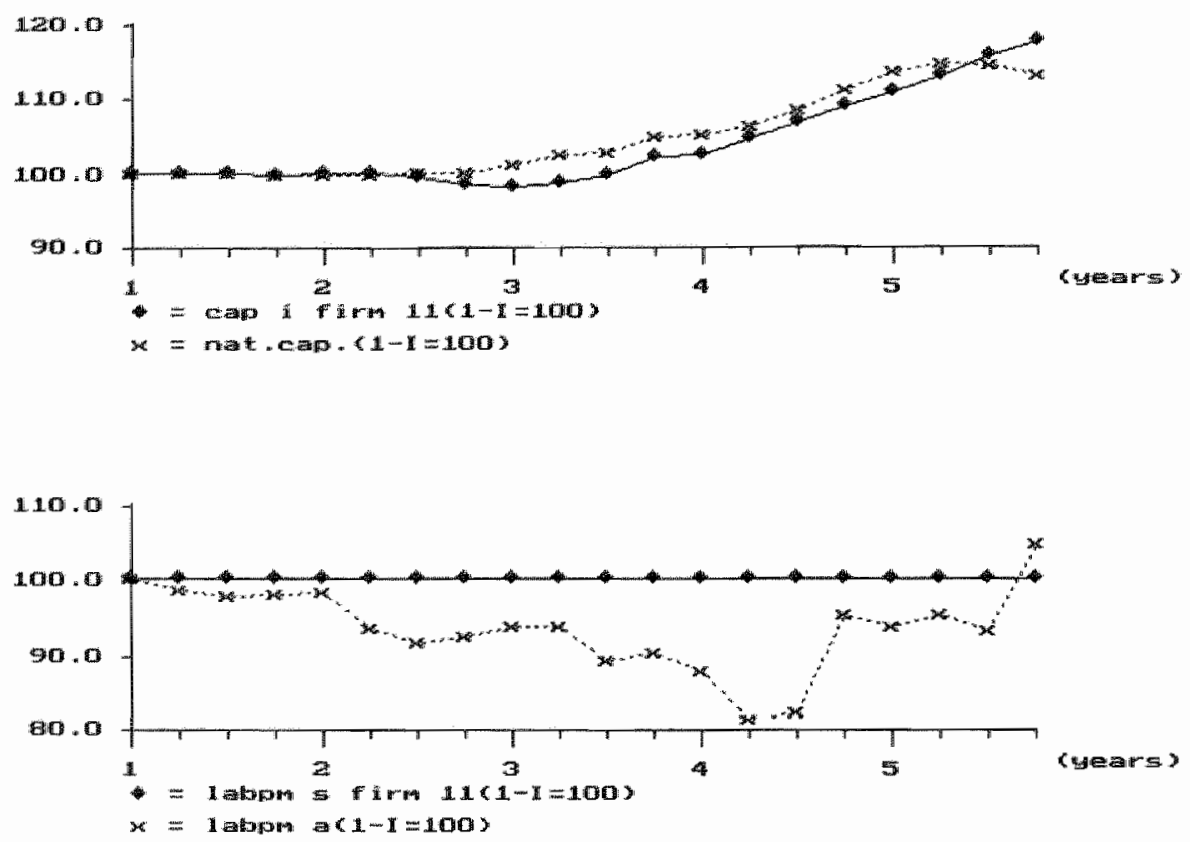

Figure 6.5 Capital stock and labourlcapital ratio of machines for firm 11 in ECO9.

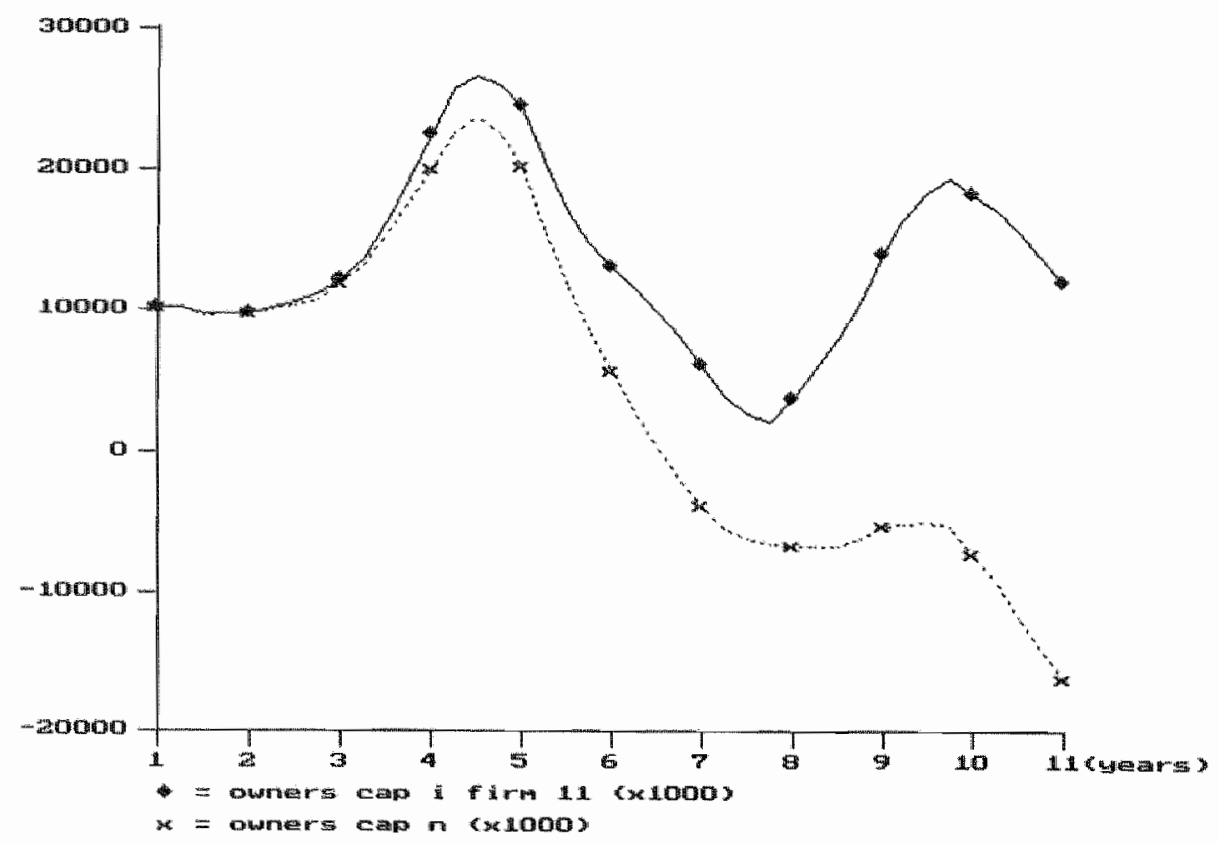

Figure 6.6 The devellopment of equity capital of firm 11 in ECO9. 


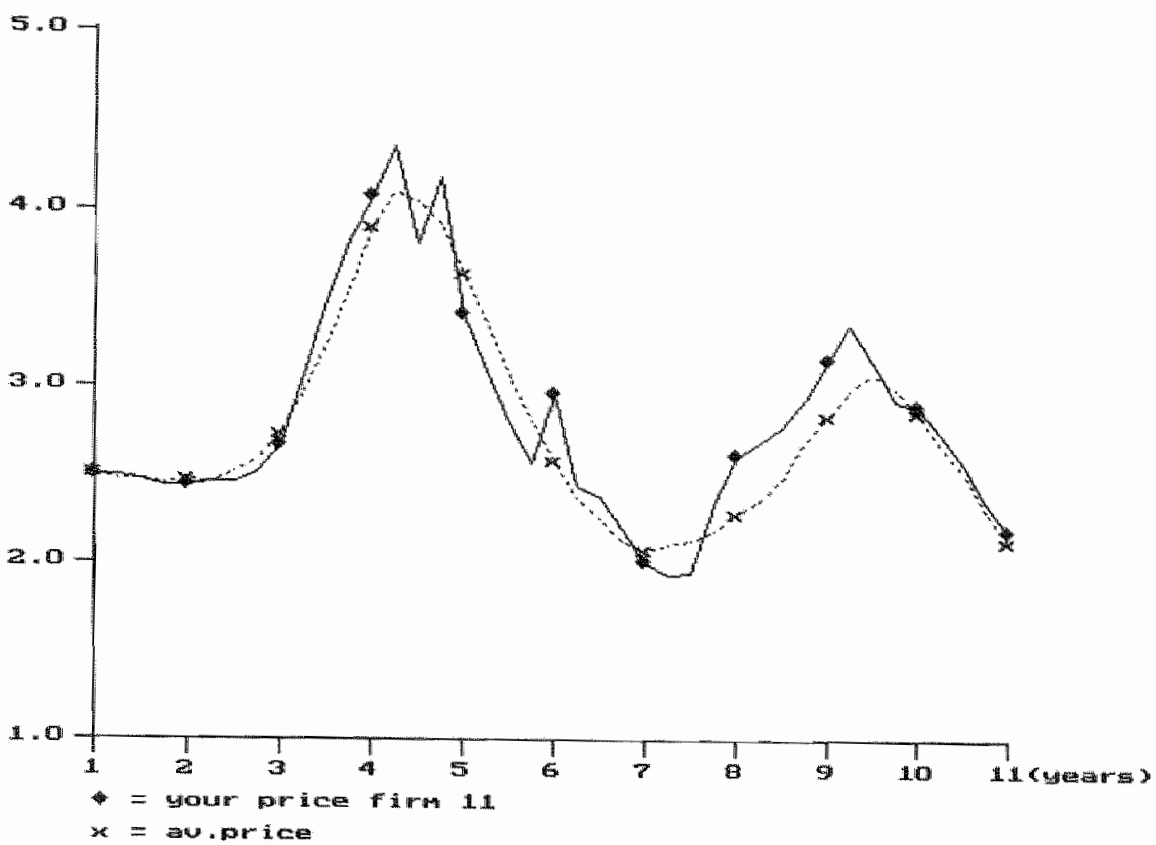

Figure 6.7 The price policy of firm 11 in ECO9.
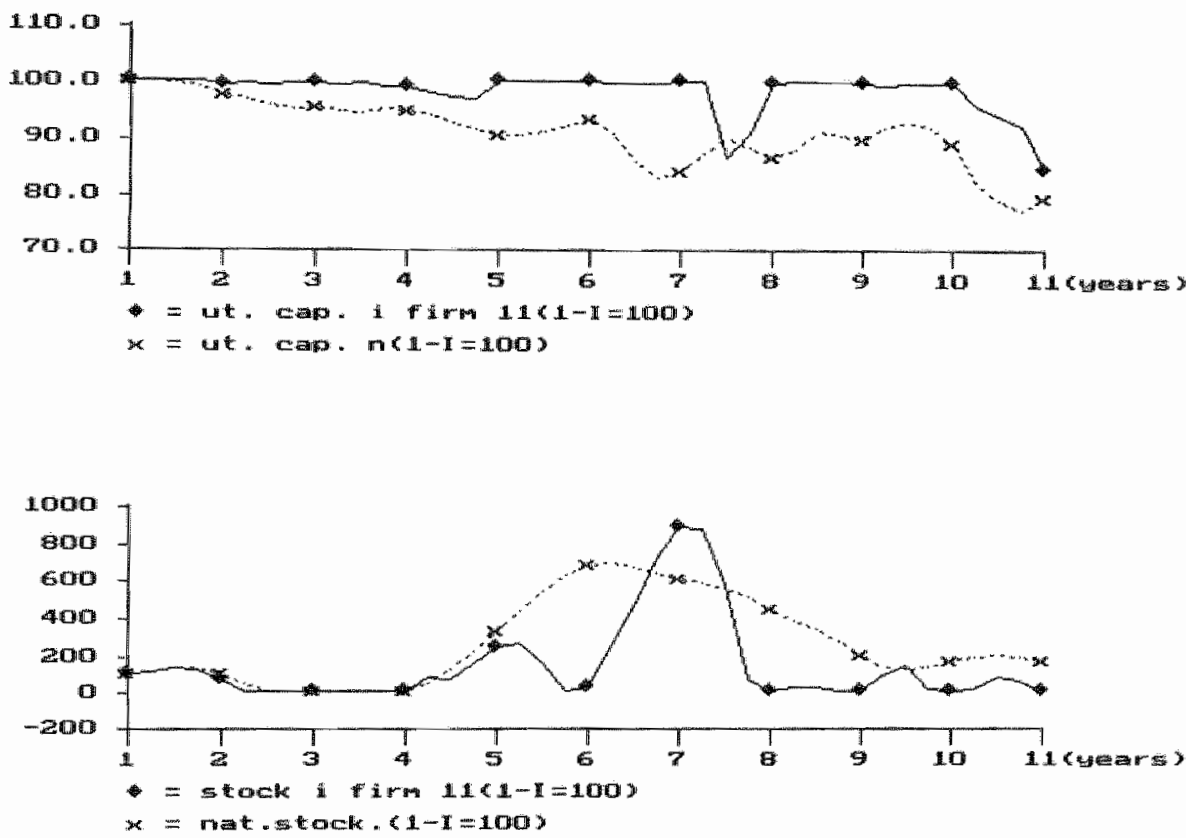

Figure 6.8 Utilization rate and stock for firm 11 in ECO9. 

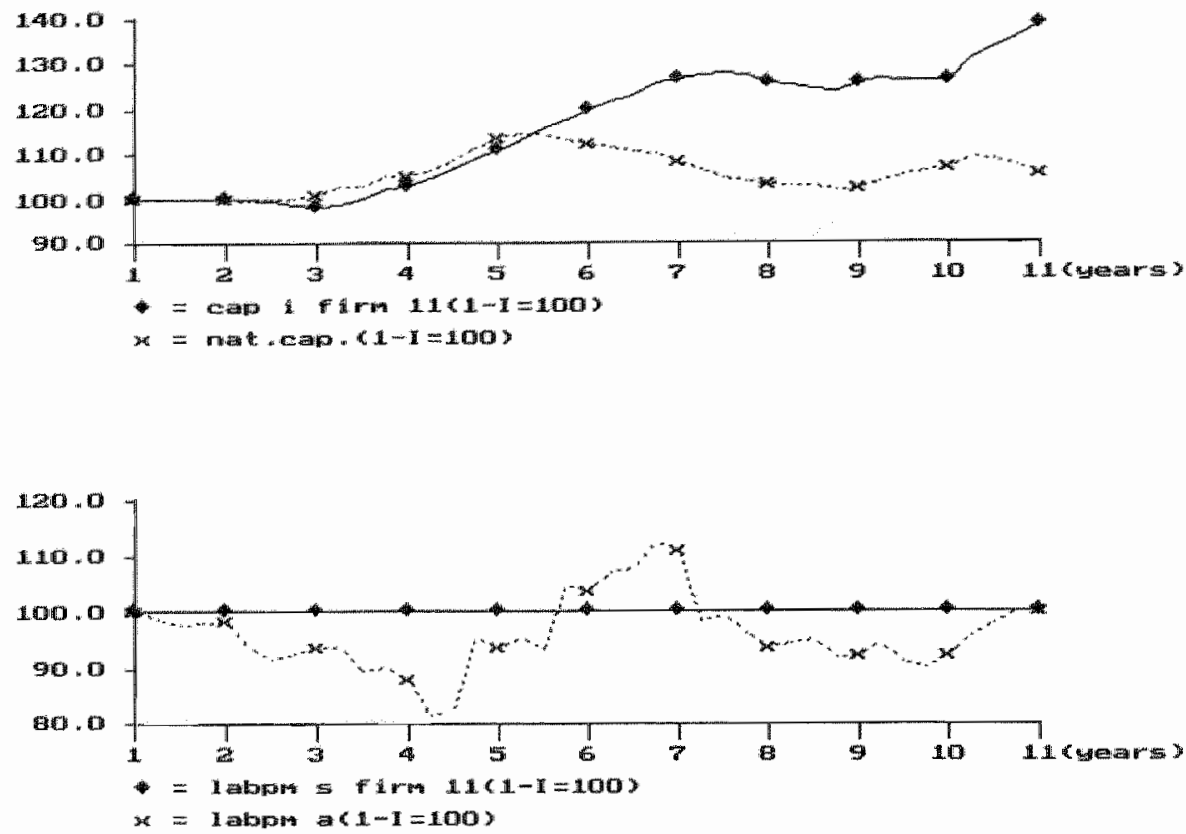

Figure 6.9 Capital stock and labour/capital ratio for furm 11 in ECO9.

Finally, players are asked to define the policy for the near future. Firm 11 may decide to continue with its wage and price policy. It may also decide to use the labour/capital ratio as an instrument in tackling the business cycle.

The application of the new policy requires a little bit more time. An hour (5 years) seems reasonable. After that time the players can evaluate the effects of their policy. For example, figure 6.6 shows that firm 11 was rather successful in tackling the problems of the economy. In year 6 the game economy was bankrupt. Figure 6.7 shows that in contrast to other firms, firm 11 continued its expansion of capital stock. Figure 6.8 shows that in year 6 firm $\| 1$ stopped its policy of low prices. Extremely high stocks in year 7 were the consequence (figure 6.9). This was the first moment that firm 11 was forced to fire people; in the second half of year 7 the utilization rate of capital declined sharply. In hindsight firm 11 was much too late in doing this. A revival of the economy solved the problems that developed in year 8 . Firm 11 used this period extremely well by setting very high prices (see figure 6.8). In year 10 the firms had leamed from their errors in year 6 and started to fire people before stock was too high.

One may wonder to what extent the price level of firm 11 during the recession in year 6 was efficient. The price elasticity of demand is a relevant variable in this context (see chapter 4). When one only looks at the short run, the answer can be found by elementary theory of monopoly pricing: 
$P=\frac{M C}{1+\frac{1}{E}}$

where $P=$ price, $M C=$ marginal cost, $\varepsilon=$ price elasticity of demand, $\varepsilon<0$. Because the short term price elasticity of demand for a firm is about 4 for a year, optimal price is $33 \%$ higher than marginal cost. But then it is assumed that the rise in sales holds for the whole period, while sales will rise only gradually. When we assume for year 6 that the average rise of sales is $50 \%$ of the rise in sales at the end of year 6 , the correct price elasticity of demand is -2 instead of -4 . In that case the equilibrium short term optimal profit margin would be $100 \%$.

But then the net present value of future profits is neglected. Therefore, let us anallyze the marginal profit of a rise in market share of $1 \%$ during year 6 . When price is set lower during year 6 , this has consequences not only for year 6 , but also for later years. Because starting with year 8 lagged market share has no influence on sales because of a national stock of 0 (see figure 6.9), a lower market share in year 6 has consequences only till the end of year 7 . When we assume that on average the lower price in year 6 implies a rise in sales of half the rise in market share during year 6 , average sales increases by $0.5 \%$ in year 6 , and $1 \%$ in year 7 . When we assume that the profit margin in year 7 is the same as in year 6 (and neglect interest cosi), the revenues of the increase in sales is $1.5 \%$ of the profit margin. This implies that the optimal profit margin is not $100 \%$, but $20 \%$. Therefore, the optimal price in Jamuary of year 6 was about $20 \%$ higher than labour cost per unit of product.

The second day the players are asked to design a strategy for the firm. First, the players may write down the goal variables (for example a low stock, a high utilization rate of capital, a high profit rate, and a high growth rate of capital). Then they have to define the instruments to be used. For example, when the managers of a firm decide to expand, they must design also a strategy to sell the products at a reasonable price. Priorities for the goals have to be defined when more than one goal is formulated. For example, the price strategy can be related to the employment strategy by the following decision rule: when demand declines, price will be reduced when price is higher than variable cost, while labour demand is reduced otherwise.

After players have defined their policy, a new game starts. After about half an hour a macroeconomic assignment is given. In this assignment students have to recognize the structural and cyclical situation of the economy.

Let us first define the relevant concepts. Let $L^{*}$ be aggregate labour supply when the labour market is in equilibrium. This level is defined in the game at an unemployment rate of $5 \%$. The actual employment level $L$ can be higher than $L$ when the wage rate is sufficiently high. Normally such a high wage indicates excess demand for labour. When the economy is in general equilibrium, actual employment equals aggregate labour supply, while the utilization rate of capital is $100 \%$. When employment at full capacity is lower than labour supply, there is structural unemployment. Therefore, structural unemployment can be computed as unemployment minus frictional unemployment minus the labour that can be employed on the unused capacity on machines. When employment at full capacity of machines is higher than labour 


\begin{tabular}{|c|c|c|c|}
\hline yeatr: & $\begin{array}{l}\text { utilization } \\
\text { rate of } \\
\text { capital }\end{array}$ & $\begin{array}{r}\text { memployment } \\
\text { rale }\end{array}$ & $\begin{array}{r}\text { structural } \\
\text { unemployment } \\
\text { rate }\end{array}$ \\
\hline 1 & 9967 & 512 & $-0,21$ \\
\hline 2 & 9625 & 560 & 315 \\
\hline 3 & 94.82 & 497 & 521 \\
\hline 4 & 9904 & 4,90 & 70 \\
\hline 5 & 91.06 & 4.92 & -90 \\
\hline 6 & 8812 & 1002 & 68 \\
\hline 7 & 8730 & 13.23 & $-4,4$ \\
\hline 8 & 88.96 & 1304 & -3.0 \\
\hline 9 & 9151 & 67.1 & -6, \\
\hline 10 & 8174 & 20.08 & -3.1 \\
\hline
\end{tabular}

Table 6.11 Structural and cyclical unemployment in ECO9
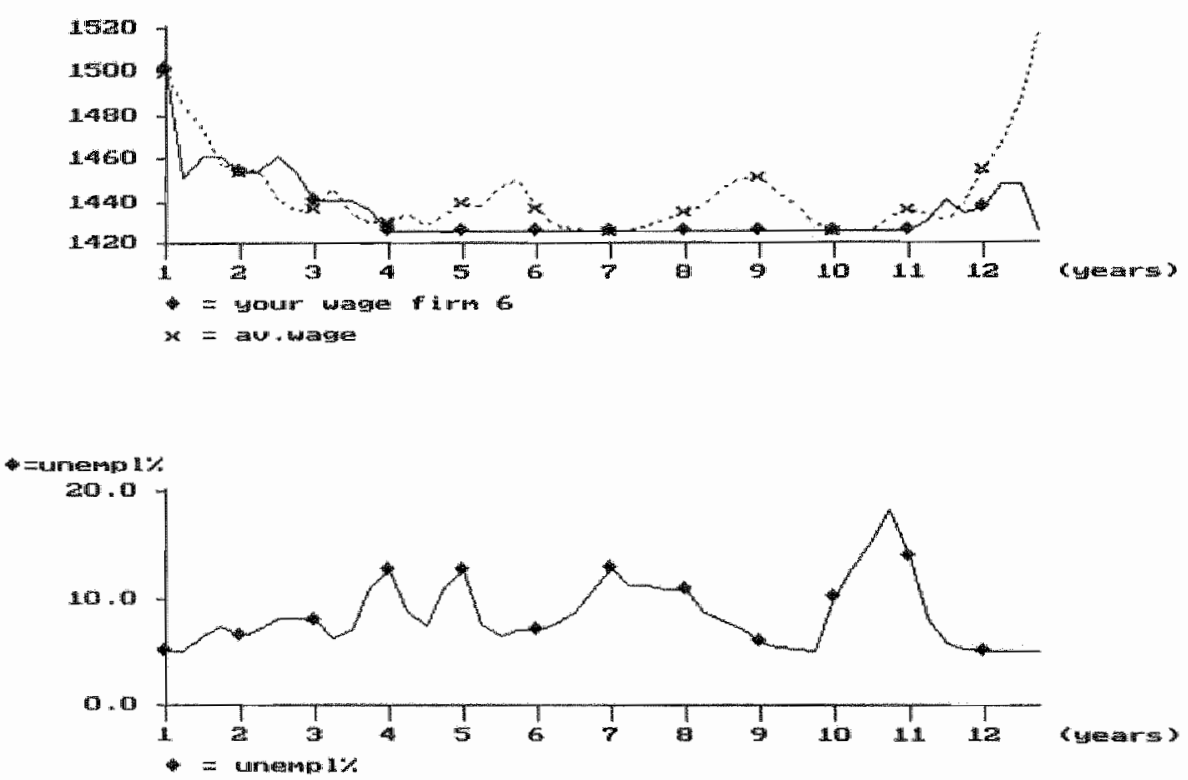

Figure 6.10 The relation between the wage rate and unemployment in ECOI1.

supply, there is a stuctural shortage of labour. For example, table 6.11 shows that ECO9 had a structural shortage of labour during the whole game.

Nomally, actual unemployment is not lower than structural unemployment plus frictional unemployment, because this would imply that firms employ more labour than they can use on their machines. But unemployment can be much higher. In that case cyclical unemployment emerges. Cyclical unemployment is caused by a lack in aggregate demand. It can be observed by the utilization rate of capital as long as structural restrictions on the labour market do not determine the utilization rate of 
capital. For example, in year 6 of ECO9 the cyclical rate of unemployment is about $12 \%$ where in year 4 there is aggregate excess demand because the unemployment rate is lower than $5 \%$.

\begin{tabular}{|c|c|c|c|c|c|}
\hline year & $\begin{array}{l}\text { utiliz } \\
\text { rate of } \\
\text { capital }\end{array}$ & $\begin{array}{r}\text { Unemployment } \\
\text { rate }\end{array}$ & $\begin{array}{l}\text { strucnual } \\
\text { amemployment } \\
\text { rate }\end{array}$ & $\begin{array}{l}\text { ordered } \\
\text { machines }\end{array}$ & $\begin{array}{l}\text { Tabour } \\
\text { per } \\
\text { machine }\end{array}$ \\
\hline 1 & 9888 & 5.91 & 0.20 & 137 & 89 \\
\hline 2 & 9656 & 732 & 1,12 & 132 & 79 \\
\hline 3 & 96.16 & 8.03 & 0,81 & 114 & 8.2 \\
\hline 4 & 9588 & $9: 89$ & 0,77 & 149 & 837 \\
\hline 5 & 98.55 & 834 & 189 & 151 & 918 \\
\hline 6 & 98.22 & 833 & 156 & 98 & 9.52 \\
\hline 7 & 95.51 & 11.41 & 190 & 124 & 956 \\
\hline 8 & 9818 & 853 & 170 & 172 & 94 \\
\hline 9 & 9897 & 538 & 0.66 & 129 & 9. \\
\hline 10 & 9100 & 13.95 & -0.05 & 122 & 82 \\
\hline 11 & 9531 & 8.13 & -156 & 151 & 8.64 \\
\hline 12 & 95.71 & 4.97 & 4.31 & 98 & 300 \\
\hline
\end{tabular}

Table 6.12 The structural rate of unemployment in ECO11.

When one wants to train players in neoclassical thinking, one may focus the exercises in the game on structural developments. Therefore, in the first exercise of ECO11 students were asked to compute the structural situation of the economy. You can see in table 6.12 that in year 2 of ECO11 there was a small structural shortage of labour. The teacher explained that this implied structural problems on the labour market. Therefore, when this tendency continued, a shortage on the labour market would arise. Hence, it would be wise not to invest. ${ }^{13}$ Therefore, it is not surprising that investment demand declined. This explains the recession in year 3 . During this period structural unemployment arose that surprisingly remained during the boom in years 5 and 6 . The explanation for this can be found in table 6.12 where it can be seen that labour intensity of ordered machines is 8 or 9 persons per machine instead of the equilibrium value of 10 . Therefore, the structural unemployment in years 5 and 6 is caused by the substitution of labour by capital instead of by the level of investment. This behaviour of the players can be explained by the fact that during the first game (i.e. ECO9) there was a continuous structural shortage of labour.

The sharp decline in investment in year 6 seems to be surprising. Therefore, a break was useful to investigate the causes of this problem. The explanation requires an investigation of the monthly data (cable 6.13). This table shows that labour demand increases suddenly in January of year 5 , the year that aggregate stock reached a value of 0 . This rise in demand induced a rise in employment and producLion in April, May and June. As a consequence, the stock of final products rose. Because a rise in stock normally indicated the start of a recession, firms stopped investing. This explains the decline in investment that induced a decline in national income.

"Or to invest in labour-saving technology. 


\begin{tabular}{|c|c|c|c|c|c|c|c|}
\hline month & $\begin{array}{l}\text { labour } \\
\text { demand }\end{array}$ & employ ment & $\begin{array}{l}\text { utiliz } \\
\text { rate } \\
\text { f copital }\end{array}$ & $\begin{array}{l}\text { produetion } \\
(\times 1000)\end{array}$ & $\begin{array}{l}\text { income } \\
\text { (x 1000) }\end{array}$ & $\begin{array}{r}\text { stock } \\
\text { (1) } 1000)\end{array}$ & $\begin{array}{l}\text { ordered } \\
\text { invesment }\end{array}$ \\
\hline Nor 4 & 9213 & 9191 & 9414 & 6945 & 7428 & 483 & 700 \\
\hline Dec 4 & 9213 & 9232 & 9538 & 7023 & 7023 & 0 & 20,00 \\
\hline $\operatorname{san} 5$ & 9704 & 9223 & 9561 & 7016 & 7016 & 0 & 1800 \\
\hline rebs & 9853 & 9213 & 95.65 & 7006 & 7006 & 0 & 300 \\
\hline Mrts. & 9822 & 9213 & 9537 & 7011 & 7011 & 0 & 16000 \\
\hline Apr 5 & 9812 & 9608 & 98.72 & 7305 & 7305 & 0 & 1700 \\
\hline May 5 & 9862 & 9805 & 9978 & $737 \%$ & 1272 & 0 & 7,00 \\
\hline Jun $s$ & 9857 & 9822 & 9974 & 7382 & 7199 & 107 & 10000 \\
\hline $\mathrm{Jul} 5$ & 9828 & 9822 & 99.84 & 7314 & 7099 & 290 & 10,00 \\
\hline Akig 5 & 9738 & 9847 & 99.63 & 7407 & 7076 & 505 & 14,00 \\
\hline Sep 5 & 9803 & 9857 & 9972 & 7339 & 7126 & 836 & 19.00 \\
\hline $0 \mathrm{ct} 5$ & 9813 & 9828 & 9937 & 7366 & 713 & 1048 & 7.00 \\
\hline Nor 5 & 9803 & 9748 & 9985 & 7328 & 7117 & 1301 & 1200 \\
\hline Dee 5 & 9803 & 9793 & 9930 & 7351 & 7261 & 1511 & 18.00 \\
\hline $\operatorname{Jan} 6$ & 9858 & 9803 & 9971 & 7308 & 7118 & 1601 & 3.00 \\
\hline Feb 6 : & 9785 & 9793 & 9935 & 7311 & 7096 & 1791 & 1100 \\
\hline Mrt 6 & 9590 & 9803 & 9986 & 7276 & 7030 & 2006 & 1100 \\
\hline Apr 6 & 9715 & 985 & 9952 & 7337 & 6943 & 2252 & 3,00 \\
\hline May 6 & 9614 & 9785 & 99.55 & 7331 & 7005 & 2645 & 1000 \\
\hline Jun 6 & 9475 & 9595 & 9779 & 7183 & 7062 & 2971 & 1200 \\
\hline Jul 6 : & 9520 & 9715 & 9772 & 7199 & 6969 & 3092 & 3,00 \\
\hline
\end{tabular}

Table 6.13 The causes of the decline in ordered investment.

When this analysis is finished, one may ask how one could improve the policy of the firm in such a situation. First, one may ask to what extent it would have been possible to predict the excess demand that began in December of year 4. If a firm had been able to predict this high demand, it would have been able to attract new employees before all firms were running out of stock. Second, one may ask to what extent the problems in July of year 6 are structural in character. Because at that point of time a little bit of structural unemployment exists, one may expect that the decline in demand is temporary in character. Therefore, there was no fundamental reason for a decline in investment demand. When firms believe that the development depends on structural opportunities in the economy, it will be wise for them to invest before other firms start to invest. Such an explanation may induce at rise in investment. The educational goal is to show the relevance of macroeconomic analysis for the policy of firms.

The cyclical disturbance increased the level of structural unemployment in year 7 a little bit. But then the boom of year 4 restarted and the structural umemployment problem was solved, with a little bit of overshooting that can already be seen in year 11 with its structural shortage of labour of -1.56 . Therefore, firms that recognize this structural shortage already in year 11 would have been able to adapt their pollicy before the other firms were doing so in year 12. Nevertheless, this did not happen...

One explanation of this phenomenon can be found in the uncertainty in the economy. The rate of structural unemployment is computed on the assumption that the equilibrium full employment rate is at a utilization rate of capital of $100 \%$. But in 


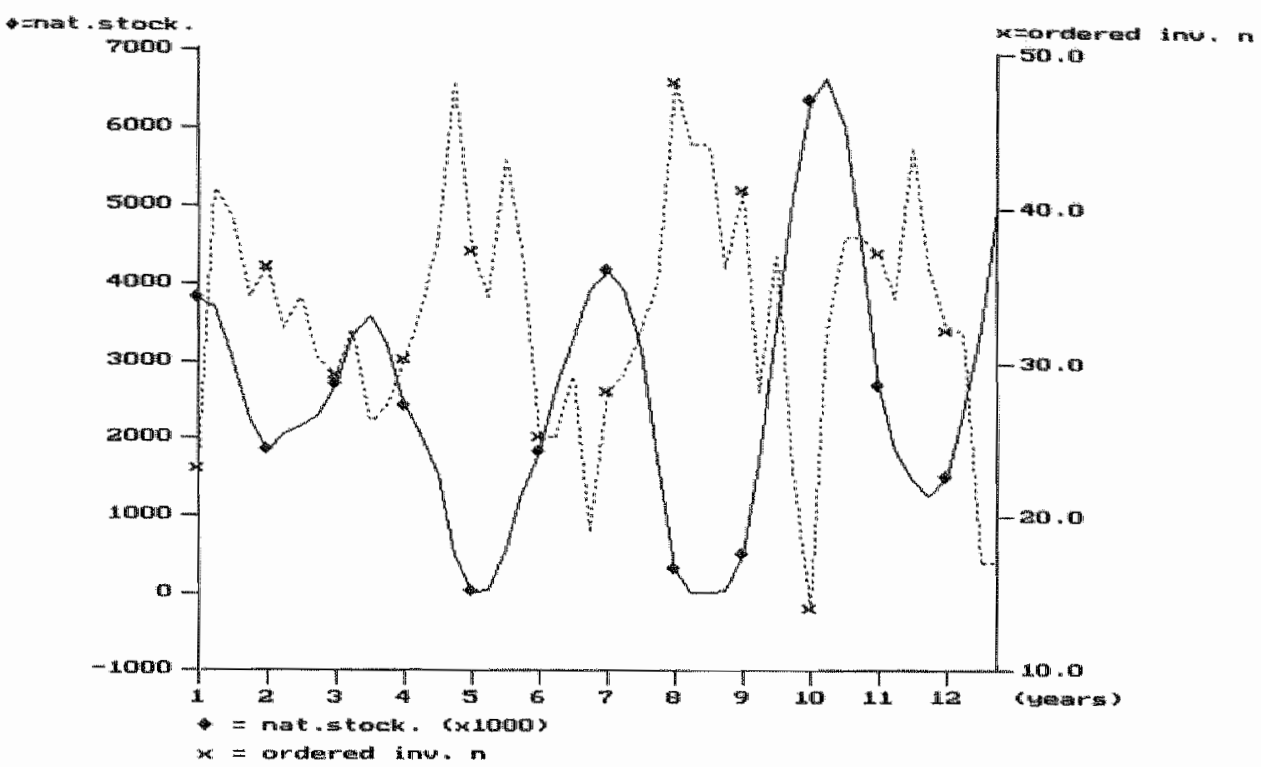

Figure 6.11 National stock and ordered investment in ECOI1.

an uncertain world, the equilibrium utilization rate of capital may be lower than $100 \%$ (see section 5.3). Therefore, it may be that the high level of coordination during the first 10 years of the economy were accomplished by the explanations of the game leader about the structural rate of unemployment, while at the end of the game the players found out that the real game world was different. ${ }^{14}$

It is evident that structural analysis is only helpful when the other players perceive the structural opportunities and threats. As an alternative or extra part of the training of the players one may focus on the perception of the business cycle. One may focus assignments on the early indicators of the business cycle. For example, the stock of final products is such an indicator. But the level of ordered investment is in many situation an earlier indicator; all recessions (i.e. rises in stock) in figure 6.11 are preceded by a decline in ordered investment some time before. Therefore, a recession can be anticipated some time before the stock of final products rises. As already mentioned in the discussion of ECO11, an explanation focused on recognizing business cycles may generate new dynamic features in the economy.

It is evident that depending on differences in purpose and duration of the game the training programme will differ. For example, when the game is incorporated in a course of macroeconomics, the evaluation of the first game may be focused on macroeconomic dynamics instead of business policy. When the game is embedded in a course on microeconomic principles, one may focus on the labour intensity of machines and price and wage policy rather than on quantity restrictions. When the game is embedded in a course on strategic decision making, the focus will be on long term effects of decisions and the interdependency of goals. When one does not want

14 Because we did not ask the players about their argumentation, this is speculative. 
to stimulate neoclassicall adjustment to the structural opportunities in the economy, one must skip the exercises that investigate the structural situation of the economy.

As discussed in chapter 2 it is very important that experiences in the game can be related to real world examples. It is evident that no game situation exactly matches a real world problem. But a creative game leader can find a lot of examples. Let us discuss some. First, the severe inflation in ECO9 was a consequence of excess demand. Real world inflation in the 1960 s and 1970 s seems to have been caused by aggressive labour unions. But is it not true that the labour unions could do this because the firms could easily sell their products? Second, the recession in ECO9 started in year 5. This was caused by a decline in investment. Around 1980 a change in monetary policy caused a decline in demand. In both cases a long period was needed to correct the big errors that were made during the preceding boom. "Third, when you compare firms behaving well with firms behaving badly in the game, it is evident that the firms that adjust late have the biggest lay-offs. Therefore, the firms that seem to be social in first instance, become the anti-social ones in hindsight. A lot of firms in the real world can be used as an example. Fourth, many students will recognize that the impossibility to go bankrupt reinforces the duration of a recession in the game. In Western Europe firms can go bankrupt. This may explain why Eastern Europe has such severe problems; they started a free market economy, but without introducing bankruptcy. Fifth, firms find out that competition during a recession results in very low prices. Especially firms performing badly dump products. In the steal industry, for example, you can perceive the same phenomenon because subsidies allow firms to set prices at levels below cost. This list of examples may be sufficient to show possibilities of relating game experiences to the real world.

\subsection{Game instruction and teaching principles}

A good training programme for the game should be consistent with the six teaching principles discussed in chapter 2. First, the game has to be related to prior knowledge of the players. The intuitive introduction of the game described in section 6.3 may help, but is not sufficient. It is essential that the game is related to theoretical knowledge of the students. When students are trained in business strategy, they must get explanations or exercises that help them to set explicit goals and teach them to investigate the enviromment of the firm. When students are trained in microeconomics, the game can be related to market structure, monopoly profits, and the role of cost. With respect to macroeconomics, it may be usefull to sketch the problem of the stability of the economy. When the game is included in a course as developed in chapter 2 , the explanation may focus on the role of expectations, but when the game is included in a traditional course in macroeconomics, the choice between price and quantity adjustments can be elaborated. When the game is used for education, it is important that players are able to connect the game to some theory. ${ }^{15}$

But not only the relation with theory is important. Both game and theory are intended to improve the understanding of the real world. For most players, it will be

15 This may be done by a lecture or some special assignments. 
Ewaluation of firms in round 145 of the ganne ecoll

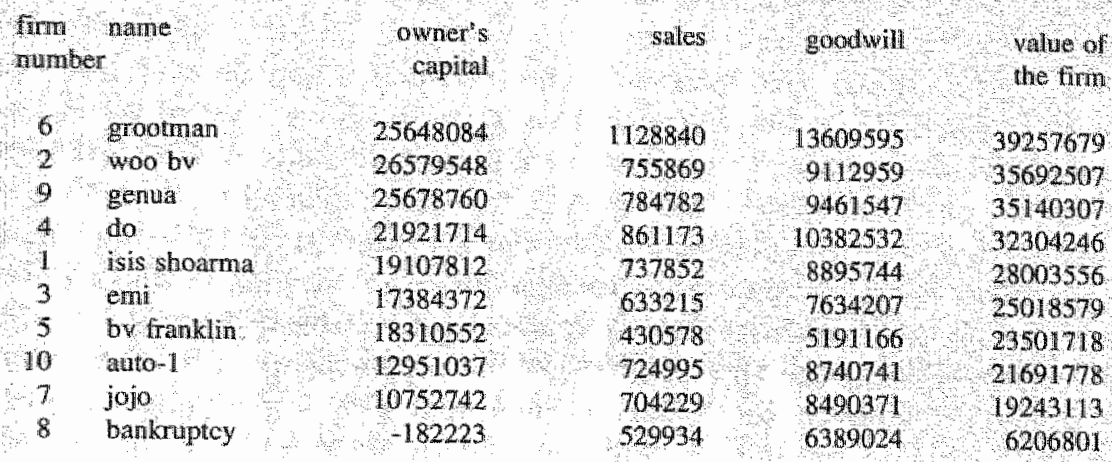

Table 6.14 The value of the firms.

motivating and increase their understanding when experiences in the game are related to real world issues. For example, when inflation occurs in the game, one may compare this with real world inflationary periods. To what extent are both the same and to what extent do they differ? Is it possible to stabilize an economy by changing the interest rate or the government deficit? In summary, when the game is played without explicit reference to theory and/or real world examples, it can be felt as an empty exercise.

The second educational principle, causal organization, requires that experiences in the game are related as much as possible to a limited set of fundamental principles. Let us take cost-benefit analysis as an example. You may use the game to investigate costs and benefits of rising the price, decreasing labour demand, as well as investment in new machines. When the turning point in the business cycle is explained, explicit reference to this cost-benefit analysis of the decision makers can increase the coherence of the knowledge of the students. The challenge for the teacher is to find these types of fundamental principles. ${ }^{16}$

The third educational principle, motivation, is essential for a proper functioning of the game. As in a lot of other games, competition and the use of skills are import. ant motivators. Regularly a list of results can be presented to the players (table 6.14). "This has a direct effect on the efforts of the students. In most games even players with bad results try to improve their position on this list and are very proud when they are effective.

Although a ranking of the firms may help to motivate, it is not sufficient. The players must also see a relation between the skills of the players and their position on the list. This requires carefully designed exercises or explanations of the differences between the players. We found that it is essential that the players that are lower on

\footnotetext{
${ }^{36}$ When the results of the game are used in experiments, the choice of fundamental explanations is one of the experimental variables that can be manipulated.

1? When the players can choose a name for themselves, this may improve the pleasure in the game.
} 
the list get some help in improving their policies; in many cases they did not have any idea how they could improve their policy. One may also invite students to defend their strategies to the other students.

In chapter 2 we argued that inconsistencies between schemata can be very important for motivation. Therefore, exercises may focus on these types of inconsistencies. The macroeconomic controversy between Keynes and the Classics can be such a challenging problem. Many students will feel the explanation of structural causes of business cycles as plausible. But when they are confronted with an instable game economy where everyone tries to be the first one in perceiving a turning point in the business cycle, they may feel the importance of the stability issue. One may also ask students to predict the future development of the game, and afterwards compare the prediction with the result. Furthermore, it is very important for motivation that students perceive the relevance of the game in understanding theory and explaining real world problems. In the long run students will only enjoy a game when they think they learn something from it.

The fourth educational principle, elaboration, implies that students must be helped to think as much as possible about the relation between experiences in the game and other events. For this purpose explicit exercises are needed to relate the game with formal theory as well as with real world phenomena. Some examples have been shown before. It is also very important that the students try to explain the different experiences in the game.

The fifth educational principle, context, requires that students are helped to recognize in other environments patterns they learned in the game. Therefore, it is very important that the patterns found in the game are also related to real world situations. For example, one may compare structural unemployment in the game with structural unemployment in the real world economy. When in a game a long recession causes structural unemployment, one may try to recognize the same phenomenon in the $1930 \mathrm{~s}$ or the second half of the 1980s.

Finally, the sixth principle, routine, implies that students must routinize pattern recognition. This implies that in presenting the game a limited number of thinking patterns have to be trained in depth. For example, one may try to present all decisions as cost-benefit analyses. In every assignment about decisions one may ask about the costs and benefits of the decision compared with another decision. When stock rises ${ }_{*}$ one may ask about the relevant alternatives to solve this problem, i.e. do nothing, fire employees or reduce the price. For each alternative you may ask students to estimate the costs and benefits. Also macroeconomic phenomena like inflation can be explained by cost-benefit analysis; inflation is the consequence of decisions of firms to change their price.

Another example of routine thinking may be the differentiation between structural and cyclical problems. During the game students can be asked to analyse and predict the economy many times. One may also investigate the consequences of the structural situation for business strategy, both in the game and in the real world (for example, the 1930s, the 1950s, the 1960s, and the 1980s). It has to be emphasized that this type of exercise not only helps to routinize thought patterns, but is also an elaboration of the theory and the application of the theory in different contexts.

The six teaching principles show that it is very important to train the students to 
understand the game with the help of a limited number of fundamental principles that are related to prior knowledge, and show how the same type of mechanisms also apply to the real world.

\subsection{Concluding comments}

This chapter has shown how players may learn to behave in the game economy. We have seen that this not only requires a good introduction, but also a training programme with intensive feedback. In section 6.4 a story about two games has been told that shows how students may learn to interpret game results. The complexity of the explanation shows that this is not an easy task and requires a lot of knowledge and experience of the game leaders. Although well-designed exercises may relieve the task of the game leaders, most students will need help from the game leader in interpreting the data. The design of adequate exercises requires not only a thorough insight in the dynamics in the game economy, but also insight in the role of those exercises in developing adequate schemata in the minds of the players. This is not only irmportant for the role of the game in teaching economics (see chapter 7), but also for the experimental results of the game (chapter 8 ). 


\section{MENU FOR THE GAME ON A NETWORK}

2 - The commumiedion path is dd

3 - The name of the game test!

4 The number of players (max, 40), 1

5 s The length of a month is 60 seconds

a - Start the game without starting the players

b $=$ Start the game

6 - Change the coefficients of the game

$e=$ Retum to main menu

Table 6.15 A menu for the game leader

1 - number of division per firm

$=$ scale parameter for the production function

1200.00

3 - scale parameter for the production finction of machines

0.010000

- coefficient for cipital in the Cobb Dourglas pf

0.200000

- life time of machines in months

100,00

6 - growth of labour supply per month ( $=0,00 \%$ per year)

7 a growth of money supply per month ( $=0.00 \%$ per year)

- growth of the eapital stock per month $(00.00 \%$ per year)

- microeconomic price elisticility of demand per quarter

- microecionomic wage elasticity per quarter

11 - natural decline of labour stock per wonth

$=$ marginal consumption quote non labour income

= capital stock per player at the stan of the game

10000

14 - labour stock per player at the start of the game

15 - real interest rate at the start $(=4.91 \%$ per year $)$

- nominal wage tale at the start of the game

$17=$ stock as a percentage of production

18 - owner s capital as a percentage of total capital

19 = narginal consumption quote wage ibcome

21 - risk prenitum on the ittiorest rate:

-3 Standard coefticlents

4 S Youk own stanitard coefficients

$-5=$ Save as your own blandard coeficlents

Make your choice ( 2 - wexit)

Table 6.16 The menu for the coefficients in the game. 
Appendix $6 \mathrm{~A}$. The start procedure for the game.

At the start of the game the game leader can manipulate some of the coefficients of the model and some coefficients that influence the process of the game. The communication between the players and the game leader has been modelled straightforward. When the game starts, the programs search for a communication path that is available (see table 6.15). The game leader types a name for the game and decides about the number of firms. He may change the length of a month when he likes. A standard configuration of the coefficients of the game is implemented, but the game leader can change it by choosing option 6: "change the coefficients of the game".

After choosing this option table 6.16 emerges. The following coefficients of the game can be changed in this menu: the coefficients of the Cobb Douglas production function, the lifetime of machines, the exogenous growth rate of labour supply, the equilibrium characteristics of the game (number 7 and 8 ), the price elasticities, the coefficients of the consumption function and the risk premium on the interest rate. Furthermore, the starting position of the game is cletermined in this menu: stock of capital per firm, stock of labour per firm, real interest rate, nominal wage, stock of final products, equity capital. The game leader may also decide that after a certain time the player programs start an automatic policy. This last option is especially relevant when the game is played with a variable number of players. 


\section{Chapter $7 \quad$ Educational evaluation}

\subsection{Introduction}

In chapter 6 we have seen how the game can be explained to students. But to what extent do students appreciate the game? And how much do they learn from the combination of the game and a type of course as developed in chapter 2? In this chapter several research methods will be discussed to investigate this type of problem. First, a combination of factor analysis and correlation analysis will be used to analyse tests of students and questionnaires about the teaching programme (sections 7.2.2, 7.2.3 and 7.4.2). Second, regression and correlation analysis will be used to investigate the relation between questionnaires and test results (section 7.2.4 and 7.4.2). Third, a test has been developed to measure conceptual capabilities of students (section 7.4.3). Finally, a test for pattern recognition has been developed (7.3.2).

The methods are applied to courses where the principles approach to teaching and/or the game have an important role. First, the game has been used at the end of the first year of the study in economics and business administration (section 7.2). After this game the students were asked to fill in a questionnaire and two weeks later they did a general test on economics, the so-called Overall Test (OAT). The answers on the questionnaire and the results of the OAT will be combined to evaluate some educational aspects of the game in this course. Second, the game is used in a very short introductory course in economics for students in cultural and scientific studies. The focus of this course is on the basic concepts of economics and the ability to recognize some economic tendencies (section 7.3). At the beginning and end of this course students had to read a sketch of an imaginary economy and to characterize the situation of this economy. The results suggest a strong improvement in their ability to recognize patterns in data about for example inflation, unemployment and interest rates. Third, the game has been used as a small part of an introductory course in economics for law students (section 7.4). The setup of this course is more or less consistent with the principles-based approach discussed in chapter 2 of this dissertation. This course is evaluated by correlation analysis of participation in teaching, an examination test, and a conceptual capability test.

All methods used in this chapter are exploratory in character. This is partly because it is the first time they have been used, but also because the educational approach developed in this thesis is only partly incorporated in the courses discussed. With respect to the game you cannot expect that one or two half days of participation 
in the game has significant effects on test results. Therefore, except for a tendency of the law students who participated in the game to have a higher score on one factor of the examination test, no learning effects of the game have been investigated.

\subsection{The game in the study of economics and business administration}

\subsubsection{The organization of the game}

Since 1992 the game has been played at the end of the first year of the study in economics and business administration. The purpose of the game is to illustrate the relationship between the different topics the students were confronted with during the first year of their study. Because the game was in an experimental phase in 1992 and 1993, it was not obligatory. Only a small incentive had been introduced; about 10\% of the questions in a test after the game referred to the game. Therefore, we could not require that the students make exercises at home, the more because the game was played in a period where most students had to focus on their final examinations.

The educational features of the game improved a lot between June 1992 and June 1993. In 1992 the game was played as half a day of introduction and a full day playing a game with two sectors (see chapter 8). Assignments during the game were focused on the application of theories learned during the courses in economics and business administration. But those assignments were not very helpful in improving the strategy during the game. For example, students were asked to recognize a decline in the prices of machines in the account of the firm. But no help was given to apply this knowledge in improving the strategy of the firm. Furthermore, pn the second day a more complicated game with two sectors was used. Therefore, the alleady complicam ted one-sector game became even more complicated. Consequently, the fluctuations in the game economies were very big. More than the decisions of players, restrictions in the game on prices and wages determined the dynamics of inflation. The best strategy during a boom was to set prices and wages as high as possible. During a recession the lowest price was the best, and therefore most firms went bankrupt. This made the game a little bit boring.

Sometimes technical problems disturbed the progress of the game in 1992. As at consequence many students left class during the second day of the game or even did not show up the second day. As an indication, only $60 \%$ of the students who played the game the first day showed up the second day. Not more than $40 \%$ of the students who started the game finished the second day. Of those students only 54 completed the questionnaire after the game.

In 1993 the educational setup of the game was much better. First, no new game was introduced the second day. Instead, students were stimulated to improve their policy in the same game as the first day. Therefore, during the second day students could apply their skills developed during the first day. Second, the duration of the game on the second day was limited to half a day instead of a full day. Third, exercises were focused on improving strategy instead of on artificial applications of theory. Fourth, standard graphs and tables were developed to help students to organize 
the information available in about eighty time series. As a consequence of these improvements a lot more students remained in the game; about $60 \%$ of the students who started the first game finished the second game. Of those students 117 filled in the questionnaire about the game.

\subsubsection{The questionnaire after the game}

To evaluate the game, a questionnaire was provided to the students who finished the game course of two half days. This questionnaire is presented in appendix $7 \mathrm{~A}$. The first two questions ask about the extent to which the goals and instruments of the game were clear. Then six questions examine the feedback during the game and improvements in strategy during the game. Questions 9 to 11 are about the preparation of the student and the introduction by the game leader. Questions 12 to 20 consider the information given by the computer program and the organizational setup of the game. A last set of questions (21 to 33) asks about the appreciation of the game and its relation to the study in economics and business administration.

Table 7.1 shows the results for 1992 and 1993. The students who finished the game were very satisfied about it. On a scale of 1 till 5 the average rating of questions as 'The game is interesting', 'I learned a lot of the game' and 'Such a game has to be repeated' was about 4.3 in 1992 and 4.15 in 1993. The higher score in 1992 may be explained by a selection effect: in 1992 only 54 students filled in the questionnaire against 117 in 1993. This interpretation is consistent with another result; the score for the question on preparation (9) declined from 3.87 to 3.16. The same holds for the self-study that was induced by the game (from 2.98 to 2.10 ).

Despite the bad preparation in 1993, students improved their strategy during the game more easily; the score on the questions about the improvement of strategy (4) and the ability to evaluate the effect of strategy (5) rose from 3.85 to 4.05 respectively from 3.39 to 3.57 . This is consistent with the perception of the game leaders and the better performance of the game economies of 1993.

Factor analysis may be a useful method to organize the data of the questionnaire. Factor analysis or "principal components analysis is a statistical technique that linearly transforms an original set of variables into a substantially smaller set of uncorrelated variables that represents most of the information in the original set of variables" (Dunteman, 1989:7). Its purpose is to explain as much as possible of a set of variables by a few underlying dimensions.

Each factor is a weighted average of the scores on the separate variables. Those weights are called loadings. Each factor maximizes variance given that it is orthogonal to the other factors. Therefore, when $x$ factors are distinguished they create an $x$-dimensional space that explains as much of the variance in the original data set as possible. In principal components analysis the first factor is derived by maximizing the variance that can be explained by one factor. For an examination test this is the best single dimensional score to differentiate between students. When a second dimension is introduced this is required to be orthogonal to the general test score. So, when the first dimension measures a combination of knowledge and intelligence, the second dimension may be a rating from knowledge to intelligence. 


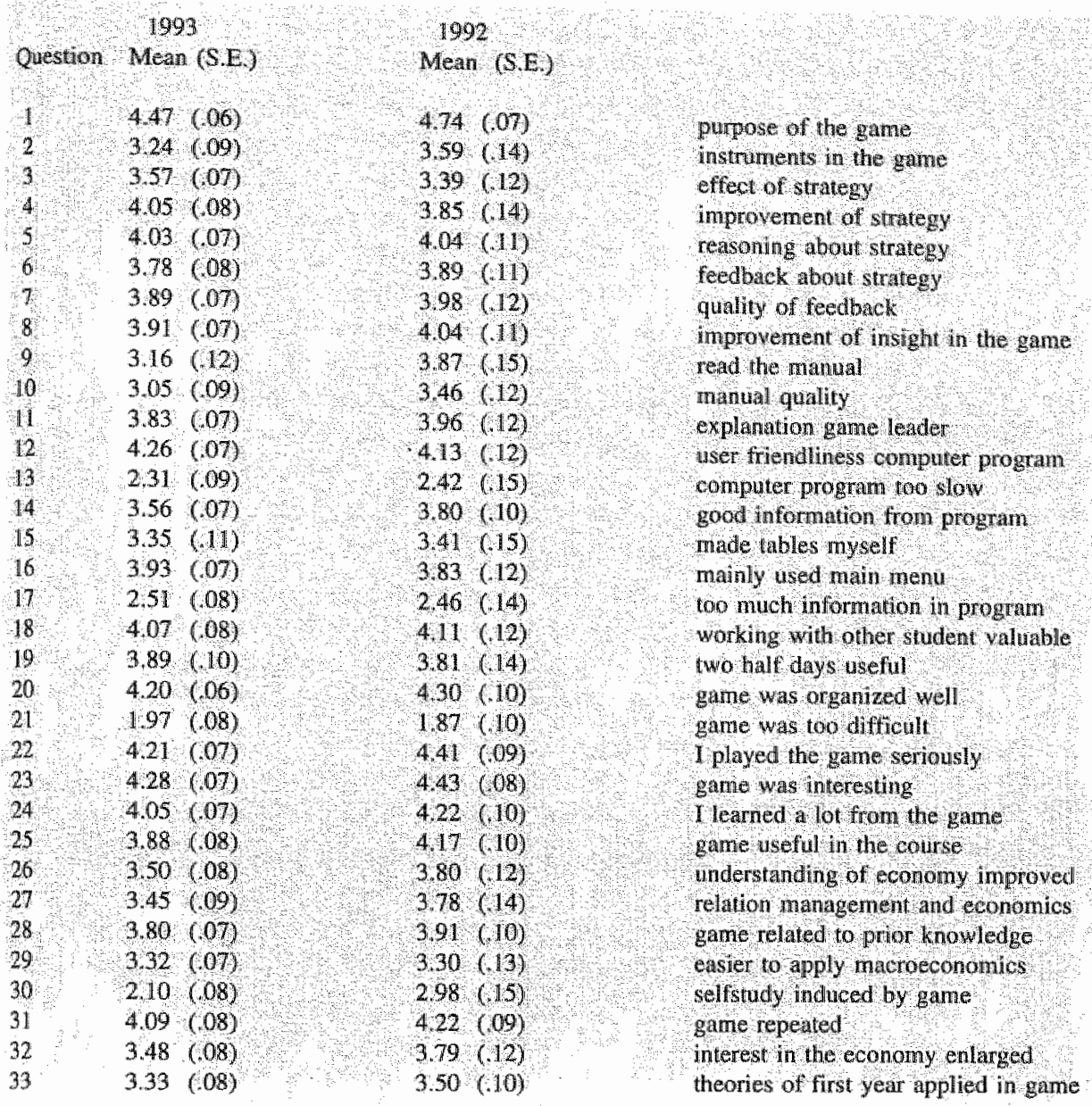

Table 7.1. Answers on the questionnaires for 1992 and 1993

Because an infinite number of pairs of axes is able to describe a two-dimensional space, for ease of interpretation it can be useful to rotate the factors in such a mamer that one axis measures intelligence and the other knowledge. The varimax rotation method maximizes the variance in the loadings of the factors; when some questions are especially focused on intelligence and others on knowledge, this may result in the required improvement in the ease of interpretation.

Table 7.2 shows the results of a factor analysis on the questionnaire of 1993 . The utmost left column represents the numbers of the questions. The correlation coefficients between the factors and the separate questions are presented. The first five 


\begin{tabular}{|c|c|c|c|c|c|c|}
\hline & & 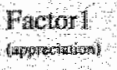 & actor 2 & factor 3 & faction 4 & factors \\
\hline & pose of the gane. & 1798 & 0476 & 2106 & $4894 \ldots$ & -2057 \\
\hline 2 & struments in the game & 0.0927 & 00024 & 2371 & 5848 m: & 0722 \\
\hline 33 & effect of strategy & -1420 & 1294 & $6327 *$ & 1374 & 0966 \\
\hline 84 & Inprovenent of strategy & 1936 & 0909 & $5994^{* *}$ & -1704 & -1749 \\
\hline Es & reasonnng about strategy & 2190 & $2279 *$ & $6492^{* *}$ & 0480 & 0780 \\
\hline 6 & feedback about strategy & 2009 & 1754 & $4681 *$ & $3989 *$ & $.2412^{*}$ \\
\hline E7 & quality of feedback & 3215 & .1743 & 4540***; & $3484 \%$ & $2583^{*}$ \\
\hline 0 & mproved insight in the game & $3888 *$ & $5359 *$ & 2018 & 0829 & 0237 \\
\hline at & read the manual & 00006 & 1619 & $2374^{\circ}$ & $9^{* *}$ & -1220 \\
\hline 210 & manual quality & 0657 & 2170 & 0906 & 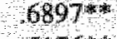 & -1569 \\
\hline E11 & explanation game leader & $3170^{\text {th }}$ & 1423 & 1719 & $5176^{*}$ & 0787 \\
\hline 12 & Thendliness computer program & 1833 & 10276 & $5762^{* *}$ & 1484 & $2271 *$ \\
\hline Q13 & conputer program too slow & $.2570^{*}$ & 0147 & -1098 & 0085 & -0656 \\
\hline D14 & good information from progran & $3386 *$ & $2623^{*}$ & $4332^{* *}$ & -1227 & -1281 \\
\hline A1s & made tables myself & -1091 & $2865^{*}$ & $4546 *$ & 0049 & $2782^{\circ}$ \\
\hline E16 & mainly cised main menu & .1286 & .0880 & 00763 & 1463 & $-7058^{*}$ \\
\hline $\mathrm{E} 17$ & too much information in program & -2245 & 0507 & 0075 & 1303 & $3539 *$ \\
\hline E18 & working logether was wluable & $6300 \%$ & 1256 & 0340 & 0233 & -2036 \\
\hline E19 & two half days usefü! & $6776 *$ & $2298 *$ & -0669 & $315^{\text {*tm }}$ & .0421 \\
\hline $\mathbf{E} 20$ & game was organized well & $6423^{* *}$ & 0830 & $3579 *$ & 1639 & 0457 \\
\hline E21: & gane was too diffieult & $2241 *$ & 0572 & $-6323^{4 *}$ & 0073 & 22601 \\
\hline $\mathrm{E} 22$ & I played the gante seriously & $5708^{*}$ & 0245 & $2585 \%$ & 05 & .0643 \\
\hline 123 & gane was interesting & $7019 *$ & 1317 & 0811 & $3528 * *$ & $2481^{*}$ \\
\hline e24 & Ilearned do lor from the game & 6896 & $3657 \%$ & 0805 & 2099 & $2701 *$ \\
\hline E25 & game useful in course & $5389^{9 * *}$ & $5298 * 6$ & 0376 & 1880 & 0014 \\
\hline $\mathrm{E26}$ & nsight of economy mproved & $4181^{\text {* }}$ 月 & $7482^{\text {*ir }}$ & 0732 & -0309 & -0240 \\
\hline H27. & management and economics & 1140 & $7708 *$ & 0074 & 1967 & -1199 \\
\hline E28 & gaine related to prior knowledge & 1827 & $485]$ * & $2552 *$ & $3226 *$ & 1024 \\
\hline E29 & essier to apply macroeconomics & 2333 & $5536 \%$ & 1654 & $3302 *$ & 171 \\
\hline 230 & selfstudy induced by game & 1425 & $5615^{*}$ & 0172 & 0256 & 0701 \\
\hline E31 & gane repeated & $3527 *$ & 0668 & 0311 & $5231 *$ & $4056^{*}$ \\
\hline E32 & interest in the economy enlarged & 1863 & $4414 \%$ & 1588 & $3586 * *$ & $3681^{* k 2}$ \\
\hline E33. & theones of first year applied & 0642 & $7082 \%$ & 2026 & 1420 & .0873 \\
\hline
\end{tabular}

Nunber of cases: 112 intalled Signif: $401 * 01 \%$

Talble 7.2 Correlations between factors and the questions of the questionnaire 1993.

factors can be interpreted as follows. "The first factor represents the general appreci ation of the game. It has high loadings on items as 'the game was interesting' (23), "fi learned a lot of the game" (24), and "the game was organized well" (20). The second factor has high loadings on questions about the relation of the game with theory. Let us call this factor theory-relatedness. Items as ' $\mathrm{My}$ understanding of the relationship

\footnotetext{
1 The choice of the number of factors is determined by the number of factors that could be interpreted. A lot more than five factors had eigenvalues bigger than 1 . When some factors are left out, the other factors do not change significantly. For example when the varimax rotation is executed on the first four factors of the principal components analysis, these factors are almost the same as the first four factors presented in the table. When the rotation is done on three factors, the first and third factor are incorporated in factor 1 of the factor analysis with three factors.
} 
between business administration and economics has been improved' (27), "My understanding of the economy has been improved" (26), "Selfstudy was induced by the game' (30), 'I applied theories of the first year' (33), and 'The game makes it easier to apply macroeconomics' (29) have high loadings. The third: factor shows that students who were able to give feedback on their strategies (3-7) were more satisfied about the computer program (14), made tables for themselves (15) and did not perceive the game as too difficult (21). Therefore, this factor represents strategic capability. The fourth factor represents students who prepared well $(9,10)$ and did understand the purpose and instruments of the game $(1,2)$. They were satisfied about the game leader (11) and would like to repeat the game (31). One may call this factor preparation. The last factor shows that students who did not mainly use the main menu (16) and did not have too much information (17), did like the game to be repeated (31). The interpretation of this factor is much more difficult than the interpretation of the other factors. Let us call this factor informational activity.

The results of the factor analysis of the questionnaire of 1992 are similar to those of the questionnaire of 1993 . Table 7.3 shows the results of a factor analysis on the questionnaire of 1992 , where table 7.4 compares the variables with high loadings of the two questionnaires. The first factor of 1992 is similar to the second of 1993 , i.e., theory-relatedness. The second factor of 1992 is similar to the third of 1993 , i.e., strategic capability. The third factor of 1992 is similar to the first factor of 1993 , i.e., general appreciation. The fourth factor, i.e., preparation, is similar. Only the fifth factor in 1992 differs a lot from the fifth factor in 1993, although they have both as the main variable that the students do not mainly use the main menu (16). In 1992 the use of information $(15,16)$ is related with the perception that they are able to relate the game to theory $(5,6,33)$. But they were not satisfied about the quality of the information that was available. In 1993 the use of information $(15,16)$ was related also related with strategy $(5,6)$, but not with dissatisfaction about the quality of the information that was available (14). In contrast to the results in 1992, the use of information was related with the general appreciation of the game $(23,24,31,32)$. This difference in the fifth factor may be interpreted as follows. In 1992 informational actrity was useful for understanding what was going on, while in 1993 the standlard exercises were sufficient to interpret the results. In contrast to 1993 , in 1992 students searching for information were not able to find enough information for their strategy and therefore were not satisfied about the information. Because the amount of information available was the same in the two years, the difference between them must be explained by the way it was presented. "This illustrates the importance of the quality" of the organization of information.

Comparison of the other factors of the two questionnaires suggests the following conclusions. First, where in 1992 the general appreciation factor was related to the satisfaction about the computer program $(13,15)$, in 1993 the game leader was perceived as more important $(7,11)$. Second, the relation between theory and the game was in both years related to the insight in the causes of economic development in the game (8), but in 1992 this was highly related to the explanation of the game leader $(6,11)$, while this was not the case in 1993 . Third, in both years strategic capability was highly related with the satisfaction about the organization of the game (20), the satisfaction about the computer program (12) and the feeling that the game was easy 


\begin{tabular}{|c|c|c|c|c|c|c|}
\hline & & Factor 1 & $\begin{array}{l}\text { factor } \\
\text { (matcogy }\end{array}$ & factors & factors & factions \\
\hline E1 & purpose of the game & .2378 & 2485 & 2192 & 5444 \% & .1961 \\
\hline 12. & instruments in the game & 2444 & 2341 & -1267 & $5800^{* * *}$ & 0950 \\
\hline $\mathrm{E}$ & effect of strategy & 2899 & $6786 \%$ & 0016 & 2996 & 1281 \\
\hline $\mathrm{A}$ & Inpprovement of strategy & 2370 & $6052 *$ & 1294 & 2262 & 1831 \\
\hline 15 & reatoning about strategy & $4638 * \%$ & $4016^{\circ}$ & 0802 & 3182 & 3239 \\
\hline E6: & feedback about strategy & $5074 *$ & 4308 & 0149 & 0159 & 3699 \\
\hline E7 & quality of feedback & $5082 *$ & $6463 *$ & 1045 & 0550 & 2081 \\
\hline 86 & mprovement of insight in game & $.7850^{*}$ & 2799 & 0509 & 0178 & -0001 \\
\hline 69 & read the manulal & 1307 & 0226 & 0452 & 8001 tem & .0288 \\
\hline Elo & nantal quality. & 1526 & 0226 & 0472 & 7828 & -1482 \\
\hline EII & explanation game leader & 3220 & $5646 *$ & 1227 & 1951 & -1622 \\
\hline $\mathrm{E} 12$ & firuendiness computer program & -1562 & $7413 *$ & 0295 & 0657 & -1583 \\
\hline $\mathrm{E} 13$ & computer program too slow: & .0363 & $-4937 *$ & $-4507^{\circ}$ & $3 \longdiv { 2 8 }$ & .0697 \\
\hline D14 & good infornation from program & .1432 & 1621 & 3043 & 1902 & $-5673^{* *}$ \\
\hline E15 & made tables myself & .0469 & .2425 & $3544 \%$ & .0248 & $635^{*}$ \\
\hline $\mathrm{B16}$ & manly used main nenu. & -0794 & 1079 & 0315 & 0528 & $-8330 \%$ \\
\hline E17 & too mueh intormation & .1211 & .0022 & $-3525 \%$ & $5260 *$ & 0156 \\
\hline E18: & cooperation was valuable & .1888 & $1627 \%$ & 1217 & 1687 & -1310 \\
\hline $\mathrm{B19}$ & wo half day usefiul & .1979 & 1516 & 3662 & 2528 & $4570^{\circ}$ \\
\hline $\mathrm{B} 20$ & game was organized well & $.4357^{\circ}$ & $5386 \%$ & 1844 & -.0354 & 0144 \\
\hline E21 & game was too difficult? & 0133 & $7202 \%$ & .0914 & 2610 & 0145 \\
\hline 22 & If platyed the game seriously. & 2533 & 0373 & 7627 * & 1164 & .1823 \\
\hline E23 & game was interesting & 2613 & 0795 & $8210^{1 *}$ & 1236 & -0471 \\
\hline 124 & Tleamed a lot from the gane & $.7155^{*}$ & 1329 & $4699 * 4$ & 0002 & 2344 \\
\hline $\mathbb{E} 25$ & game useful in course & $.6453^{*}$ & 1415 & 4345 & 1892 & 1203 \\
\hline $\mathrm{E} 26$ & insight of economy inproved. & $.8075 \%$ & 3088 & 1116 & 0366 & 1695 \\
\hline E27 & menagement and economics & .7797 * & -0495 & 1754 & 0148 & .2085 \\
\hline E28 & game related to prior knowledge & $6120 \%$ & 2836 & 2667 & 1170 & 2766 \\
\hline E29 & easier to ajpply mucroeconomics & $.60007^{* k}$ & .1303 & $5383^{*}$ & 0.0634 & 0.0293 \\
\hline E30 & selfstudy indiuced by game & 4708 *a: & -0423 & .1185 & 1899 & $\$ 0914$ \\
\hline E31 & game repeated & 3116 & 3461 & $6005 *$ & 3123 & 0603 \\
\hline E32 & interest in the economy enlarged & $3520^{*}$ & $3682 \%$ & $5146 \%$ & .0021 & -0437 \\
\hline E33 & theories of first year applied & $.5190 * *$ & 1724 & 1996 & 0554 & $.4124 *$ \\
\hline
\end{tabular}

Nof cases: 44 l-tailed Signif $* .01$ * $^{*}$ - -001

Table 7.3 Correlations between factors and the questions of the questionnaire 1992.

(21), but only in 1992 to the evaluation of the explanation by the game leader (11). This may be explained by the increase in standardization of the evaluation. Fourth, where in 1993 preparation of students $(9,10)$ was in the same factor as interest in the game $(23,31)$, and evaluation of the feedback about the strategy $(6,7)$, this relation was absent in 1992; in 1992 preparation was only related to the ability to handle information in the computer program (17).

In summary, the two factor analyses of the questionnaires are consistent. This gives some confidence in the results. Furthermore, it is possible to interpret the factors. They consist of general appreciation, theory-relatedness, strategic capability, preparation and informational activity. The difference in the loadings of the fifth factor (informational activity) may be explained by the improvement of the exercises and the organization of the information in the game. The improvement in the organiz- 


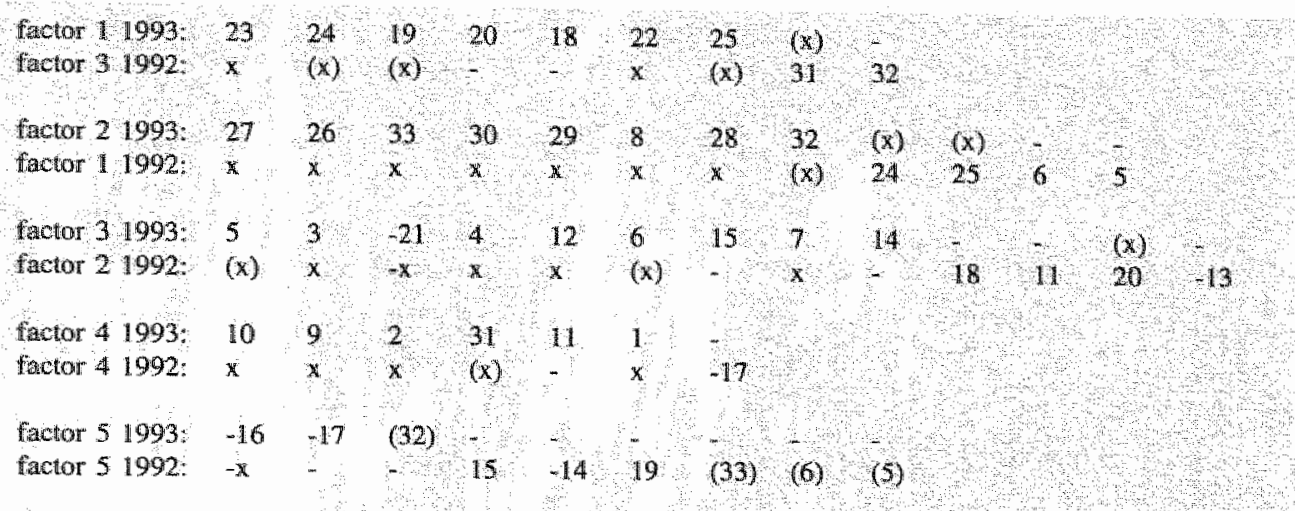

Note: all the main factor loadmgs are included; the numbers nefer to the numbers of the guestions on nimus

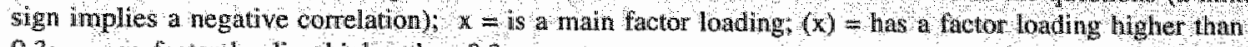
$0.3:-$ no factor loading higher than 0.3 .

Table 7.4 Relation between the factors of 1992 and 1993.

ation of the game not only resulted in a better participation rate, but generated also a stronger relation between preparation and satisfaction, and made strategy and information use less dependent on the game leader.

\subsubsection{The overall test after the game}

When students play the game, they should learn something. But because students played the game over only two half-days, it cannot be expected that this can be measured easily. Nevertheless, the results of an examination test may generate some information about the students who participated. Therefore, we analysed the results of an examination test, the so-called Overall Test (OAT), that the students made a short period after the game. This analysis will be related with the game in the next section.

The purpose of the OAT is to test the ability of students to apply knowledge in practical situations, the ability to integrate different disciplines, and the problem solving skills of students (see Tempelaar, 1993:365). The OATs of: 1992 and 1993 consist of 12 and 13 open questions and 57 and 49 closed questions respectively about finance, accounting and macroeconomics. The closed questions are of the "correct?/incorrect' type. The questions are organized around a number of articles that are handed out some weeks before the test. In 1992, 341 students udertook the test, in 1993,354 . Tempelaar (1993:387) shows with the help of factor analysis on a cross section of the OAT and other tests that wo factors can be distinguished. He labels them as representing "passive knowledge" (related with the closed questions) and 'active knowledge' (related with the open questions).

Tempelaar used only the aggregate scores on the open and closed questions of the tests. I made a factor analysis on a more desaggregated level (table 7.5); the average scores per article or group of articles about the same topic. Table 7.5 shows that most 


FACTOR 1
(applid
knowledge)

Table 7.5 Rotated Factor Matrix of the OAT 1993.

open questions load on the first factor, where the closed questions are distributed over the second and third factor. Appendix 7D shows the allocation of the separate queslions over the question groups and the correlation coefficients of the separate questions with the factors.

Appendix 7D shows that the first factor consists of all open questions, and a sample of the closed questions (especially questions $7-11,13,17$ and 19 remain in this factor when different samples of the students are used). Question 7 is about the relation between tax rate and government deficit, 8 about a-cyclical fiscal policy and government deficit, 9 and 10 about monetary finance of government deficits, the LMcurve and national production, and 11 about the development of the monetary deficit. Question 13 is about the definition of zero-coupon bonds, 17 about the relation between the yield curve and an inverse interest structure, and 19 about the multiplier and the openness of an economy. All those questions require a basic knowledge of macroeconomics in combination with the ability to reason about it. When we acknowledge that all open questions are included in the first factor, this dimension seems to measure the ability to apply basic knowledge.

The second factor has a significant positive correlation for question about costs 
and benefits of selecting convertibles (i.e. questions 28-31) or borrowing money (24), and the effect of inflation on valuation methods of stock (LIFO, FIFO, replacement value). All those questions require only elementary concepts in combination with logical thinking. The factor has a significant negative correlation for questions 41 and 42 about the application of detailed knowledge about formal accountancy rules. This factor may be called logic without knowledge.

The third factor consists of a group of closed questions about different risk measures (betas; questions 25-27), two open questions (O10 and Ol1) requiring detailed analysis of accountancy terms, and an open question about argumentations on wage restrictions $(\mathrm{O} 1)$. For all these questions detailed knowledge seems helpful. The factor is correlated negatively to closed questions 20-23 and open question 7, all about the economic value of a firm. Although these questions require knowledge, they require also a lot of insight. Therefore, this factor measures detailed knowledge without the ability to reason.

In summary, the factors found in the OAT can be interpreted. The first dimension of the OAT of 1993 mainly tests the ability to apply knowledge; this is the purpose of the test, and is consistent with the findings of Tempelaar (1993). This dimension scores high on the open questions. The second dimension is something like the ability to reason without much knowledge. The third dimension in the test measures detailed knowledge without ability to reason. This dimension scores high on closed questions. Therefore, this more detailed analysis of the OAT shows that Tempelaar's second dimension (i.e. the closed questions) does not represent 'passive knowledge'; the closed questions in the OAT distinguish mainly with respect to detailed knowledge and elementary logic without knowledge.

\subsubsection{Differences between OAT scores of players and non-players}

Because students played the game only two half-days, one cannot expect that significant differences can be found on a test about the contents of half a year. Nevertheless, such a test can be used to investigate which type of student participates in the game. Because the games were played in two half-days, the students can be divided in three groups: non-players, students who played only the first half day, and students who played both days. ${ }^{2}$ Table 7.6 shows all significant results of a regression analysis of the open and closed questions, organized by article. The OAT results are explained by participation in the first day and participation till the end of the game.

On a scale of 10 the score of students who showed up for the first session was 0.59 higher than the score of students who did not show up. The score of students who played the game till the end was 0.43 higher than those who disappeared after the first session. Therefore, where the students who did not show up during the game only had a score of 5.67 , those who came both sessions had on average a score of $5.67+0.59+0.43=6.69$.

The OAT results can be split up in open and closed questions. The difference between the persons only showing up the first session and the non-players was sig-

${ }^{2}$ The number of students who only played the second half day was very small. 


\begin{tabular}{|c|c|c|c|c|c|}
\hline $\begin{array}{l}\text { Dependent } \\
\text { Nartable }\end{array}$ & Indep & ndent variables & first game & $\begin{array}{l}\text { those } \\
\text { the qu } \\
\text { after }\end{array}$ & $\begin{array}{l}\text { who fi } \\
\text { iestion } \\
\text { he sec }\end{array}$ \\
\hline Endscore & 57 & (463) & $0.6 \quad(30) \%$ & 0.4 & $(2.0)^{*}$ \\
\hline Open & 234 & $(292)$ & $42(32) \cdot$ & 20 & (15) \\
\hline Closed & 18,3 & $(29.6)$ & $15(15)$ & 28 & $(26)^{*}$ \\
\hline Factor I & 0267 & $(34)$ & $0.29(23)^{2}$ & 0.33 & $(24) *$ \\
\hline Open1 & 3.6 & $(216)$ & $02 \quad(0,8)$ & 0.8 & $(2.6)^{*}$ \\
\hline Open 3 & 60 & $(23,5)$ & $11(26)^{*}$ & 0.5 & $(1,3)$ \\
\hline Open6 & 4.3 & $(18.2)$ & $13(3,1)^{*}$ & 0.1 & $(0.3)$ \\
\hline Opent & 11 & (6.9) & $09(3.6)^{2}$ & $-0,2$ & $(0.8)$ \\
\hline Closed2 & 28.6 & $(108.5)$ & $02(04)$ & 11 & $(2,3)^{*}$ \\
\hline Closed6 & 93 & $(66.3)$ & $0.5(2,3)$ & 02 & 00 \\
\hline Closed8 & 3.8 & $(40.9)$ & $-02(12)$ & 0.4 & $(2.7)^{*}$ \\
\hline Open2 & 42 & $(26,2)$ & & 0.84 & (29) \\
\hline Closed9 & 16.3 & $(118,2)$ & & 071 & $(29)$ \\
\hline
\end{tabular}

COpen = open questions in the OAT, Closed = closed questions in the OAT, except for the constant tem, significanl coefficient on a $5 \%$ level are marked with an *)

Table 7.6 Regression coefficients of OAT93 scores with respect to game participation (t-values between brackets; only the question groups with at least one significant coefficient are presented)

nificant for the open questions, but not for the closed questions, while the result on the closed questions was especially high for students who played till the end.

It is surprising that only the first factor of the OAT shows significant coefficients for participation in the game. This implies that game participation is influenced by the ability to apply basic knowledge, but not by the ability to reason without knowledge or the amount of detailed knowledge students show on the OAT.

It is interesting that question groups differ in the extent to which they are explained by game participation. It is fascinating that for most questions except open2 and closed 9 either participation in the first game or participation in the second game is significant. Students who showed up at the first session had a significantly higher score than non-players for open question groups 3,6, and 7, and closed question group 6. For open question group 1 and closed question groups 2 and 8 students who finished the game had a higher score than those who did not.

Open question group 2 and closed question group 9 have a special result in that only the combined effect of the two half-days was significant (where the second game is about $70 \%$ of the coefficient). Closed question group 9 was a set of questions about the game. Therefore, this result is evident and holds especially for questions 43,46 and 48 (question 49 has a negative relation with the first day players!). A more detailed examination of the questions shows the following results. Question 43 is about stmctural unemployment, an explicit exercise in the game, where question 44 
(without correlation) is about cyclical unemployment, not included in an exercise. Question 46 is about the relationship between market share and relative prices; this is an assignment during the game. Therefore, it is not surprising that especially the more experienced students are able to answer this question. Question 48 is about the relation between the business cycle and the delivery time of machines, something that can be perceived directly during the game. Question 49 is about the behaviour of demand for consumer goods compared with investment goods in a recession. This is not a part of a one-sector game. Students who played the game answered this question more frequently than the other students, but gave the wrong answer. Open question group 2 was about the application of IS-LM analysis to the real world. Therefore, it required both knowledge of macroeconomics and the ability to reason with it.

If this interpretation is correct, the game selects those students who are motivated to acquire detailed knowledge for the $\mathrm{OAT}$, and are analytic enough to reason with this knowledge. The more industrious students show up during the first game, while only students who have a combination of intelligence to interpret the results of the game and are industrious enough to invest an extra half day in the game show up the second day.

Let us now investigate the group of students who finished the game. Table 7.7 investigates the correlation between the factor scores of the OAT and the questionnaire for 1993 . First, preparation for the game is correlated significantly with the OAT dimensions 'ability to apply knowledge' and 'detailed knowledge'. The net effect is a positive correlation with the total score. This is not a surprise. Second, the table shows a correlation between the informational activity dimension of the game and the knowledge dimension of the OAT. This is also obvious. Third, and this is not clear a priori, the informational activity has a negative correlation with the dimension of the OAT that measures the ability to apply knowledge. This suggests that students who search actively for detailed information have difficulty in interpreting the information. It appears that they look for specific information in the text of the OAT articles, but are not able to apply it. The net effect on the total score is negative. Fourth, and this is very surprising, none of the first three factors of the questionnaire have a significant relation with the factors of the OAT or a subset of questions. So, neither the general appreciation, nor the ability to relate the game to theory, nor the ability to improve strategy has a relation with the OAT. This is a disappointing result.

In summary, the factors distinguished in the OAT behave differently with respect to the factors of the questionnaire. Especially, the students who were better prepared for the game, were also better prepared for the OAT. The students who searched more for information during the game were students who were able to answer questions requiring detailed knowledge in the OAT. But those students did not have higher scores on the OAT because they had difficulties in the application of their detailed knowledge. Perhaps these students are inclined to take on an overload of information.

\footnotetext{
${ }^{3}$ This shows that the differentiation in dimensions gives more information about the sludents than the end-score of the test.
} 


\begin{tabular}{|c|c|c|c|c|c|c|}
\hline & $\begin{array}{l}\text { FO1 } \\
\text { (anplications }\end{array}$ & $\mathrm{FO}$ & FO3 & open & Closed & Soore \\
\hline 1 (appreciatiran) & 00733 & 1275 & 0915 & 00707 & 0316 & 0592 \\
\hline FE? (theory) & 0044 & -0172 & 0490 & 0171 & 0390 & -0264 \\
\hline Hes (strategy) & -1401 & -0247 & -0521 & -1033 & -1827 & -1569 \\
\hline FA (preparation) & $1784 *$ & 1063 & 2267 & $2292 \cdot$ & 2599 \% & $2963^{* * *}$ \\
\hline FES (information) & -1928 & 4159 & $2008 *$ & 1602 & $2558 * *$ & $2781 \%$ \\
\hline
\end{tabular}

E1 FES represent the Iive factors of the questionnaire. $\mathrm{FO}-\mathrm{FO} 3$ represent the three rotated factors of the OAT Number of casest 104 -tailed Signift $* 05$

Table 7.7 Correlation between the factors of the OAT and the questionnaire, 1993.

\subsubsection{Conclusion}

The research methodology used in this section seems fruitful for analysing the effectiveness of teaching. This methodology consists of the following steps:

1. Frequency distributions of the questionnaire

2. Factor analysis of the questionnaire

3. Factor analysis of the test

4. Correlation analysis of the factors of the test and the questionnaire.

5. Regression analysis of participation in teaching and factors and groups of questions of the OAT.

Analysis of the questionnaires reveals five dimensions (i.e. appreciation, relation with theory, strategy, preparation and information), that are consistent over the two questionnaires. This implies for example that the appreciation of the game is independent of the ability to relate the game to economic theory, and that the ability to improve strategy is not related to appreciation, but highly related to the feeling that the game is easy and the active use of tables. The factor 'preparation' shows that the perceived quality of the manual is highly related to preparation and satisfaction about the game.

In the OAT three dimensions can be distinguished (i.e. application of basic principles, detailed knowledge and logic without much knowledge). The dimensions 'application' and 'knowledge' behave differently with respect to the use of information in the game, where only the first dimension is found to have an impact on the scores of the student. This shows the relevance of factor analysis of questionnaires and examination tests. 


\subsection{A short introduction to economics with the help of the game}

\section{3 .1 Design of the course}

Students studying a programma in culture and science get an introduction in economics in only 24 hours (including class and study at home). The purpose of this course is to give students an intuition for economic thought. For the students who had economics at high school, the focus of the course is on the application of principles learned at high school. For the other students it was an extremely short introduction into the world of economic thought. Economics is presented as a theory about decision making of human beings.

The course started with an introductory lecture about economics and cost-benefit analysis. It was focused on the principle of opportunity cost, and discussed the difference between fixed and variable cost as well as marginal and average cost. A week later students applied those principles in the game. The second lecture focused on market competition. Theory was applied to data of the game as well as of the real world oil market in the 1970s. The third lecture focused on the fundamental macroeconomic coordination problem (see chapter 1). The theory was illustrated witl the recessions of the $1920 \mathrm{~s}$ and 1930 s. With this knowledge about competition and macroeconomics in mind students played the game a second time. The focus was on the macroeconomic assignments discussed in chapter 6. Finally, the last lecture was devoted to macroeconomics. The development of the game was compared with macroeconomic development of the Netherlands between 1960 and 1990 .

During each lecture, students got an assignment. In the first lecture students had to read a story about the economic situation of an unknown economy called Utopia. After reading this story they had to write down everything they remembered from the story and to characterize the situation of the economy. In the second lecture (about competition) they were asked for the best policy of the firm in a specific recession of the game economy. In the third lecture (about macroeconomics) they were asked to recognize periods of structural unemployment in the data of the first game. During the last lecture the assignment of the first lecture was repeated. The comparison of the results of the assignments of the first and last lectures are used to measure the effectiveness of the programmame.

\subsubsection{A test for pattern recognition}

After a course in economics you may hope that students are able to recognize patterns in economic data. To test this capability a pattern recognition test has been developed. A sketch of a country is presented to the students (see appendix 7B). The students get 75 seconds to read the text. Then they are asked to recall everything they remember. Finally, they are invited to characterize the situation of the economy. The students had to do those tests as assignments during the first and last lecture. Two different cases were presented to the students. Case $\mathrm{A}$ is about an economy at the end of a boom

${ }^{4}$ The design of the test has been developed in collaboration with Wim Gijselaers. 
with signs that a recession approaches, and case B is an economy in a deep recession with bad short term perspectives. Students were allocated randomly over the two cases. The analysis of the two cases will be presented in two steps. If the discussion is limited to one case, case $\mathrm{A}$ is used.

First, the answers on the test have been categorized with respect to the information in the text that is recalled. The information consists of two parts: institutional and economic. The topics distinguished in case $\mathrm{A}$ are:

\section{Institutional:}

- Utopia is a democratic country

- labour unions are important

- labour unions are reasonable

- Central Bank is formally independent

- Central Bank can be influenced

Economic:

- unemployment rate is low but rising ${ }^{5}$

- national product is growing

- consumption is growing

- labour productivity has increased

- stocks are rising

- delivery time of machines is high

- delivery time of machines has decreased

- inflation is rising

- prices of investment goods has risen more than those of consumption goods

- labour cost has risen more than labour productivity

- employers report that their profits are low

- the nominal interest rate was increased half a year ago.

Table 7.8 shows the percentage of student recall after reading the text. The table shows that the recall of students in culture evolved from institutional towards economic between the first and last lecture. As a comparison the test has been done with economics students and university teachers. Table 7.8 shows that the economics teachers and fourth year students in economics were more institutionally oriented than the students in culture and the first year students in economics. This suggests that at the beginning of their study students are focused on economic variables, while more advanced students and teachers are aware of the important role of institutions.

A significant difference is found between the amount of recall of case $A$ and $B$. For case B much more of the economic part is recalled in all groups, where for most groups recall is also higher for the institutional part. This may be explained by the greater complexity of case A compared with case B. Where case A describes a turning point, case $B$ is about an economy in the middle of a recession. Recall becomes easier when it is easier to relate the data. Second, when the economic data are clearer, more memory is available for the other data. This may explain the better recall of the

"In the first cases this was incorrectly represented. 


\begin{tabular}{|c|c|c|c|c|c|}
\hline & $\begin{array}{l}\text { calcunat } \\
\text { first } \\
\text { lecture }\end{array}$ & $\begin{array}{l}\text { econon } \\
\text { second } \\
\text { lecture }\end{array}$ & thrst & $\begin{array}{l}\text { mucro } \\
\text { rounth }\end{array}$ & $\begin{array}{l}\text { howncs } \\
\text { texishers }\end{array}$ \\
\hline Assigmment A & $(n=17)$ & $(0-2)$ & $(\mathrm{n}=11 \mathrm{~s}$ & & $(n=6)$ \\
\hline Institutional & $48 \%$ & 390 & $50 \%$ & 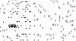 & 700 \\
\hline economice & $26 \%$ & $36 \%$ & $40 \%$ & & $49 \%$ \\
\hline Assignmerit B & $(m-16)$ & $(n=17)$ & $(\mathrm{g}=\pi 0)$ & $(n-7)$ & $(1=6)$ \\
\hline mostitution & $58 \%$ & 436 & $44 \%$ & $86 \%$ & $77 \%$ \\
\hline economic & $40 \%$ & $51 \%$ & $63 \%$ & 510 & $57 \%$ \\
\hline
\end{tabular}

Notes percentages of the total number of facts that are nenenoned

Table 7.8 Recall of the details of two assignments.

institutional data in case $B$.

The second step in the analysis of the Utopia cases is the characterization of the economy. After students finished the recall assignments they were invited to characterize the economy in a few words. In case $A$ the situation in Utopia can be interpreted as follows. The high inflation rate, the high delivery time of machines, and the small stocks show that the economy is in a boom. But the rise of stock and decline in delivery time of machines suggest that the boom is reaching its end. Because during this boom labour cost have risen more than labour productivity, profits have declined. Structural unemployment will be the long term consequence. The recent rise of the nominal interest rate may be caused by an attempt of the Central Bank to stop the acceleration of inflation and the rise in structural unemployment. The high real interest rate is a sign of a tight monetary policy. This seems necessary because half a year ago the real interest rate was $-5 \%$. It has risen to $10 \%$ during the last half year. One may expect a decline of investment at such a high real interest rate; this explains the declining delivery time. In summary, after a soaring boom a severe recession may be expected.

Table 7.9 shows that most students in culture perceive the economy as okay when they start the course. In the last session of the course they recognize the emerging problems. This improvement of the recognition of the situation in such a short course is remarkable. It shows that before the course most students only perceived the surface: everything seemed to be okay. But after the course most students recognized. that the boom would become a recession. This result is consistent with the purpose of the course.

In contrast to the students in culture at the end of the course, less than half of the students in economics recognized the signals of a recession. But surprisingly, also teachers in (macro)economics do not seem to perform well. Teachers do recognize the boom, but only two recognize the recession. This may be caused by the design of the cases according to the theories discussed in chapter 1 instead of mainstream theory. But perhaps it is related to the fact that observation of some authors that the professional focus is on technical research. For example, Kasper et al. (1991:1105) conclude that most teachers in the US have specialized in the few topics related to their dissertation, but have an inadequate grasp of the broad material to be taught in junior 


\begin{tabular}{|c|c|c|c|c|}
\hline 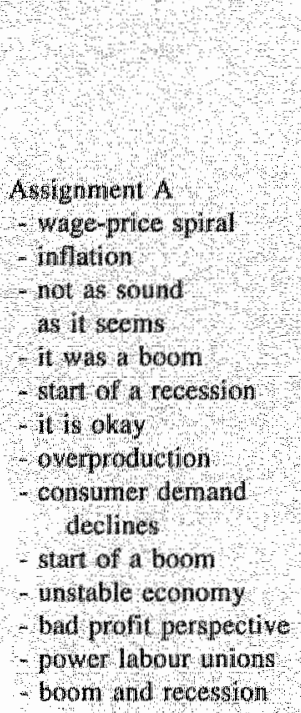 & $\begin{array}{l}\text { cullural } \\
\text { students } \\
\text { frst } \\
\text { lechure } \\
(n-17) \\
2 \\
2 \\
2 \\
2 \\
7\end{array}$ & $\begin{array}{l}\text { eulural } \\
\text { students } \\
\text { second } \\
\text { lecture } \\
(\mathrm{n}=21) \\
2 \\
1 \\
8 \\
5 \\
1\end{array}$ & $\begin{array}{l}\text { ecomonises } \\
\text { students } \\
\text { first } \\
\text { year } \\
(n-11) \\
1 \\
2 \\
1 \\
1 \\
3\end{array}$ & $\begin{array}{l}\text { Macroeconomics } \\
\text { teachers }\end{array}$ \\
\hline
\end{tabular}

Table 7.9 Characterization of the economy assignment A.

courses. Hansen (1991:1086) recognizes that "academic economics and graduate training have become increasingly preoccupied with formalism and technique, to the exclusion of studying real-world problems and issues that can be illuminated by some blend of theoretical, empirical, and institutional research". Krueger et al. (1991:1039) perceive the underemphasis on the linkages between tools, both theoretical and econometric, and real world problems as the weakness of graduate education in economics. Although drawing strong conclusions out of the simple pattern recognition test is preliminary, the results are not inconsistent with this view on the economics discipline.

\subsubsection{Concluding comments}

The pattern recognition test for phases of the business cycle is a first step towards measurement of pattern recognition skills. Although the open recall test has an advantage that the subjects are not forced into a line of thought, the openness has also disadvantages. Recall of the data provides information about what one remembers, but it can be influenced by other factors, too. For example, what a subject writes down can be biased by the perception of what the experimenter expects. A multiple choice test may be an alternative or an extra source of information to test recall.

The results of the pattern recognition tests show the potential of this instrument to measure the skill to interpret logically related data, and perhaps even to measure the approach in the economics profession. The results imply that the combination of the game and the lectures resulted in a noticeable improvement in recognizing and interpreting business cycle data. The comparison with first year economics students shows 
1 . Scarcity, cost, comparative advaniage, Pareto mprovement

2. Demand, supply sompetition

3. Extenalutes and he prisoners dilemma

4 Money and nnlation

5. Classical and Keynesian unemployment in the 1920 and 1930

6. Shruchral and cyclical unemployment benween 1945 and 1990

7. Mncome distributon and social security

Table 7.10 Topics discussed during the lectures for law students

that their recall is less, but the interpretation of the situation in the business cycle is better. Comparison with experts in economics and advanced students shows that expertise is related with a greater emphasis on institutional factors.

\subsection{An introductory course in economics for law students}

\subsection{Design of the course}

The course in economics at the law faculty is an introduction in economics of 100 study hours. The purpose of the course is the training in economic thought. This implies that students must learn to recognize economic principles in the real world. Therefore, the course focuses more on economic concepts than on formal analysis. It consists of five teaching devices. First, a syllabus is used as a textbook. Second, students discuss in teaching groups of about 12 students problems about economics, political philosophy, and the history of the Netherlands. All problems about economics are related to historical situations. For example, market theory has to be used to explain the low wages in the 19th century, externalities are applied on a case about pollution in Amsterdam in the 19th century, Classical and Keynesian theories of the business cycle are applied on the 1920s and 1930s, and developed further on the period after the Second World War. This last period is also used to explain the difference between structural and cyclical unemployment.

Third, seven lectures in economics were arranged to help students to organize their thought about economic theory (table 7.10). Fourth, during the session after the fifth lecture, students were invited to play the macroeconomic simulation game. Finally, 12 computer modules have been developed to help students to apply economic principles to historical cases (see table 7.11). Those computer modules consist of multiple choice questions and simple open questions that are checked by the computer. After the check the correct answer is explained. ${ }^{6}$

As already addressed implicitly, the theory is illustrated by real world examples. The number of examples on macroeconomic theory of the business cycle is much higher than on other parts of the course. Therefore, we expect that the students have

${ }^{6}$ The computer program used has been developed by R. Pinckaers and J. Schöpping. The texts have been developed by Geert Woltjer. 
1. Scarcity, ownerhop und the development of nations

2. Costs and beneluts fin fims

3. Demand, and supply in the oil manket

4. Competition, Adam snith and the mik markes

$5 . \quad$ Externallues and fishery

6. The histery of mioney

73 Money and the chassical ex phantion of the recession in the 1920 s

8. A monetarist explatuation of the crisis in the 1930 s

9. A Keynestan explanation of the crists in the 1930

10 , The Wetherlands in the 1950 s:

11 . The Netherland in he $1960 \mathrm{~s}$ and $1970 \mathrm{~s}$

12 The Netherlands in the 1980 s

Table 7.11 The contents of the computer modules

learned to recognize theoretical issue behind surface features relatively well, especially when the business cycle is concerned. In this section a test is developed to investigate the conceptual capabilities of the students. But first the economics part of a test after the course will be analysed and related with data from a questionnaire.

\subsubsection{Test score and participation of students}

During the last lecture in economics 44 students filled in a questionnaire about their participation in the course. A few days later all students took a multiple choice test on economics and other topics of the course (history and political philosophy). The economics part of this test was covered by questions 25 to 48 . Just as the OAT in section 7.2, the test was analysed by factor analysis. The multiple choice character of the test gave the opportunity to investigate to what extent specific errors were related to specific factors. Third, regression analysis was applied to investigate the relation between the factors and participation in the course.

The general characteristics of the economics part of the examination and the questionnaire are as follows. Out of 24 questions the mean number of questions on economics that were answered correctly was 15.34 for the students that filled in the questionnaire. The average number of hours studied was 5.32, while the students were expected to studly about 10 hours. ${ }^{8}$ Both are very low. ${ }^{9}$

Table 7.12 shows the results of a regression analysis on the economics part of the test ( 24 multiple choice questions) and the educational activities of the students. It shows significant coefficients for 'hours of study economics' (three hours of study

\footnotetext{
"The standard error was 0.419 , the standard deviation 2.96 . With 24 questions one may expect that by chance 8 questions will be answered correctly. Therefore, the level of knowledge is $7 / 16 x$ $100 \%=45 \%$. When you set the minimum level of knowledge at $55 \%$, the minimum acceptable score is 17 .

The standard error was 0.354 , the standard deviation 2.55 .

${ }^{9}$ The low number of hours sudied may be explained by the high study load of a parallel course and the fact that the test on economics of the year before was too easy.
} 


\begin{tabular}{|c|c|c|c|c|c|c|}
\hline Dependent & Independent & ables \&C & coeffic & sin 1 - values bet & en brackets; & 4)) \\
\hline & constant & $\begin{array}{l}\text { hours } \\
\text { of study }\end{array}$ & & 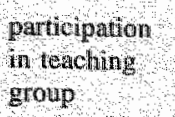 & $\begin{array}{l}\text { ganie } \\
\text { participation }\end{array}$ & $\begin{array}{l}\text { partieipation } \\
\text { in lectures } \\
\text { in economirs }\end{array}$ \\
\hline $\begin{array}{l}\text { hotal score } \\
\text { factor: }\end{array}$ & $717(2,4)$ & 035 & $(2.2)$ & $0.42(2,3)$ & & \\
\hline - I (knowledge) & $-180(2.7)$ & 008 & (22) & $014(31)$ & & $1011(17)$ \\
\hline 2 (analytical) & $00,02(0,1)$ & & & & $66(24)$ & $[0.1111,6)]$ \\
\hline-3 (high school) & $0,38(1,3)$ & 011 & $(-23)$ & & & $1-014(-19)$ \\
\hline
\end{tabular}

Table 7.12 Explanation of examination result.

increases the score by one) and 'attending the student group' (attending an extra session results in a rise in score of 0.42 ). This implies that attending the student group during all 16 sessions results in 6.7 points, and studying 10 hours economics outside the groups and lectures gives 3.5 points. Because the number of points without preparation is 7.2 , the score with 10 hours of study and attending all teaching groups is 17.5 points. The other coefficients (attending lectures, doing computer modules, playing the game, and knowledge of economics at high school level) are very low and insignificant." This implies that no relation can be found between economics at high school level and the score on the test, even when it is corrected for hours of study"

A factor analysis on the test results shows three factors. After analysis of the specific questions included in the factors, the following interpretation of the factors is the result. The first factor may be called specific knowledge. The second factor shows analytical skills in combination with a good basic knowledge of the economic theory of the course." The third factor seems to represent high school knowledge (with a Keynesian bias) in combination with some ability to reason logically.

Regression analysis of the test results on questionnaire data is useful to test the interpretation of the factors and to investigate the benefits of different activities of students. It shows the following results (see table 7.12). First, factor 1 is the best explained factor and, just like the general score, it is highly correlated with hours of study and attendance of the teaching group. It is not surprising that the more industrious students have better knowledge. Factor 3 is related negatively with hours of study and attending economics lectures; the correlation coefficient with high school aconomics is rather high $(\mathrm{r}=0.27 ; \mathrm{p}=0.06)$. This is consistent with the interpretation that this factor represents students who rely on their high scllool knowledge and therefore do not participate in lectures and do not study enough. Finally, factor 2 is correlated

The score of 7.2 would be the result when all questions were answered randomly.

1) An almost significant correlation can be found between hours of sudy and dolng computer modules $(t=0.27 ; p=0.061)$. Therefore, the effect of computer modules on the economics score $(r=.265 ; \mathrm{p}=0.068)$ is caught by the variable "hours of study" in the regression analysis.

12 The interpretation of this factor is less clear than that of the other two factors. Perhaps the varimax rotation method is not optimal for this factor, because most questions have other elements in combination with this factor. It may be that this factor is not onthogonal to the others. 
with participation in the game. One may speculate about a causal relation from game participation on the factor score, because in this factor at least three questions are loaded that can be answered from experience in the game (33a, 37b, 41b).

In conclusion, the method used in this section seems a fruitful approach in analysing the results of the teaching process. The steps used are:

- global analysis of participation and test scores

- factor analysis on the multiple choice test

- correlation analysis between factors and the separate options of each question.

- regression analysis between participation data and factors of the test.

The analysis shows that the factor analysis generates interpretable factors, which have a plausible relation with participation in teaching and high school knowledge. The results suggest that even a game played for half a day has some effects on the capabilities of the students; there may be a causal relation between game participation and some items in the test.

\subsubsection{A conceptual capability approach ${ }^{13}$}

In chapter 2 it has been argued that students have to learn to represent economic problems in terms of economic theory. Therefore, after attending a course, students should be able to conceptualize economic problems correctly. In this chapter an approach will be discussed that is inspired by Chi et al. (1981), who investigated the representation of physics problems by experts and novices. They define a problem representation as "a cognitive structure corresponding to a problem, constructed by a solver based on his domain-related knowledge and its organization" ( $p$ 122). It is generally acknowledged that the ability to solve problems is influenced by the quality of the problem representation. ${ }^{14}$ According to Reif (1979:1) the first step in problem solving is the redefinition of the problem in concepts provided by a knowledge base that is arranged around problem schemata containing information to solve a specific category of problems. ${ }^{15}$

Chi et al. (1981:124) developed a method to investigate problem representation by novices and experts in physics. They took a number of textbook exercises and wrote them on cards. They asked subjects to sort the cards in groups based on similarities of solution, and to explain the reasons for their groupings. First, they found that experts needed much more time to sort the problems (for 24 cards the experts needed 18 minutes compared with novices 12 ). ${ }^{16}$ Second, the explanations about the categories revealed that the experts used categories around underlying physical principles, while

\footnotetext{
13 The design of the approach has been developed in collaboration with Wim Gijselaers.

"Hayes and Simon (1976), Newell and Simon (1972), Simon and Simon (1978); see Chi et al $(1981: 122)$.

${ }^{\text {is }}$ Hinsly, Hayes and Simon (1978) found that college students categorize algebraic problems that are formulated in nomal language quickly into types. This suggests that problem schemata exist. See Chi et al. (1981:123).

16 The rumber of categories did not differ much berween novices and experts.
} 
the novices used surface features for their groupings. The groupings of advanced students were somewhere in between ( $p$ 134). Therefore, this study suggests fundamental differences in the knowledge structure of novices and experts in physics.

Inspired by this approach we developed a similar research strategy for economics. As already discussed in chapter 2 , the application of basic principles in economics is less developed than in physics. Therefore, I developed a number of problems in which I saw a surface level and a deep (i.e. explanatory) level (see appendix 7C) ${ }^{17}$ For example, while questions 1 and 2 are both about unemployment (surface level), question 1 is about a monetary explanation, whille question 2 is about an explanation by structural adjustment. In my perception an organization of the cards at a deep level is as follows: ${ }^{18}$
A business cycle.
B. structural adjustment:
C. disequilibrium prices:
D. social dilenma
E. social choice:

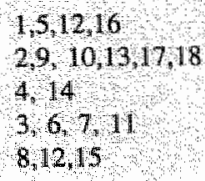

Table 7.13 Categorization of cards at a deep level.

where an arrangement at surface level is:
F. unemployment:
$1,2,3,14,16,17,18$
G. inflation
$4,5,7,12$
H. pollution:
$6,13,15$
I. protectionism:
$8,910,11$

Table 7.14 Categorization of cards at a surface level.

Because in economics there is not one sole deep level of analysis, the optimal order represents the opinion of one specific expert. Categories on a deep level refer to causal explanations, while categories on a surface level do not refer to explanations.

The subjects were asked to categorize the cards on similarities in the theory they would use to answer the question, and to label the categories created. The time needed for the task was registered. Four categories of persons were used for this categorization experiment: first year students in economics after a block of microeconomics and a block of macroeconomics (in total about 360 study hours), fourth year students in economics, university teachers in economics, and law students

${ }^{17}$ The reader can check the correctness of the categorization for himself. It will be clear that the choice of categories is partly related to the ideas about teaching discussed in chapter 2.

18 Card 12 can be both in category $\mathrm{A}$ and $\mathrm{E}$. 


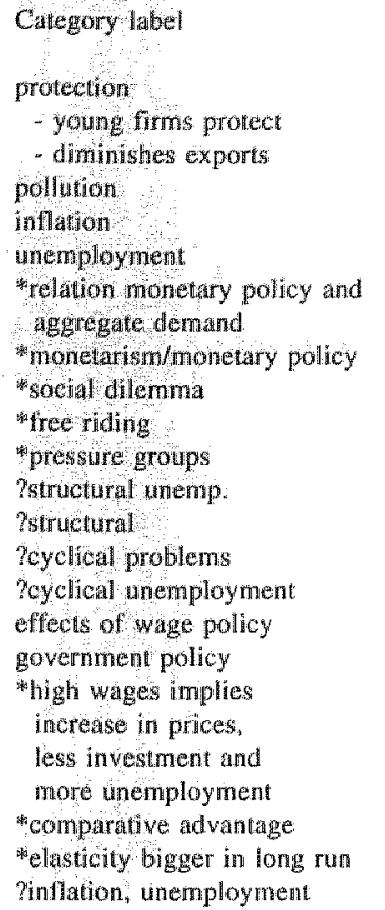

card numbers included

(2),37,8,9,10,11,(18)

89

10,11

$6,3,5$

$4,5,712,16$ ?

$1,2,3,14,16 ; 17,18$

\section{$1,42,5,12,16$}

$15,16(7 ?, 12 ?, 14 ?)$

$3 !, 6,7,1,13,15$

6,13

3,7

$2,32,10 \%, 14,15 \%, 17,18$

$1,4,7,12,14$

$1,3 ?, 4,5,11,12,16$

$1,14,16,17,18$

$1,4,5,7,12,14,16$

$1,4,12,16$ number of cards mentioned

$5,5,4,4,4,5,6,4,4,4,4,4,4,4,4,4,6,4$ 2

2

$3,3,3,3,3,3,3,3,3,3,3,3,3,3,3,3,3,2$

$3,4,5,4,4,4,5,3,1,2$

$6,5,7,4,4$

$5,3,2 \%, 3$

$2,3,6,3$

$5,1,1$

21

2.

$3,4,4,4,4$ ?

5

473,5

3,4

$7,3,4$

3,4

\section{$3,2,3$}

$2,2,3$

2

$\begin{array}{ll}13,14 & 2 \\ 4 ?, 1.2 & 2\end{array}$

times

mentioned

19

18

10

5

$4+4$

$3+2+1$

$5+1$

$3+2$

$3+2$

Table 7.15 Categorization by law students $(n=23)$

\begin{tabular}{|c|c|c|}
\hline Category label & Card numbers included & number of cards mentioned \\
\hline protection & $6 ?, 8,9,10,11,(18)$ & $4,3,4,5,5,6,4,4,4,4,5,4,5,4,4,2$ \\
\hline pollution & $3,(6), 13,15$ & $3,3,3,3,2,3,2,3,3,3,3,3,3,3$ \\
\hline tinemployment: & $1,2,3,7,12,14,16,17,18$ & $2,7,4,4,3,7,5,6,2,6,6,5,5$ \\
\hline inflation & $1 ?, 4,5,7,12,14 ?, 16$ & $4,4,4,2,5,4,6,2$ \\
\hline * monetary pollicy & $1,(4), 5,(12), 16$ & $2,2,3,5,5,3$ \\
\hline Wages & $2,3,4,5 ?, 7,14$ & $3,4,2,4,3$ \\
\hline wage & $37,47,12$ & 3,4 \\
\hline internationalisation of law & $2,6,(9), 13,(15)$ & 3,5 \\
\hline tusk government,prices & 6,15 & $2 \eta 2 ?$ \\
\hline $\begin{array}{l}\text { conseçuences of } \\
\text { econonic measures }\end{array}$ & $1,2,3,4,11,11,16,17,18$ & $3+6$ \\
\hline whiges and prices & $5,7,14$ & 3 \\
\hline $\begin{array}{l}\text { labour pioductivity } \\
\text { international }\end{array}$ & 14,17 & 2 \\
\hline chuses of unempl. & $2,17,18$ & 3 \\
\hline Pstruetural unemployment & $2,3,14,17,18$ & 5 \\
\hline how to dimimish unenaployment? & 12,16 & 2 \\
\hline government policy & 1,$12 ; 16$ & 3 \\
\hline
\end{tabular}

times

Table 7.16 Categorization by first year economics students after block $1.3 \quad(n=16)$ 


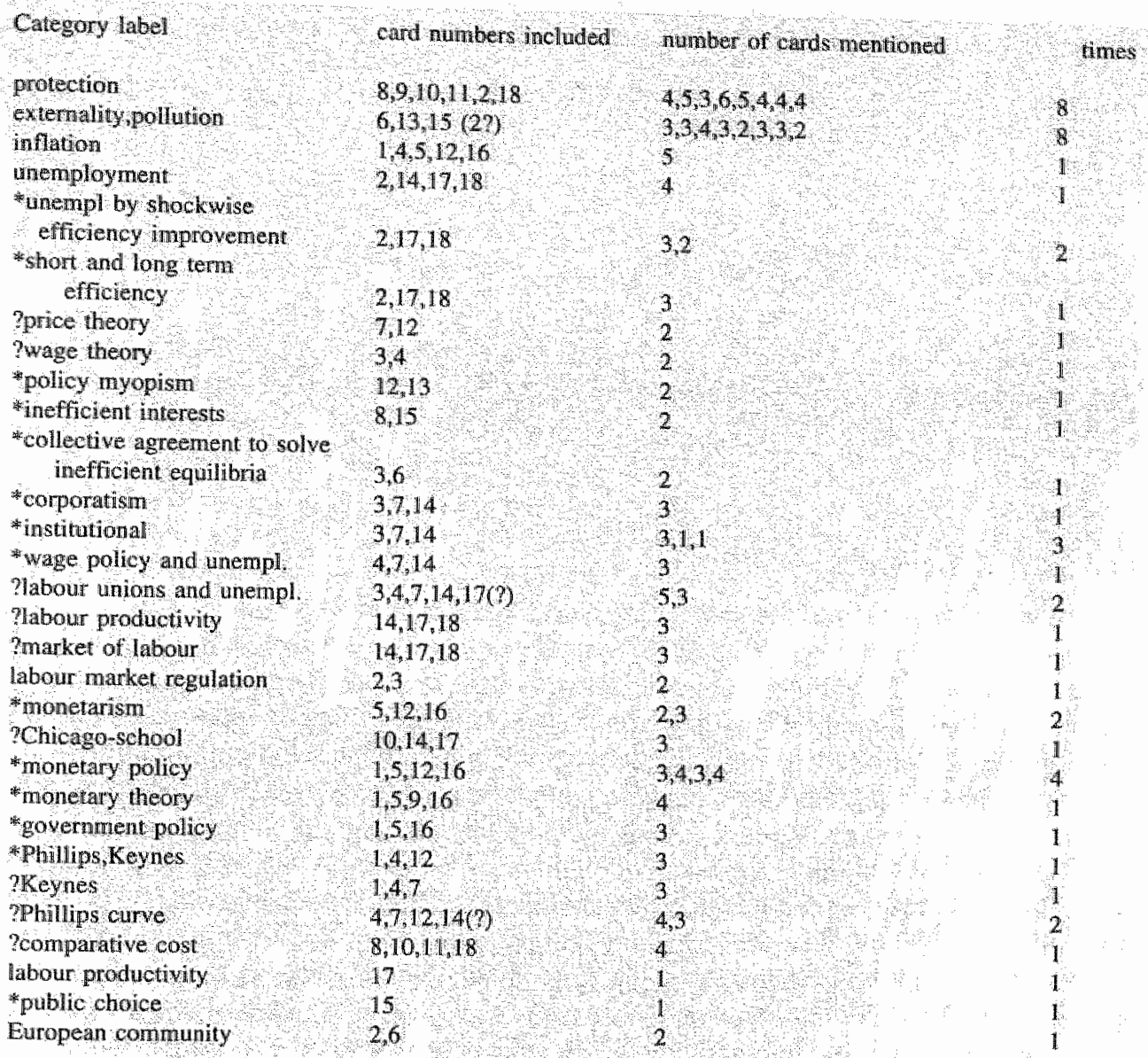

Tabie 7.17 Categorization by 4 th year economics students $(n=9)$

after the 100 hours course in economics.

In tables $7.15-7.18$ the categorization results are presented. The first four categories are the surface categories as defined in table 7.14. Some of the other categories are also based on surface characteristics. Those are presented without mark. The ones that may be at a deep level have a question mark, while the ones that are almost certain categories on a deep level are marked with an asterix. For example, question $S$ is about the relation between inflation and money supply. This refers to a monetary theory of excess demand, and therefore is comparable with question 1 about unemployment in the beginning of the $1980 \mathrm{~s}$. But it has nothing to do with question 4 that relates the low wages to anti-inflation policy, or with question 7 that is about social tensions as an explanation of inflation. So, although both questions 4,5 , and 7 are about inflation, they represent different mechanisms. When question 5 is included in a category called 'cyclical problems' this suggests a correct categorization. But when in the same category also question 4 is included (as some law students did), it 


\begin{tabular}{|c|c|c|c|}
\hline Category label & card numbers included: & number of cards mentioned & times \\
\hline protection & $8,9,10,11,2,8$ & $4,5,6,5,4$ & 6 \\
\hline externally, pollution & $6,13,15$ & $3,3,3,3,3$ & 5 \\
\hline fuflation & $57(4,12)$ & $2,3,2,2$ & 4 \\
\hline unemployment & $2,1,1,1,18(1,3,16,7)$ & 4,6 & $1(+1)$ \\
\hline tmonetary policy & $1,5,12,16$ & 3,3 & $2(+2)$ \\
\hline Thonetarism/neoclass & $5,4,16$ & 3 & 1 \\
\hline W monetaris / neoclas & $4,57,12,14,16$ & 6 & 1 \\
\hline Philtiss: & 7,12 & 2 & 1 \\
\hline Thnempl, cost & $2,3,14,17,18$ & 5 & 1 \\
\hline 7unempl, exogenoms & 17,18 & 2 & 1 \\
\hline Tunempl, endogenows & $1,7,12,14$ & 4 & 1 \\
\hline institutional & 316 & 2 & 1 \\
\hline tbuireaucracy. & $8,13,15$ & 3 & 1 \\
\hline Tinstitutions & 3,4 & 2 & 1 \\
\hline nkeynes & 1,3 & $1,2,1$ & 1 \\
\hline ?coordination & $2,3,4,6,9,10,11,17,18$ & 9 & 1 \\
\hline tmeso-sector approach & 2,17 & 2 & 1 \\
\hline
\end{tabular}

Table 7.18 Categorization by macroeconomic uniwersity teachers $(n=6)$

is not clear that the subjects really had an explanatory principle in mind. In such a situation a question mark is used for the category. When the question is included in a category called "wages and prices", this is clearly a surface level. Then the category has no mark.

The first result is about the amount of time needed for the assignment. According to cognitive theory we may expect that subjects without much knowledge in economics do not need much time for the task because they do not see the problem. Advanced students see the problem, but have difficulties in solving it; therefore, they need a lot more time. Experts will need less time because much of the theoretical categorization proceeds automatically. The first year economics students needed on average 12 minutes (with only one of the sixteen students more than 15 minutes, i.e., 23 minutes), where the law students needed 17 minutes (where 14 out of 20 needed more than 15 minutes). Therefore, the time needed suggests that with respect to their ability to categorize law students after the principles-based course of 100 hours, were further than the first year economics students after their course of 350 hours (but we must remember that besides economic concepts students in economics learn a lot about formal theory). 


\begin{tabular}{|c|c|c|}
\hline & $\begin{array}{l}\text { number of categories } \\
\text { on a surface level }\end{array}$ & $\begin{array}{l}\text { number of items on } \\
\text { a surface level }\end{array}$ \\
\hline W sturdents & 2.2 & 8.6 \\
\hline st year economics: & 3.2 & 125 \\
\hline ourth year economics & 20 & 74 \\
\hline conomics teachers & 27 & 9.5 \\
\hline
\end{tabular}

Table 7.19 Comparison of level of analysis

The second result is about the depth level of categorization. It will be clear that the indicators used in the descriptions of the categorizations of table 7.15-7.18 are highly subjective. The least subjective check is to compare the number of items that are categorized in the four surface categories as defined in table 7.14. When we compare the results of macroeconomic university teachers, first year economics students, fourth year economics students, and law students, we get the general result that the 4th year students in economics have the fewest surface categorizations, where the first year economics students have the most. The law students and the university teachers are somewhere in between, although the law students categorize less on a surface level than the university teachers.

This result is very surprising. It may be explained as follows. First, university teachers and first year economics students spent much less time on the assignment. It may be that this is not caused by their ability to categorize on a deep level, but because they are more in a hurry when doing the assignment. ${ }^{19}$ Another explanation of the bad performance is that the economics profession has not a single generally accepted fundamental level of analysis. It may be that teachers categorize in a different manner than assumed in the categorization experiment.

The fact that law students after a short principles-based course categorize less on the surface level than first year economics students after a much longer course shows that the course induces a different manner of thinking. Although this demonstrate an effect of the teaching approach, this does not imply that the law students are better in economics. It is obvious that university teachers in macroeconomics are much better economists than law students after an introductory course in economics. Therefore, the test does not capture economic professionalism.

The third result is that some topics are more categorized on a deep level than others. Tables 7.15-7.18 show that protection and pollution are categorized by almost everyone on a surface level, where inflation and unemployment are easier to tackle at a deep level. One third of the first year students in economics and the law students are able to recognize the monetary aspects of questions $1,5,12$ and 16 . But the law students recognize also other theoretical aspects. For example, some of them recognize the social dilemma, the principle of comparative advantage, and the problem of long term versus short term price elasticities of demand.

The differences in ability to categorize on a deep level may be related to the

"But some teachers did the assignment three times, without much increase in the depth of the level of analysis. 
attention paid to the topics in teaching. Let us try investigate this for the law students. First, more than $80 \%$ of the law students categorized protection and pollution on a surface level. For protection this is easy to understand. The chapter on protection is not written as an application of the basic principles used in the other parts of the course, and is neither explained in a lecture nor discussed in a computer module. The students use the theory only in one task. Also pollution is only discussed in one task, and is not reloted explicitly to other topics. But it is included in a separate computer module and discussed in a lecture together with the social dilemma. This may explain that at least a small number of students were able to recognize the social dilemma. aspect in the questions. Second, the monetary theory of the business cycle is recognized by $35 \%$ of the students. This theory of the business cycle is a central topic in the last three chapters of the book, and is discussed in the computer modulles, in the game, and in three lectures. ${ }^{20}$ Therefore, it is not surprising that the students are able to approach this problem in a more analytical manner. Third, a lot of students differentiated between structural and cyclical aspects. But the content of the categories is not analytically correct. Although for the law students structural unemployment was a central topic, structural adjustment is not introduced as a separate issue. Both students in law and students in economics combined the effect of disequilibrim wages with the problem of adjustment, although some students recognized in a rather extensive description the relation between real wages and unemployment. It is interesting that one law student recognized the difference between long term and short elasticity in the pollution problem and the wage problem. The fact that not more students did this may be explained by the fact that this problem is discussed only in one chapter of the syllabus, while most students didnot use the computer modules that investigated this. problem. Finally, some law students recognized the comparative advantage problem as a problem that is separated from the other questions on international trade. This comparative adwantage problem was used in two tasks of the teaching groups and two chapters of the syllabus.

We may conclude that the categorization test shows that the law students categorize more problems on what I call a deep level than the economics students. The ability to categorize is clearly related to the teaching approach. Topics with a lot of real world examples and a systematic relationship with fundamental principles seem to be categorized more easily on a deep level. ${ }^{21}$ When the recognition of principles on a deep level is the purpose of a course in economics, this result suggests that the approach discussed in chapter 2 has to be used much more systematically than in the current course.

\footnotetext{
${ }^{20}$ If is also a central approach in the macroeconomic textbook used in the course for economics students, i.e., Hall and Taylor (1991).

${ }^{21}$ These results and the fact that students who followed a economics at a high school level did not have better results than other students suggests that such a course adds something to high schooll knowledge.
} 


\subsection{Conclusion}

In this chapter different methods for research of the teaching process have been investigated. First, factor analysis has been used to analyze the dimensions of knowledge in an examination test. By correlation analysis a rather detailed analysis of the content of the factors could be made. Regression analysis with data gathered by a questionnaire shows that the factors really measure different things. For example, the economics part of the test for law students shows that the factor "knowledge' is related with hours of study, the factor 'insight' with participation in the game, and the factor that contains answers that depend on high school knowledge correlate negatively with hours of study and positively with participation in a high school course in economics. The factors in the overall test for economics students show a factor 'ability to apply knowledge', a factor 'detailed knowledge', and a factor that measures "reasoning capabilities without much knowledge". The behaviour of factor I (application ability) differs significantly between players and non-players of the game. Preparation for the game is related to the knowledge factor, where the informational capability factor is also related to the knowledge factor, but surprisingly also negatively to the factor 'ability to apply knowledge'.

A second method in evaluating a course is the pattern recognition test. Recall of students is expected to be related with the ability to organize information. The results show that during a course around the game, recall improved a lot and changed from institutional to economic facts. The ability of students to recognize the signals of a turning point in the business cycle improved significantly during the course.

A third method in evaluating a course is the conceptual capability approach. It investigates to what extent students can recognize theoretical issues behind their surface appearance. The analysis shows that the course for law students helps them to recognize deeper categories than the economics students after a much longer (but more formal) course. But it also demonstrates the weaknesses of such a course in that only a small number of students recognized fundamental concepts like the social dilemma, and macroeconomics dynamics.

As already mentioned, the game has not been played long enough to expect fundamental changes in the capabilities of the students. This requires more training during the game than one or two half-days. The students must be stimulated to relate their experience in the game to economic theory. Therefore, it is surprising that the third factor of the test for the law students (i.e., analytical skills) shows a significant correlation with participation in the game. This suggests that the factor analysis on tests is a fruitful approach for the investigation of causal connections between teaching programmas and teaching results. 
Appendix 7A. The questionnaire at the end of the game for students in economics and business administration.

All questions are scaled from 'I totally disagree' (1) till 'I totally agree' (5). The text is a translation of the Dutch questions in the questionnaire.

1. The purpose of the game was clear.

2. The available instruments to reach the goal were clear.

3. During the game I was able to evaluate the effect of my strategy.

4. My strategy improved during the game.

5. My ability to reason about my strategy improved.

6. When the game was finished I got sufficient feedback about my strategy.

7. This feedback had sufficient quality.

8. My insight in the causes of economic development in the game improved.

9. I read the manual.

1.0. The manual showed clearly how to play the game.

11. The explanation of the game leader at the beginning of the game was clear.

12. The computer program was "user friendly".

13. The computer program was too slow.

14. The computer program showed sufficient information about the development of the game.

15. I made tables and graphs myself.

16. I mainly used the main menu.

17. The computer program gave too much information.

18. It was useful to play the game with more than one student per firm.

19. It was useful to play the game spread over two days.

20. The game was well organized.

21. The game was too difficult.

22. I played the game seriously.

23. The game was interesting.

24. I learned a lot from the game.

25. The game was useful in the first year study.

26. My understanding of the working of a market economy has been improved by the game.

27. My understanding of the relation between business administration and economics has been improved by the game.

28. The game was related to my prior knowledge.

29. The game makes it easier to apply macroeconomics.

30. The game induced self-study.

31. Such a game must be repeated.

32. My interest in economics increased by playing the game.

33. I applied theories I learned during my study in the game. 


\section{Appendix 7B. The business cycle descriptions}

Procedure: the subject reads the introduction and the description of Utopia. For the description of Utopia the subject has one minute. Then they are asked to write down everything they remember. After finishing this assignment they have to characterize the situation of Utopia.

\section{General introduction}

You work at the ministry of economic affairs and normally have to answer questions about the Dutch economy. This time you get a special assignment. You have to advice about the economic development of an unknown economy, called Utopia. Until now this economy did not have any contact with other countries. Therefore, it is a completely closed economy. On the following page you find a description of a visitor of Utopia. No other information is available.

\section{Case A.}

Utopia is a democratic country. Labour wnions bave an important role, but are reasonalde. The Central Bank is formally independent of government, but is influenced by the political opinion. During a long time the umemployment rate has been historically low. The untmployment rate rose last year. The growth of the coonomy seems healthy. During the last few years national production rose by about 4 percent per yent. Labour productivity rose a lot. In many firms stocks have statted to rise. The delivery time of machines, that was high for a long period, declined a little bit. The growth of consumption of $4 \%$ per year seems to be stable. The inflation rate rose from $3 \%$ to $20 \%$ during the last four years. Prices of investment goods rase more than those of consumer goods. Labour costs rose more than labour productivity during the last ten years. Employers complain about the low profit rate. The nominal interest rate increased in the last half year from $15 \%$ to $30 \%$.

\section{Case B.}

Utopia is a democratic country. Labour unions have an important role, but are reasonable. The Central Bank is formally independent of government, but is influenced by the political opinion. The unemployment rate rose during the last three years from $3 \%$ to $16 \%$. Investment is half the nomal level and momimal national income has dectiried by $35 \%$. The stocks of the firms are very high. Prices declined by about $20 \%$ during the last few years. The prices of machines are even half the price of 3 years back. Because wages have declined less than prices, Jabour costs are a problem for almosi every firm. Employers complain about low profits. Those are partly caused by the low willzation rate of their machines, and partly by high wage costs. It is a small solace that the interest rate declined from $4,5 \%$ lo $2 \%$ during the last the years.

Assignment 1. Write down everything you remember about Utopia (You are not allowed to read back).

Assignment 2. Characterize in your own words the situation of the economy of Utopia (You are not allowed to read back) 


\section{Appendix 7C. The questions in the categorization experiment.}

1. In the beginning of the 1980 s the unemployment rate increased a lot. This can be explained by the restrictive monetary policy. Explain. [A.]

2. The integration of the EC and the end of tariffs in the EC increased unemployment for custons officers. Explain. [B]

3. In the 1930s the unemployment rate increased a lot. This increased the probability that the unemployed would bid a lower wage. The general binding of collective labour agreements is a solution for this problem. Explain.[D]

4. At the end of the 1950s. government tried to restrict intlation by low wages. A shortage of labour was the consequence. Explain. [C]

5. In the 1970 s the prices of almost all goods rose fast. This can be explained by the fast rise of money supply in that period. Explain.[A]

6. A lot of Dutch firms think it is too expensive to decrease pollution. Despite this fact they may appreciate international laws with respect to pollution. Explain.[D]

7. In the 1970s the labour unions required high wages, partly because of the high social security taxes. The firms accepted those wages in order to prevent social problems. As a consequence prices rose faster and faster. Explain.[D]

8. A lot of protectionist measures are introduced as temporary. Nevertheless, many of them remain for a very long time. Explain.[E]

9. In developing countries a lot of people plea for protection. Each product that is imported increases the international debt of the country with very sewere financial consequences. Explain. [B]

10. At the end of the 19th century transport costs declined fast and the civil war in the US ended. As a consequence it was possible to export wheat from the US to Europe. This was the cause of a crisis in Europe and reinforced protectionist tendencies. Nevertheless this protection was not beneficial in the long term. Explain. [B]

11. In the 1930s the US protected the economy by high tariffs (Smoot-Hawley Act). This protection by the US increased protection in the whole world. In the end the US was less well off with protection than it would have been without protection. Explain.[D]

12. In the 1960 s it seemed that more inflation would result in less unemployment. This idea made a stimulating government policy acceptable. It took a long time before one saw that the inflation would become uncontrollable. Explain. $[A, E]$

13. Even when it becomes obvious that pollution is increasing too much and the laws are adjusted to this insight, it takes a long time before pollution decreases. Explain.[B]

14. In the 1970 s real wages rose more than labour productivity. At the beginning of the 1980 s the unemployment rate was high. Explain. [C]

15. Employers fight against the use of taxes to limit pollation. One of their argurnents is that a tax not only regulattes but also implies benefits for the government. Explain.[E]

16. During a recession government may reduce unemployment by an easy monetary policy. Despite this fact government must not do this. In the long run such a policy results in more unemployment. Explain. [A]

17. As a conseguence of the fast growing computerization in offices the unemployment rate rose. Explain. [B]

18. Unemployment in the Netherlands increased. This is partly the consequence of increased imporis, for example, of textiles out of developing countries. Explain.[B] 
Appendix 7D. Correlations between the separate questions and the factors of the OAT 1993.

Question Question group

\section{$\mathrm{Cl}$}

$\mathrm{C} 2$

$\mathrm{C} 3$

$\mathrm{C} 4$

C5

C6

C7

$\mathrm{C} 8$

C9

C10

CII

$\mathrm{C} 12$

$\mathrm{C} 13$

$\mathrm{Cl} 4$

C15

C16

C17

C18

C19

$\mathrm{C} 20$

$\mathrm{C} 21$

$\mathrm{C} 22$

$\mathrm{C} 23$

C24

$\mathrm{C} 25$

$\mathrm{C} 26$

$\mathrm{C} 27$

$\mathrm{C} 28$

C29

C30

C31

C 32

C33

C34

C 35

C36

C37

C38

C39

C40
Factor 1

(applied

knowledge)

$.2161 * *$

.1046

$.1407 *$

$-.0071$

.0947

$.1790^{* *}$

$.3527^{* * *}$

$.2470^{* * *}$

$.2579^{* * *}$

$.3275^{* * *}$

$.2708 * *$

.0387

$.2754^{* * *}$

$.2121 * *$

$.1637^{*}$

$-.0521$

.2843*当"

$.1317^{*}$

$.2443^{* * *}$

$.2352^{* * *}$

$.1644^{* * * *}$

$.2429 * *$

.0298

$-.0066$

$-.0354$

$.1287^{*}$

.0853

.1048

$-.0538$

.1386*

$.1248^{*}$

.0250

$.1714 * *$

.0987

.1323 *

.0826

$.2191 * *$

.0791

.0561

. .0764
Factor 2

(bogic)

$\begin{array}{lc}.2232 * & -.0525 \\ .1336 * & .0002 \\ .0916 & .0309 \\ .1510^{*} & -.0134 \\ .1420 * & .1433 * \\ .1961 * * & -.0173 \\ .2762 * * & .0536 \\ .0288 & .0324 \\ .0403 & .0094 \\ .1048 & -.1858 * \\ .1610^{*} & -.0011 \\ .1323 * & .0347 \\ 0702 & -.0324\end{array}$

.0004

.0492

$-.0030$

.0766

$.1960^{* * *}$

$.1271^{*}$

.1186

.0988

.2321 **

.0711

$.5568^{* * *}$

.0336

.0888

$.2085^{* * *}$

$3146 *$

$.2043^{* * 2 *}$

$.2595^{* * *}$

.3689 *․

$.2283^{\text {*中* }}$

$.2294^{* * *}$

.0773

$.1535^{*}$

$.1917^{\text {*** }}$

$1807 * *$

1441 *

$.1405^{*}$

.0780

.0353
Frator 3

(dewailed knowledge)

$-.0019$

$-.0072$

$-.0497$

.0157

$-.0097$

$-.3839^{\text {** }}$

$-.3059 * *$

-3341 *

-4400 和

.0543

4581 水幽

$.3752^{2}$ **

.3792***

.0228

.0367

.0529

.0187

.0118

$-.0696$

$-.0629$

.0472

$-.0058$

$-.1138$

$-.0730$

$-.0625$

. .0686 
Question Question group

C41

$\mathrm{C} 42$

$\mathrm{C} 43$

$\mathrm{C} 44$

$\mathrm{C} 45$

$\mathrm{C} 46$

$\mathrm{C} 47$

$\mathrm{C} 48$

C49

01

$\mathrm{O} 2$

03

04

05

06

07

08

O9

O10

011

$\mathrm{O} 12$

013
CLOSED8

CLOSED8

CLOSED9

CLOSED9

CLOSED9

CLOSED9

CLLOSED9

CLOSED9

CLOSED9

OPEN 1

OPEN2

OPEN3

OPEN3

OPEN3

OPEN 3

OPEN4

OPENS

OPEN5

OPEN6

OPEN6

OPEN6

OPEN7

$\begin{array}{ll}\text { Factor } 1 & \text { Factor } 2 \\ \text { (applied } & \text { (logic) } \\ \text { knowledge) } & \end{array}$

$.2392 * *$

.0322

$.1834 \%$

.0816

.0668

$.1321 *$

$-.0253$

$.1979 * *$

$-.0364$

.4637 *

$.6849 * *$

$.4471 *$

$3847 *$

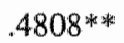

$.5169 *$ *

.5041 *

$.2940^{\text {s. }}$

$.4545^{\text {水水 }}$

$.5241 * *$

$.5229 * *$

$.3318 *$

$.3574 *$
Factor 3

(detailed knowledge)

$\begin{array}{ll}-.3758 * * & -.0065 \\ -.3796 * & .1038 \\ .1134 & -.0300 \\ .1573^{*} & .1477^{*} \\ .2813^{* *} & .0760 \\ .1510^{*} & .1021 \\ .0954 & .1064 \\ .1675 * & .1488^{*} \\ .0317 & .0952 \\ .1652^{*} * & .3372^{* *} \\ .1237 * & .1185 \\ .0699 & .0385 \\ . .0345 & .0570 \\ .0304 & -.0835 \\ .0569 & .0623 \\ .0732 & -.2442 * * \\ -.0344 & -.1061 \\ .0078 & -.1430^{*} \\ -.0490 & .1803 * * \\ -.0747 & .2050 * * \\ -.0282 & .1023 \\ -.0460 & -.0460\end{array}$

Number of cases $354 ; 1$-tailed significance: $*=.01 * * *=.001$ $\mathrm{C}=$ closed question; $\mathrm{O}=$ open question 


\section{Chapter 8}

\section{The game as an experimental method}

\subsection{Introduction}

In chapters 1 and 3 I have suggested that a game like this can be used for empirical research. But the proof of the pudding is in the eating. In this chapter some first results will be presented. In June 1993 six groups of first year students in economics played the game twice. The first time, they had to learn the basic principles of the game. The second time we expected they could play the game more rationally. But despite these efforts, the quality of playing was not satisfactory for sound experimental research. At this moment a new computer program is under development that will simplify both instruction of the players and analysis of the results. With this new computer program it will be much easier to analyse game economies. Therefore, the purpose of this chapter is only to indicate the possibilities of research with a game like this.

First, the requirements for good experiments were developed in chapter 3 will be applied to the game. Second, some research methods (descriptive analysis, econometric estimation and simulation) are applied to the game. Third, it is argued that the design of the game can be valuable in itself because it forces you to implement explicit institutions in the model. Fourth, although the game has been designed for the investigation of the fundamental macroeconomic coordination problem as discussed in chapter 1 , variations on the game can be developed that create the opportunity to investigate a lot of other problems. The game itself represents a potential research strategy.

\subsection{Experimental requirements of the game}

The game has been designed for experimental purposes. This implies that the results are not fixed a priori. In chapter 3 a number of requirements for experiments were formulated. Here we will investigate these requirements more thorough with respect to the game.

First, consistency with assumptions was an important focus in the development of the game. In chapter 1 the fundamental free market macroeconomic coordination 
problem was described as an important issue of macroeconomics. In chapters 4 and 5 the model of the game has been developed consistent with the institutional and environmental assumptions of the theories that discuss the fundamental macroeconomic coordination problem, i.e perfect competition, free decision making, long term possibulities for substitution between capital and labour, short term restrictions on substitution , profit maximization of firms. In section 6.2 some operational problems have been tackled, while in section 6.4 attention has been focused on the educational aspects of the game. Because theories have some implicit or explicit assumptions about the motivation and skills of the actors, the results of the game are only relevant when the motivation and skills of the players are consistent with those behavioural assumptions. Most macroeconomic models assume long term profit maximization as a goal, but acknowledge that other motives are also relevant. In sections 3.5 and 6.4 it has been argued that a good educational set-up is essential for motivation, while monetary incentives seem to be less important. Much more important is the development of the required skils. A good training programme for the players is a sine qua non.

Second, for good results it is important that no disturbances are generated by the system. The game has been designed to avoid those disturbances. For example, a lot of the problems in the Expansio game discussed in section 3.5 could be avoided by the introduction of a large number of short decision periods. But also in the training programme one has to be very careful. For example, in chapter 6 it has been shown that the game leaders' centrally-given advice can systematically influence decisions by the players.

This brings us to the problem of internal validity. For internal validity it is essential that the essential variables can be controlled. The type of explanation given to the players is such a control variable. Both the explanation before the game starts and the feedback during the game may infuence the behaviour of the system. Therefore, for controlled experiments explanation and leedback must be standardized. For this reason and for the ease of the game leader the instruction for the players and the feedback during the game will be incorporated in the computer program. Also changes in the settings of coefficients and decisions made by the game leader (interest rate, credit restrictions and minimum wages) may increase the difficulty to interpret the results of the game, and therefore must be avoided as much as possible.

When one investigates the interaction between firms in an economic system, it is important to distinguish between the dynamics generated by the structure of the system, the policies of the firms, and the more complex process of human decision making. Therefore, it is useful to vary the set-up of the game from computer simulation with automatic players, one human player against a carefully designed set of automatic players, to a game with only human players. This may help to separate the mechanic, human and social effects in the coordination mechanisms. Furthermore, the behaviour of the system may depend on the type of players used. Therefore, it can be important to control for the personality and educational background of the players.

For a thorough research project it is very important to have valid measurement instruments. During the game, the decisions of the players as well as the coefficients of the game are automatically stored. One may try to measure the skills, capabilities and motivation by questionnaires. For example, the factors of the factor-analyses of 
multiple choice tests and questionnaires as discussed in chapter 7 could be used as measurement instruments. Personality tests may be useful, too. But it is more difficult to investigate the players' strategies. One may ask the players to write down their strategies in advance or afterwards. But a lot of help is necessary before students are able to formulate a strategy. And even then it is questionable to what extent the verbal argumentation is consistent with their policy. Therefore, one may search for an alternative by forcing the students to program their policies on the computer. One may even organize tournaments of computer programs written by players. ${ }^{\prime}$ In that case the game is transferred into a simulation program.

But even if one knows the players' strategies, it will be difficult to categorize the results adequately. In contrast to the strategies in simple games like Prisoners' dilemmas, the number of strategies in the macroeconomic game is very big, and may be difficult to compare. Therefore, the categorization of strategies in a game like this will be an exercise in itself.

Also the measurement of expectations is very difficult. As discussed in section 3.5 it is difficult to get informed expectations. The use of questionnaires like those of statistical offices may help a little bit in finding good questions. But it is also important that the players are motivated to predict as well as possible. A reward system may help. Furthermore, the obligation to write down expectations could influence the development of the economy. Especially when other players know the expectations of others, this may influence the economy. Therefore, we have to be very careful in using measurement instruments.

When we are doing experiments, our final focus is on finding results that have some external validity. But the first requirement for good experiments is internal validity. Therefore, we have to start with the investigation of the fundamental coordination problems. When we are able to manage them, we may gradually include more variables or more types of players into the game. To increase external validity it is also important that a variety of groups play the game. When the results do not differ much between groups or can be explained by the characteristics of the players, the results can be extrapolated to real world situations. Otherwise, we have to conclude that the theory is too incomplete to understand the game results. But because the real world is much more complicated than the game, this holds a fortiori for the real world.

Another way to increase external validity is variation in institutional settings. For example, the distribution function of market shares in the consumption function may be varied by introducing more marketing variables.

In summary, the training programme for the players may be of fundamental importance for the results of the game. Both the control and the measurement of the behaviour of the actors in the game generates difficulties. The challenge is to solve them.

'See for axample Keser (1992). 


\subsection{Investigation of game economies}

Neither the current computer program nor the current data are very suitable for experimental research. The development of a new computer program for the game (that will be finished around June 1995) will improve the opportunities for systematic research with the game. For this reason, it is not worthwhile to invest a lot of efforts in systematic research at present. But to illustrate the opportunities of research with the game, some simple exercises will be performed with the game results. First, a descriptive analysis of the results can be useful to generate some initial hypotheses. Second, an econometric analysis can be used to investigate the behaviour of the players. Third, the game can be used as an instrument for simulation. In order to give some information about the games that are analysed, we start with the settings for those games.

\subsubsection{The setting of the game economies}

All games were played with the coefficients as presented in table 8.1. As discussed in chapter 4 the game economy has a general equilibrium growth path. In all games that have been played the growth rate was 0 and the economy started in long term equilibrium. This is an easy point of reference. Therefore, it is easy to compare the developments of the economies with the general equilibrium path.

The duration of a month was about 1 minute; somewhat more in the beginning of the game, about 45 seconds at the end of the game. In all games about 10 years were simulated in 3 or 4 hours. The number of players varied between 20 and 40 , divided over 9 to 20 firms. For example, ECO 8 was a game with 36 players divided over 15 firms, and two automatic players. ECO 11 was a game with 20 players divided over 9 firms, and one automatic player. All players were first year students in economics and business administration. The game was explained in a lecture of about half an hour by the game leader. The feedback was given by means of the game leader's personal advice, and the exercises described in chapter 6 .

Figure 8.1 and 8.2 show the development of national income in two game economies that will be investigated in this section: $\mathrm{ECO} 8$ and ECO11. Both games were played by students who had already participated in another game. ECO8 was a game with normal instructions, whereas ECO11 had instructions focused on the detection of the structural situation on the labour market (see chapter 6). The results show that ECO8 was a very unstable economy, with a tendency towards decline, whereas ECO11 was an economy that fluctuated around $95 \%$ of general equilibrium full capacity. The fluctuations in ECO11 were much smaller than in ECO8. This may be sufficient to show that the settings of the game economy allow for very different economies. 
Scale coefficient of the production function ( $\alpha$ )

Coefficuent of capital in the production function ( $\beta$ )

Life the of machines in months

Growth rate of labour supply, money supply, and capitil stock

Quarterly price elasticities in the lahour market and the cutput narket

Nominal wage per month

Real interest rate per year

Marginal consumption quote of labour income

Marginal consumption quote of non-labour incone

Stock of labour

Stoek of capital

Stock of final products as a percentage of production

Equity capital as a percentage of total capital

Natural rate of unemployment:

Table 8.1 The coefficients of the games played in June 1993.

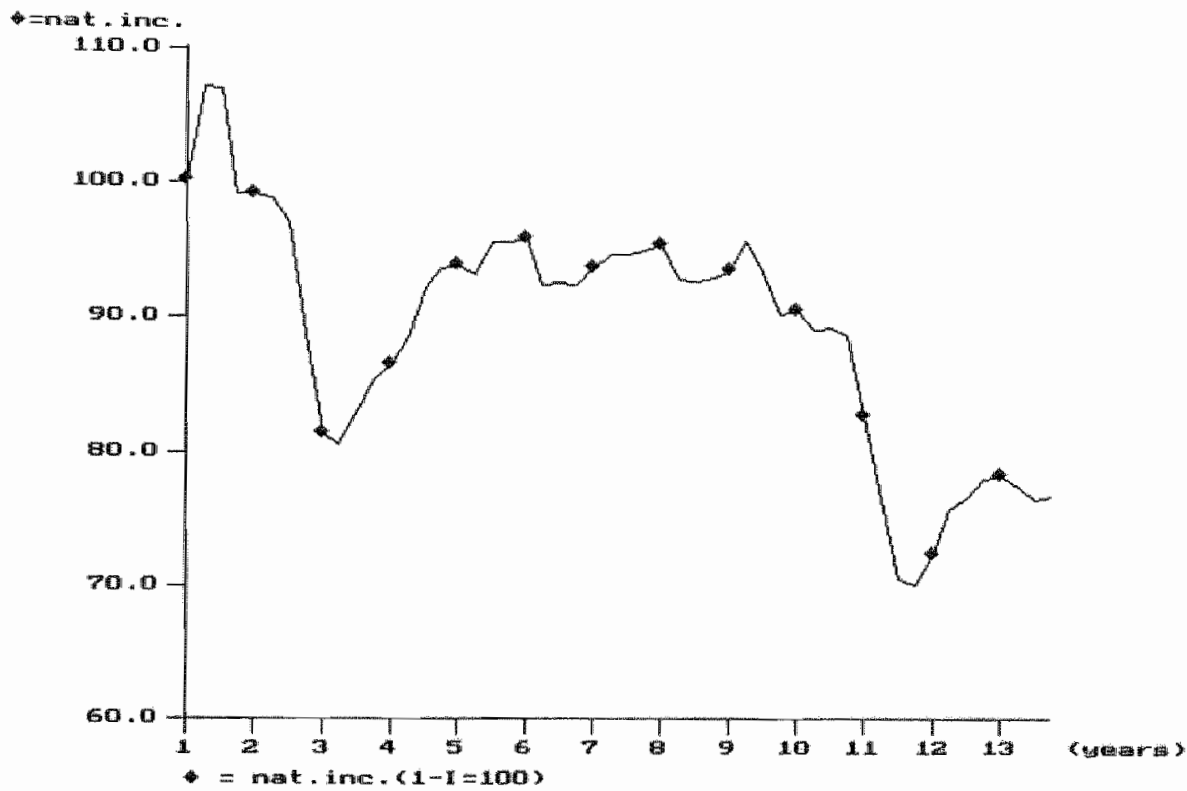

Figure 8.1 National income in ECO8.

\subsubsection{Descriptive analysis: Expectations and stability}

Descriptive analysis of the game economies can be useful to investigate the mechanisms at work. In this section we will investigate to what extent the fundamental coordination problem discussed in chapter 1 can be recognized in the game economies. The main focus will be on Classical and Keynesian mechanisms in the game economies.

Recessions can be explained as coordination failures because of unexpected disturbances. In all games the economy starts in a general equilibrium. No exogenous 


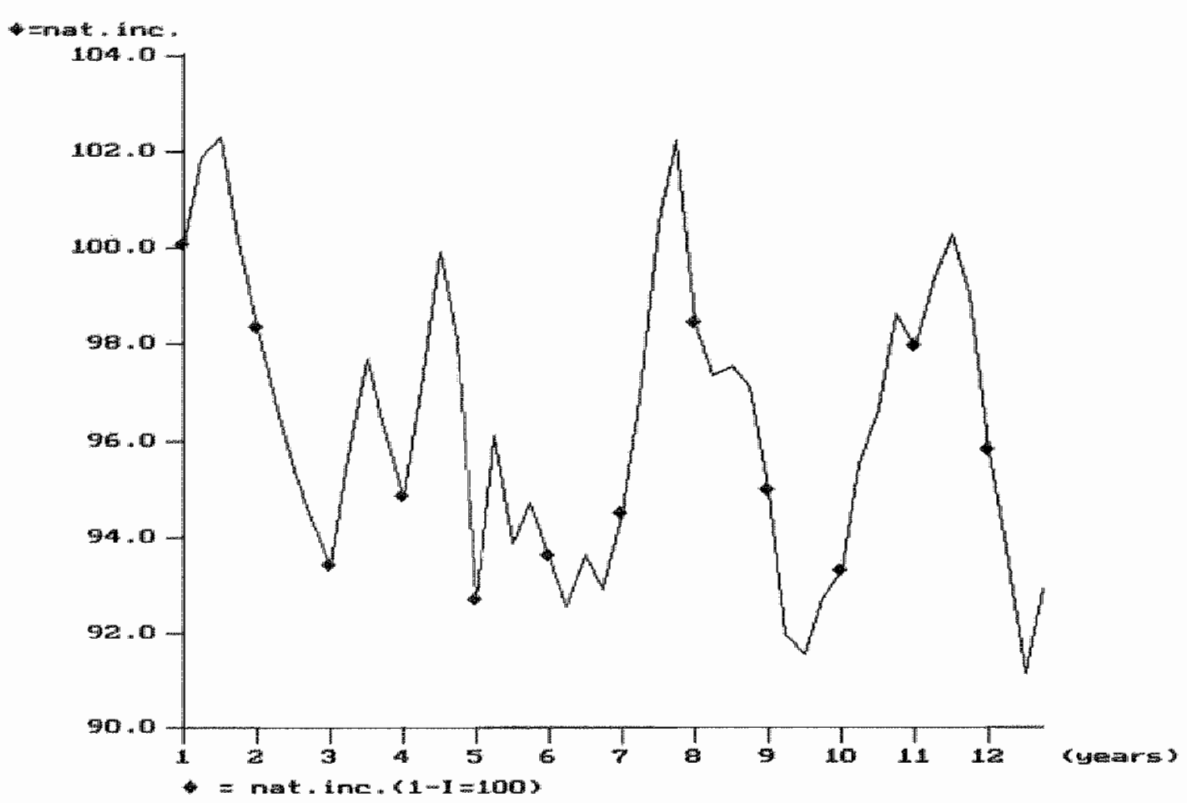

Figure 8.2 National income in ECO11.

disturbances are introduced. Therefore, all dynamic aspects of the game are caused by the behaviour of the players.

In order to investigate the disequilibria, we distinguish between structural and cyclical disturbances. Structural disturbances are caused by aggregate investments that are not consistent with the full employment rate of unemployment of $5 \%$. Therefore, the difference between the unemployment rate when all machines are used at their normal capacity ${ }^{2}$ and the frictional level of $5 \%$ is the structural rate of unemployment. When this structural rate of unemployment is negative, there is a structural shortage of labour.

The cyclical situation can be perceived by comparing short term aggregate output supply and short term aggregate output demand. Aggregate output supply is the maximum output that is possible with the current stock of machines and labour supply. Aggregate output demand is the sum of the demand for machines and the demand for consumer goods. When aggregate demand is lower than aggregate supply, there is a recession. When aggregate demand exceeds aggregate supply, there is a boom.

The structural situation on the labour market may influence the situation on the output market. For example, when there is a structural shortage of labour, some firms can employ more labour than is available. These firms may either reduce investment or invest in labour-saving technology. The first choice implies a decline in aggregate demand and therefore a recession. Structural unemployment has the opposite effect on

\footnotetext{
2In the computations we assume that the normal utilization rate of capital is $100 \%$; as discussed in chapter 5 , in an uncertain world such an equilibrium rate will be lower.
} 


\begin{tabular}{|c|c|c|c|c|c|c|}
\hline year & $\begin{array}{l}\text { utiliz } \\
\text { rate of } \\
\text { eapital }\end{array}$ & $\begin{array}{l}\text { unerrpl } \\
\text { rate }\end{array}$ & $\begin{array}{l}\text { structural } \\
\text { unempl } \\
\text { rate }\end{array}$ & $\begin{array}{l}\text { nachines } \\
\text { ordered }\end{array}$ & $\begin{array}{l}\text { labour } \\
\text { intensily } \\
\text { or imi }\end{array}$ & $\begin{array}{l}\text { stork } \\
(1000)\end{array}$ \\
\hline 1 & 99.72 & 5.08 & $-0,19$ & 382 & 974 & 3339 \\
\hline 2 & 95.19 & 4.98 & -4.83 & 202 & 867 & 390 \\
\hline 3 & 92.34 & 4.86 & 781 & 181 & 8.66 & 5088 \\
\hline 4 & 90,35 & 6.31 & 8.34 & 185 & 799 & 96104 \\
\hline 5 & 8602 & 1220 & -677 & 186 & 8.52 & 36028 \\
\hline 6 & 86.08 & 17.28 & -1.63 & 193 & 8.22 & $25 \| 186$ \\
\hline 7 & 93.22 & 13.11 & 1,33 & 161 & 8.75 & 17465 \\
\hline 8 & 92.43 & 17.58 & 5.01 & 153 & 8.10 & 10657 \\
\hline 9 & 97.31 & 14.14 & 6.45 & 388 & 929 & 2259 \\
\hline 10 & 98.91 & 12.17 & 6.08 & 294 & 9.96 & 10 \\
\hline 11 & 9885 & 11.76 & 5.61 & 119 & 9.22 & 9231 \\
\hline 12 & 90.01 & 24.21 & 9.21 & 131 & 7.32 & 32703 \\
\hline 13 & 80.24 & 3805 & 1329 & 104 & 687 & 25578 \\
\hline
\end{tabular}

Table 8.2 Structural and cyclical unemployment in ECO8.

investment. One may expect that labour is cheap and investment will be more labour intensive. Furthermore, investment is not restrained by the labour market. Therefore, structural unemployment may induce a boom.

So far the analysis is consistent with Neoclassical and Hayekian theory. Recessions are the consequence of errors in the past and are necessary for adjustment. But during the adjustment process Keynesian mechanisms may emerge. Because during a recession aggregate demand is lower than aggregate supply, firms may expect that the recession is a long term problem, even long after the structural shortage of labour has been solved. When most firms do not invest, aggregate demand is low, and expanding firms may have problems in selling their output. As a consequence, those firms also do not invest. Therefore, investment is low because aggregate demand is low, and conversely aggregate demand is low because investment is low. A fiscal Keynesian policy may solve this prisoners' dilemma.

Table 8.2 illustrates this theory. In ECO8 there was a boom till year 2 , as can be seen by the stock of final products. ${ }^{3}$ Because according to the general equilibrium model investment would be 204 , this boom can be explained by over-investment in year 1. Four years (i.e. year 3-6) were needed to solve this problem. Because in the second half of year 6 the structural shortage of labour was vanished, it would have been possible to start investment at that moment. But because of Keynesian dynamics the recession continued till the second half of year 8 , as can be seen by the low utilization rate of capital. ${ }^{4}$ Such a long Keynesian recession implies a destruction of capital and therefore induces a new boom that should continue till the structural unemployment problem is solved. But long before that, in year 12, a new recession emerged. This recession is completely Keynesian in character. Casual observation

\footnotetext{
${ }^{3}$ See also figure 8.1.

${ }^{4}$ Because of the high unemployment rate the low wtilisation rate of capital cannot be explained by a shortage of labour.
} 
indicates that this recession is caused by the fear that good years are always followed by bad years, as was the case in year 2 . Therefore, the fear for a recession created a recession without structural causes. If this interpretation is correct, it shows the importance of expectations in economic stability.

Table 8.3 shows the development of ECO11, a game where recessions and booms can be explained by the structural situation on the labour market. The game leader focused attention of the players on the structural unemployment rate and its consequences. Therefore, when the structural unemployment rate was negative, players cut back on investment for fear of a recession and problems on the labour market. This induced a recession. When structural unemployment was positive, firms decided to invest and therefore induced a boom. ECOll 1 seems an ideal economy in the sense that the economy fluctuated around an equilibrium level and never had a national income that was lower than $90 \%$ of equilibrium national income (see figure 8.2).

But ECO11 had one problem: almost the whole game was characterized by a rate of unemployment that was higher than the equilibrium value of $5 \%$. Ironically, this may be explained by the computation of the structural unemployment rate as the unemployment rate when machines are used to full capacity. As discussed in chapter 5 , in an uncertain world, the equilibrium utilization rate of capital will be lower than $100 \%$. First, some players make errors and therefore have a utilization rate of less than $100 \%$. Second, in an uncertain world it is beneficial to buy flexibility at the cost of a utilization rate below $100 \%$. This may explain why the equilibrium output fluctuates around $95 \%$ of equilibrium national income. Therefore, the prolonged boom at the end of the game may be caused by the awareness in some players that some unemployment remains when the figures show a structural shortage of labour. Although this statement camnot be proved with the data that are avallable at this moment, the description illustrates how the dlynamics of the economic system in the game is determined by a subtle interaction of expectations, technical restrictions, and the supply of information.

From the descriptive analysis of ECO8 and ECO11 the following conclusions can be derived. First, the Keynesian disequilibrium discussed in chapter 1 is a real possibility in the game economies. Second, the corridor hypothesis of Leijonhufvud (see section 1.4) that small disturbances are self-correcting, where big disturbances induce Keynesian disequilibrium processes seems consistent with the difference between ECO8 and ECO11. Third, it seems that the disequilibria are not the consequence of insufficient flexibility of prices and wages, but of disequilibrating expectations. Those expectations can be caused by a lot of different mechanisms, such as experience in other games, the structure of information, and explanations about the dynamics of the economy by the game leader. The dynamics of learning in the game economies require more detailed investigations. Fourth, although explanations of the game leader (i.e. government) may determine the game economy for some time, the development of the end of ECO11 suggests that market forces in the game economy finally win. 


\begin{tabular}{|c|c|c|c|c|c|}
\hline year & $\begin{array}{l}\text { natiliz } \\
\text { rate of } \\
\text { capital }\end{array}$ & $\begin{array}{l}\text { unempl } \\
\text { rate }\end{array}$ & $\begin{array}{l}\text { structural } \\
\text { unempl. }\end{array}$ & $\begin{array}{l}\text { ordered } \\
\text { investrnent }\end{array}$ & $\begin{array}{l}\text { labour } \\
\text { ntenisity } \\
\text { of inx. }\end{array}$ \\
\hline 1 & 9888 & 591 & -0.20 & 137,00 & 8.9 \\
\hline 2 & 9656 & 732 & 1.12 & 132,00 & 79 \\
\hline 3 & 96.16 & 8.03 & 0.81 & 114,00 & 82 \\
\hline 4 & 9588 & 989 & 0.77 & 14900 & 83 \\
\hline 5 & 98.55 & 834 & 189 & 15100 & 91 \\
\hline 6 & 98.22 & 8.33 & 1.56 & 98.00 & 95 \\
\hline 7 & $95,51$. & 11.41 & 19 & 124.00 & 9.5 \\
\hline 8 & 98,18 & 853 & 1.70 & 172.00 & 94 \\
\hline 9 & 9897 & 538 & 066 & 129,00 & 93 \\
\hline 10 & 91,00 & 1995 & 00 & 122,00 & 82 \\
\hline 11 & 95,31 & 813 & -1.56 & 15100 & 86 \\
\hline 12 & 9571 & 497. & 43 & 98.00 & 80 \\
\hline
\end{tabular}

Table 8.3 Structural and cyclical unemployment in ECO11.

\subsubsection{Econometric investigation}

Although an informal analysis of the game results is useful to generate hypotheses, quantitative econometric analysis can be important to test those hypotheses more systematically. When descriptive analysis and theoretical deduction suggest a mechanism that can be formalized in a set of equations, those equations can be estimated on the data of the game economies. In that sense the world created in the game is a world just like the 'real world'. Compared with the real world the use of games has the advantage that games can be repeated and the experimenter has a lot more control over the processes in the game economy.

The behaviour of the game economy is determined by the decisions of the players. Therefore, it is reasonable to search for the relevant behavioural equations in the game economy. Because the real part of the business cycle is determined by investment and labour demand, we will focus our attention on these two equations. We will try to find equilibrium values of stock and utilization rate (see chapter 5), and measure the size of stabilizing and destabilizing forces that determine the decisions of the players. We expect that compared with the stable economy ECO11 the coefficients of the destabilizing mechanisms will be higher and the stabilizing coefficients lower in the more unstable economy ECO8.

The first equation explains investment demand. We start with two equilibrium conditions. Equilibrium on the output market implies:

$$
K^{*}=Y \frac{K}{\omega^{*} K^{200 \%}}
$$

where $\omega^{*}$ represents the equilibrium utilization rate of capital and $K / K^{\text {Qcap }}$ the average capital/output ratio at full capacity use. Equilibrium on the labour market implies that: 
$K^{* *}=L^{s} \frac{K}{\omega^{s} K^{L \omega s p}}$

where $\mathrm{K} / \mathrm{K}^{\mathrm{L} \text { cap }}$ represents the average capital/labour ratio at full capacity use.

Equilibrium investment depends on depreciation and the change in equilibrium capital stock (in general equilibrium $\mathrm{K}^{* *}=\mathrm{K}^{*}$ ):

$I^{\text {ord } d^{*}}=R i\left(1+D T-D T_{-1}\right)+K_{+D T}^{*}-K^{*}{ }^{*}+D T_{-1}$

where $\mathrm{DT}_{\mathrm{t}}=$ delivery time for machine ordered in month $\mathrm{t}$, and $\mathrm{Ri}=$ replacement investment per month. Replacement investment depends on the change in the delivery time of machines; when the delivery time rises from 8 to 9 months, equilibrium replacement investment doubles for that month.

Normally, players will not be very alert in perceiving changes of the delivery time. Therefore, we may assume that replacement investment is not very sensitive to changes in the delivery time. Second, in month $t$ players do not know equilibrium capital stock in period $t+D T_{t}$. Therefore, they have to predict equilibrium capital stock. It is plausible that those expectations depend on the growth rate of sales in the past. This is the traditional investment accelerator. Furthermore it is likely that a firm tries to adjust its stock to an optimal level:

$E\left(\frac{K_{+D T}^{*}-K_{-1+D T_{-t}}^{*}}{K_{t}}\right)=\alpha_{2} d \ln Y_{-1}+\alpha_{3}\left[\frac{S t_{-1}}{Q_{-1}}-\left(\frac{S t}{Q}\right)^{\cdot}\right]$

Because ordered investment equals the sum of replacement investment and the change of capital stock, and it is plausible that differences between actual capital stock and equilibrium capital stock are corrected, the equation to be estimated becomes:

$$
\begin{aligned}
\frac{I^{\text {ard }}}{K} & =\delta_{0}+\alpha_{11} \Delta D T+\alpha_{2} \Delta \ln Y_{-1} \\
& +\alpha_{3}\left[\frac{S T_{-1}}{Q_{-1}}-\left(\frac{S t}{Q}\right)^{*}\right]+\alpha_{4}\left(\ln Y-\ln K_{+D T-1}^{\text {Quar }}-\ln \omega^{*}\right) \\
& =\alpha_{0}+\alpha_{1} \Delta D T+\alpha_{2} \Delta \ln Y_{-1}+\alpha_{3} \frac{S t_{-1}}{Q_{-1}}+\alpha_{4}\left(\ln Y-K_{+D T-1}^{Q \text { Qcap }}-\ln \omega^{*}\right)
\end{aligned}
$$

The second equation explains labour demand. Because labour capacity of machines is determined by ordered investment from orders some time ago, the firm has to accept its labour capacity when making labour demand decisions. This implies:

$$
L^{d} \leq K^{\text {Lap }}
$$

In the long run, sales equal production. As the labour/capital ratio equals $\mathrm{K}^{\mathrm{Lcap}} / \mathrm{K}^{\mathrm{Qcap}}$, equilibrium labour stock is:

$L^{*}=\min \left(\frac{K^{L(\alpha p)}}{K^{\text {Qcap }}} Y, K^{L \text { Lap }}\right)$ 


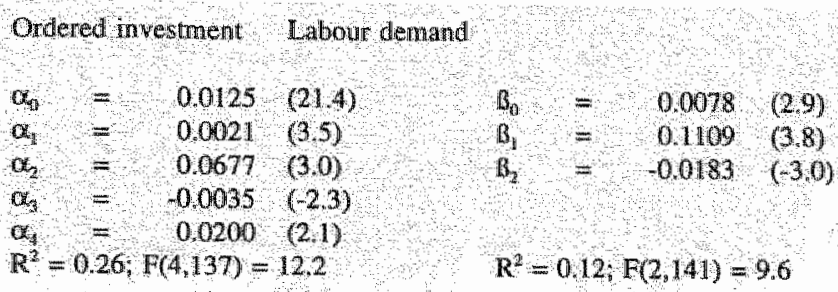

Table 8.4 Estimation results of ECOIl (t-values between brackets).

When we assume partial adjustment to equilibrium, the change in labour demand can be written as:

$d \ln L^{d}=\beta_{1}\left(\ln L_{-1}^{*}-\ln L_{-1}^{d}\right)$

When errors are made in the labour demand decision, the actual stock of final products differs from the level warranted. Firms will set a lower labour demand when stocks are higher. Therefore:

$$
\begin{aligned}
d \ln L^{d} & =\beta_{1}\left(\ln L_{-1}^{*}-\ln L_{-1}^{d}\right)+\beta_{2}\left[\frac{S t_{-1}}{Q_{-1}}-\left(\frac{S t}{Q}\right)^{*}\right] \\
& =\beta_{0}+\beta_{1}\left(\ln L_{-1}^{*}-\ln L_{-1}^{*}\right)+\beta_{2} \frac{S t_{-1}}{Q_{-1}}
\end{aligned}
$$

When this equation is solved for its long run equilibrium value, the result is:

$L^{d}=L^{*} e^{\beta_{3}\left(\frac{s}{Q} \cdot \frac{\beta_{0}}{\beta_{2}}\right)}$

Therefore, equilibrium stock relative to production equals $\mathbb{B}_{0} / \mathrm{B}_{2}$.

For the estimation monthly data have been used. The equations are estimated with ordinary least squares. Aggregate variables like the stock of final products are averages per firm. The estimation results for ECOL 1 are presented in table 8.4. Let us start with the labour demand equation. First, the coefficient $B_{1}$ represents the speed of adjustment. Somewhat more than $10 \%$ of the disequilibrium per month is removed. Second, when the stock of labour is out of its equilibrium level, labour demand changes in such a manner that this disequilibrium is reduced by $11 \%$ per month. Third, $-\oiint_{1} / B_{2}=0.43$ represents equilibrium stock relative to production. This equilibrium stock is about two weeks, a very plausible value.

The investment equation generates an estimation of equilibrium stock and the utilization rate of capital together: 


$$
\begin{aligned}
\alpha_{0} & =\delta+\alpha_{3}\left(\frac{s i}{Q}\right)^{*}-\alpha_{4} \ln \omega^{*} \\
\ln \omega^{*} & =\frac{\delta+\alpha_{3}\left(\frac{s t}{Q}\right)^{*}-\alpha_{0}}{\alpha_{4}}
\end{aligned}
$$

When we assume, consistent with table 8.3, that replaced machines are more capital intensive than the original machines, while each month one machine has to be replaced, then $\delta=0.0111$. This implies that the equilibrium utilization rate is about 0.86 . $^{5}$ This is lower than table 8.3 suggests.

The second coefficient of the investment equation, $\alpha_{1}$ represents the sensitivity of investment demand for changes in the delivery time. The effect is significant; about $20 \%$ of the players react. This is a plausible value because a small number of players use the automatic replacement routine of the computer. The accelerator effect $\left(\alpha_{2}\right)$, the effect of disequilibrium stock, and the adjustment parameter( $\left.\alpha_{4}\right)$ are all significant.

The results for ECO8 are to a large extent comparable with those of ECO11. ECO8 is a less stable economy than ECO11. To what extent can this be perceived in the estimated behavioural equations? First, according to the labour demand equation equilibrium stock in this economy is $118 \%$ of production, much higher than in ECO11. This is to be expected in a less stable economy. Second, the estimated equilibrium utilization rate of capital is only 0.59 , much lower than can be expected. If this estimation is correct, it suggests irrational decision making. Third, as can be expected in a less stable economy, the stabilizing adjustment parameter $\alpha_{4}$ is much lower than in ECO11, while the destabilizing accelerator $\alpha_{2}$ coefficient is higher. Fourth, also the labour demand equation shows much smaller coefficients for the stabilizing adjustment parameters $\beta_{1}$ and $\beta_{2}$. In summary, the estimation results of the behavioural equations seem to be related with the stability of the macroeconomies.

In summary, except for the equilibrium utilization rate of capital in ECO8, stock and utilization rate have plausible equilibrium values. The differences in behaviour in the two game economies found in the descriptive analysis of the previous section can be identified in the estimated equations.

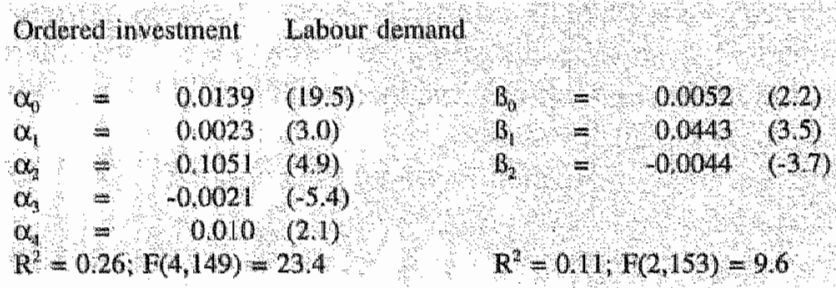

Table 8.5 Estimation results of ECO8 ( $\mathrm{t}$-values between brackets).

\footnotetext{
${ }^{s} \ln \omega=(0.0111-0.0035 * 0.43-0.0125) / 0.020 ; \omega=\exp [-0.145]=0.86$
} 


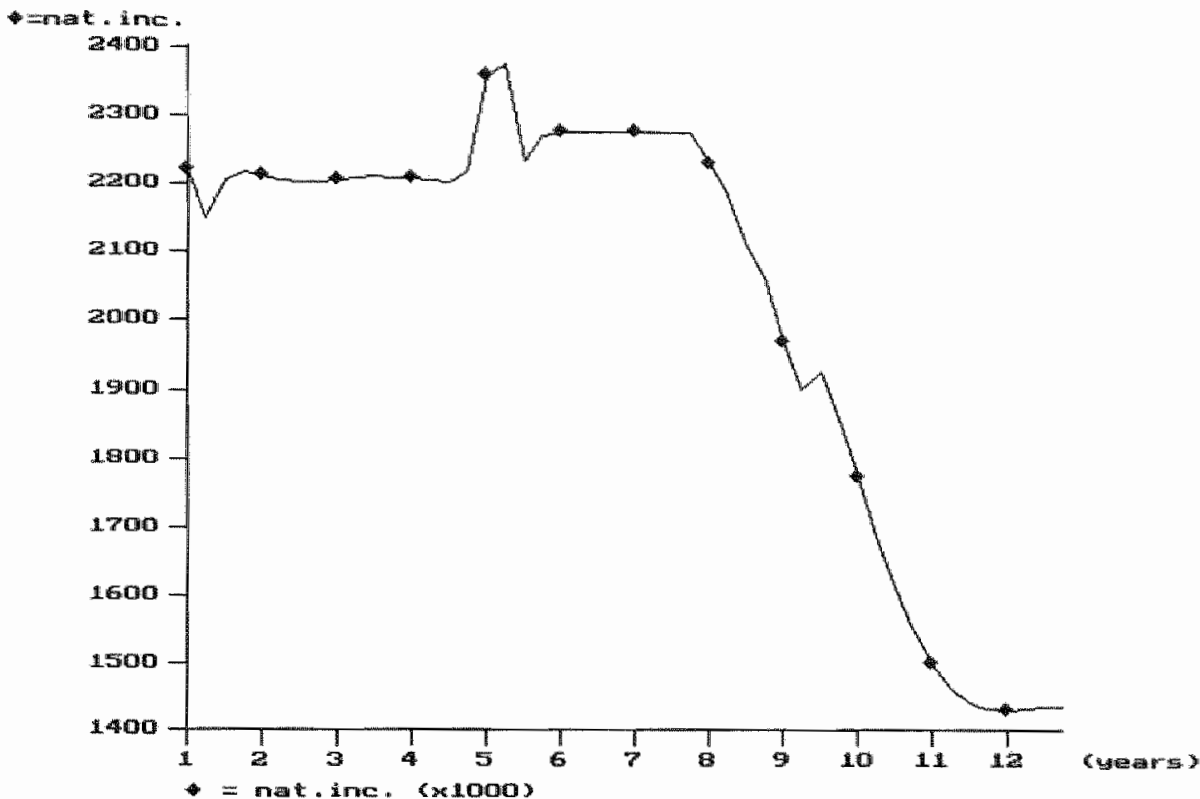

Figure 8.3 The development of national income in a simulated economy.

\subsubsection{The game as a computer simulation}

The central point of the macroeconomic coordination problem is the investigation of the relation between microeconomic decision making and macroeconomic performance. The plain estimation of behavioural equations is not sufficient to investigate this relation. The behavioural equations are only correct from this point of view when the use of those equations for firms in the game economy generate macroeconomic dynamics consistent with the dynamics in the game they describe.

Computer simulation may be used as an addition to econometric and theoretical research and as a separate research strategy. As an example of the latter strategy the equations of ECO11 are used as behavioural equations for an economy. The result of this simulation after 12 years is presented in figure 8.3. Figure 8.3 shows that the economy declines very rapidly, in contrast to ECO11. Therefore, essential parts of the behavioural equations are missing. Especially the investment equation does not react sufficiently to structural changes. ${ }^{6}$ It seems that the decision making process is much more subtle than has been modelled in the investment equation. This is not surprising because the equations have been developed on an ad hoc basis. A further investigation of investment behaviour in the game requires a more thorough theoretical investigation. But the result may be sufficient to illustrate how experiments, simulation and theoretical developments may be combined into a general research strategy.

\footnotetext{
to Some variations thave been tried. Although the estimated coeflicients sometimes were more significant, the simulation results were allwy sorse.
} 
One may also use the game as an instrument for pure simulation. The structure of a simulation program as a game has the advantage that it forces researchers to formulate strategies for firms that are based only on information that can be available for the players. Simulation may help to find out what type of policies survive in different institutional contexts. Simulation may also help to find out to what extent the mixing of different policies stabilizes or destabilizes an economy.

\subsubsection{Mixing human and computer players}

One may also combine the computer simulation strategy with the experimental research strategy. During most games that were played with students a simple automatic player was used as a reference player. In general, the simulated player ended with the highest value when the human players played the game for the first time, while the computer player was one of the worst in games with more experienced players.

Because it is difficult to develop a plausible set of decision rules directly, it seems a useful research strategy to develop the decision rules recursively. You may start with a plausible set of rules, simulate an economy where some firms apply those rules and then perceive the behaviour of the automatic firm in such an economy. The investigator perceives inefficiencies in the behaviour of the automatic players that would also be perceived by real players, and therefore improves the behavioural routines. In this manner a plausible set of decision rules can be developed. One may also try to develop optimal decision routines out of theory and test how they perform in the game world.

In the new game program it will be possible to program decision rules for automatic players interactively. This implies that one can ask human players to model automatic strategies and to adjust those strategies when they think that the automatic strategy is incorrect. In this manner one may get a large variety of automatic players that can be used for systematic simulation experiments. It is premature to present results here.

\subsubsection{Conclusion}

Both theory, simulation and experimentation have their role in the development of theory. Theory is essential for the formulation of consistent strategies. Simulation may be very useful to investigate the dynamics of a system. But the use of human players is essential to study learning behaviour and can be very useful to develop reasonable computer routines. 


\subsection{Macroeconomic gaming as a research strategy}

The game has been designed for the investigation of the fundamental macroeconomic coordination problem as discussed in chapter 1. But variations on the game can be developed that create the opportunity for the investigation of a lot of other problems. The game represents a potential research strategy. But in the first instance we look for improvements of the game that are relevant for the investigation of the fundamental coordination problem.

\subsubsection{Simplism versus realism}

The game developed in this dissertation has been kept as simple as possible. When the simple game has been accomplished, one may search for extensions of the game. But those extensions have to add valuable insights. This implies that they must have fundamental links with the coordination problem. First, the one-sector game is unsatisfactory from a theoretical point of view. Therefore, it is important to develop a game with two sectors: consumption and investment goods. Second, the market institutions require improvement. The labour market in the game is modelled consistent with assumptions of classical theory (Marx, Malthus, Ricardo), but does not seem very relevant in the modern Western world. The introduction of labour unions (as models or as players) is therefore useful to increase external validity of the game. On the output market the fixed number of suppliers is unsatisfactory. Free entry and exit is an important assumption in free market theory. Therefore, it is interesting to model this phenomenon in the game. Fourth, it has been emphasized many times that the modelling of the monetary sector is too rudimentary in the game. For this reason a better developed banking sector may be useful. This extension will complicate decision making for normal players in the game, because it will become necessary for them to develop a treasury policy. A stock market may be the crown on this line of development. Fifth, technological change and maintenance cost for machines can be another line of development. Especially technological change has an important role in modern theories of the business cycle. Sixth, a more developed government sector can be useful when one wants to investigate opportunities for the government to intervene in the economy.

\subsubsection{More sectors}

The model behind the game is fundamentally a two-sector model. It is rather artificial to simplify it into a one-sector model on the output side and divide this output by a computer routine over the two sectors. For this reason the development of a twosector game has high priority. At this moment a version is operational where each firm has two divisions: one for machines and one for consumption goods. But experience with this game shows that for untrained players it is very difficult to manage such a firm. For this reason it is better to introduce separate firms that produce machines. But in order to maintain sufficient competition in each sector the number 
of firms in the game has to be higher in a two-sector than in a one-sector game.

The model of the game with two sectors (but with one sector per firm) can be as follows. The firms in the consumer sector are modelled in the same way as in the one-sector model. The investment sector is different in structure with respect to the sales market. Ideally one would have a market for machines in which the demanders. of the machines bargain with the suppliers of the machines. In practice, players do not have enough time to accomplish this. Therefore, a fictive intermediary merchant of machines has been introduced who is managed by the computer program. This merchant buys machines at the machine factories and sells them to the buyers of machines.

Just as in the one-sector game, the firms can buy machines at a price and deliwery that is known at the moment the firm orders the machine. This implies that the intermediate seller (i.e. the computer program) sets the machine price and delivery time in such a manner that he can buy the machines from the machine suppliers. The procedure is as follows. First, the estimated delivery time of each firm $\mathrm{j}$ is computed:

$$
D T_{j}^{M}=\frac{O_{i}^{M}}{Q_{j}^{M}}
$$

where $\mathrm{DT}_{\mathrm{j}}^{\mathrm{M}}=$ delivery time of firm $\mathrm{j}$ in months, $\mathrm{O}_{\mathrm{M}, \text { unp }}^{\mathrm{M}}=$ number of machines ordered that have not been produced, and $\mathrm{Q}^{\mathrm{M}}{ }_{\mathrm{j}}=$ production of machines per month by firm $j$. The stock of machines ordered declines as a result of production and increases through new orders:

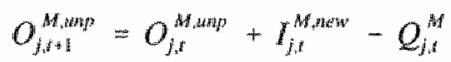

where $O^{\text {Mnew }}=$ new orders of machines for firm $j$ in period $t$. The stock of machines produced but unsold for firm $j$ is:

$S t_{j, r+1}^{M}=S t_{j, 4}^{M}+Q_{j, M}^{M}-I_{* j, 4}$

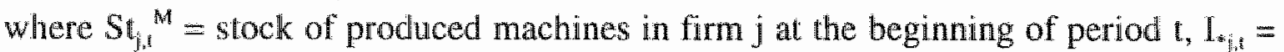
deliveries of machines by firm $j$ in period $t$.

Second, the new orders are divided over the machine suppliers according to their attractiveness. This attractiveness is assumed to be a simple function of the price and the estimated delivery time:

$$
A \Delta t_{j,}=\alpha_{a} \frac{p_{j}^{M}}{p^{A}}-D T_{j}^{M}
$$

where: $A t t_{j}=$ attractiveness of a machine sold by firm $j, \mathrm{P}^{M}=$ average price of machines (computed as a weighted average; weighted by the average production. level), $P_{j}^{M}=$ machine price of firm $\mathrm{j}$.

Third, because the computerized intermediary trader of machines sets the delivery time in advance, he must set a delivery time that is sufficient to get enough machines. Because the players have great freedom in their decision to invest, a buffer has to be created for changes in machines ordered. For this reason the delivery time 
of machines for the ordering firms is set as:

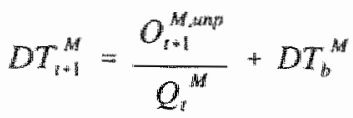

where $\mathrm{DT}_{b}{ }^{\mathrm{M}}=$ the buffer delivery time that prevents that the intermediary machine trader runs out of stock.

Fourth, the machine price has to be set in advance, too. This price is computed as the average price set by the machine producing firms corrected for the inflation rate:

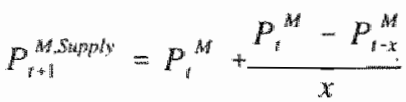

where $\mathrm{P}^{\mathrm{M} \text { swpply }}=$ price of machines set by the intermediary trader, and the last term gives the average rise in price over the last $x$ months.

Because the model of the investment good sector differs from that of the consumer good sector, the data presented to the players are a little bit different, too. Because in many cases less than one machine per month is produced, sales must necessarily be zero in many months. Furthermore, most machines are built on order instead of for stock. For this reason 'orders in stock' is the relevant variable that indicates the position of the firm on the output market. When machines are finished, they will be delivered. Only in a deep recession is the size of the stock of unsold machines likely to rise above one per firm.

This completes the basic two-sector game. It will be clear that the decisions of each firm are the same as in the one-sector game (i.e. price, wage, labour demand and machine orders). The two-sector game shows that a rise in investment does imply a rise in demand for only a limited number of firms. And it provides the opportunity to model demand for investment goods in a different manner from demand for consumer goods.

\subsubsection{Improvement of market structure}

Although the structures of the markets in the game are sufficient for an interesting game, they are open to improvement. For example, the distribution of labour supply over the firms is rather primitive in the sense that one can always get labour when the unemployment level is above $5 \%$. This is caused by the homogeneity of labour and the absence of labour unions. Although such a world is consistent with the assumption of subsistence wages in the Classical theories of, for example, Malthus and Marx, it is not consistent with the modern Western world.

At this moment the game leader can set a minimum wage level. This minmum wage level is only used in order to prevent too much deflation in extreme recessions. But one may also introduce it as an effective instrument for the investigation of the effects of labour unions on the economy. In that case, computer programs for wage settements can be made, that can set minimum wages. Those wages may be deter- 
mined after negotiations between labour unions and employers" organizations, where both have a goal function defined by the game leader. One may ask the labour union to maximize the total wage sum of the employees or another function of real wage and employment. The employers" organization may maximize total profits in the economy or the average return on capital. One can also think of employers' organizations that are elected by the firms in the game. Each game year both groups have to find an agreement that is implemented through the wage settlement player program. One may implement strikes as an instrument to put pressure on the negotiations by stopping all or part of the production in some or all firms for a period.

Also on the output markets the rationing schemes are rather simple. First, the players are not able to ration supply as long as they are not out of stock. For this reason it may be useful for players to be able to set the maximum number of sales at a certain level. Second, the players are not able to lower production without reducing their employment level. When players want to reduce the cost of stock without losing their employees, labour hoarding can be useful. Therefore, it is useful for players to be able to set a maximum production level.

Every elementary textbook on free markets mentions that free entry and exit is important for free competition. Especially, the exit of bankrupt Iirms is important. In order to prevent the number of firms declining as the game progresses, the possibility for entry has to be introduced too.

The criterion for bankruptcy is obvious: when the net present value of a firm is negative, it is bankrupt. In order to devise a more operational definition, one may define a firm bankrupt when equity capital becomes negative.

If furms can go bankrupt, it is essential that also new firms can start. For such new firms plausible starting conditions must be introduced. According to the formula that defines market shares in the game, new firms have no opportunities to sell anything as long as other firms are able to sell. Therefore, the institutional setting defined in the market share formula must be changed.

The extensions suggested in this section do not need to complicate decision making for firms. Extra decision variables like maximum sales and maximum production are only relevant in special circumstances, and may be added to the game as extra features. The introduction of labour unions complicates the structure of the game because it implies extra players.

\subsubsection{A monetary sector}

Because money has an important role in the discussion about stability of macroeconomic systems, it is usefull to incorporate this sector in the economy. In the current game firms can lend at the going interest rate without a severe limitation. Only some restrictions on the ratio of equity to total capital, a maximum investmentcapital ratio, and a maximum ratio between future labour requirements and

\footnotetext{
${ }^{7}$ Because of linited storage capacity it is plausible that firms are forced to limit their production when storige capacity is full. This may be imposed as a restriction on the decisions of the firms.
} 
current labour stock are implemented now. While in the game the Central Bank can only influence the interest rate, in the real world the instruments of the Central Bank are more subtle.

The first step in introducing money is to differentiate between long term loans and short term loans, such that short term loans have a higher interest rate than long term loans. In such a setting the number of decisions for firms is extended by one decision, the decision for long term Loans. ${ }^{8}$ When a firm has borrowed insufficient money on a long term base, it is forced to borrow on the money market at a high interest rate.

The most obvious method to introduce a banking sector is to institute banks as players. This implies that the minimum number of players rises. Those banks are free to set interest rates at which they accept loans, and they may negotiate long term contracts with the firms. The banks start with a cash position and the Central Bank may set a minimum cash requirement. It seems not too difficult to model the banks consistent with introductory textbook monetary theory. The managers of those banks are forced to set optimal interest rates (in competition with other banks) and develop procedures for lending to firms. One of the important challenges for a bank is to investigate the solvability of a firm. To create an incentive for this, it is important that firms can go bankrupt.

Both because the stock market has an important role in economic theory (for example Tobin's q in investment theory), and because the stock market is an important research topic in itself, it is valuable to introduce a stock market into the game.

At this moment equity capital only grows through profits. It seems reasonable to create the opportunity to set out equity on a stock market. Such a stock market can be managed as a separate game, where investors have to sell and buy equities of the firms. The investors may get money from the banking sector, from firms, or from consumers. The auctioneer may type the settled contracts on one equity computer. Therefore, the computer network does not have to be expanded much to seltle such a system.

When one introduces a stock market, the supply of equity funds is not clear a priori. One may assume that the investors on the stock market get part of the money that has been saved by the consumers. For this reason, an explicit function has to be introduced that distributes savings over stock market suppliers. If one wishes, a bond market may also be introduced.

The introduction of a stock market will have consequences for the objective function of the players. Goodwill was an artificial construct that had to be used because of a lack of more natural methods to evaluate the performance of firms. With the introduction of a stock market, the objective function can be defined more easily as maximization of the value of the firm on the stock market. This implies that the firm's accounts acquire a natural meaning; it may influence the markel value of the firm. For this reason, the game may become interesting for a new group of players: accountants.

Although the technical details of the introduction of a stock market will require a lot of further investigations, there seem to be no fundamental barriers to add such a

"The loans of a firm can be modelled analogous to the capital structure in the putty-clay function. 
market to the game. From a research point of view it is useful to investigate the influence of such an institution on the dynamics of the game economy. Furthermore, the results of stock markets in the game may represent an interesting case lying between the very simple experimental stock markets and the very complex real world stock markets. Finally, playing the stock market game may be rewarding in itself for people who want to learn about fundamental mechanisms in stock markets. Because of the importance of microeconomic as well as macroeconomic variables for the stock market, one may expect that the game model has important advantages compared with more artificial stock market games where the developments in the stock market are modelled completely in a computer model.

In summary, from a theoretical point of view it is desirable to introduce a welldeveloped monetary sector into the game. But such a sector will always complicate the game for the players.

\subsubsection{Technological development and maintenance cost of machines}

The current game has no technological progress. Because in modern theories of the business cycle technological progress has an important role both as a destabilizing and a stabilizing factor, it can be useful to introduce this aspect into the game. On the other hand technology is more flexible than is assumed in the game. Especially the fixed lifetime of machines has destabilizing effects. The introduction of maintenance cost makes lifetime more flexible.

The simplest method to introduce technological change is the creation of a production function where the coefficients depend on time. This implies the introduction of vintage effects into the model. It complicates the insight of the players a little bit, but does not influence the essential characteristics of the game.

Endogenous technological development is more important, but also more difficult to introduce. For endogenous technological development a new decision variable has to be introduced: research and development (R\&D). One may define the effect of R\&D as a chance for a more efficient production function. One may assume that new technologies are only available for the firms who developed then, but they can also be embodlied in the machines. In that case investment of machine factories in $R \& D$ causes technological change. One could also think about the possibility for firms to sell their techniques to other producers. This introduces a lot of research opportunities, both about the macroeconomic effects of technological change and about the microeconomic analysis of competition.

One may imagine investment in human capital as another extension of the game. One may introduce a learning curve for labour (this implies that the labour force has to be modelled analogous to the putty-clay machines). As long as this learning effect is firm specific and not specific for the employees, it will not influence the game fundamentally. But when the effects become specific for specific employees, one has to introduce non-homogeneous labour. This is also the case when one would define training cost. Non-homogeneous labour implies differentiation in rewards. For the time being, this is much too complicated.

It appears to me that technological development is not a first priority to introduce 
into the system, but can be used as an interesting extension. It may introduce valuable opportunities for research.

At this moment the machines have a fixed technical lifetime. In the real world the technical life of a machine is influenced by mantenance. Therefore, the decision to stop using a machine is a management decision. It increases the flexibility of capacity in the economic system and therefore can be of importance for the fundamental coordination problem.

Maintenance is rather easy to introduce into the game. For example, one may create a maintenance cost function with cost increasing with age of the machine. One can introduce a decision variable that defines the maximum cost at which a machine of a certain age will be repaired. When technology is introduced in a more complicated manner, the management of maintenance will require rather sophisticated decision making that is only possible when the opportunity is available to program a policy.

What will be the benefits of introducing maintenance? First, one may improve the game as an instrument for training the reaction to business cycles by means of production policy. Second, maintenance creates more flexibility in the system. This may have important consequences for the behaviour of the macroeconomic system.

In summary, both technological change and maintenance cost can be important in the analysis of the fundamental coordination problem: technological change mainly as a destabilizing factor, maintenance cost as a stabilizing factor.

\subsubsection{Government as a player}

At this moment the game leader may influence the consumption function and the minimum wage level. This can be regarded as a substitute for a Keynesian government policy. Furthermore, the game leader can set restrictions on wages and prices. It is an obvious extension to expand those instruments by introducing a government budget and more advanced instruments to influence the changes of wages and prices in the economy. But the introduction of a tax system and government expenses is required to introduce a more realistic government into the game. One may create the opportunity for the government to design a tax system that can be implemented. But such a system will complicate the game. Furthermore, it will obscure the functioning of the market economy. Therefore, in the short run it is not useful to introduce more than a marginal role for government in the game.

\subsubsection{Conclusion}

The purpose of this section was to show that the game can be extended, and that such an expansion can increase insight in the fundamental macroeconomic coordination problem. But for the ease of interpretation it is important that not too many new mechanisms are introduced at the same moment. A strong point of the current game is its relative simplicity. And even in this game it is difficult to disentangle the 
mechanisms at work. Therefore, from an experimental point of view one has to be very parsimonious in introducing new features into the game. But for the creation of robust theoretical results variations in the game are essential.

\subsection{Conclusion: the game as a potential research strategy}

The experimental purpose of the game is the development of an experimental research strategy in macroeconomics. This chapter has presented some first results of the simplest version of the game. The design of an effective game can already be a part of such a research strategy in that it forces one to model the structure of an economy in such a manner that human players are able to make all decisions. A lot of implicit behavioural assumptions and coordinating devices in traditional theory have to be modelled explicitly in a game. When one is successful in designing a game that is consistent with the assumptions of many theories, it may be helpful to settle controversies between different camps of economic thought.

When a game has been developed, it can be used as a simulation program. This creates the opportunity to investigate the dynamics of the macroeconomic system. But it is also useful to investigate optimal decision making of firms in the institutional context of the game. One may develop optimal decision rules from formal theory, but one may also develop those decision routines from practical experience with the game. When one asks players to play the game by programming their policy, a great variety of decision rules will be developed with all the fantasy players have. When those decision routines have been developed, they create the opportunity to simulate games with different mixes of those routines and investigate which routines have the best performance.

The use of players in designing decision routines is one application of the game economy as a game. But when one assumes learning in an economy, the decision routines will change over time. This implies that there is not one optimal decision routine, but that the type of decision routine that is optimal changes over time. With real players one may investigate the change of those decision routines over time.

Finally, the research strategy developed in this thesis has much broader applications than only for the investigation of the stability of a macroeconomic system and the role of expectations in it. The concept of this macroeconomic game can be used for research on a lot of topics of microeconomic and macroeconomic theory. 
Appendix 8A. The development of national income of 11 game economies.
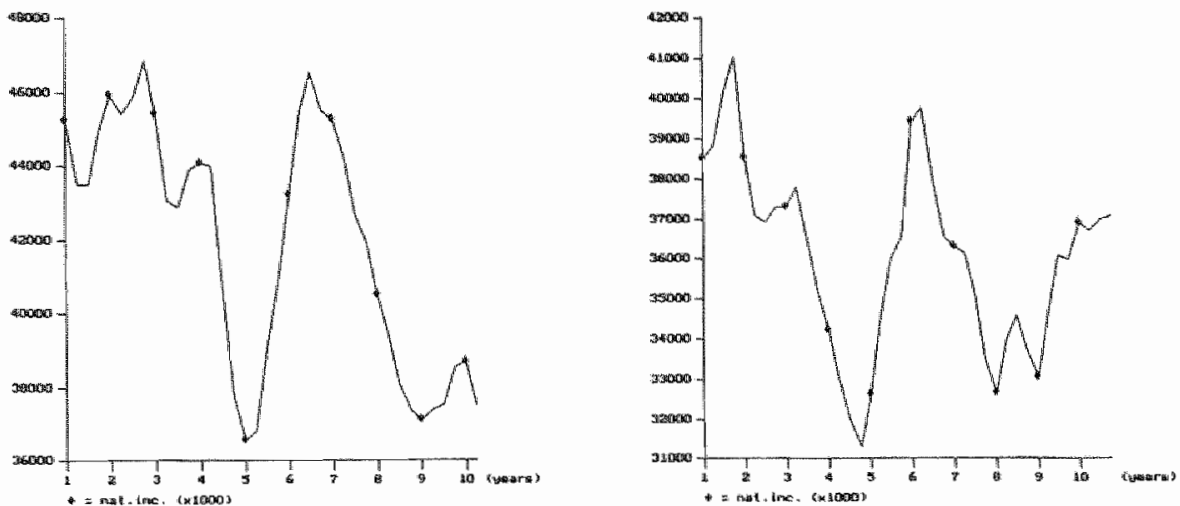

$\mathrm{ECO} 1$

$\mathrm{ECO2}$
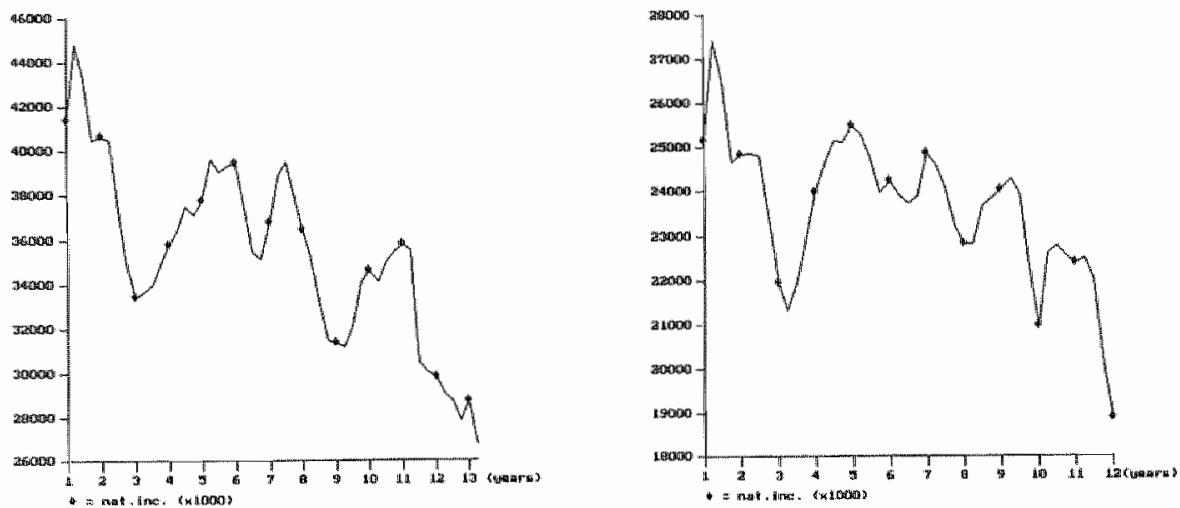
$\mathrm{ECO} 3$ $\mathrm{ECO}$

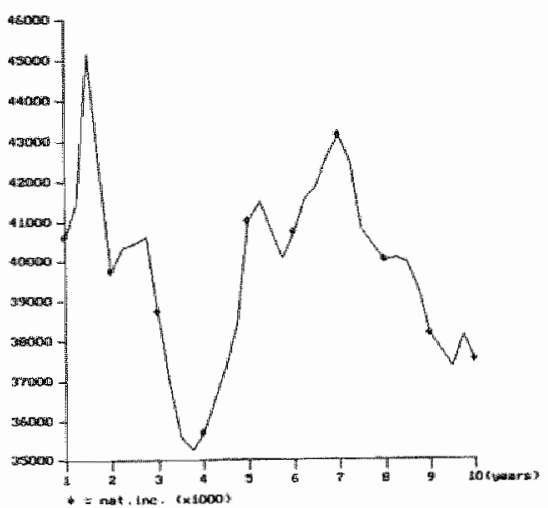

ECO5

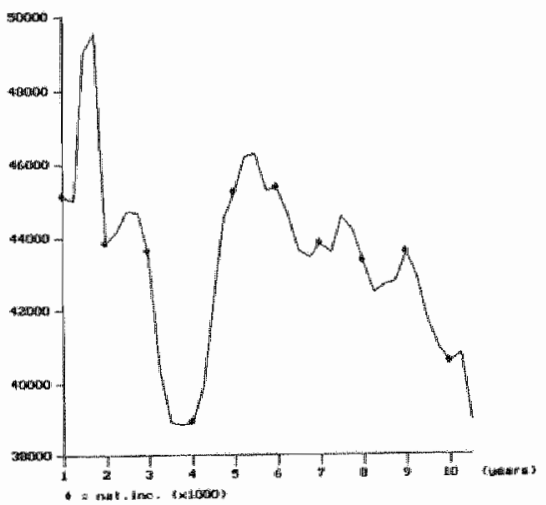

$\mathrm{FCO6}$ 


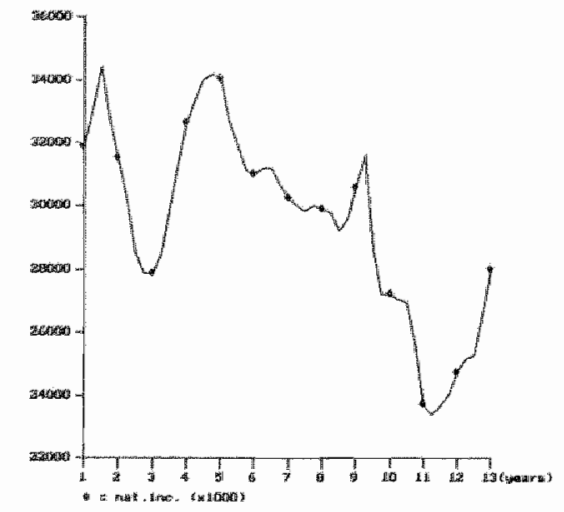
ECO7

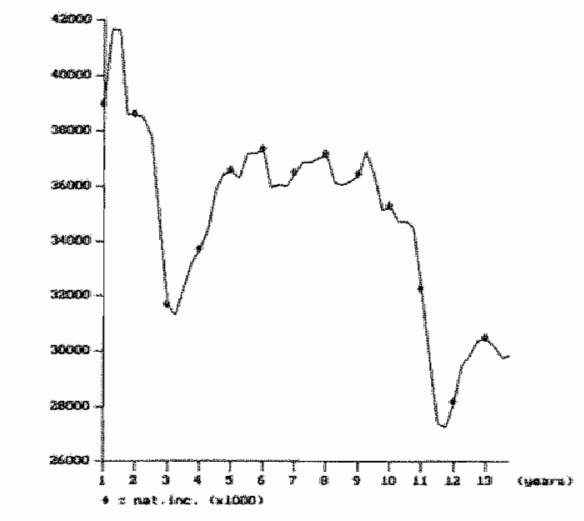

ECO8
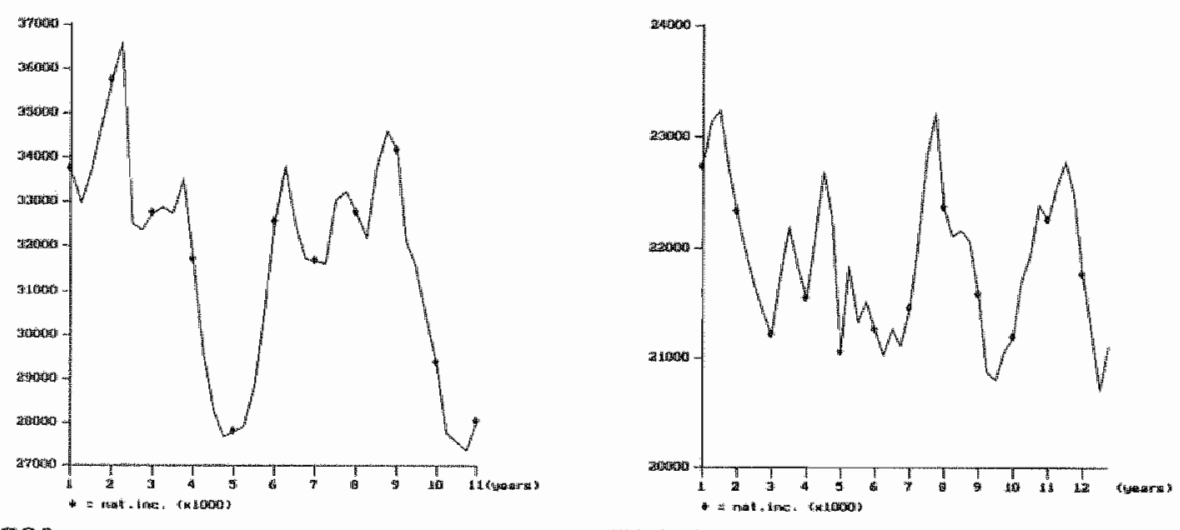
ECO9 ECO11

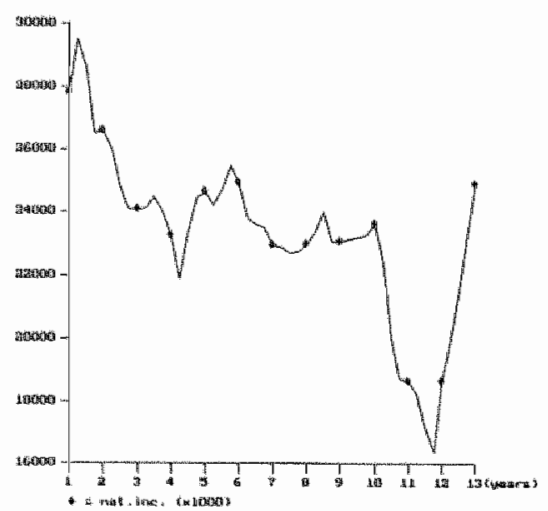

ECO12 


\section{Appendix 8B. The content of the automatic players.}

If you want to play the game with a limited number of real players, you have to program automatic players to guarantee a sufficient number of players for the market to be competitive. For this reason a simple decision routine has been developed. This routine is as follows:

\section{Investment decision.}

If production capacity after delivery time is higher than $x_{1} \%$ of current demand, or if labour capacity after delivery time is higher than $x_{2} \%$ of current labour stock, investment is 0 . Otherwise investment equals $y$.

\section{Price decision}

If stock is less than $x_{3} \%$ of production, price is $z_{1} \%$ higher than the awerage market price. If stock is higher than $\mathrm{x}_{4} \%$ of production, price is $\mathrm{z}_{2} \%$ lower than the average market price. Otherwise, price equalls average market price."

\section{Labour demand}

If sales are lower than $x_{5} \%$ of production capacity, while the stock of final products is higher than $x_{5} \%$ of production, labour demand will be set at labour capacity times sales divided by production capacity at the delivery time. Otherwise labour demand equals labour capacity.

\section{The wage rate}

If labour demand is lower than $x_{6} \%$ of current stock of labour, the wage rate will be set $z_{3} \%$ lower than the market wage. If labour demand is higher than $x_{7} \%$ of the current stock of labour, the wage rate will be set $z_{4} \%$ higher than the market wage.

\section{Correction of wages and prices at low profit rates}

The profit margin (past inflation is used in determining this profit margin) at full capacity is set at $x \%$ at least, first by adjusting the price, and if this is not possible, by adjusting the wage rate.

\footnotetext{
Average market price is average price of the last month.
} 


\section{Chapter 9}

\section{Conclusion}

This dissertation is about a cluster of interrelated ideas. The basic idea is that economics is not about well-defined theories, but about a limited number of basic principles that are connected with each other. One of this fundamental principles is the issue of macroeconomic coordination and its relation to Walras law. Investigation of this coordination problem shows the importance of expectations and decision making routines in economic coordination. The game that has been developed in this dissertation is focused on the macroeconomic coordination problem.

The basic principles approach to economics implies that economic theories have to be taught as application of fundamental principles. In chapter 2 it has been shown that this approach is consistent with cognitive psychological learning principles. The purpose of teaching has to be to develop a well-integrated knowledge structure that is related to other knowledge. Therefore, students must be trained to recognize the basic principles in economic theories as well as in real world situations. Beside case studies and a presentation of the theories along basic principles, games can be a useful teaching device in this context.

In a rudimentary fashion the basic principles approach has been used in teaching economics for law students. In chapter 6 some research methods have been developed to investigate the effectiveness of teaching. First, factor analysis of multiple choice and true-?-false questions distinguishes different dimensions of knowledge. Factor analysis of questionnaires about the game show different dimensions of game participation. Regression analysis shows that participation in the courses or in the game have different results for different factors. Sometimes those correlations have to be explained as the result of some student characteristics, but sometimes a causal relation is plausible.

Second, the ability to recognize basic principles behind questions on economics has been investigated by a categorization experiment. Students were asked to categorize a set of questions on the theories that had to be applied to solve the questions. The result shows that law students who followed a short course in economics, partly organized according to the basic principles approach, were better able to do this than economics students who followed a more technical course that was twice as big. Although this result does not justify the conclusion that the basic principles course was better, it suggests that the basic principles approach has some effect on the way students think.

The test has also been applied to fourth year students in economics and to macroeconomic teachers. The results suggest that fourth year economics students are much better in recognizing basic principles behind questions than first year eco- 
normics students and students studying a program in culture and science. But macroeconomic teachers performed worse than fourth year students in economics. This is very surprising, but may be partly explained by the fact that the students had recently studied all topics whereas macroeconomics teachers were focused more on their specialization. But what is perhaps more important is the practical problem that economics teachers took less time for the categorization than the fourth year economics students and the law students.

Third, a pattern recognition test was designed. Students had to recognize phases in the business cycle behind a sketch of a fictive economy. After reading the small text they were asked to write down everything they could remember. Then they were asked to characterize the situation of the economy. The result with a group of cultural students after a short course around the game shows that those students remembered a lot more about the economy after the course than before and they were much better able to recognize the position of the economy. Perhaps as a consequence of the focus on economic principles, the recall of institutional aspects was much lower after the course. Those results suggest that the course was effective.

The test has also been applied to first year and fourth year students in economics and to macraeconomic teachers. The results of the first year economic students were worse than those of the cultural students. The recognition of the position of the economy in the business cycle seemed to be better by cultural students than by economics teachers, where both fourth year economics students and economics teachers recalled many more institutional factors than first year economics students and cultural students. This suggests that expertise is related with a greater focus on institutions.

Although the tests suggest some effect of the principles-based courses, they also suggest that the principles based approach has to be applied much more rigorously. The systematic application of the teaching principles combined with raining the course designer in the basic principles of economics may result in a much better course than the one that is used now. This also shows how difficult it is for an economist trained in mainstream economics to think in a basic principles way.

The principles-based approach has some consequences for research, too. When one searches for fundamental mechanisms it is very disappointing when discussions focus on models that are difficult to test in the real world because of a lack of data and a lack of opportunities to control for external influences. For this reason experimental economics has emerged. Especially in the fields of game theories, auction markets and public choice it has become rather popular. The basic experimental methodology is that one tests well-defined formal theories that are based on utility theory. By a monetary reward schedule one tries to induce behaviour consistent with the formal utility functions. This is called induced preference theory.

Such an approach is not easy to accomplish in macroeconomics because the macroeconomic system is very complex. In my opinion, part of the complexity arises because the macroeconomic system is not defined according to basic economic principles. For example, mainstream economics (as represented for example in textbooks of Samuelson or Hall and Taylor) states without proof that in the long run a free market economy is stable, whereas short run (Keynesian) instability arises from 
inflexible prices. Chapter 1 has shown that this is in contrast with the view in the General Theory of Keynes and avoids the investigation of money as a coordinating device in the economic system. In such a manner the law of Walras, and therefore the general equilibrium character of the macroeconomic system, is defined away. The macroeconomic game presented in this thesis is developed to investigate this fundamental coordination problem in macroeconomics.

The fundamental coordination problem is about the ability of human economic agents in a free market economy to coordinate their activities in such a manner that excess supply and excess demand disappear automatically. Therefore, the problem is defined in a specific institutional setting: the free market economy. Therefore, in the game technology and market forms had to be consistent with the institutional assumptions of neoclassical general equilibrium growth theory. But because the differences between theories have to be found in assumptions about expectations formation and decision making, the economic system built is consistent with other economic perspectives, such as the Keynesian and Hayekian approach.

In chapter 4 the framework for the game has been developed. To create a free market economy players had to be as free as possiblle in their decision making. The game had to include institutions that were essential in stabilizing the economy, but are mostly not explicit in economic theories. For example, a dynamic market structure as well as a putty-clay production function have an important role in stabilizing the economy. The market structure had to be consistent with free competition, but without forcing market equilibrium in any market. This implies that the adjustment processes had to be done by the players. In order to have a plausible speed of those adjustments, the simulated decision period had to be rather short. But in order to investigate long term developments the game had to be played a lot of periods. For this reason intensive interaction between the players on a computer network was necessary.

In the development of a game there is a tension between realism and simplicity. When one tries to create a game where all relevant aspects of business policy are included, the game becomes impossible to play and the results will be difficult to interpret. For this reason I have chosen to search for the simplest that was sufficient to investigate macroeconomic dynamics. This implied that the monetary adjustment mechanism, that is so important in, for example, the theories of Wicksell and Keynes, was modelled in a very rudimentary way. The result was a game with only four decision variables per player. But even in this simple structure there is an immense amount of data to analyse.

Chapter 7 has shown that the concept used in this game can be used to develop a lot of variations on the game that may be relevant for more thorough analyses. In the current model especially the one sector type of output and the exclusion of a sound capital and money market are unsatisfactory, because those markets have a crucial role in theories of the business cycle.'

1 Besides a more thorough analysis of the macroeconomic coordination problem, one can also use the game or variation of it for the investigation of other topics of interest. For example, if a stock market is introduced in the game, there is created an opportunity for experiments somewhere between the very stylized traditional experiments of stock market dynamics and the real world. 
The macroeconomic game can be used in a very broad research strategy. First, the design of the institutional structures of the game is interesting in itself because it forces one to create a world where real human beings can play. Second, the game can be used for microeconomic simulation. When one simulates the player decisions by computer routines, one can investigate the consequences of those decision routines for the performance of the firm. Those routines can be derived from formal theories. Third, one may use the program for macroeconomic simulation. Simulation with one representative player can be used to investigate the dynamics of the system. Simulation with a number of different players can be used to investigate the effects of the interaction between different types of actors in an economic system. Fourth, the game can be used as a game with human players. Human players may have more subtle expectation formation mechanisms than can be implemented in a decision routine. So, one may investigate to what extent the economic system behaves differently when human beings make decisions than when computer routines do it. The results of those experiments can be used for econometric investigation. To check to what extent the estimated equations really capture the dynamics of the behaviour of the players, the estimated behavioural equations can be used as decision routines. One may also compare the performance of human players with automatic players. Finally, one can ask the players to program automatic policies. During the game they can adjust those policies. In such a manner a great number of policies can be developed in an evolutionary process. Those decision routines may reveal a lot of the reasoning process that is normally hidden. Furthermore, those decision routines can be used as input for microeconomic and macroeconomic simulations.

The game fits well in a principles-oriented course in economics. For good results the players must be able to apply microeconomic principles like fixed and variable costs and long versus short run elasticity of demand. But those decisions have consequences for the macroeconomic system. Therefore, they get an intuitive feeling for the macroeconomic mechanisms at work. For example, investment accelerator type of processes in the system can be recognized easily during the game because the players are participating themselves in the generation of this mechanism. Therefore, they will become automatically aware of the important role of expectations in such a mechanism. Furthermore, the students will be able to profit from understanding the macroeconomics dynamics. This motivates them to apply the theories. But because the macroeconomic dynamics is so much related to their own decision process, they elaborate the theories in a lot of different contexts. Therefore, it is plausible that the game can be helpful in creating a well-developed knowledge structure that is embedded in intuitive knowledge.

As discussed in chapter 6 , the development of the game is much more than the design of a feasible technical setup. The training of the players is essential both for education and experimental research. Especially systematic feedback and active assignments are essential for understanding and appreciating the game. Most students need some help in relating the experience in the game to economic theory. This is especially the case for students who have experience in theory-based courses (in contrast to principles-based courses). Carefully designed assignments are needed to help students to structure and interpret the more than eighty time series that become 
awallable in the game. The broader appreciation of the game after the assignments had to be implemented in the game proves the importance of them.

For experimental research the availability of carefully trained players is a sine qua mon. Until now most games mainly show the players" rather elementary errors, while the controversy about the macrocconomic coordination problem is about the behaviour of an economic system with more or less rational human beings. When players do not have much insight into the game, severe disequilibria emerge that generate an economy in deep recession and/or an economy in a raging boom. This is not only boring to play but also not very relevant from a theoretical point of view; in an economy with non-rational players it is not surprising that Keynesian mechanisms have an important role. But evidence with some economies (for example the game ECO11) suggests that economies with more experienced players are more stable and therefore both more interesting to play and of a higher theoretical impact.

In conclusion, this dissertation is about new methods in teaching and research. The macroeconomic game, the experimental research style and the principles-based approach are all in their infancy. This dissertation shows that principles-based courses seem to be viable. But they require a lot of reflection about what is basic in economics. The approach of macroeconomic experiments with games seems to have a fruitful future. Theory, econometric investigation, simulation and experiments with human beings are used as an integrated whole in this approach. In chapter 8 some promising results have been presented. But results that are really relevant have to wait till the computer program of the game has ended its childhood. The game will be available shortly, and then this experimental approach can show its value. It may be that the game will be the starting point of a tradition of experimental research in macroeconomics, and the game will be the father of a big family of other games. May be not. 


\section{References}

Ackley, G. (1978), Macroeconomics: theory and policy, Macmillan, New York/Collier Macmillan, London.

Arestis, P. (1992), The post-keynesian approach to econmics: an alternative analysis of economic theory and policy. Elgar.

Banaszak, R.A., Brennan, D.C. (1983), Teaching economics: content and strategies, Addison-Weslye, Menlo Park, California, etc.

Barro, R.J., Grossman, H.I. (1976), Money, employment and inflation, Cambridge University Press.

Barro, R.J., Grilli, V. (1994), European macroeconomics, MacMillan.

Beck, I.L., McKeown, M.G. (1988), "Toward meaningful accounts in history texts for young learners", Educational Researcher, 31-39.

Begg, D., Fischer, S., Dornbusch, R. (1994), Econowics, fourth edition, MeGraw-Hill, Muidenhead, Berkshire, England.

Bereiter, C., Scardamalia, M. (1992), 'Cognition and Curriculum', in: Jackson, P.W., Mandbook of research on curriculum: a project of the American Educational Research Association, Macmillan, New York, etc, 517-542.

Berlyne, D.E. (1960), Conflict, arousal, and curiosiry, McGraw-Hill, New York.

Birner, J., van Zijp, R. (1994, ed), Hayek, co-ordination and evolution, Routledge, London and New York

Bobrow, D.G. (1985), Qualitative reasoning about physical systems, MIT Press, Cambridge, MA.

Butos, W. (1986), "Hayek and general equilibrium analysis", Southern Economic Jownal, $52,332-43$. 
Carlin, W., Soskice, D. (1990), Macroeconomics and the wage bargain: a modern approach to employment, inflation and the exchange rate, Oxford University Press, Oxford, etc.

Chamberlin, E.H. (1948), "An experimental imperfect market", Joumal of Political economy, 56:95-108.

Champagne, A.B., Klopfer, L.E., Desena, A.T., Squires, D.A. (1981), "Structural representations of students" knowledge before and after science instruction", Journal of Research in Science Teaching. 18-2, p 97-111.

Champagne, A.B., KJopfer, L.E., Gunstone, R.F. (1.982) "Cognitive research and the design of science instruction', Educational psychology, 17-1, p 31-35.

Chi, M.T.H., Feltovich, P.J., Glaser, R. (1981), 'Categorization and representation of physics problems by experts and nowices", Cognitive science, 5, p 121-152.

Chiang, A.C. (1974), Fundamental methods of mathematical economics, McGraw-Hill Kogakusha, Tokyo, etc.

Clower, $\mathbb{R}$. (1965), "The Keynesian Counter-Revolution: a theoretical appraisal', in: F. Brechlin, F.H. Hahn (eds), The theory of interest rates, Macmillan, London, 103-125.

Colander, D. (1990), "Workmanship, incentives, and cynism", in: Klamer, A., Colander, D. (1990), The making of an econonist, Westview Press, Boulder/San Francisco/London, 187 206.

Cooper, R., John, A. (1988), "Coordinating coordination failures in Keynesian models", Quarterly Journal of Economics, 100(3), 441-65, reprinted in: N.G. Mankiw, D. Romer (ed), New Keynesian Economics, Vol. 2 Coordination Failures and Real Rigidities, MIT Press, Cambridge, Massachusetts, London, England.

Cyent, R.M., March, J.G. (1963), A behavioural theory of the firm, Prentice-Hall.

DeVroey, M. (1990), "The base camp paradox", Economics and Philosophy, 6, 235-253.

Disessa, A.A. (1982), 'Unlearning Aristotelian physics: a study of knowledge-based learning ${ }^{*}$, Cognitive Science, 6, p 37-75.

Dunteman, G.H. (1989), Principal components analysis, SAGE publications, Newbury Park, London.

Dyer, D., Kagel, J.H., Levin, F. (1989), 'A comparison of naive and experienced bidders in common value offer auctions: a laboratory analysis', Economic Joumal, 99, p 108-15.

Ees, H. van (1990), Macroeconomic fluctuations and individual behaviour: the implications of real and nominal inerria, Dissertation Groningen.

Eylon, B., Reif, R. (1984), 'Effects of knowledge organization on task performance', Cognition and instraction, $1,5-44$. 
Ferguson, C.E. (1969), The neoclassical heory of production and distribution, Cambridge University Press, Cambridge.

Fiedler, Urich (1979), Experimentelle Untersuchung eines geschlossenes gesamtwiotschaftliches systems, Darmstadt, Dissertation Berlin.

Fisher, F.M. (1969a), "Approximate aggregation and the Leontief conditions", Economerica, vol. $37,457-469$.

Fisher, F.M. (1969b), 'The existence of aggregate production functions', Econometrica, vol. $37,553-577$.

Fisher, F.M. (1983), Disequilibrium foundations of equilibriwn economics, Econometric Society Monographs in Pure Theory, Cambridge University Press.

Frank, R.H. (1994), Microeconomics and behavior, Mc Graw-Hill, New York, etc., second edition.

Friedman, M., Schwartz, A.J. (1982), Monetary trends in the United States and the United Kingdom, University of Chicago Press, Chicago, London.

Gremmen, H.J.F.M. (1989), SIER, a macroeconomic computer gane on cooperation and conflict in international economics, Dissertation Katholieke Universitteit Brabant, The Netherlands.

Friedman, M. (1968), "The role of monetary policy", Americon Economic Review, vol. 58, 1 17.

Friedman, M., Schwartz, A.J. (1963), A monetary history of the United Sirates, Princeton University Press, Princeton, 1971.

Gabisch, G., Lorenz, H. (1989) "Business cycle theory: a sturvey of methods and concepts, second edition, Springer Verlag, Berlin, etc.

Gagné, E.D. (1985), The cognitive psychology of school leaming, Little, Brown and Company, Boston, Toronto.

Garretsen, H. (1994), "The relevance of Hayek for mainstream economics", in: J. Birner, $R$. van Zijp (ed), Hayek, co-ordination and evolution, Routledge, London and New York.

Gametsen, H. (1992), Keymes, coordination and beyond: The development of macroeconowic and monetary theory since 1945, Elgar.

Glaser, R. (1984), 'Education and thinking: The role of knowledge", American Psychologist, 39-2, p $93-104$.

Glaser, R. (1991), "The maturing of" the relationship between the science of learning and cognition and educational practice', Learning and Instruction, vol. $1,129-144$. 
Glover, J.A., Ronning, R.R., Bruning, R.H. (1990), Cagnitive psychology for teachers, Macmillan, New York.

Gordon, R.J. (1990), 'What is New-Keynesian Economics?', Journal of Ecomomic Literaure, $28,1115-1171$.

Gordon, R.J. (1993), 'Why the principles course needs comparative macro and micro', AEA Papers and procedings, $83(2), 17-22$.

Habn, F.H. (1962a). "A stable adjustment process for a competitive economy", Review of Economic Studies, 29.

Hahn, F.H. (1962b), 'On the stability of a pure exchange equilibrium', International Economic Review. 2.

Hal1, R.E., Taylor, J.B. (1991), Macroeconomics, Norton, New York/London, Third Edition.

Hansen, W.L. (1991), "The education and training of economics doctorates", Joumal of Economic Literature, vol XXIX, 1054-1087.

Harberger, A.C. (1993), "The search for relevance in economics", AEA Papers and procedings, $83(2), 1-16$.

Hargreaves Heap, S.P. (1992), The new Keynesian macroeconomics: time, belief and social interdependence, Elgar.

Hayek, F.A. von (1937), 'Economics and knowledge', Economica, 4, 33-54.

Hayes, J.R., Simon, H.A. (1976), 'The understanding process: problem isomorphs', Cognitive Psychology, 8, 165-190.

Heiner, R.H. (1983), "The origin of predictable behavior", American Economic Review, 73, $560-596$.

Hey, J.D. (1991), Experiments in economücs, Blackwell, Cambridge, USA.

Heyne, P. (1983), The Economic Way of Thinking, Science Research Associates, Chicago, fourth edition.

Hicks, J.R. (1937), "Mr. Keynes and the "Classics"; a suggested interpretation", Econometrica, Volume $\mathrm{V}, 147-159$.

Hinsley, D.A., Hayes, J.R., Simon, H.A. (1978), "From words to equations: meaning and representation in algebra word problems', in: P.A. Carpenter and M.A. Just (ed), Cogritive processes in comprehension, Erlbatum, Hillsdale.

Hoogduin, L. (1991). Some expects of uncertainty and the theory of a monetary economy, Dissertation Groningen. 
Kahneman, D., Twersky, A. (1984), 'Choices, walues, and frames', Anerican Psychologist, $39,341-350$.

Kahneman, D. (1988), "Experimental economics: A Psychological Perspective", in: Tietz, $\mathbb{R}$, W. Albers, R. Selten (eds.), Bounded rational behavior in experimental games and markets, Springer Verlag, Berlin, etc.

Kasper et al. (1991), "The education of economists: from undergraduate to graduate study", Journal of Economic Literature, (XXIX), 1088-1109.

Keser, C. (1992), Experimental duopoly markets with demand inertia, Springer Verlag, Berlin, Heidelberg.

Keynes, J.M. (1936), The general theory of employment, interest and money, Macmillan, London, Cambridge University Press, New York, 1973.

King, P.G., LaRoe, R.M. (1991), "The laboratory-based economics curriculum", Joumal of Economic Education:285-300.

Kirzner, I.M. (1973), Competition and entrepreneurship, University of Chicago Press, Chicago.

Klamer, A., Colander, D. (1990), The making of an economist, Westview Press, Boulder/San Francisco/London.

Knight, F.H., Risk, uncertainty and profit, New York, 1921.

Krueger et al. (1991), "Report of the commission on gradtuate education in economics", Joumal of Economic Literature, (XXIX), 1035-1053.

Krugman, P.R. (1993), "What do undergrads need to know about trade?", AEA Papers and procedings, $83(2), 23-26$.

Kuipers, S.K., van Ees, H. (1990), "Macro-economische theorie en economische politiek", Economisch Statistische Berichten, 32-43.

Lachmann, L.M. (1943), The role of expectations in economics as a social science Economica, 108-119, reprinted in: Lachmann (1977).

Lachmann, L.M. (1956), Capital and its structure, Kansas City, 1978.

Lachmann, L.M. (1977), Capital, expectations and the market process, Kansas City, 1978.

Larkin, J., McDermott, J., Simon, D.P., Simon, H.A. (1980), 'Expert and novice performance in solving physics problems', Science, 208, $1335-1442$.

Leijonhufvud, A. (1967), 'Keynes and the Keynesians: a suggested interpretation", American Economic Review, reprinted in: Leyonhufvud (1981:3-16). 
Leijonhufvad, A. (1968), On Keynesian Economics and the Economics of Keynes, Oxford

Leijonhufvud, A. (1969), "Keynes and the Classics: two lectures", Institute of Economic Affairs, London, reprinted in: Leyonhufvud (1981:39-78).

Leijonhufvud, A. (1981), Infornation and coordination: essays in macraeconomic theory, Oxford University Press, New York/Oxford.

Lindert, P.H. (1970), Macro - a game of growth and policy, New York.

Linn, M.C. (1986), "Science", in: R.F. Dillon, R.J. Stemberg, Cognition and instruction, Academic Press.

Loasby, B.J. (1976), Chocie, complexity and ignorance, Cambridge.

Long, J.S. (1983), Confirmatory factor analysis: a preface to LISREL, Sage University Paper series on Quantitative Applications in the Social Sciences, 07-033, Sage Pubns, Beverly Hills and london.

Lucas, R.E. (1981), Studies in business-cycle theory, Blackwell, Ox ford.

Malinvaud, E. (1977), The theory of unemployment reconsidered, Basil Blackwell, Oxford.

Mandler, J.M. (1984), Stories, scripts, and scenes: aspects of schema theory, Erlbaum, Hillsdale, NJ.

Mankiw, N.G. (1992), Macroeconomics, Worth Publishers, New York.

Marris, R. (1964). The economic theory of "managerial' capitalism, Macmillam.

Mayer, T. (1993), Truth versus precision in economics, Elgar.

McCloskey, M., Kohl, D. (1983), "Naive physics: The curvilinear impetus principle and its role in interactions with moving objects', Joumal of Experimental Psychology: Learning. Memory, and Cognition, $9, \mathrm{p} 146=156$.

McCloskey, M., Washburn, A., Felch, L. (1983), "Intuitive physics: The straight-down belief and its origin", Jounal of Experimental Psychology: Leaming, Menory, and Cognition, 9, p. $636-649$.

Meijdan, A.C. (1991), "Prijszetting versus prijsneming in een dynamisch onevenwichtigheidsmodel met rationele anticipatie', Maandschrift Economie, Vol 55, 36-54.

Miller, G.A. (1956), 'The magical number seven, plus or minus two: some limits on our capacity for processing information', Psychological Review, 63(2), 81-97.

Muth, J. (1961), "Rational expectations and the theory of price movements', Econometrica, $29,315-35$. 
Nentjes, A. (1979), De onwikkeling van de economische theorie, Wolters-Noordhoff, Groningen.

Newell, A., Simon, H.A. (1972), Hwwan problem solving, Prentice-Hall, Englewood Clifs.

Nickell, S.J. (1978), The investment decisions of firms, James Nisbet \& Co, Digswell Place, Welwyn, Cambridge University Press, Cambridge.

Patinkin, D. (1965), Money, interest and prices: an integration of monetary and value theory, Harper and Row, New York, second edition.

Piaget, J. (1967), 'The mental development of the child', in: Elkind, D., Six psychological studies, Random House, New York. (Original work published in 1940).

Piaget, J. (1980), Adaptation and intelligence: organic selectiom and phenocopy, University of Chicago Presss, Chicago. (Original work published in 1974)

Plott, C.R., George, G. (1992), "Marshallian vs. walrasian stability in an experimental market', The Economic Journal, 1.02, pp. 437-460.

Plott, C.R., Smith, V.L. (1980), "An experimental examination of two exchange institutions", Review of Economic Studies, vol. 45, no. 1, 133-153.

Plott, C.R. (1989), "An updated review of industrial organization: applications of experimental methods", in: R. Schmalensee, R.D. Willig (ed.), Handbook of Industrial Organization, Volume II, Elsevier Publishers.

Resnick, L.B. (1987), "The development of mathematical intuition', in M. Perlmutter (ed), Minnesota Symposium on Child Psychology, 19, Erlbaum, Hillsdale, NJ, 159-194..

Ridgeway, D. (1983), Personal communication, University of California, Lawrence Hall of Science, Berkeley.

Robbins, L. (1932), An essay on the nature and significance of economic science, Macmillan, London and Basingstoke. 1984.

Roth, A.E. (1989), "An updated review of industrial organization: application of experimental methods", in: R. Schmalensee, R.D. Willig (eds.), Handbook of Industrial Organization,

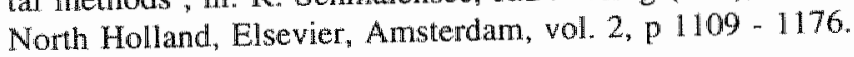

Roth, A.E. (1986), "Laboratory experimentation in economics', Economics" and Philosophy, vol. 2, pp. 245-73.

Roth, A.E. (1987). Laboratory experimentation in economics:six points of view, Cambridge Unitversity Press, Cambridge.

Roth, A.E. (1988), "Laboratory experimentation in economics: a methodological overview", Economic Journal, vol. 98, pp 974-1031. 
Rowe, M.B. (1983), "Science education: a framework for decision makers", Deadalus, $112(2), 123-142 . h$

Samuelson, P.A., Nordhaus, W.D. (1992), Economics, fourteenth edition, McGraw-Hill.

Schmidt, H.G., Foster, S., Bouhuijs, P.A.J. (1989), "Theoretische en empirische grondslagen van probleemgestuurd onderwijs", in: P. Keizer (ed.), Probleemgestuurd onderwijs in de economische wetenschap, Van Gorcum, Assen/Maastricht, 11-29.

Sears, D.O., Peplau, L.A., Taylor, S.E. (1991), Social Psychology, seventh edition, PrenticeHall.

Selten, R. (1965), 'Spieltheoretische Beharndlung eines Oligopolmodells mit Nachfrageträgheit', Zeirschrift für Gesamte Staatswissenschaft, Bd. 121, 301-324.

Selten, R. Tietz, R. (1980), 'Zum Selbstverständnis der experimentellen Wirtschaftsforschung im Umkreis won Heinz Satuermann', Zeitschrift für die gesamte Staatswissenschaft, 136,12-27.

Silverberg G. (1988), 'Modelling economic dynamics and technical change: mathematical approaches to self-organisation and evolution', in Dosi, G., Freeman, C, Nelson, R. Silverberg, $\mathrm{G}_{n,}$, Soete, L. (1988), Technical change and economic theory, Pinter, London/New York.

Simon, D.P., Simon, H.A. (1978), "Individual differences in solving physics problems", in: R.S. Siegler (ed), Children's thinking: What develops? Erlbaum, Hillsdale.

Smith, V.L. (1976), "Experimental Economics: Induced Value Theory", American Economic Review Proceddings, vol. 66, 274-279, reprinted in: Smith (1991).

Smith, V.L. (1980), "Relevance of laboratory experiments to testing resource allocation. theory", in: Smith(1990), 154-186.

Smith, V.L. (ed.) (1990), Experimental econowics, Elgar Publishing, Hants, England, Gower Publishing, Brookfield, USA.

Srnith, V.L. (1991), Papers in experimenal economics, Cambridge University Press.

Snippe, I. (1985), Macroeconomic adjusmemt processes: a sequential analytical approach, Dissertation Groningen.

Snodgrass, J.G., Levy-Berger, G., Haydon, M. (1985), Humaw experimental psychology, Oxford University Press.

Solow, R.M. (1956), 'A contribution to the theory of economic growth', Quaterly Joumal of Economics, 65-94.

Spiro, R.J. (1977), "Remembering information from text: the "state of schema" approach", in: Anderson, R.C., Spiro, R.J., Montague, W.E., Schooling and the acquisition of knowledge, Erlbaum, Hilsdale, NJ, 336-351. 
Spiro, R.J. (1980), "Constructive processes in prose comprehension and recall", an: Spiro, R.I., Bruce, B.C., Brewers, W.F., Theoretical issues in reading comprehession. Bribaum, Hillsdale, NJ, 245-278.

Stein Greenblat, C. (1988), Designing games and simulations.

Stiglitz, J.E. (1988), 'On the market for principles of economics textbooks: innovation and product differentiation", Joumal of Econtomic Education, 171-182.

Stiglitz, J.E. (1993), 'International perspectives in undergraduate education', AEA Papers and procedings, $83(2), 27-33$.

Tempelaat, D. (1993), Handleiding toetsconstructie, Rijksuniversiteit Limburg, Faculteit der Economische Wetenschappen, Maastricht, The Netherlands.

Tietz, R., Fischer, K.H., Schuster, K.G. (1972), "On handling experimental data of the KRESKO game with factor analysis and some remarks on interpersonal relations', in: Beiträge zur experimentellen Wirtschaftsforschung, 3. Band, hrsg. von H. Sauermann; Tuibingen, p 289-299.

Tietz, R., Assmus, V. (1972), "Some experiences with regression analysis of the wage determination in the KRESKO-Game", in: Beirräge zur experimentellen Wirtschaftsforschung, 3. Band, hrsg. von H. Sauermann; Tübingen, p 300-304.

Tietz, R (1973), 'Ein anspruchsanpassungsorientiertes Wachstums- und Konjunkturmodel] (KRESKO)', in: Beiträge zur experimentellen Wirtschaftsforschung, 4. Band, hrsg. von $H$. Sauermann; Tübingen.

Tietz, R. (1972), "The macroeconomic experimental game KRESKO- experimental design and the influence of economic knowledge on decision behavior', in: Beiträge zur experimentellen Wirtschafisforschung, 3. Band, hrsg. von H. Sauermann; Tübingen, p 267-288.

Tietx, R. HJ. Weber (1972), 'On the nature of the bargaining process in the KRESKOGame", in: Beiträge zur experinentellen Wirtschaftsforschung, 3. Band, hrsg. won H. Sauermann; Tubingen, p 305-334.

Tietz, R., W. Albers, R. Selten (eds.) (1988), Bounded rational behavior in experimental games and markets, Springer Verlag, Berlin, etc.

Tongeran, F.W. van, Corporates in an economy-wide model: a microsimulation approach, Dissertation Erasmus Universiteit Rotterdam, 28-10-1993.

Trevithick, J.A. (1992), Involuntary wnemployment: macroeconomics from a Keynesian perspective, Harvester Wheatsheaf, New York, etc.

VanLehn, K., Problem solwing and cognitive skill acquisition, in: M.I. Posner, Foundations of cognitive science, 
Voss, J.F., Blais, J., Means, M.L., Greene, T.R., Ahwesh, E. (1986), "Informal reasoning and subject matter knowledge in the solving of economics problems by naive and novice individuals", Cognition and instruction, 3(4), p 269-302.

Voss, J.F. (1986), "Social Studies", in. R.F. Dillon, RJ. Sternberg, Cognition and instruction, Academic Press.

Weintraub, S. (ed.) (1978), Keynes, Keynesians and Monetarists, University of Pennsylwania Press, second edition, 1983.

Weintraub, S., Habibagahi, H. (1972), 'Money supplies and price-output indeterminateness: The Friedman Puzzle', Joumal of Economic Issues, reprinted in: Weintraub, S., Keynes, Keytesians and Monetarists, Uniwersity of Pennsylvania Press, 1978, 124-138.

Weintraub, S., Davidson, P. (1973), "Money as cause and effect", Economic Joumal, reprinted in: Weintraub (1978:139-160).

Wessel, M.G. (1982), Cognitive pshychology, Harper \& Row, New York.

Wicksell, K. (1935), Lectures on political economy, Kelley, Fairfield, 1978.

Williamson, O.E. (1964), The economics of discretionary behaviour, Prentice-Hall.

Zijp, R. van (1992), Austrian and new classical business cycle theories, Tinbergen Institute Research Series No 33, Thesis Publishers Amsterdam, P.O. Box 14791, 1001 LG. Amsterdam.

Zijp, R., Visser, H. (1994), 'Mathematical formalization and the domain of economics': the case of Hayek and the New Classical Economics, in: J. Birner, R. wan Zijp (ed), Hayek, coordination and evolution, Routledge, London and New York, 67-93. 


\section{Nederlandse samenvatting}

Dit proefschrift gaat over de achtergronden en eerste resultaten van de ontwikkeling van het zogenaamde Economiespel. Het Economiespel is een spel over de relatie tussen bedrijfsbeslissingen en macro-economische ontwikkelingen. Macro-economie gaat over verschijnselen zoals inflatie en werkloosheid. Het spel wordt gespeeld op een computernetwerk. Er is één centrale computer, die alles doorrekent. De andere computers representeren bedrijven. Op elke computer leidt een groepje spelers een bedrijf. Al deze bedrijven concurreren met elkaar op de afzetrmarkt. Ook op de arbeidsmarkt, de markt voor investeringsgoederen en de vermogensmarkt zijn de bedrijven van elkaar afhankelijk. Alle andere actoren in de economie, zoals consumenten, overheid en banken, worden door het computerprogramma of de spelleider geleid. De spelleider leidt het spel in, coördineert het verloop van het spel, adviseert de spelers bij hun beslissingen en kan desgewenst in het spel ingrijpen. Om de resultaten van het spel niet teveel te beïrvloeden, probeert hij echter zo min mogelijk het inhoudelijke verloop van het spel te sturen. Aangezien een belangrijk gedeelte van de macro-economische dynamiek door de beslissingen van bedrijven wordt veroorzaakt, kan een groot deel van de werkloosheid, inflatie, en dergelijke, worden verklaard uit de beslissingen van de spelers.

Het Economiespel kan zowel voor onderwijs als onderzoek worden gebruikt. Hoewel het ontwikkeld is vanuit een vrij kritische invalshoek met betrekking tot de gebruikelijke benadering van economie in onderwijs en onderzoek, is deze achtergrond niet van belang voor het gebruik van het spel. Toch wordt in hoofdstuk 1 aandacht besteed aan het feit dat een fundamenteel macro-economisch coördinatieprobleem wordt ontweken in de meeste leerboeken en ook in het onderzoek. Dit coördinatieprobleem is voor het eerst beschreven door Keynes in een boek getiteld "The General Theory of Employment, Interest and Money' (1936). In dit boek valt Keynes de wat hij noemt 'Klassieke' opvatting aan volgens welke een vrije en flexibele markteconomie zonder overheidsingrijpen automatisch leidt tot een evenwichtige macro-economie zonder langdurige werkloosheid. In de Klassieke theorie moet werkloosheid worden opgelost door het verlagen van de lonen en het flexibiliseren van de economie. In de gedachtengang van Keynes kan zo een verlaging van de lonen het probleem verergeren doordat een lager loon tot minder inkomen leidt en dit lagere inkomen de consumptie doet dalen. Deze verlaging van de consumptie verlaagt de vraag naar produkten van bedrijven, zodat deze bedrijven mensen zullen ontslaan.

Het door Keynes beschreven probleem heeft direct te maken met de rol van geld in een economie. Immers, als consumenten minder consumeren zullen ze volgens de 
zogenaamde 'Kwantiteitstheorie' hun geld gaan beleggen, bijvoorbeeld door het op een spaarrekening van een bank te zetten. Deze bank zal proberen dat geld uit te lenen. Als dat tegen de huidige rente niet lukt, zullen ze de rente gaan verlagen; het is immers beter om uit te lenen tegen een lagere rente dan helemaal niet uit te lenen. De verlaging van de rente stimuleert de bestedingen weer. Als er dus vanwege een of andere reden te weinig vraag is, zal vanzelf een daling van de rente de vraag weer doen aantrekken.

Als het hiervoor beschreven rente-mechanisme niet werkt, is er nog een tweede stabiliserend mechanisme: prijsaanpassing. Als er te weinig vraag naar eindprodukten is, zullen ondernemers beslissen om hun prijzen te verlagen. Hierdoor kan er met dezelfde hoeveelheid geld meer gekocht worden, hetgeen de economie weer doet aantrekken. De hier beschreven rente- en prijsmechanismen leiden er dus toe dat geld altijd direct of indirect besteed wordt, zodat een tekort aan geaggregeerde (= nationale of totale) vraag op lange termijn uitermate onwaarschijnlijk is.'

De kritiek van Keynes richt zich op deze Klassieke aanpassingsmechanismen. Met name het rente-mechanisme veronderstelt dat het geldaanbod als gegeven kan worden beschouwd en dat de rente zich soepel kan aanpassen. Bij grote verstoringen zou de rente negatief moeten worden om de vraag voldoende te stimuleren. Het zal duidelijk zijn dat bij een rente lager dan 0 procent miemand meer geld zal willen uitlenen. In praktijk ligt deze grens nog veel hoger.

Volgens Keynes spelen verwachtingen een belangrijke rol in het aanpassingsproces. Als de rente laag is en men verwacht dat de prijzen gaan dalen, is de reële rente toch nog hoog en zal men niet meer gaan besteden. Als de rente laag is en men verwacht dat deze nog verder gaat dalen, zal men wachten totdat dit gebeurd is en eerder minder dan meer gaan besteden. Tenslotte, ook al zijn de rente en prijzen nog zo laag, als men verwacht dat de vraag voorlopig niet zal aantrekken, zullen bedrijven niet gaan investeren om hun produktiecapaciteit uit te breiden. Keynes zette dus grote vraagtekens bij de werking van het rente- en prijsmechanisme van de Klassieken, en legde daarbij een groot accent op de rol van onzekerheid en verwachtingen.

Hoewel naar aanleiding van de General Theory van Keynes de economische wetenschap fundamenteel veranderd is, is vrijwel direct na zijn publikatie het probleem van onzekerheid en verwachtingen op de achtergrond geraakt. Onevenwichtigheden werden verklaard uit te weinig flexibele lonen en prijzen. Dit is de benadering in bijna alle leerboeken (het zogenaamde IS-LM model). Daarmee was de Keynesiaanse theorie een onderdeel geworden van wat Keynes de Klassieke theorie had genoemd.

In de gebruikelijke benadering wordt impliciet of expliciet verondersteld dat onevenwichtigheden zoals inflatie en werkloosheid het gevolg zijn van een gebrek aan prijsflexibiliteit, ondoordacht overheidsingrijpen of overmatige groei van het geldaanbod. Een vrije markteconomie met flexibele marktaanpassing en een stabiel geldaanbod zou via de werking van de principes van vraag en aanbod automatisch tot stabiliteit leiden. Deze fundamentele veronderstelling wordt zelden onderbouwd, mede

'Deze schets van het Klassieke aanpassingsmechanisme is sterk vereenvoudigd. Het is achter voldoende om de essentie van het probleem te begrijpen. 
doordat de wereld te complex is om deze veronderstelling empirisch te onderzoeken. In de naturkunde gaat men in zo een geval over tot laboratorium experimenten. Zulke laboratorium experimenten zijn nuttig on fundamentele wetmatigheden te onderzoeken in een beheersbare omgeving. Er werd lange tijd verondersteld dat experimenten niet mogelijk waren in sociale wetenschappen zoals economie. Het Economiespel dat in dit proefschrift is ontwikkeld, is bedoeld als een laboratoriumopstelling om fundamentele wetmatigheden op het grensvlak van micro- en macroeconomie te onderzoeken.

Hoewel experimentele economie al enkele decennia bestaat, wordt het de laatste tijd steeds populairder. Tot nu toe hebben experimenten zich vooral beperkt tot eenvoudige markten en besluitvormingsmechanismen. Experimenteel onderzoek nat de coördinatie van beslissingen wordt uitgevoerd in extreem eenvoudige omgevingen. Nog nooit zajn er succesvolle experimenten gedaan met betrekking tot de coördinatie van beslissingen door bedrijven in gesloten macro-economische systemen.

In hoofdstuk 3 wordt ingegaan op de experimentele methode, en worden enkele criteria voor goede experimenten gepresenteerd. Allereerst moet een experimentele opstelling consistent zijn met de veronderstellingen die de te testen theorie hanteert. Ten tweede mogen er bij de implementatie van de theorie in een experimentele opzel geen irrelevante verstoringen ontstaan. Ten derde moet het experimentele systeem voldoende beheersbaar zijn. Ten vierde moeten de relevante variabelen betrouwbaar kunnen worden gemeten. Tot slot zou het prettig ziju als de resultaten die in experimenten bereikt zijn, ook toepasbaar zijn op de werkelijkheid (externe validiteit). Deze toepasbaarheid is echter meer een eis die moet worden gesteld aan de aan de experimenten ten grondslag liggende theorieën dan aan de experimenten zelf.

In de hoofdstukken 4 en 5 wordt het model achter het Economiespel beschreven. Op grond wan het eerste criterium voor goede experimenten moet het spel consistent zijn met de veronderstellingen die de te toetsen theorieën hanteren. Aangezien in de meeste macro-economische theorieèn de algemene evenwichtstheorie impliciet of expliciet een rol speelt als referentiepunt, worden eerst de eigenschappen van het algemene evenwichtsgroeipad achter het spel besproken. In de Klassieke gedachtengang zal een economie zonder verstoringen van binnen- of buitenaf zich langs dit groeipad ontwikkelen. Om de te toetsen gedeelten van deze theorie te scheiden van de veronderstellingen met betrekking tot de omgeving, wordt het groeimodel zodanig gepresenteerd, dat de institutionele vormgeving en de gedragsveronderstellingen worden gescheiden. Vervolgens wordt de bedriffsector opgesplitst in aparte bedrijven, en worden er vraaginertia op de markt voor eindprodukten en aanbodinertia op de arbeidsmarkt geîntroduceerd. Dit impliceert onvolkomen concurrentie op korte termijn. Ex wordt aangetoond dat bij deze marktvorm onder bepaalde condities (als de groeivoet van de reële verkopen lager is dan de reële rente) de winst hoger is dan zonder imperfecte concurrentie. Dit heeft echter geen effecten in do reele sfeer zolang het arbeidsaanbod inelastisch is.

In boofdstuk 5 wordt onzekerheid en daarmee de mogelijkheid van onevenwichtigheid in het model geintroduceerd. Allereerst wordt de zeer flexibele produktietechniek uit het evenwichtsgroeinodel (putty-putty produktiefunctie) vervangen door een minder flexibele produktietechniek (putty-clay). Deze minder flexibele produktietechniek is intuitief inzichtelijk te maken voor de spelers. Spelers schaffen machines van 
een bepaald type aan en kunnen dit type gedurende de levensduur van deze machines niet meer veranderen. Deze inflexibiliteit kan het economische systeem destabiliseren doordat verkeerde investeringsbeslissingen langer doorwerken. Aan de andere kant kan deze inflexibiliteit ook stabiliserend werken; juist omdat onevenwichtige investeringen langer door werken, zal men voorzichtiger hiermee omspringen.

Bij onevenwichtigheden moeten er buffers voor de opvang van deze onevenwichtigheden zijn: voorraden eindprodukt, variaties in de bezettingsgraad van machines, levertijden van machines en werkloosheid. Orm het spel te vercenvoudigen en voldoende concurrentie op de afzetmarkt te garanderen, is er slechts één afzetmarkt in het spel. Deze eindprodukten worden echter ten dele geleverd aan consumenten en ten dele aan de bedrijven die investeren. Daarom is er een model ontwikkeld dat de geproduceerde eindprodukten over de twee markten verdeelt. Om het model te completeren, wordt de rente als beleidsinstrument geïntroduceerd. Ook een beperkte mogelijkheid tot overheidsbeleid wordt geimplementeerd.

In de experimentele economie is het gebruikelijk om proefpersonen in geld uit te betalen. De monetaire prikkel zou noodzakelijk zijn om realistisch gedrag te stimuleren. Dit is met name van belang om theorieën rond rationaliteit te toetsen, of effectief vraag- en aanbodgedrag te simuleren. In hoofdstuk 3 wordt betoogd dat in complexe macro-economische systemen de problematiek om informatie te structureren veel meer problemen geeft dan de motivatie om zo goed mogelijk te presteren. De complexiteit van het spel en de introductie van een ranglijst van bedrijven, stimuleren voldoende om zo goed mogelijk te presteren. Een spel dat, net zoals schaken, voldoende intrinsieke motivatie geeft om te winnen, heeft weinig baat bij het toevoegen van externe prikkels zoals geld. Uiteraard is deze stelling toetsbaar door met geld gespeelde spelen te vergelijken met spelen die zonder geld zijn gespeeld.

Een centraal probleem bij de ontwikkeling van het Economiespel vormt de training van de spelers. Terwijl in de 'echte' wereld mensen via opvoeding, de media, bedrijfstrainingen en jarenlange ervaring in management de eigenschappen van de wereld leren kennen, moeten de spelers in korte tijd leren beslissen in de wereld van het Economiespel. Als de resultaten van het spel voor experimentele doeleinden worden gebruikt, mag de training van de spelers niet ongecontroleerd het gedrag van de spelers beïnvloeden. De opzet van de training mag wel als beheersingsvariabele worden gebruikt.

De training van de spelers wordt besproken in hoofdstuk 6 . Het in de hoofdstukken 4 en 5 besproken model kan op intuittieve wijze worden uitgelegd. Hierbij is het niet noodzakelijk om de macro-economische structuur uit te leggen. Wel moeten de spelers een goed inzicht krijgen in de structuur van de bedrijven en de markten. Een goede uitleg is echter niet voldoende. Spelers moeten ook vaardigheden in het bedrijfsbeleid ontwikkelen. Er is een reeks opdrachten ontwikkeld om de spelers stapsgewijs met het spel en het computerprogramma te leren omgaan.

Het spel wordt op het ogenblik bij verschillende soorten studenten gebruikt. Economiestudenten spelen het spel aan het einde van hun propaedeuse. Rechtenstudenten spelen het spel in het kader van een inleidende cursus in de economie. Studenten Cultuur- en Wetenschapsstudies volgen een zeer gecomprimeerde cursus, die rond het Economiespel gebouwd is. De onderwijskundige principes die achter het spel liggen, worden ook gebruikt bij met name de inleidende cursus economie voor stu- 
denten rechten. Deze onderwijskundige principes vormen een apart thema in het proefschrift.

In hoofdstuk 2 worden onderwijskundige principes ontwikkeld op basis van inzichten uit de cognitieve psychologie. Deze principes kunnen zowel worden toegepast op de training van de spelers als bij de ontwikkeling van een inleidende cursus algemene economie. Volgens het eerste principe moet alle nieuwe kennis worden ingepast in een bestaande kennisstructuur. Dit betekent dat eerst voorkennis moet worden geactiveerd. Ten tweede moet kennis zo efficiènt mogelijk in het geheugen opgeslagen worden en snel toegankelijk zijn. Dit betekent dat oorzakelijke samenhangen in de kennis zoveel mogelijk aan de oppervlakte moeten worden gebracht. Ten derde is een vereiste voor leren dat de student wordt gemotiveerd. Het laten zien van inconsistenties in de intuïties van studenten kan een belangrijke motiverende kracht zijn. Ten vierde moeten studenten met de basisprincipes leren werken. Door op verschillende manieren met de te verkrijgen kennis bezig te zija, leert de student de stof pas echt kennen. Met name achter formeel-wetenschappelijke kennis moet een goede intuïtie ontwikkeld worden. Ten vijfde moeten studenten de kennis niet alleen op het tentamen kunnen reproduceren, maar ook in de praktijk leren herkennen. Vaak. kan men kennis niet toepassen omdat men zich de kennis niet in de betreffende context bewust is. Daarom moet kennis in zoveel mogelijk contexten worden toegepast. Ten slotte vereist snelle toepassing van kennis routine. Veel denkpatronen zullen daarom automatisch moeten worden. Regelmatige training met feedback is een belangrijke methode om denkvaardigheden te trainen.

De toepassing van de onderwijskundige principes is niet alleen een uiterlijk fenomeen. Hoewel deze principes eigenlijk vanzelfsprekend zouden moeten zijn, wordt er vaak tegen gezondigd. Zoals in paragraaf 2.3 wordt gelllustreerd, voldoen ook gerenommeerde tekstboeken in de algemene economie niet aan die principes. Met name de causale organisatie van het denken rond een aantal grondprincipes vraagt een inhoudelijk aanpassing van hetgeen gedoceerd wordt. Dit betekent niet dat de economische theorie anders wordt, het betekent wel dat de ordening ervan belangrijke verschuivingen ondergat. In paragraaf 2.4 wordt een voorbeeld gegeven van hoe cen beginsel-georienteerde benadering van het economie-onderwijs eruit zou kunnen zien. Deze cursus, die een perfectionering is van de cursus die nu an de Faculteit der Rechtsgeleerdheid wordt gegeven, is gecentreerd rond de gedachte dat economie uiteindelijk gaat over beslissingen van mensen. De voordelen van het gekozen alternatief worden als opbrengsten gedefinieerd, de nadelen als kosten. Dit is het zogenaamde alternatieve kostenbeginsel ("opportunity cost'). Vanuit deze gedachte wordt het hele bouwwerk van economische theorieën opgebouwd. Zelfs de macro-economie, die zeker in inleidende tekstboeken als een apart onderwerp wordt beschouwd is een toepassing van het alternatieve kostenbeginsel. Om de macro-economie op deze wijze te kunnen presenteren, mag het macro-economische coördinatie-probleem uit hoofdstuk I niet worden ontweken.

In hoofdstuk 7 wordt een aantal onderzoeksmethoden ontwikkeld die van belang kunnen zijn bij het meten van de effectiviteit wan onderwijs, waaronder het Economiespel. Allereerst zijn tentamenresultaten met behulp van factoranalyse geanalyseerd. Het blijkt dat in economietentamens drie dimensies kunnen worden onderscheiden: de vaardigheid om basisprincipes uit de behandelde stof toe te passen, de 
vaardigheid om zonder kennis van zaken op grond van logisch redeneren tot conclusies te komen, en de aanwezigheid wan gedetailleerde kennis. Bij een toets voor studenten rechten blijkt de tweede dimensie gerelateerd te zijn aan woorkennis op het gebied van algemene economie.

Ten tweede zijn de tentamenresultaten gerelateerd aan enquêtes ter evaluatie van het onderwijs. Uit enquêtes over het studiegedrag van de rechtenstudenten blijkt dat elke drie uur extra studie per week een extra goed beantwoorde vraag op het tentamen van 24 meerkeuzevragen oplevert, net zoals de aanwezigheid bij twee onderwijsgroepsbijeenkomsten van 2 uur. Het is niet verbazingwekkend dat de studieactiviteiten alleen zijn terug te vinden in de kennis-dimensie van het tentamen. Het is echter boeiend dat deelname aan het spel alleen gecorreleerd is met de dimensie die de vaardigheid tot het toepassen van basisprincipes meet.

Bij eerstejaars economiestudenten is geen informatie beschikbaar over studieactiviteiten, maar wel met betrekking tot de evaluatie en deelname aan het Economiespel. In de enquête na afloop van het Economiespel kunnen vijf dimensies worden onderscheiden (algemene waardering, vaardigheid om het spel aan theorie te koppelen, verbeteringen in strategie tijdens het spel, voorbereiding, en het gebruik van informatie in het spel). Verrassenderwijs blijkt er geen relatie te zijn tussen de eerste drie dimensies uit het spel en de dimensies van de toets. Voorbereiding voor het spel is gecorreleerd met de dimensies uit het tentamen die gedetailleerde kennis en de vaardigheid kennis toe te passen meten. Het gebruik van informatie in het spel is positief gerelateerd aan de gedetailleerde kennis vergende vragen uit het tentamen, maar negatief met de vaardigheid om basisprincipes toe te kunnen passen. Dit laatste is verrassend.. Misschien proberen deze studenten zoveel te leren, dat ze het overzicht over de stof verliezen.

Een derde onderzoeksmethode probeert vaardigheden in het conceptualiseren van economische problemen te meten. De methode is geïnspireerd door een gelijksoortige aanpak voor de conceptualisering van natuurkundige problemen. Zoals al bleek uit de eerste twee hoofdstukken van dit proefschrift is, in tegenstelling tot in de natuurkunde, de overeensternming over wat fundamenteel is binnen de economie beperkt. Ik heb ervoor gekozen om de in hoofdstuk 2 ontwikkelde gedachtengang als de meest diepgaande te beschouwen, en heb op basis daarvan 18 kaartjes met economische problemen gemaakt. Elk probleem heeft een oppervlakteniveau en een diepteniveau. Het diepteniveau heeft betrekking op een verklarend principe, het oppervlakteniveau op een gelijkvormig verschijnsel. Zo kan de oppervlaktecategorie werkloosheid verklaard worden uit de verklarende principes conjunctuur, niet-evenwichtslonen, of structurele aanpassingen. Aan de proefpersonen werd gevraagd om de kaartjes te ordenen in overeenstemming met de theorieën die nodig zijn om het probleem op te lossen. Het bleek dat studenten rechten na het volgen van een principe-gebaseerd onderwijsprogramma zoals beschreven in hoofdstuk 2 van dit proefschrift, meer op diepteniveau categoriseerden dan eerstejaars economiestudenten na een veel langere cursus economie. Het is overigens verrassend dat universitaire docenten macro-economie het ook slechter deden dan studenten rechten. Bij dit laatste moet worden opgemerkt dat de docenten macro-economie beter categoriseerden met betrekking tot problemen die op hun eigen terrein lagen. Gezien de beperktheid van de steekproef en de explorerende status van deze onderzoeksmethode, moeten geen voorbarige 
conclusies uit deze resultaten worden getrokken.

Ten vierde is er een test ontwikkeld om patroonherkenning te toetsen. Twee casussen met betrekking tot de conjunctur zijin aan studenten Cultuur- en Wetenschapsstudies voorgelegd. ledere student moest ến casus aan het begin en één aan het einde van de cursus maken. Na het lezen van de casus moesten de studenten zoveel mogelijk opschrijven van wat ze zich van de casus herinnerden, en vervolgens de situatie van de economie karakteriseren. De casussen bevatten een aantal institutionele elementen zoals de positie wan de Centrale Bank en de vakbonden, en een aantal economische elementen zoals de werkloosheid, de levertijd van machines en de inflatie. Het bleek dat de studenten na afloop van de cursus veel meer opschreven met betrekking tot de economische karakteristieken van de economie en dat ze veel beter in staat waren om de conjuncturele situatie te karakteriseren. De uitermate korte cursus van 24 studie-turen lijkt dus effectief voor het leren herkennen van patronen in conjunctuurschetsen.

De vier beschreven onderzoekmethodieken zijn een aanzet tot nieuwe methoden om de effectiviteit van het economieonderwijs (waaronder het Economiespel) te meten. Al deze methoden staan nog in hun kinderschoenen. Dit geldt ook voor de eerste pogingen die in dit proefschrift zijn ondernomen om experimenten met het Economiespel te doen. Pas als het computerprogramma van het Economiespel voltooid is, zullen volwaardige experimenten kunnen worden gedaan.

Toch is in hoofdstuk \& van het proefschrift een poging gedaan om de resultaten van twee door eerstejaars economiestudenten gespeelde spelen nader te analyseren. Het ene spel, ECO8, lijkt zeer instabiel, terwijl het tweede spel, ECO11, een conjuncturele ontwikkeling rond het evenwichtsgroeipad te zien geeft. De werkloosheid. aan het einde van ECO 8 is bijvoorbeeld 38 procent, terwijl in ECO11 de werkloosheid nooit hoger dan 14 procent is geweest. Dit vraagt om een verklaring. Hiertoe is het gebruikelijke onderscheid gemaakt tussen structurele en conjuncturele werkloosheid. Structurele werkloosheid is het gevolg van een tekort aan machines, terwijl conjumcturele werkloosheid het gevolg is van een tekort aan vraag naar eindprodukten. In tegenstelling tot bij ECO8 is in het spel ECO11 door de spelleider veel aandacht besteed aan de structurele problemen in de economie. Hierdoor werden structurele problemen snel gecorrigeerd. Als gevolg daarvan konden ze niet leiden tot extreme pieken of dalen in de economie. Het is overigens frappant dat aan het einde van het spel deze economie gaat afwijken van het door de spelleider gesuggereerde structurele evenwicht. Dit kan waarschijnlijk worden werklaard uit het in hoofdstuk 5 geanalyseerde verschijnsel dat bij volledige zekerheid de optimale bezettingsgraad van machines 100 procent is, maar in een situatie van onzekerheid lager zal zujn om onregelmatigheden in de vraag en verschillen tussen bedrijven op te vangen. Het lijkt er dus op dat de ondernemers in het spel na verloop van tijd vanzelf het evenwicht in de economie kunnen ontdekken, ook als de spelleider iets anders vertelt.

Econometrische analyse van de spelen ECO8 en ECOIl lijkt deze conclusie enigszins te bevestigen. In hoofdstuk 8 worden een investeringsvergelijking en een arbeidsvraagvergelijking voor de speleconomie afgeleid en geschat op basis van gegevens uit ECO8 en ECO11. De resultaten suggereren dat in ECO11 de stabiliserende mechanismen beter werken en de destabiliserende mechanismen minder. Als gevolg van de grotere stabiliteit van de economie is het niet verbazend dat de even- 
wichtsvoorraad in ECO11 lager is dan in ECO8: twee weken in plaats van vijf weken. Eveneens is het logisch dat de bezettingsgraad van machines in het evenwicht hoger is: 85 procent in plaats van 60 procent. Toch is deze bezettingsgraad lager dan de 95 procent die op basis van de beschrijvende analyse te verwachten is.

Bij een goede modellering van het gedrag in een economie moet simulatie met de econometrisch geschatte vergelijkingen leiden tot een soortgelijke dynamiek als in het echte spel. Er blijkt echter dat het gebruik van de geschatte vergelijkingen van ECO11 voor het beleid van een representatief bedrijf niet tot een stabiele economie, maar tot een grote recessie leidt. Het modelleren van het ondernemersgedrag in het Economiespel zal nog een gedegen analyse vergen.

Naast het hiervoor genoemde gebruik van simulatie met computerroutines in het Economiespel, kan simulatie ook onafhankelijk van met spelers gespeelde spelen gebruikt worden. Door verschillende soorten bedrijfsstrategieën met elkaar te laten concurreren, kan onderzoek worden gedaan naar de efficiëntie van verschillende soorten bedrijfsstrategieën in een macro-economische context. Bovendien kan de invloed van het bedrijfsgedrag op de conjunctuur op deze wijze systematisch worden geanalyseerd. Toch zullen 'echte' spelers essentieel blijven om nieuwe strategieën te ontwikkelen en om te analyseren of 'echte' ondernemers zich niet anders gedragen dan onveranderlijke computerroutines.

Tot slot van het proefschrift wordt een indicatie gegeven van mogelijke richtingen waarin het Economiespel zich verder zou kunnen ontwikkelen. Prioriteit heeft het onderscheid tussen twee soorten bedrijven: machinefabrieken en overige bedrijven. Ook de introductie van een monetaire sector, die in de theorieën rond het macroeconomische coördinatieprobleem zo een belangrijke rol speelt, heeft prioriteit. De modellering van banken als spelers kan van groot theoretisch belang zijn. De introductie van een aandelenmarkt misschien minder. Een aandelenmarkt in de context van het Economiespel kan echter wel een goede aanvulling zijn om de gebruikelijke experimenten en analyses van aandelenmarkten te verrijken. Technologische ontwikkeling is cen derde belangrijke aanvulling op het spel, die in elementaire vorm makkelijk te introduceren is, en in meer geavanceerde vorm een belangrijke rol speelt in moderne theorieën over de conjunctuur. Tot slot kan een verdere uitwerking van de overheid zinvol zijn om de mogelijkheden tot stabilisatie van de conjunctuur nader te onderzoeken. Bij al deze mooie uitbreidingen moet echter worden bedacht dat te complexe modellen hun verklarende waarde verliezen als ze onbeheersbaar en onoverzichtelijk worden: eenvoud is de kenmerk van het ware! 


\section{Curriculum Vitae}

Geert Woltjer werd op 6 november 1956 geboren te 's Gravenhage. $\mathrm{Na}$ het behalen van het VWO-diploma aan het Rijnlands Lyceum te Oegstgeest in 1974, studeerde hij van 1974 tot 1983 algemene economie aan de Erasmusuniversiteit te Rotterdam. Vanaf 1983 is hij werkzaam als universitair docent algemene economie aan de Rijksuniversiteit Limburg. Zijn wetenschappelijke interesse richt zich met name op macro-economische coördinatieproblemen, de relatie tussen de verschillende menswetenschappen, en experimentele economie. In het kader van het onderwijs richt hij zich op de rol van menselijke beslissingen in economische theorieën. Hij is de ontwikkelaar van het Economiespel, een spel over de relatie tussen bedrijfsbeslissingen en macro-economische ontwikkelingen.

Geert Woltjer was born on November 6, 1956 in 's Gravenhage, the Netherlands. He studied economics at the Erasmus University in Rotterdam from 1974 till. 1983. Since 1983 he has been assistant professor in economics at the Faculty of Economics of the University of Limburg, Maastricht, the Netherlands. His scientific interest is mainly focused on macroeconomic coordination, the relationship between human sciences, and experimental economics. In the context of teaching he stresses the importance of the understanding of human decision making for understanding economics. He developed a simulation game on the relationship between decisions of firms and macroeconomic developments. 